UNIVERSIDADE DE SÃO PAULO

Faculdade de Arquitetura e Urbanismo

Curso de Pós-Graduação

Tecnologia da Arquitetura

Tese de Doutorado

A INCLUSÃO DOS “HOME OFFICES” NO SETOR RESIDENCIAL NO MUNICÍPIO DE SÃO PAULO

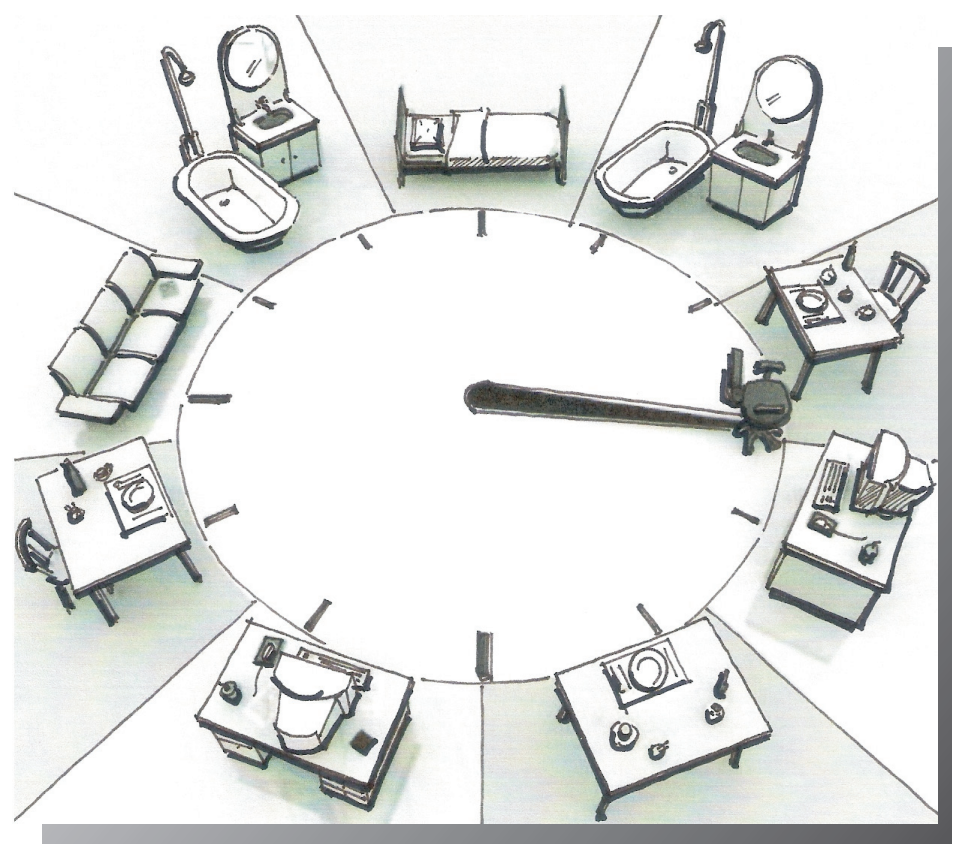

Autor

Marcelo Mendonça 


\section{A INCLUSÃO DOS "HOME OFFICES" NO SETOR RESIDENCIAL NO MUNICÍPIO DE SÃO PAULO}

\section{UNIVERSIDADE DE SÃO PAULO FACULDADE DE ARQUITETURA E URBANISMO CURSO DE PÓS GRADUAÇÃO TECNOLOGIA DA ARQUITETURA}

Orientador PROF $^{\circ}$ Dr. MARCELO DE ANDRADE ROMÉRO 


\begin{abstract}
AUTORIZO A REPRODUÇÃO E DIVULGAÇÃO TOTAL OU PARCIAL DESTE TRABALHO, POR QUALOUER MEIO CONVENCIONAL OU ELETRÔNICO, PARA FINS DE ESTUDO E PESQUISA, DESDE QUE CITADA A FONTE.
\end{abstract}

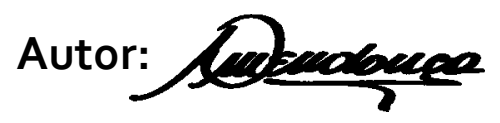

e-mail: m.mendonca@terra.com.br

M539i A inclusão dos "home offices" no setor residencial no município de São Paulo / Marcelo Mendonça. - São Paulo, 2010.

$$
3 \text { v. : il. }
$$

Tese (Doutorado - Área de Concentração: Tecnologia da Arquitetura) - FAUUSP.

Orientador: Marcelo de Andrade Romero

1. Trabalho em domicílio 2. Teletrabalho 3. Tecnologia da Informação 4. Tecnologia da comunicação I. Título 


\section{TESE DE DOUTORADO}

\section{A INCLUSÃO DOS "HOME OFFICES" NO SETOR RESIDENCIAL NO MUNICÍPIO DE SÃO PAULO}

Tese apresentada à Faculdade de Arquitetura e Urbanismo da Universidade de São Paulo como parte dos requisitos necessários à obtenção do título de Doutor em Arquitetura e Urbanismo.

Área de Concentração

Tecnologia da Arquitetura

Orientador

PROF.` DR. MARCELO DE ANDRADE ROMÉRO

Aprovado em:

Banca Examinadora

Profo Dr.

Instituição: Ass:

Profo Dr.

Instituição: Ass:

Profo Dr. Instituição: Ass:

Profo Dr.

Instituição: Ass:

Profo Dr. Instituição: Ass:

Profo Dr. Instituição: Ass: 
"O mais importante para o homem é crer em si mesmo. Sem esta confiança em seus recursos, em sua inteligência, em sua energia, ninguém alcança o triunfo a que aspira." 
Dedicatória

Aos meus pais, Orlando e Geni, pelo exemplo de vida;

aos meus filhos, Guilherme e Isabella, todo meu amor e carinho e a quem procuro passar os valores de respeito, honestidade e cidadania;

e para Adriana, muito mais que uma companheira de vida, a quem dedico não só este trabalho, mas o que eu puder oferecer de melhor. 


\section{Agradecimentos}

A vida acadêmica nos concede a oportunidade única de desenvolvermos a pesquisa e a investigação, e o doutoramento nos faz produzir conhecimento e nos instiga a procurar por respostas.

Durante as atividades voltadas à busca do conhecimento, inúmeras pessoas fizeram parte desta aventura. Muitas nos acompanharam desde o início, para algumas a vida mostrou outros caminhos, e outras tantas nos encontraram em momentos oportunos, porém, a todas estas pessoas o meu grande "muito obrigado", pois de alguma maneira contribuíram para a realização deste trabalho.

Mais uma vez um especial agradecimento ao Prof ${ }^{\circ}$ Dr. Marcelo de Andrade Roméro, muito mais que um orientador, um amigo e conselheiro e sem dúvida a linha mestra de toda esta produção.

Especial agradecimento aos integrantes do Núcleo de Arquitetura e Urbanismo do Laboratório Nacional de Engenharia Civil - LNEC, e aos amigos arquitetos Antônio Batista Coelho e João Branco Pedro, pelas conversas, parcerias, e pelos momentos inesquecíveis desfrutados nas Terras do Além-mar.

Não poderia deixar de citar mais uma vez, o mestre arquiteto João Alberto Cantero, amigo e irmão, presente em todos os momentos desta caminhada.

A todos aqueles que permitiram as pesquisas em suas residências e às empresas Banco Santander, Cisco, IBM Brasil, Ticket Accor e Virtual Call, sem as quais este trabalho não seria realizado.

Finalmente, um especial agradecimento à arquiteta Adriana Valli, pelo amor, carinho dedicação, pela infinita paciência e por mostrar que a vida é uma grande dádiva e Quem está lá em cima nos é muito generoso. 


\section{Resumo}

Mendonça, M. A Inclusão dos "Home Offices" no Setor Residencial no Município de São Paulo. Tese de Doutoramento - Faculdade de arquitetura e Urbanismo, Universidade de São Paulo, São Paulo, 2010.

A função de trabalho de escritório e suas atividades pertinentes, cada vez mais se fundem com a rotina da vida doméstica dos grandes centros urbanos, impulsionados pelas novas tecnologias de comunicação e informação, pelas novas modalidades de relações trabalhistas e pela condição de mobilidade urbana cada vez mais caótica.

Os lançamentos imobiliários recentes adotaram o Home Office em seus prospectos de vendas como mais um atrativo na decisão de compra do cliente, o que pode ser analisado como uma tendência de que $o$ mercado promotor de unidades habitacionais esteja indo de encontro com as necessidades e exigências dos usuários e o Escritório Residencial é uma delas.

Em um primeiro momento, este trabalho investiga as inserções dos espaços para o trabalho de escritório nos lançamentos imobiliários com o objetivo de identificar quais os ambientes que cederam área física ou que coexistem com as atividades desta função; e, posteriormente investiga as condições dos postos de trabalho no que se refere a algumas questões ergonômicas, estudando estas condições à luz de parâmetros de conforto pré estabelecidos. 


\begin{abstract}
Mendonça, M. The inclusion of Home Offices in the residential sector in the city of São Paulo. Doctoral Thesis - Architecture and Urbanism College, University of São Paulo, São Paulo, 2010.
\end{abstract}

The office work and its activities are mixing with the routine of the domestic life of the great urban centers, stimulated by new communication and information technologies, new modalities of working relationships and the chaotic conditions of urban mobility.

The recent real estate launchings had adopted the home office in its sales prospects as one plus attractive in the customer's decision of purchase, what it can be analyzed as a trend of that the promotional market of dwelling units target is to supply the necessities and requirements of the users and the home office is one of them.

This research investigates the insertions of the spaces for the office work in the residential real estate launchings with the objective to identify to which the environments that had yielded physical area or that they coexist with the activities of this function; and, later investigates the work place conditions, analyzing some human factors questions, comparing these conditions with the comfort standards. 


\section{Glossário}

\section{Banda Larga}

capacidade de transmissão que é superior àquela da primária de 1.5 ou 2 Megabits por segundo.

\section{Desktop}

Microcomputador de mesa.

\section{Downsizing}

Redução e otimização dos recursoa humanos da empresa.

\section{E-commerce}

comércio eletrônico feito com utilização de equipamentos de informática.

\section{Free Address}

Estações de trabalho na área física da empresa para serem utilizadas eventualmente por funcionários com pouca necessidade do uso destas estações.

\section{Handhelds}

Microcomputador portátil de bolso.

\section{Home banking}

termo utilizado para caracterizar transações, pagamentos e outras operações financeiras e de dados pela Internet por meio de uma página segura de banco.

\section{Hoteling}

Espaços privativos, inserido ou não na área física da empresa, com serviços administrativos de secretária, salas de reuniões e de estar, infraestrutura de comunicação e atendem aos funcionários que não têm a necessidade de permanecer na empresa durante todo o período do expediente, e devem agendar previamente o uso da sala.

\section{Lan House}

Centro Público de Acesso à Internet.

\section{Lay-out}

Arranjo.

\section{Notebook}

Microcomputador portátil.

\section{Red Carpet Club}

São ambientes fora das empresas que dispõem de áreas informais, espaços privativos, salas para reuniões e conferências onde empresas ou profissionais que não possuem de infraestrutura própria podem usufruir de facilidades de um espaço administrativo por um determinado período de tempo.

\section{Show Room}

Local de exposição.

\section{Smartphone}

Dispositivo para telefonia celular com funções de microcomputador.

\section{Teletrabalho}

Trabalho desenvolvido à distância com a utilização de equipamentos de comunicação e informática. 


\section{Índice Remissivo}

Figuras

Figura 1

Figura 2

Figura 3

Figura 4

Figura 5

Figura 6

Figura 7

Figura 8

Figura 9

Figura 10

Figura 11

Figura 12

Figura 13

Figura 14

Figura 15

Figura 16

Figura 17

Figura 18

Figura 19

Figura 20

Figura 21

Figura 22

Gráficos

Gráfico 1

Gráfico 2

Gráfico 3

Gráfico 4

Gráfico 5

Gráfico 6

Gráfico 7

Gráfico 8

Gráfico 9

Gráfico 10

Gráfico 11

Gráfico 12

Gráfico 13

Gráfico 14

Gráfico 15

Gráfico 16

Gráfico 17

Gráfico 18

Gráfico 19

Gráfico 20
Trabalhadores em Casa $\quad 03$

Dubrovnik: Typical Urban House 11

Atividade de escribas nos monastérios $\quad 12$

Escrivão 14

Escritório doméstico $\quad 15$

Ficha cadastral das plantas selecionadas $\quad 114$

Dimensões corporais $\quad 141$

Postura - Uso da mesa $\quad 143$

Postura - Uso de microcomputador e periféricos 143

Postura - Armazenamento 143

Postura - Uso da cadeira 148

Ajustes ergonômicos de cadeiras $\quad 149$

Alcances horizontais $\quad 150$

Alcances verticais $\quad 151$

Arranjo compacto $\quad 153$

Mapa do Município de São Paulo $\quad 192$

Ficha de empreendimento $\quad 244$

Empreendimento Tribeca - Planta opção "A" 245

Empreendimento Tribeca - Planta opção " $B$ " 246

Escritório residencial - família Velásquez $\quad 255$

Promoção de acesso à banda larga $\quad 237$

Sala de telepresença $\quad 275$

Usuário da internet na América do Norte $\quad 48$

Teletrabalhadores Europeus

Freqüência da atividade

55

Flexible Working 2009

Flexibilidade do trabalho na Europa e Rússia $\quad 56$

Where employees telework 60

Main telework tasks 2009

Proportion of employees Who telework 61

Time spent teleworking $\quad 62$

Facilities used for teleworking $2009 \quad 63$

Facilities used for teleworking $2005 \quad 63$

Países asiáticos com maior número de

usuários da internet

64

Distribuição de acesso às TICs - Brasil $\quad 67$

Faixa etária de acesso às TICs 68

Locais de acesso à Internet - Brasil 69

Comparativo dos principais locais de acesso à

Internet - Brasil

69

Porcentagem de domicílios que possuem

equipamentos TIC

70

Evolução da posse de computadores em

domicílios brasileiros

Evolução da posse de computadores e aceso à Internet em domicílios brasileiros

Evolução dos usuários de computadores

e da Internet

Evolução das modalidades de acesso à Internet

Porcentagem de empreendimentos residenciais

lançados por zona do Município de São Paulo

\section{8}

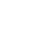

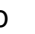

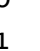
.

.

6

\section{9}

0


Gráfico 21

Gráfico 22

Gráfico 23

Gráfico 24

Gráfico 25

Gráfico 26

Gráfico 27

Gráfico 28

Gráfico 29

Gráfico 30

Gráfico 31

Gráfico 32

Gráfico 33

Gráfico 34

Gráfico 35

Gráfico 36

Gráfico 37

Gráfico 38

Gráfico 39

Gráfico 40

Gráfico 41

Gráfico 42

Gráfico 43

Gráfico 44

Gráfico 45

Gráfico 46

Gráfico 47

Gráfico 48

Gráfico 49

Gráfico 50

Gráfico 51

Gráfico 52

Gráfico 53

Gráfico 54

Gráfico 55
Porcentagem de plantas analisadas por

tipologia da habitação

Area Média das plantas cadastradas por tipologia da habitação ambientes para Home Office postos de trabalho para Home Office

Porcentagem de empreendimentos lançados com Home Office por zona na cidade 196 Porcentagem de plantas com Home Office por tipologia da habitação

Porcentagem por tipologia de implantação 
Gráfico 56

Gráfico 57

Gráfico 58

Gráfico 59

Gráfico 60

Gráfico 61

Gráfico 62

Gráfico 63

Gráfico 64

Gráfico 65

Gráfico 66

Gráfico 67

Gráfico 68

Gráfico 69

Gráfico 70

Gráfico 71

Gráfico 72

Gráfico 73

\section{Quadros}

Quadro 1

Quadro 2

Quadro 3

Quadro 4

Quadro 5

Quadro 6

Quadro 7

Quadro 8

Quadro 9

Quadro 10

Quadro 11

Quadro 12

Quadro 13

Porcentagem por ambiente de implantação

em ambiente adaptado

Porcentagem por ambiente de implantação

em parte de ambiente

Porcentagem de implantação por

setor da habitação

Porcentagem de postos de trabalho com

áreas abaixo da recomendação

Porcentagem de cadeiras por material

Porcentagem de cadeiras por material por itens de não conformidade

Porcentagem de cadeiras por material

por conformidade

224

Porcentagem de mesas por material

Porcentagem de mesa de trabalho com

altura de tampo recomendada

Porcentagem de mesas por material

de revestimento de tampo

Porcentagem de microcomputador por tipologia $\quad 226$

Porcentagem de monitores por tipologia $\quad 226$

Porcentagem de monitores em

conformidade segundo a altura

Porcentagem de teclado em conformidade

segundo a altura

Porcentagem de iluminação em não conformidade 227

Porcentagem dos fatores positivos sobre

a atividade de escritório na habitação

Porcentagem dos fatores negativos sobre

a atividade de escritório na habitação

Porcentagem de pontos negativos de

conforto do posto de trabalho implantado

Modelo tradicional de trabalho e

novas tendências

43

Fluxograma de atividades

Classificação das empresas construtoras

e incorporadoras

108

Lançamentos residenciais por bairro

108

Distribuição das amostras

Aplicações da ergonomia na arquitetura

109

136

Roteiro de análise da atividade 139

Parâmetros e critérios de desempenho $\quad 162$

Classes sociais $\quad 171$

Grupos sociais $\quad 172$

Papéis do cliente $\quad 177$

Compatibilização de zonas da

Cidade de São Paulo

192

Lançamentos residenciais por bairro 


\section{Tabelas}

Tabela 1

Pesquisa 1 - Suécia 1951 | 1954

Atividades pessoais

Tabela 2

Pesquisa 1 - Suécia 1951| 1954

Tempo na habitação

Tabela 3

Teletrabalhadores Americanos

Freqüência da atividade

Tabela 4

Teletrabalhadores Americanos

Local da atividade

51

Flexible Working 2009

Disponibilidade para flexibilização

Tabela 6

Grau de confiabilidade estatística

106

Formas de contato

142

Tabela 8

Requisitos de Uso 


\section{Siglas e Abreviaturas}

$\begin{array}{ll}\text { ABINEE } & \text { Associação Brasileira de Indústria Elétrica e Eletrônica } \\ \text { ABNT } & \text { Associação Brasileira de Normas Técnicas } \\ \text { ANATEL } & \text { Agência Nacional de Telefonia } \\ \text { CBI } & \text { Confederation of British Industry } \\ \text { CCOHS } & \text { Canadian Centre for Occupational Health and Safety } \\ \text { CGI } & \text { Comitê Gestor da Internet no Brasil } \\ \text { COHAB } & \text { Companhia Metropolitana de Habitação } \\ \text { CPU } & \text { Unidade Central de Processamento } \\ \text { DORT } & \text { Distúrbios Osteomusculares Relacionados com o Trabalho } \\ \text { EMBRAESP } & \text { Empresa Brasileira de Estudos do Patrimônio } \\ \text { EWCO } & \text { European Working Conditions Observatory } \\ \text { FAUUSP } & \text { Faculdade de Arquitetura e Urbanismo } \\ & \text { da Universidade de São Paulo } \\ \text { IBGE } & \text { Instituto Brasileiro de Geografia e Estatística } \\ \text { IBM } & \text { International Business Machines } \\ \text { IBOPE } & \text { Instituto Brasileiro de Opinião Pública e Estatística } \\ \text { ICMS } & \text { Imposto sobre a Circulação de Mercadorias e Serviços } \\ \text { IESNA } & \text { Iluminating Engineering Society of North America } \\ \text { INSS } & \text { Instituto Nacional de Seguridade Social } \\ \text { LER } & \text { Lesão por Esforço Repetitivo } \\ \text { LNEC } & \text { Laboratório Nacional de Engenharia Civil } \\ \text { LUOS } & \text { Lei de Uso e Ocupação do Solo } \\ \text { NBR } & \text { Norma Brasileira } \\ \text { OIT } & \text { Organização Internacional do Trabalho } \\ \text { OSHA } & \text { Occupational Safety and health Administration } \\ \text { PNAD } & \text { Pesquisa Nacional de Amostra de Domicílios } \\ \text { SOBRATT } & \text { Sociedade Brasileira de Teletrabalho e Teleatividades } \\ \text { TIC } & \text { Tecnologias de Informação e Comunicação } \\ \text { TIC Domicilios } & \text { Tecnologias de Informação e Comunicação Domicílios } \\ \text { TIC Empresas } & \text { Tecnologias de Informação e Comunicação Empresas } \\ \text { SEADE } & \text { Fundação Sistema Estadual de Análise de Dados } \\ \text { SECOVI } & \text { Sindicato das Empresas de Compra, Venda, Locação e } \\ & \text { Administração de Imóveis Residenciais e Comerciais } \\ \text { SEMPLA } & \text { de São Paulo) } \\ \text { Mbps } & \text { Secretaria Municipal do Planejamento Urbano } \\ \text { dB (A) } & \text { Megabites por segundo } \\ \text { LUX } & \text { decibéis } \\ \text { Unidade de iluminância }\end{array}$


SUMÁRIO

Agradecimentos

Resumo

Abstract

Glossário

Índice Remissivo

Siglas e Abreviaturas

\section{Capítulo 1. INTRODUÇÃO}

1.1. Considerações Preliminares 01

1.2. Hipóteses 02

1.3. Relevância da Pesquisa 03

1.4. Objetivos da Pesquisa 06

1.5. Universo de Estudo 08

1.6. Histórico 09

1.7. Teorias, Conceitos e Definições 27

1.8. Cenário Mundial 48

1.8.1. O Cenário da America do Norte 48

1.8.1.1. Os Estados Unidos da América $\quad 49$

1.8.1.2. O Canadá 53

1.8.2. O Cenário Europeu 54

1.8.3. O Cenário Australiano 59

$\begin{array}{ll}\text { 1.8.4. Os Cenários Asiático, Africano e } & \\ & \text { Oriente Médio }\end{array}$

1.9. O Cenário Brasileiro, Empresas Nacionais e

$\begin{array}{ll}\text { Legislação } & 66 \\ \text { 1.9.1. O Cenário Brasileiro } & 66\end{array}$

1.9.2. Empresas Nacionais 75

1.9.2.1. Cisco 80

1.9.2.2. IBM Brasil 82

1.9.2.3. Ticket Accor 83

1.9.2.4. Virtual Call 85

1.9.3. Legislação 87

1.10. Trabalho à distância e Sustentabilidade 91

\section{Capítulo 2. METODOLOGIA}

2.1. Considerações Preliminares 100

2.2. Etapas do Desenvolvimento do Trabalho 103

2.2.1. Etapa 1. Levantamento de dados secundários 103

2.2.2. Etapa 2. Levantamento de informações de campo $\quad 104$

2.2.2.1. Parte A - Inclusão de Home Offices lançamentos imobiliários $\quad 104$

2.2.2.2. Parte $B$ - O uso de ambientes da habitação para atividades de escritório

2.2.3. Etapa 3. Tabulação das informações pesquisadas

2.2.4. Etapa 4. Análise e diagnóstico das informações levantadas

2.2.5. Etapa 5. Verificação e comprovação da hipótese

2.2.6. Etapa 6. Conclusões, reflexões, Recomendações e pesquisas futuras 


\section{Capítulo 3. PARÂMETROS ERGONÔMICOS E INDICADORES}

3.1. Considerações Preliminares 133

3.2. Análise da Atividade 138

3.2.1. Objeto e local de estudo 140

3.2.2. Funções do objeto de estudo 140

3.2.3. Informações do usuário 141

3.2.4. Informações da atividade de uso 142

3.2.5. Informações da área física 144

3.2.6. Informações dos requisitos de uso 144

3.2.7. Diagnóstico ergonômico 145

3.2.8. Recomendações de conforto 146

3.3. Conforto Ergonômico e Dimensional 147

3.3.1. Cadeira 147

3.3.2. Mesa 149

3.3.3. Microcomputador e periféricos 150

3.3.4. Conforto dimensional 152

3.4. Conforto Visual 153

3.5. Conforto Higrotérmico, Ventilação e
Qualidade do Ar

3.6. Conforto Acústico 159

3.7. Conclusões 161

\section{Capítulo 4. A INCLUSÃO DE ESCRITÓRIOS RESIDENCIAIS EM LANÇAMENTOS IMOBILIÁRIOS}

4.1. Considerações Preliminares 165

4.2. Introdução 166

4.3. Desenvolvimento da Pesquisa 179

4.4. Processamento dos Dados Pesquisados 180

4.5. Análise e Diagnóstico das Informações Levantadas 201

\section{Capítulo 5. O USO DE AMBIENTES DA HABITAÇÃO PARA} ATIVIDADES DE ESCRITÓRIO

5.1. Considerações Preliminares 208

5.2. Introdução 209

5.3. Desenvolvimento da Pesquisa 212

5.4. Processamento dos Dados Pesquisados 213

5.5. Análise e Diagnóstico das Informações Levantadas 229

\section{Capítulo 6. CONCLUSÕES, REFLEXÕES E RECOMENDAÇÕES}

6.1. Considerações Preliminares 241

6.2. Verificação de Comprovação das Hipóteses 241

6.2.1. Verificação da Hipótese - parte A 242

6.2.2. Verificação da Hipótese - parte B 247

6.3. Conclusões, Reflexões e Recomendações 253

6.4. Pesquisas Futuras 276

\section{Capítulo 7. BIBLIOGRAFIA}

7.1. Bibliografia Referenciada

7.2. Bibliografia Consultada 

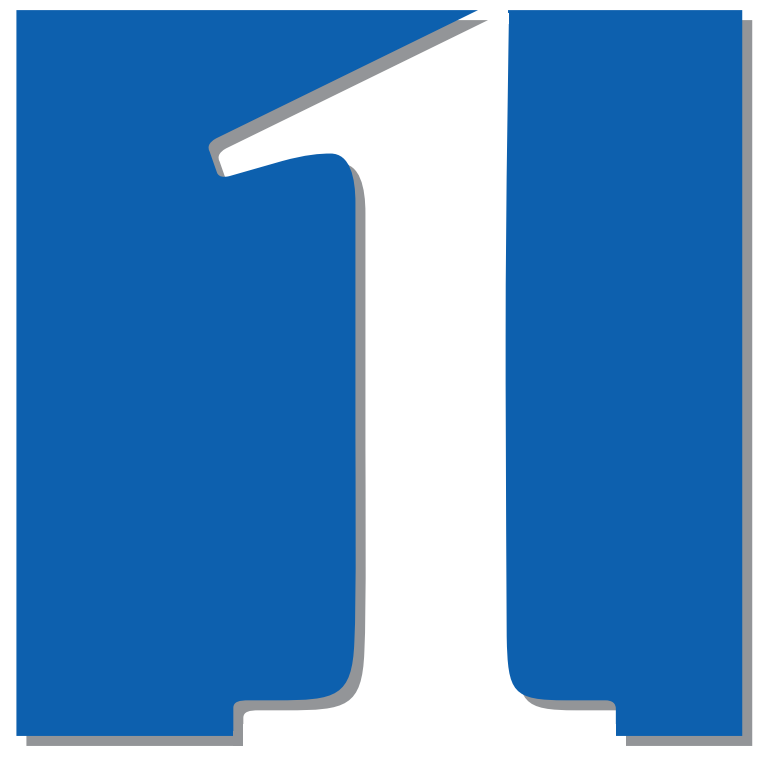

Introdução 


\section{CAPÍTULO 1.}

INTRODUÇÃO

\subsection{Considerações Preliminares}

O binômio "casa-trabalho" sempre esteve relacionado à história da humanidade e, principalmente no cotidiano dos grandes centros urbanos, percebe-se cada vez mais que esta inter-relação está tão ativa quanto foi na época dos artesãos que se utilizavam do espaço sob sua habitação para desenvolver as atividades profissionais.

A presente tese estuda este tema, sob a luz do uso dos ambientes da habitação para o desenvolvimento de atividades de escritório, percorrendo a história dessa relação, chegando até nossos dias, investigando as demandas e respostas que usuários, tecnologias, legislação e promotores da habitação estão desenvolvendo sobre esta questão.

Esta tese, embora voltada à produção acadêmica, é um convite a pesquisadores, promotores de empreendimentos imobiliários, alunos e usuários que fazem da habitação seu foco de estudo ou local de trabalho, no intuito de colaborar com informações que possam ser utilizadas para o aprimoramento dos espaços inseridos na habitação destinados para estas atividades, quer seja no âmbito do projeto ou na melhoria das condições de trabalho para o usuário. 


\section{$1.2 \quad$ Hipótese}

Os projetos de arquitetura que afirmam contemplar o "home office", na verdade não inseriram um novo ambiente na habitação, mas sim estão adaptando espaços já existentes à estas atividades e disponibilizando a possibilidade de serem utilizados para esta finalidade e;

Existe uma atividade com características de trabalho de escritório e que é distinta das atividades administrativas pessoais e familiares que são realizadas no ambiente residencial e este ambiente não oferece condições de abrigar estas atividades, nomeadamente nos seguintes aspectos e condições de conforto:

- Área física

- Mobiliário

- Equipamentos

- lluminação

- Atividade doméstica | Atividade profissional 


\subsection{Relevância da Tese}

Segundo o Instituto Brasileiro de Geografia e Estatística IBGE, o volume de trabalhadores brasileiros que desenvolvem suas atividades remuneradas no ambiente doméstico cresceu $47 \%$ (quarenta e sete por cento) entre 2005 e 2008 - de 141 mil para 208 mil trabalhadores incluindo aqueles que possuem carteira assinada e aqueles que não possuem carteira assinada. Figura 1
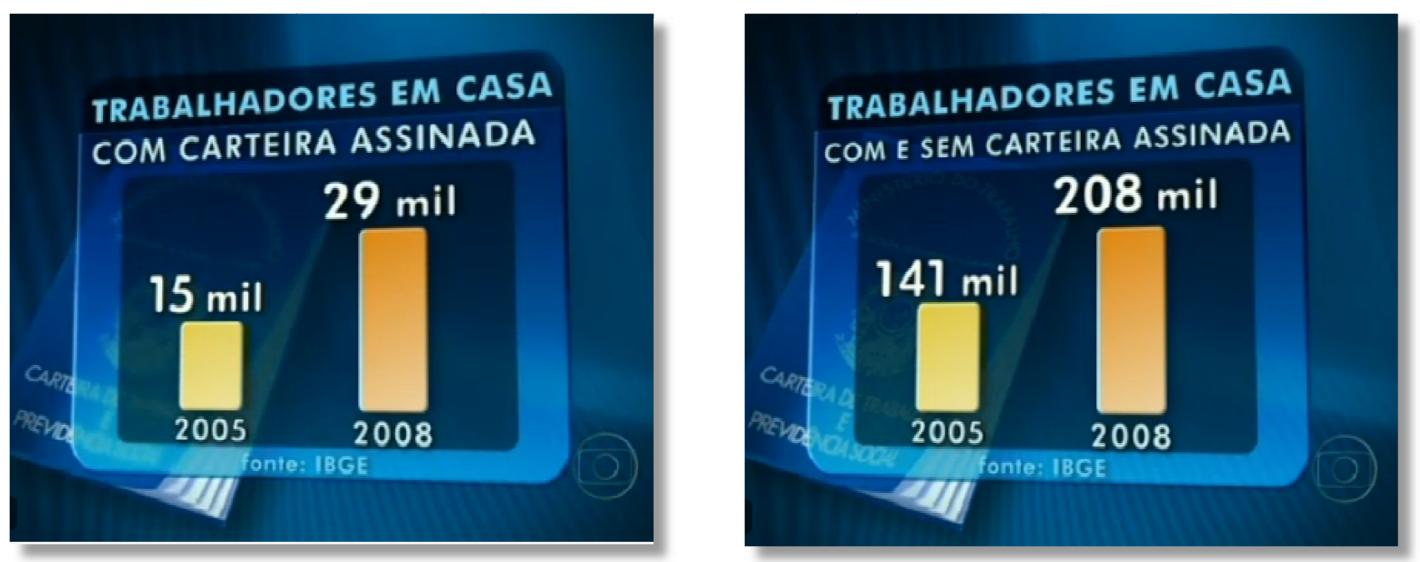

$10 / 2009$

Empresas no Brasil como a Natura, Cisco do Brasil, Dell do Brasil, Semco, Virtual Call, AT \& T Brasil, dentre outras, permitem que parte de seus funcionários desenvolvam seu trabalho à distância, ou seja, fora da área física da empresa.

Segundo a Sociedade Brasileira de Teletrabalho e Teleatividades - SOBRATT, em 2008 o Brasil contava com cerca de 10 milhões e seiscentos mil teletrabalhadores. 
Esta estimativa foi feita a partir de dados gerais sobre o acesso dos brasileiros a computadores e a Internet levantados por diferentes pesquisas de diferentes instituições (PNAD/IBGE, TIC Domicílios, TIC Empresas, Painel IBOPE/NetRatings), e não diferencia regiões ou estados do país, e inclui todos os setores e áreas, bem como todos os tipos de teletrabalhadores: formais, informais, empregados ou por conta própria, autônomos, liberais, em tempo integral, parcial, complementar e eventual, numa ampla faixa etária que vai dos 18 aos 60 anos, com utilização de acesso à Internet de 1 vez por semana a 1 vez por dia, considerando-se a utilização de desktops, notebooks, handhelds, smartphones, com acesso discado e/ou banda larga, para trabalhos completos ou atividades parciais, ou seja, são cerca de $5 \%$ da população brasileira, sem considerar regiões específicas.

No mês de junho de 2009, o Jornal "O ESTADO DE SÃO PAULO", divulgou dados da pesquisa realizada pelo instituto Market Analysis sobre teletrabalhadores no Brasil que apontam que pelo menos $23,2 \%$ da população adulta em atividade no país (cerca de um em cada quatro brasileiros) adota ao longo do mês alguma forma de teletrabalho, sendo que, entre todos, o trabalho em casa é a modalidade mais comum ( $52 \%)$.

Não obstante o crescimento do número de pessoas que se utilizam da modalidade de trabalho remoto, fatores como qualidade de vida, sustentabilidade, mobilidade urbana, em maior ou menor escala, sofrem alterações devido esta tendência de comportamento, tornando o objeto de estudo - Escritórios Residenciais - ainda mais relevante e necessário, já que, conforme pesquisado, a habitação como local de trabalho à distância é o local mais utilizado pelos teletrabalhadores, ultrapassando a casa dos $50 \%$ dos casos. 
Finalmente, o estudo torna-se relevante neste momento pois, no Brasil, o processo encontra-se em estágio inicial de implementação, com casos esporádicos de empresas que começam a adotar o teletrabalho como opção aos seus funcionários, portanto, analisar as condições dos postos de trabalho na habitação pode trazer à luz eventuais desacordos que poderão ser tratados com maiores cuidados, colaborando com a melhoria das condições de trabalho dos usuários. 


\subsection{Objetivos da Pesquisa}

O objetivo da pesquisa é analisar como a arquitetura do setor residencial está respondendo à recente demanda por espaços destinados a postos de trabalho e escritórios residenciais e quais as condições de conforto em que estes usuários desenvolvem essas atividades.

Para tanto, algumas questões são colocadas neste momento para serem as diretrizes norteadoras do estudo:

- Os lançamentos imobiliários recentes estão de fato envolvidos em atender a uma demanda de consumidores que fazem da habitação seu local de trabalho oferecendo opções de plantas que contemplam o Home Office?

- A incorporação de espaços destinados ao desenvolvimento de trabalho na habitação nos lançamentos imobiliários do município de São Paulo pode ser considerada uma tendência?

- As opções de plantas com o Home Office incorporado, ou áreas para produção de trabalholestudo apresentadas nos lançamentos imobiliários no município de São Paulo atendem aos parâmetros de área física mínima propostos nesta tese?

- Os parâmetros de conforto propostos nesta tese estão sendo atendidos nos ambientes das habitações paulistanas utilizados para o desenvolvimento de atividades de trabalholestudo em relação a:

- Área Física

- Mobiliário

- Equipamentos

- Conforto Visual 
- Qual o principal aspecto, na opinião dos teletrabalhadores do município de São Paulo, que influenciam positivamente para a adoção do trabalho em Home Office?

- Qual o principal aspecto, na opinião dos teletrabalhadores do município de São Paulo, que influenciam negativamente para a adoção do trabalho em Home Office?

- As atividades domésticas interferem de maneira negativa nas atividades profissionais dos trabalhadores do Home Office do município de São Paulo?

- Qual o item de conforto que o usuário do município de São Paulo considera ser o que mais interfere negativamente no desenvolvimento de suas atividades de trabalho no Home Office? 


\subsection{Universo de Estudo}

O objeto tema deste estudo são os Escritórios Residenciais.

Para a primeira parte da hipótese foram consideradas as unidades habitacionais lançadas pelo mercado imobiliário no período de 2006 a 2009 no Município de São Paulo.

Para a segunda parte da hipótese foram considerados os domicílios de trabalhadores que desenvolvem suas atividades de trabalho de escritório a partir de suas residências no Município de São Paulo. 


\subsection{Histórico}

Ao final do ano de 2005, o autor apresentou junto à Faculdade de Arquitetura e Urbanismo da Universidade de São Paulo FAUUSP a dissertação de mestrado com o título: "Escritórios Residenciais: aspectos que influenciam a implantação e o uso de ambientes da habitação para o desenvolvimento de atividades de escritório", onde foram discutidos de maneira sistemática e sob diversos prismas, os itens mais relevantes para a implantação de postos de trabalho ou o uso de ambientes da habitação para o desenvolvimento destas atividades.

A seqüência natural daquele trabalho e aqui apresentada como tese de doutoramento, é o aprofundamento desta questão, onde se faz necessária uma investigação de como o tema vem sendo abordado pelo mercado imobiliário, quais as condições de trabalho em que os usuários desenvolvem suas atividades e ainda, a busca da caracterização dos principais motivos que levam trabalhadores a desenvolverem suas atividades de escritório no ambiente doméstico com o objetivo primordial de prover aos arquitetos e profissionais ligados à produção habitacional, subsídios que sejam incorporados ao desenvolvimento do programa e promovendo a qualidade do projeto da habitação na medida em que as necessidades dos usuários possam ser por eles atendidas.

É importante salientar que essas atividades de trabalho não estão necessariamente ligadas a um ambiente específico da habitação, podendo ser desenvolvidas em qualquer parte da casa onde o usuário encontre o conjunto de condições que atendam suas necessidades da melhor maneira possível e ainda, por muitas vezes estão atreladas a outra função, a de estudo e lazer, onde compartilham de um mesmo conjunto de equipamentos e do mesmo espaço físico. 
Sob esse prisma, pode-se reportar à narrativa de Norbert Schoenauer (2000), em seu livro "6.000 years of housing", que expõe exemplos dos primórdios da vida doméstica, onde os grupos humanos produziam apenas para a subsistência e que desenvolviam as atividades domésticas simultaneamente às rotinas produtivas.

Em sua narrativa, referindo-se às habitações encontradas em escavações da cidade de Ur, na Mesopotâmia, datadas de 3000 a 2400 a.C., Schoenaver(2000) coloca:

"[...] É importante lembrar que nas casas
urbanas das antigas civilizações
frequentemente eram combinadas
acomodações da vida familiar com espaços
de trabalho de seus proprietários. A
separação entre 'casa' e 'trabalho',
perfeitamente natural para nós, deveria
parecer absurda nas moradias das cidades
antigas."

Nas épocas em que as transformações sociais eram raras e percorriam longos períodos até sua sedimentação, o modelo de vida grupal foi sendo lentamente alterado e, embora a disseminação das células habitacionais unifamiliares tenham se desenvolvido, chegamos à Era Medieval onde, sob o mesmo espaço, conviviam os membros da família, chefiados pelo homem (e mestre), os aprendizes e os empregados, realizando, neste espaço único, as tarefas e atividades de produção e serviços ao lado das atividades domésticas. Figura 2 

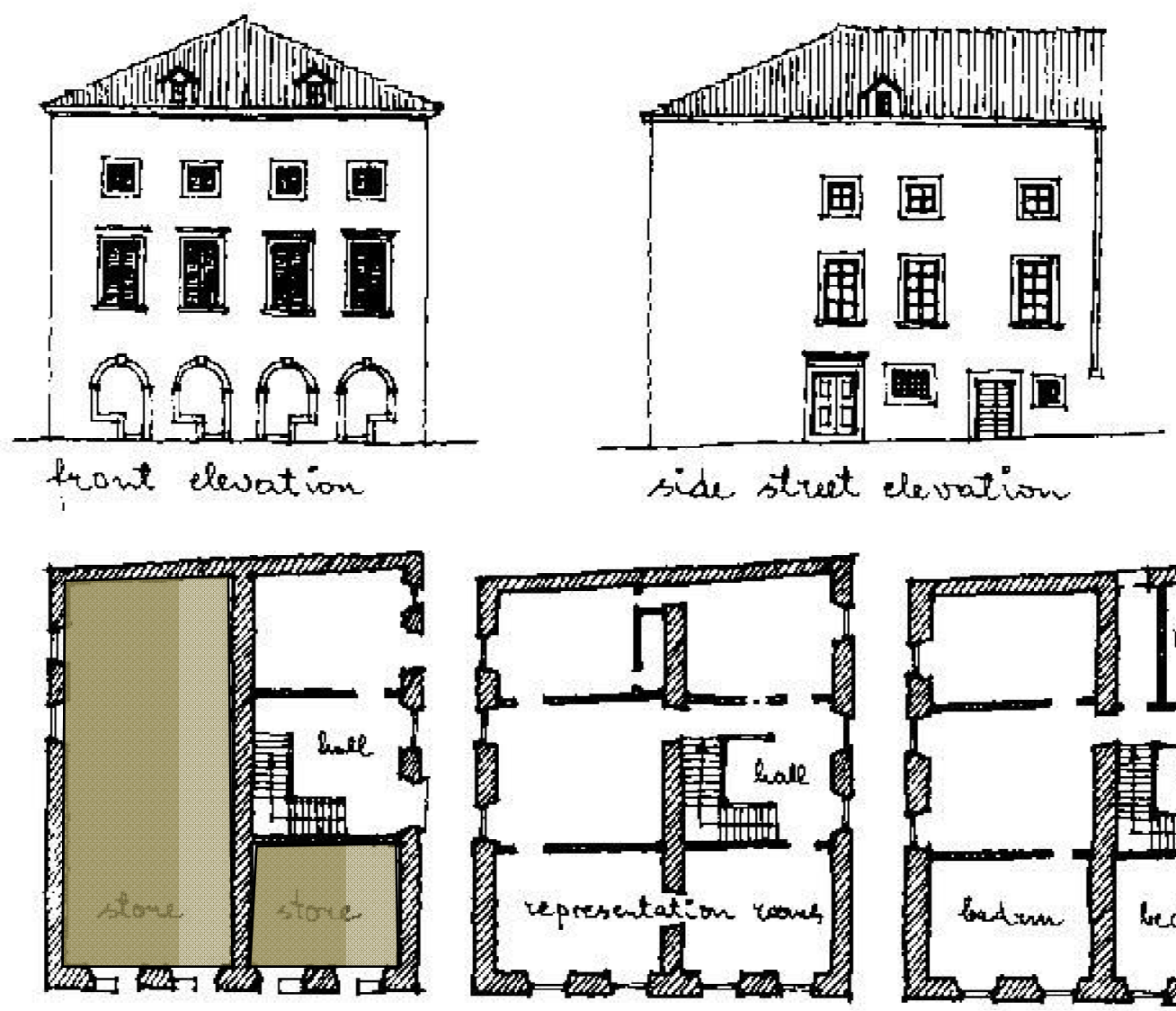

groumd pare
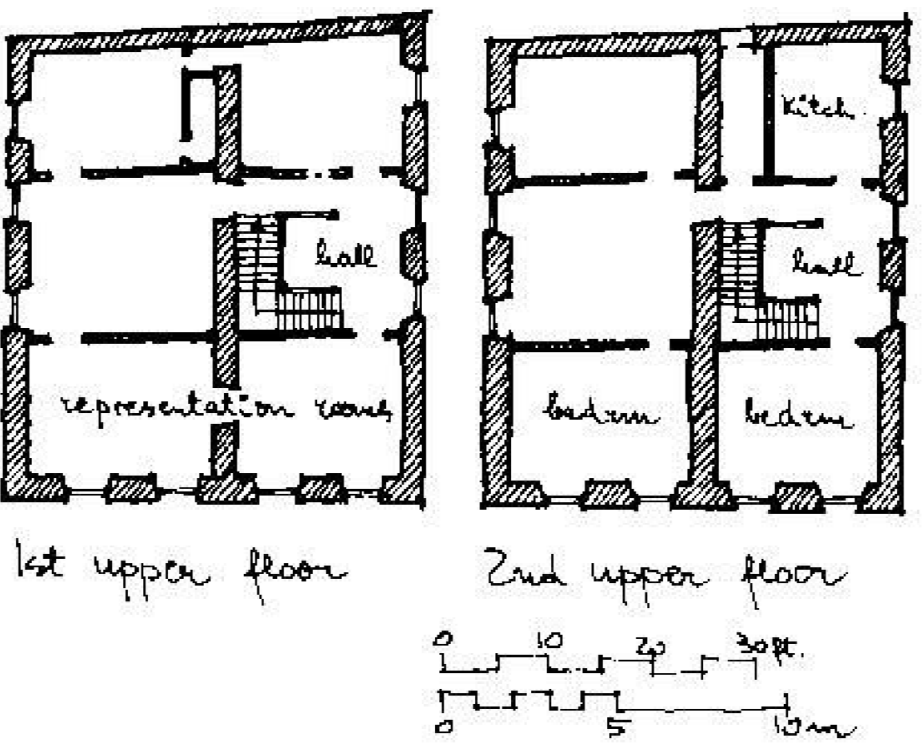

Entende-se que, paralelamente ao desenvolvimento das atividades do fazer, o ser humano desenvolvia instrumental e processos facilitadores destas atividades, ou seja, o pensamento humano ocupava-se de como fazer.

Assim pode-se pensar que, aliado ao trabalho humano relativo ao esforço físico necessário à execução de uma tarefa, estava o trabalho mental. 
Se a necessidade de espaço para o desempenho das atividades produtivas é imprescindível, também existe demanda para locais onde o pensamento pode ser desenvolvido sem interferências externas.

Segundo a autora Élisabeth Péllegrin-Genel ${ }^{2}$ (1996), em seu livro "The Office", o scriptorium aparece na história datado de três mil anos a.C., sendo um espaço no qual os escribas egípcios desenvolviam tarefas de apontamentos, desenhos de mapas, registros de transações comerciais, etc.

Com os monastérios, a escrita e a leitura silenciosa ganharam força na vida íntima dos eclesiásticos, as bibliotecas surgiram como espaços destinados a estas atividades e a partir do Séc. XII foram incorporados às escolas e universidades. Figura 3

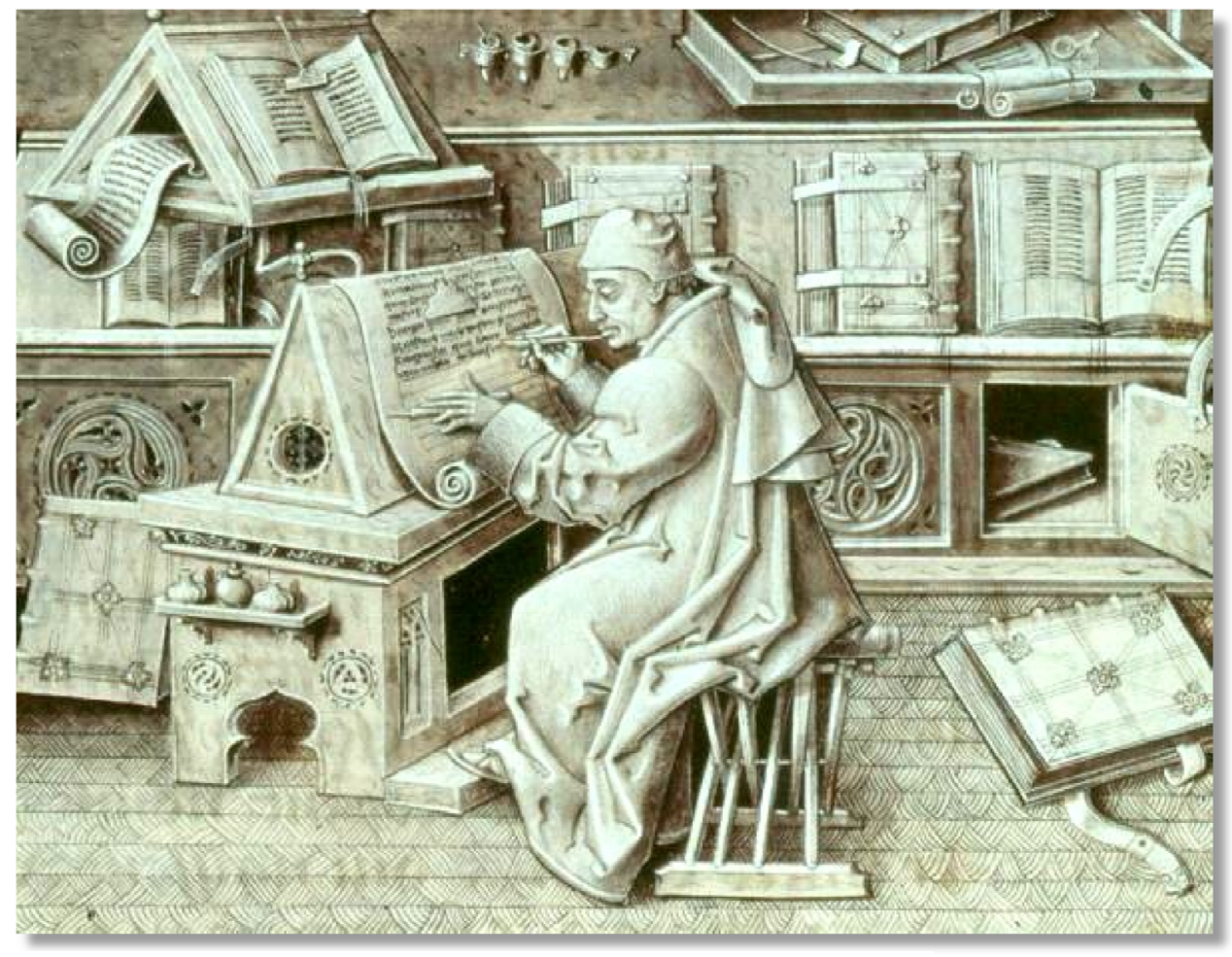

${ }^{2}$ Péllegrin-Genel, E. The Office - New York: Flammarion-Pere Castor, 1996 
Os Séculos XI e XII viram o ressurgimento das cidades européias devido ao renascimento comercial, fruto de uma nova realidade rural onde o esgotamento das terras férteis reduziu as alternativas de trabalho dos camponeses, aliado ao movimento das Cruzadas e o intercâmbio com os produtos do Oriente.

As atividades comerciais alavancaram o renascimento urbano e a classe burguesa, agora com prestígio econômico e poder, promoveu o Movimento Comunal, ou seja, a independência das cidades em relação aos feudos.

Este novo momento da vida urbana traz consigo o Renascimento Cultural.

O comércio desenvolvido entre diversos povos também colaborou com a troca de idéias e experiências culturais e, principalmente, o contato com o mundo islâmico, avançado em questões intelectuais e tecnológicas, criou um ambiente receptivo para a abertura de escolas e universidades por todo o Continente Europeu, disseminando os conhecimentos da leitura e escrita.

Nesse cenário, as atividades do scriptorium migram para as lojas do comércio, confundindo-se com as atividades domésticas. Figura 4 


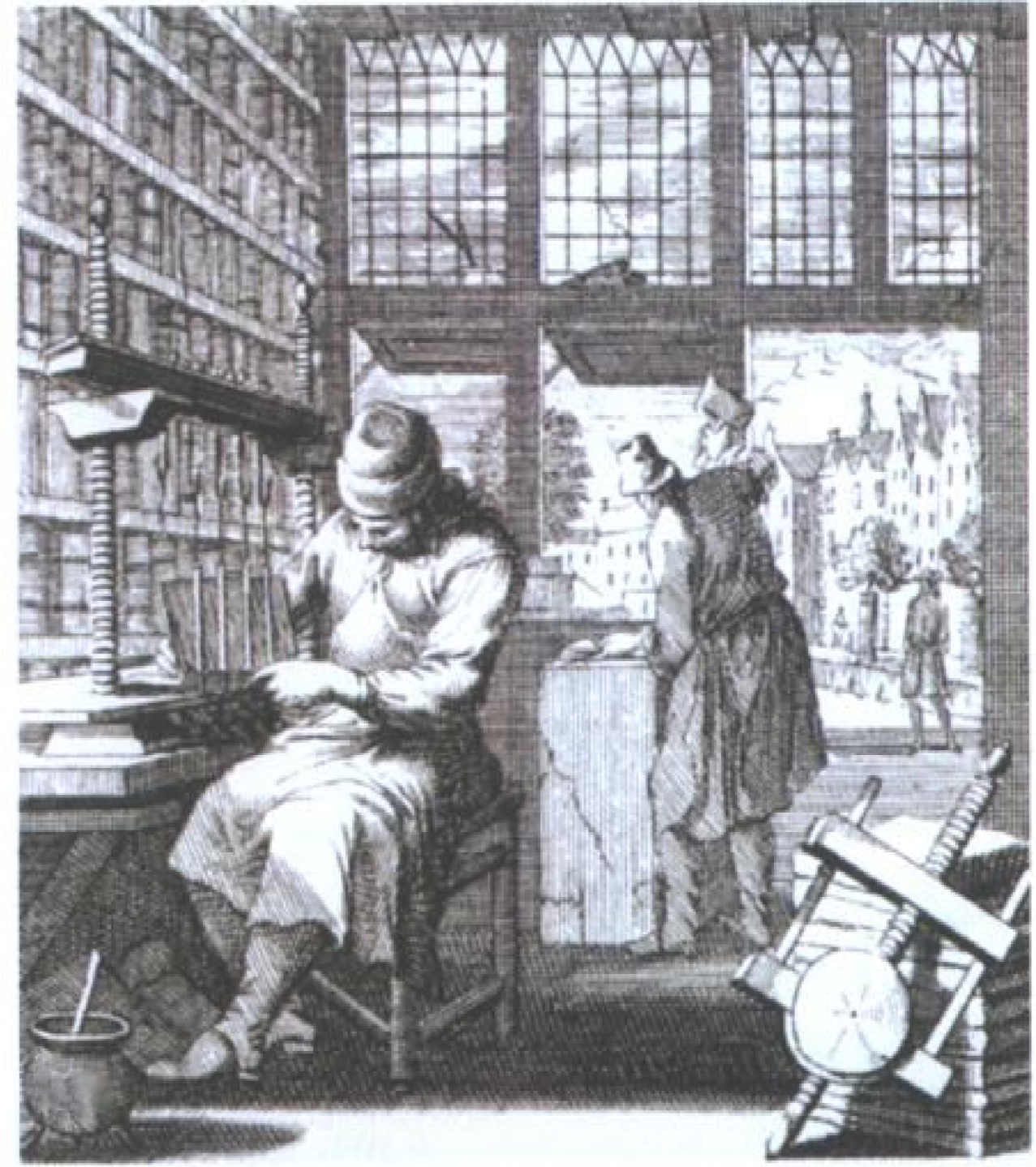

ração

O Renascimento Urbano e Cultural, possibilitou uma grande elevação na taxa de alfabetização, promovida pela ampla circulação de material impresso, e esse fato permitiu o acesso a um mundo interior, em que Péllegrin-Genel (1996) coloca: 
"[...] A leitura democratizou o aprendizado, oferecendo a todos múltiplas possibilidades intelectuais. Ao mesmo tempo, promoveu a busca da solidão: as casas passaram a contar com salas protegidas do corre-corre doméstico, onde as pessoas podiam estudar, meditar, escrever aos amigos distantes $e$ anotar os pensamentos mais intimos nas páginas de seus diários."

Péllegrin-Genel (1996) observa ainda que nesse período houve a influência das atividades de registros de propriedade como precursora do escritório privado, onde o mobiliário - e não a arquitetura - definia o ambiente. Figura 5

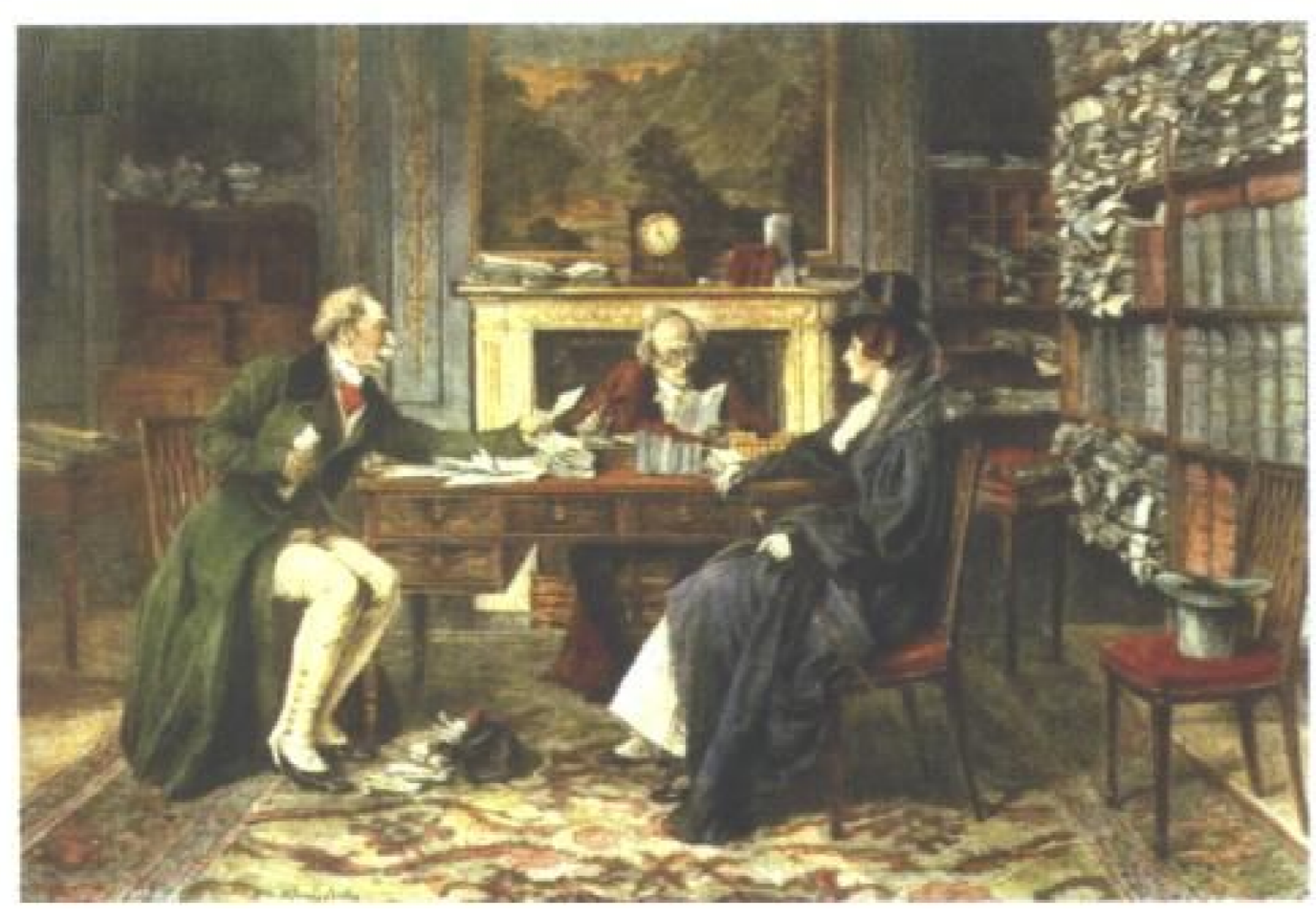

ração 
Os séculos XVIII e XIX viram a Revolução Industrial deslocar as atividades produtivas para os ambientes fabris, subtraindo das habitações a função de produção, passando a concentrar nestes espaços apenas as tarefas domésticas, caracterizando-se por um espaço de domínio da mulher, enquanto os homens se ausentavam para os ambientes de produção.

Este fenômeno é apontado por Lewis Mumford ${ }^{3}$ na narrativa "The City in History", e citado por Willian J. Mitchell ${ }^{4}$ em seu livro "City of Bits". Lewis descreve o gradual divórcio entre o lar e local de trabalho no Século XVII. Em outro trabalho, "The Culture of Cities", Lewis" (1940) retoma o tema e descreve:

\begin{abstract}
"[...] A alteração na constituição da estrutura doméstica manifestou-se de várias maneiras. Primeiro, pelo gradual divórcio entre a casa, desde então transformada em lugar para comer, para receber $e$, de um modo secundário, para criar filhos, e o local de trabalho... Como resultado de a casa doméstica transformar-se exclusivamente em organização de consumo, a dona de casa perdeu o contato que tinha com os negócios do mundo exterior: transformou-se em especialista em assuntos domésticos... Desde então a 'casa privada' passou a existir: privada em relação aos negócios."
\end{abstract}

\footnotetext{
${ }^{3}$ Mumford, L. The City in History-New York: Harcourt, Brace \& World, 1961

${ }^{4}$ Mitchell, W.J. City of Bits - Boston: M.I.T., 1995

${ }^{5}$ Mumford, L. The Culture of Cities - London: Secker \& Warburg, 1940
} 
Estas características prevaleceram até meados do século $\mathrm{XX}$, como mostram as pesquisas apresentadas no livro "Ergonomics of the Home", de Etienne Grandjean" (1973), onde a mulher é responsável pelas atividades realizadas no ambiente doméstico, especificamente das tarefas ligadas aos cuidados com as crianças, limpeza da casa, culinária e cuidados com as roupas e o homem aparece como o provedor, ocupado com atividades desenvolvidas fora do ambiente da habitação, função equivalente àquela desempenhada pelos machos na Pré-História quando estes eram os responsáveis em prover o grupo com a caça.

Tabelas 1 e 2

\begin{tabular}{|lcl|}
\hline - ATIVIDADES & (média semanal em minutos diários) \\
\hline Atividade & Mulheres & Homens \\
\hline Higiene Pessoal & 42 & 42 \\
\hline Cuidados com crianças & 76 & 25 \\
\hline Cozinhar / refeições & 236 & 81 \\
\hline Limpeza / Trabalhos dom. & 100 & 28 \\
\hline Cuidados com roupas & 154 & XXX \\
\hline Ocup. Externas / compras & 44 & 491 \\
\hline Tempo livre & 248 & 233 \\
\hline
\end{tabular}

Tabela 1 - Pesquisa 1 - Suécia 1951 / 1954

Fonte: Gradjean, E. Ergonomics of the Home. 1973. Tabela

\begin{tabular}{|lcc|}
\hline $\begin{array}{l}\text { - Tempo nos Diversos Locais da Casa } \\
\text { Local }\end{array}$ & $\begin{array}{c}\text { (das 7:00 às 19:00 Hs) } \\
\text { Mulheres }\end{array}$ & Homens \\
\hline Cozinha & 378 & 68 \\
\hline Estar & 65 & 31 \\
\hline Dormitório & 63 & 24 \\
\hline Banheiro & 39 & 8 \\
\hline Outros & 88 & 26 \\
\hline Fora & 87 & 563
\end{tabular}

Tabela 2 - Pesquisa 1 - Suécia 1951 / 1954

Fonte: Gradjean, E. Ergonomics of the Home. 1973. Tabela 
Com as transformações tecnológicas e das relações de trabalho que vêm se acentuando nos últimos 30 anos, novamente pode-se observar alterações no comportamento social, nas relações familiares e nas novas necessidades que pressupõem adequações nos ambientes domésticos capazes de suprir estas novas demandas.

"[..]. os lares voltarão a ser, como eram antes da Revolução Industrial, o centro de muitos aspectos da vida humana, em vez de simplesmente um local para se dormir e se passar o fim de semana[...]".

Esta afirmação, extraída do livro "O Fim das Distâncias", de Frances Cairncross7 (2000), a autora questiona as fronteiras entre as atividades de trabalho e a vida doméstica, desenvolvendo um raciocínio que vem de encontro com o que se observou na pesquisa, e segue:

"[...] Essas alterações (sobre o comportamento em relação ao trabalho e as comunicações) mudarão a arquitetura das casas. Os arquitetos ainda não assimilaram as transformações do lar de um lugar onde as pessoas consomem (refeições, entretenimento, etc.) para um lugar onde as pessoas produzem (as casas de hoje em dia podem ter tanto equipamento de informática quanto as grandes fábricas da década de 1970). Agora eles precisam achar uma forma confortável de acomodar o escritório em casa." 
Outro livro que segue esta linha é "E-Topia, a vida urbana mas não como a conhecemos" de William J. Mitchell ${ }^{8}$ (2002), que faz a predição:

"... A maioria de nós ainda quer viver num lugar mais ou menos fixo, na companhia daqueles a quem amamos... o lar ainda é o lugar onde o coração permanece - e onde o número cada vez maior de outras coisas acabará permanecendo também. Ele se tornará o foco da atenção e da inovação arquitetônica, pois integrará novas funções e serviços.

Da mesma forma que a Revolução Industrial forçou a separação entre a casa e o local de trabalho, a Revolução Digital está unindo os dois novamente. Veremos uma quantidade crescente de casas-escritórios equipadas eletronicamente e, ao mesmo tempo, uma demanda crescente por espaços na casa para acomodar os equipamentos necessários à execução do trabalho."

Estes textos reafirmam as preocupações com as transformações sociais que envolvem vida cotidiana, trabalho e família que vêm ocorrendo nos últimos anos, e ainda sua preocupação com o espaço que será ocupado por estas novas relações, geradoras de novas necessidades, inseridas no ambiente doméstico.

Trabalho e tecnologia sempre tiveram uma estreita relação na evolução da humanidade.

${ }^{8}$ Mitchell, W.J. E-Topia, a vida urbana - mas não como a conhecemos - São Paulo: SENAC, 2002 
Em 1776, Adam Smith ${ }^{9}$ com o livro "A Riqueza das Nações" lançava sua teoria de uma 'Economia de Livre Mercado'.

Duzentos anos se passaram para que o mundo se transformasse em um grande e único mercado, onde fluxos financeiros e produtivos operassem no sistema " 24 $\times 7 \times 365^{\prime \prime}$ (horas do dia $x$ dias da semana $x$ dias do ano).

Exemplo desse novo sistema de operações é o caso da IBM - International Business Machines, onde um grupo de programadores de computadores cria aplicativos em Pequim, envia o trabalho via internet para a sede da empresa em Seattle para que ele seja aperfeiçoado e enviado novamente para outro grupo na Letônia, após, as alterações seguem para o Tata Group na Índia, que devolve para Pequim na manhã seguinte, completando um turno de 24 horas dedicado ao desenvolvimento do projeto, consolidando a idéia do mundo globalizado que trouxe como conseqüência, a corrida por sistemas administrativos alternativos, abandonando as tradicionais filosofias de Taylor e a linha de produção de Ford.

Richard Donkin" (2003) com o livro "Sangue, Suor $e$ Lágrimas - A Evolução do Trabalho", relata as diversas fases pelas quais o trabalho se desenvolveu, ligando-as às transformações sociais e culturais que acompanharam o homem e desde seus primórdios.

${ }^{9}$ Smith, A. A Riqueza das Nações - São Paulo: Martins Fontes, 2003

${ }^{10}$ Donkin, R. Sangue, Suor e Lágrimas, a evolução do trabalho - São Paulo: M.Books, 2003 
Citadas por Donkin(2003), alternativas como a reengenharia, flexibilização, terceirização, downsizing (redução e racionalização dos recursos humanos das empresas) etc... e temas de autores como Alvin Toffler ${ }^{11}$, Manuel Castells ${ }^{12}$, Domenico de Masi $^{13}$ e Ricardo Semler ${ }^{14}$ cada qual interpretando o porquê, segundo a OIT Organização Internacional do Trabalho, um terço da população mundial estava desempregada no fim de $2000-$ sugerem tipologias de trabalho que, aliadas aos avanços tecnológicos das áreas da informática e comunicações, proporcionaram a possibilidade do desenvolvimento das atividades profissionais do trabalhador em locais distantes de seus postos de trabalho dentro da área física da empresa.

Quando se pretende a busca do embasamento conceitual das mudanças sociais que levaram às alterações nos programas habitacionais, é imperativo compreender esta inter-relação entre Tecnologia-Trabalho-Habitação, pois nela reside o conceito de Lugar e do Onde Fazer e a partir desta premissa trilhar a evolução do programa da habitação, conforme estudado na dissertação de mestrado.

Para este estudo, o fator relevante desta nova ordem - a globalização - é o deslocamento da força de trabalho das empresas para locais fora do espaço físico das mesmas.

\footnotetext{
${ }^{11}$ Toffer, A. A Terceira Onda-Rio de Janeiro: Record, 1980

${ }^{12}$ Castells, M. The Informational City-Cambridge: Blackwell, 1989

${ }^{13}$ De Masi, D. O Ócio Criativo - São Paulo: Sextante, 2000

${ }^{14}$ Semler, R. Virando a Própria Mesa-Rio de Janeiro: Rocco, 2002
} 
Tem-se aqui também outra série de exemplos de alternativas para estes novos espaços de trabalho, ou Escritórios "não territoriais" como os Escritórios Virtuais, Hotelling e Ciber Clubs (locais de arrendamento e locação de espaço e equipamentos para atividades de escritório de curta duração), e ainda o Home Office (Escritório Residencial), o qual é o objeto deste estudo.

O binômio microcomputador e redes de comunicação permitem que cada vez mais pessoas estejam habilitadas a desenvolverem tarefas de trabalho no ambiente doméstico e as novas alternativas de relações de trabalho convergem para esta migração.

Segundo o arquiteto americano Neil Zimmerman ${ }^{15}$ (1996), uma das referências em Escritórios Residenciais na América, os Estados Unidos já contam com mais de 45 milhões de trabalhadores que desenvolvem tarefas de trabalho em seus domicílios, chamados de "Home Officers" ou "Teleworkers".

A diferença é sutil. Em ambos os casos o trabalhador não tem a necessidade da presença física no ambiente da empresa, sendo que no caso dos "Home Officers", estes têm sua residência como a base de suas atividades.

No Brasil, nenhuma pesquisa conclusiva foi desenvolvida no sentido de contabilizar qual a realidade encontrada de indivíduos que desenvolvem atividades de "Home Officers" ou "Teleworkers" em ambientes domésticos, o que também vem de encontro à necessidade da continuidade dos estudos deste tema. 
A referência estatística a esta questão ainda permanece sendo a que foi apresentada pelo IBGE - Instituto Brasileiro de Geografia e Estatística, em seu censo de 2000, divulgando que $7,73 \%$ dos habitantes do Município de São Paulo mantinham atividades remuneradas em domicílios de empregadores, sócios ou clientes e que $4,6 \%$ desenvolviam estas atividades no domicílio em que moravam. Nestes casos, estão incluídos os indivíduos que têm em seu domicílio micro-empresas formais ou informais que desenvolvem produções ou prestam serviços à população, não apresentando nenhum detalhamento sobre o tipo de atividade.

$\mathrm{Na}$ questão do trabalho fora do ambiente empresarial, deve-se ter a consciência de que o tema envolve aspectos econômicos, sociais, culturais, tecnológicos, legais, ecológicos, de transporte, e ainda abriga diversos elementos que devem interagir, como empresas, indivíduos, governantes, associações de funcionários, sindicatos trabalhistas, além de empresas prestadoras de serviços, fornecedores de suprimentos e infra-estrutura, todos voltados para promoção do trabalho em ambientes domésticos.

Neste universo de interrogações, as questões da inserção dos postos de trabalho para as atividades de escritório na habitação, particularmente em relação às condições de conforto, utilização e apropriação dos ambientes da habitação para estas finalidades, serão abordadas com maior aprofundamento, e que devem ser considerados como indicadores importantes nas análises gerais do processo. 
Porém, existem outros aspectos conectados a este tema que poderão e deverão ser estudados em pesquisas futuras como complemento desta obra; a exemplo das questões de caráter econômico, onde a transferência de trabalhadores dos escritórios comerciais para suas residências deverá afetar sensivelmente a contabilidade das empresas, considerando dois pontos básicos: em primeiro lugar, o espaço físico da empresa deve diminuir o que significa que as despesas com construções e infra-estruturas ou aluguéis serão reduzidas, e em segundo lugar as despesas com manutenção, principalmente na área energética onde se especula a transferência do consumo do setor de comércio e serviços para o setor habitacional, seguindo a migração da força de trabalho.

Embora a bibliografia seja restrita, são vários os artigos em mídias escritas que abordam o tema dos escritórios residenciais ou 'trabalho a partir de casa', porém, como ocorre nas publicações estrangeiras, observa-se que a maioria refere-se a estas novas formas de se desenvolver o trabalho coligados aos novos avanços tecnológicos como possibilidades de modo de vida alternativos, concentrando informações sobre qualidade de vida, administração do tempo, marketing pessoal e relacionamentos intrafamiliares, não tratando das condições do espaço físico que devem ser adequados para esta nova condição de uso dos ambientes domésticos, salvo algumas publicações na área da ergonomia que tocam em pontos específicos de postos de trabalho com microcomputadores. 
Este aspecto vem de encontro à relevância deste trabalho, pois, distante da realidade das empresas, onde profissionais são contratados para elaborar o arranjo espacial e o controle do conforto do ambiente, os trabalhadores residenciais geralmente não dispõem da assessoria de pessoas especializadas, resultando, os espaços de trabalho, em ambientes adaptados e não apropriados para o desempenho das tarefas a que se propõem.

A necessidade ou intenção de se desenvolver atividades de escritório no ambiente da habitação, gerou uma demanda de mercado que levou à reorganização dos ambientes nos projetos de habitação.

A dissertação de mestrado apresentada pelo autor em 2005, mostrou uma evolução do arranjo dos projetos habitacionais, sem que o programa da habitação fosse alterado.

O maior exemplo desse fato foi deslocamento do dormitório de empregada que, na década de 1980 era projetado em situações de total isolamento dos setores íntimo e social, sem permitir qualquer integração a estes e, nos dias atuais, encontra-se em disposições que claramente permitem aos usuários a possibilidade de explorar uma integração deste ambiente a outros setores da habitação, alterando suas funções primordiais, muitas vezes abrigando as atividades pertinentes ao escritório residencial. 
Esta evolução de programa e de arranjo é decorrente de um processo de alteração social, gerado pela mudança de conceito de lugar, onde a realização do trabalho deixou de estar vinculada ao chão da fábrica ou presa às infindáveis lajes de escritórios espalhadas pela metrópole.

A relevância deste trabalho vem de encontro com a necessidade de conhecer este novo conceito e estas novas funções que estão sendo incorporadas ao ambiente doméstico, e quais as respostas de projeto arquitetônico para este tema, tendo como primeiro passo a busca dos elementos geradores deste processo, e que promoveram as mudanças do projeto das habitações. 


\subsection{Teorias, Conceitos e Definições}

universo que abriga os trabalhadores que desenvolvem suas atividades em locais distantes da área física da empresa engloba uma série de profissionais e atividades que nem sempre são determinados pelas pesquisas.

Existem várias terminologias, coleta de dados conflitantes, e outros fatores que implicam na real constatação deste universo.

As matérias, livros e artigos tanto da área acadêmica, quanto aqueles divulgados por empresas ou profissionais que tem o trabalho à distância seu objeto de atividades apresentam diversas terminologias na língua inglesa para estas atividades, como seguem:

- Telecommuting

- Teleworking

- Networking

- Flexible working

- Homeworking

- Remote working

- Home-based working

- Mobile working

- Electronic cottage

- Virtual organization

- Satellite centers

Nos dados secundários levantados para a tese, dois termos foram observados como os mais utilizados, "teleworking" e "telecommuting", salientando que o primeiro é utilizado pelos europeus e o segundo tem a preferência na América do Norte. 
Destacam-se quatro autores que ilustram os conceitos destas terminologias.

Para Fairweather ${ }^{16}$ (1999) "telecommuting" usa as tecnologias de informação e comunicação para levar o trabalho ao trabalhador.

Kurland \& Bailey $^{17}$ (1999) interpretaram o "telework" incluindo outras terminologias, como "home-based telecommuting", "satellite centers", "neighborhood work centers" e "mobile working". Os autores explicam que o que há de comum entre estes termos é a que a supervisão e o gerenciamento do trabalho passa a ser remoto, os contatos passam a ser por aparelhos de telecomunicações, o posto de trabalho deixa de ser fixo, na empresa e as salas de reuniões passam a ser virtuais.

Wilmer Joice ${ }^{18}$ (1999) define "telework" como uma organização do trabalho onde o empregado trabalha em locais alternativos para desenvolver as atividades pertinentes ao cargo nas horas úteis do dia.

Jack Nilles, considerado o "pai do teletrabalho", apresentada por Ellison ${ }^{19}$ (1999), define primeiramente como a utilização de qualquer forma de tecnologia de informação e comunicação para trabalho à distância, e ainda define o "telecommuting" como trabalho periódico, fora do escritório central da empresa, um ou mais dias na semana, inclusive em casa, no escritório do cliente ou em telecentros.

\footnotetext{
${ }^{16}$ Fairweather, N. B. Surveillance in employment: The case of teleworking. Journal of Business Ethics, 22 1999

${ }^{17}$ Kurland, N.B. ; Bailey, D.E. Telework: The advantages and challenges of working here, there, anywhere, and anytime. Organizational Dynamics, $53-1999$

18 Joice, W. Workshop 1: Getting educated. International Telework Association \& Council-September 2000

${ }^{19}$ Ellison, N.B. Social impacts: New perspectives on telework - Social Science Computer Review, 17 - 1999
} 
Segundo a enciclopédia livre Wikipédia ${ }^{20}(2006)$, o verbete "Teletrabalho", também dito trabalho remoto, significa, literalmente, trabalho à distância.

Trata-se de trabalho que é realizado quando se utilizam equipamentos que permitem que o trabalho efetivo tenha efeito num lugar diferente do que é ocupado pela pessoa que o realiza.

Para tanto, esta tese utiliza o termo Teletrabalho para definir o trabalho realizado à distância, em correspondência aos termos "telecommuting" e "telework".

Não obstante, observa-se que o termo "Home Office" é uma das modalidades apresentadas como teletrabalho, cujo conceito será apresentado na seqüência da tese.

No campo dos estudos, artigos, pesquisas e publicações em geral sobre o tema do teletrabalho, existem algumas abordagens recorrentes onde quatro questões são colocadas e podem resumir as principais preocupações sobre o trabalho à distância:

- Quais são as questões teóricas, conceitos e definições para fundamentar a pesquisa sobre o teletrabalho?

- Como empresas, trabalhadores e sociedade são beneficiados com programas de teletrabalho formais ou informais?

- Quais são as vantagens e desvantagens do teletrabalho para empresas e trabalhadores?

- Como o setor de recursos humanos pode colaborar com as questões de adoção, planejamento, desenvolvimento e implementação de um programa de teletrabalho?

${ }^{20}$ Wikipédia - Enciclopédia Livre - Teletrabalho-Disponivel em http://en.wikipedia.org/wiki/teletrabalho 
Ainda no aspecto teórico, segundo Hyland ${ }^{21}$ (1999) o estudo do teletrabalho recebe contribuições de várias áreas do conhecimento como economia, gerenciamento, psicologia, sociologia, ciência da família e tecnologias de informação e comunicação, inexistindo consenso entre os pesquisadores sobre qual melhor representa este tipo de atividade.

A literatura discute várias teorias derivadas destas áreas e podem ser agrupadas nos seguintes temas:

- Teorias relacionadas à decisão pelo teletrabalho são teorias que incluem o planejamento de vida, mudanças comportamentais, expectativas de adaptação, alterações de caráter institucional, massa crítica, características da atividade, aspectos econômicos e sociais.

- Teorias relacionadas ao trabalhador - incluem motivação, relacionamento pessoal, desenvolvimento de carreira e necessidades no ambiente de trabalho que garantam a produtividade.

- Teorias relacionadas ao gerenciamento e organização do trabalho - incluem motivação, teorias " $X$ " e "Y", situações de liderança, inovações, desenho organizacional, sistemas de informação, e gerenciamento.

- Teorias ligadas à comunicação e suporte técnico incluem intercâmbio social, redes comunitárias, comunicação interpessoal, ecologia e mobilidade urbana.

21 Hyland, M.M. Flexibility in work arrangements: How availability, preferences and use affect business outcomes The State University of New Jersey - Doctoral Dissertation - 1999 
- Teorias relacionadas ao trabalho e família incluem ajustes no trabalho, difusão, segmentação, tensões do trabalho, conflitos e sobrecarga.

Encontram-se, ainda, uma série de modelos que partem das teorias acima apresentadas, porém alguns poucos tratamse de dissertações originais, as quais são seguidas de inúmeras críticas, releituras e réplicas.

Segundo Swanson 22 (1997), as linhas de pensamento e teorias estão fundamentadas em três áreas básicas do conhecimento:

- Economia

- Psicologia

- Sistemas

As pesquisas recentes sobre o teletrabalho, coloca Swanson (1997), aparentemente estão ligadas às teorias econômicas do que se realizou no passado e, portanto, a menos que as análises, ações e medidas de resultados da economia contribuam diretamente para a viabilidade e rentabilidade da empresa, as teorias e resultados do passado devem ser desconsiderados.

Sobre as teorias da área da psicologia, continuam a enriquecer e aprofundar as pesquisas em teletrabalho.

Swanson (1997) explica que em apoio ao desenvolvimento dos recursos humanos, a psicologia explora estudos em teorias de aprendizado, motivação humana, processamento de informações, dinâmicas de grupo e teorias com bases psicológicas que tratam sobre as decisões e comportamento nas organizações.

22 Swanson, R.A. The theory of Human Resources Development - HRD - University of Minnesota - Human Resource Development Research Center - 1997 
As observações de Swanson (1997) sobre as teorias dos sistemas concluem que a contribuição dos estudos dos sistemas, seus elementos individuais e as interações entre eles são de valor inestimável para as pesquisas sobre o tema, e são freqüentemente utilizadas na literatura, ainda que nem sempre sejam notadas.

Conclui ainda, que a "falta de uma base teórica comum tenha inibido a larga compreensão do teletrabalho", e a consistência teórica disponível foi gerada a partir da adoção, por parte dos profissionais dos recursos humanos das organizações, de que o teletrabalho é uma intervenção com a finalidade de aprimorar o desempenho, buscando então, os autores, as bases destas teorias para desenvolver seus trabalhos.

Os principais tópicos relacionados ao teletrabalho, apresentados pela literatura são:

- Características dos usuários

- Organização do trabalho

- Satisfação do trabalhador

- Produtividade

- Comprometimento com a organização

- Recrutamento e retenção de pessoal

- Economia

- Conflitos e balanço entre a vida familiar e profissional

- Comunicação e isolamento

- Desenvolvimento profissional

- Promoção profissional

- Implementação de programas

- Cultura organizacional

- Gerenciamento 
Alguns autores, como Mokhtarian et al. ${ }^{23}$ (1998) entendem que existe uma similaridade entre os indivíduos que desenvolvem o teletrabalho, incluindo casados, mulheres, pais com filhos pequenos em casa, mães com filhos em idade escolar, trabalhadores com bom nível de escolaridade.

Para Pratt $^{24}$ (1999), as mulheres têm maiores motivações para o teletrabalho, como tempo com os filhos e a família, acomodação dos horários durante o dia e redução do stress.

Já Bruce Phillips, citado em Lister \& Harnish ${ }^{25}$ (2009) compõe um retrato do que as pesquisas apresentam sobre os teletrabalhadores e aqueles que desenvolvem o trabalho em seus domicílios:

"As pesquisas mostram que existem 5 homens para cada 3 mulheres trabalhando em suas casas; 4 entre 5 destes trabalhadores são casados ou mantém união estável; três quartos são profissionais graduados em universidades; 15\% têm acima de 55 anos; 40\% têm receitas anuais acima dos US\$75.000; e apenas um terço destes trabalhadores estão na empresa a menos de 2 anos. Portanto, um homem casado, de 45 anos, graduado em universidade, com mais de cinco anos de empresa deve ser um adepto do Home Office, certo? Não, na verdade não. Existem várias mulheres solteiras, graduadas no colegial de 35 anos de idade que exercem esse tipo de atividade."

23 Mokhtarian, P.L.; Bagley, M.N. \& Solomon, I. The impact of gender, occupation, and presence of children on telecommuting motivations and constraints. Journal of the American Society fo $r$ Information Science. 49 - 1998

${ }^{24}$ Pratt, J.H. America national telework survey 1999: cost/benefits of teleworking to manage work/life responsibilities The International telework Association \& Council-1999

${ }^{25}$ Lister, K.; Harnish, T. Undress for success - the naked truth about making money at home-John Wiley \& Sons - New Jersey - 2009 
Muitas pesquisas sugerem características específicas para o teletrabalhador, e que apenas alguns conseguem se adequar a este sistema de trabalho, porém, como coloca Loverde ${ }^{26}$ (1997), muitas destas características são baseadas em especulações e, mais que um perfil pré definido de usuário, o desempenho pessoal é o fator predominante para o sucesso do teletrabalho.

Ainda em relação à produtividade, são vários os estudos como Bernardino ${ }^{27}$ (1996), Gainey et al. ${ }^{28}(1999)$, Ross $^{29}$ (1990) ou Lister \& Harnish (2009), que mostram que o teletrabalho trás ganhos expressivos no desempenho profissional dos trabalhadores.

Pratt (1999) concluiu em suas pesquisas que a produtividade de quem desenvolve trabalhos em seus domicílios tem uma produção maior ou igual àqueles que o fazem em escritórios convencionais, e Balanger ${ }^{30}$ (1997) descobriu que os sistemas de tecnologia de informação e comunicação influenciam diretamente nos padrões de produtividade e desempenho dos teletrabalhadores.

No entanto, Belanger (1997) admite que o cálculo de produtividade e desempenho é uma questão delicada e de difícil verificação, pois existem diferenças significativas no tipo de teletrabalho desenvolvido, ambiente de trabalho e até mesmo a situação do contesto familiar em que a atividade está sendo realizada.

\footnotetext{
26 Loverde, M.A. The effects of individual's psychological needs on telecommuting's impact on job performance Illinois Institute of Technology - Doctoral Dissertation - 1997

27 Bernardino, A.T. Telecommuting: modeling the employee's decision-making process New York-Garland Publishing - 1996

${ }^{28}$ Gainey, T.W.; Kelley, D.E.; \& Hill, J.A. Telecommuting's impact on corporate culture and individual workers: examining the effect of employee isolation SAM Advanced Management Journal, 64 - 1999

29 Ross, K.A. Personality and work style characteristics of the telecommuter San Jose State University Master's Thesis - 1990

30 Belanger, F. Distributed work arrangements: impacts of advanced information technologies, coordination mechanisms and communications patterns University of South Florida-Doctoral Dissertation
} $-1997$ 
Sobre a questão da satisfação pessoal, existem também vários autores que desenvolveram estudos, principalmente no campo acadêmico, focados neste tema.

McCloskey ${ }^{31}$ (1998), De Lay ${ }^{32}$ (1995) e Coveyduck ${ }^{33}$ (1997) apontam para a maior autonomia sobre o próprio desempenho e organização do trabalho como uma das questões responsáveis por este grau de satisfação dos teletrabalhadores, o qual também é corroborado por Sturgill ${ }^{34}$ (1998) em pesquisa realizada junto a trabalhadores convencionais e teletrabalhadores.

Quando a empresa possui um programa de teletrabalho consistente e mantém suporte técnico e humanizado ao funcionário o grau de satisfação apresenta-se mais elevado concluiu Welchans ${ }^{35}$ (1996), complementado por Thompson et $a l .{ }^{36}$ (1999) que também conclui que o teletrabalho eleva o grau de satisfação cujos empregados são motivados pela autonomia, maior contato com a família e ainda apresentam maior comprometimento com a empresa.

A questão do comprometimento do funcionário com a empresa é também citada com freqüência na literatura porém, existe um conflito nas conclusões apresentadas pelos autores.

\footnotetext{
${ }^{31}$ McCloskey, D.W. The impact of telecommuting on the work outcomes of professionals Drexel University - Doctoral Dissertation - 1998

${ }^{32}$ De Lay, N.L. The effects of telecommuting and gender on work-family conflict and satisfaction Illinois Institute of Technology - Doctoral Dissertation - 1995

${ }^{33}$ Coveyduck, D.H. Investigation of selected factors on job satisfaction among telecommuters Carleton University - Master Thesis - 1997

${ }^{34}$ Sturgill, A.F.C. Relationship of telecommuting to organizational communication: a preliminary study of group process and communication satisfaction Cornell University - Doctoral Dissertation - 1998

${ }^{35}$ Welchans, T.D. The effects of telecommuting and communication media on perceived value congruence, organizational support and job satisfaction Ohio State University - Doctoral Dissertation - 1996

${ }^{36}$ Thompson, S.H.; Vivien, K.G.L.; Wai, S.H. Assessing attitudes towards teleworking among information technology (IT) personnel Singapore Management Review, 21 - 1999
} 
Hill $^{37}$ (1995) conclui que o teletrabalho influencia positivamente na produtividade e no comprometimento do empregado para com a empresa, já Tucker $^{38}$ (1997) encontrou o mesmo resultado na questão da produtividade e satisfação, porém suas pesquisas apontam para um baixo grau de comprometimento com a empresa.

Mais uma vez salienta-se que as pesquisas sobre o tema não partem de uma mesma organização e usam instrumentos diferentes em seu desenvolvimento.

A dissertação de mestrado apresentada pelo autor, Mendonça ${ }^{39}$ (2005), verificou que os programas de teletrabalho das empresas eram oferecidos como um benefício a alguns de seus funcionários.

As estratégias de recrutamento e manutenção de talentos nas empresas é um desafio cada dia maior para o setor de recursos humanos, e programas de teletrabalho fazem parte dos pacotes de benefícios oferecidos por estas organizações, como conclui Pratt (1999).

A opção do teletrabalho também passou a atrair trabalhadores cujo perfil não era apontado nas pesquisas e tornaram-se candidatos às vagas de emprego, concluem Bolin ${ }^{40}$ (1995) e Callaghan ${ }^{41}$ (1996), no entanto, Hyland (1999) concluiu que um conjunto de itens, dos quais a flexibilidade de tempo e local de trabalho foram apontados como principais fatores para a saída de profissionais das suas empresas.

${ }^{37}$ Hill, E.J. The perceived influence of mobile telework on aspects of work life and family life: an exploratory study. Utah State University - Doctoral Dissertation - 1995

${ }^{38}$ Tucker, D.M. More and less: perceptions and experience of the professional part-time employee. Virginia Polytechnic Institute and State University - Doctoral Dissertation - 1997

${ }^{39}$ Mendonça, M. Escritórios residenciais: aspectos que influenciam a implantação e o uso de ambientes da habitação para o desenvolvimento de atividades de escritório. Universidade de São Paulo - Dissertação de Mestrado - 2005

40 Bolin, D.J. The economics of telecommuting with an application on manufacturing sector. Purdue University - Doctoral Dissertation - 1995

${ }^{41}$ Callaghan, W.J. Utilization of telecommuting as a tool for retaining logistics professionals. Baker College - Master's Thesis - 1996 
"Você provavelmente não vai ganhar mais dinheiro adotando o sistema de teletrabalho, porém a economia que você fará provavelmente aumentará o seu saldo bancário no final do mês."

Lister \& Harnish (2009) concluíram que o fator econômico está mais ligado à economia do que se deixa de gastar do que com um possível ganho extra no sistema de teletrabalho, corroborando com as pesquisas do International Telework Association \& Council ${ }^{42}$ (2000) que concluiu que o teletrabalho reduz gastos com funcionários, diminui as despesas do trabalhador e ainda ajuda a reduzir o absenteísmo.

Também para Kurland \& Bailey (1999), empresas como AT\&T e IBM deixam de gastar grandes montantes com a ocupação de áreas físicas da empresa com a redução de empregados desenvolvendo suas atividades nestes locais, embora Bernardino (1996) coloque que a expectativa de ganho é superior ao que realmente é economizado com o sistema de teletrabalho, tanto para as empresas como para os empregados.

Uma das questões mais discutidas, pesquisadas e apontada como sendo também um grande ganho para os trabalhadores por diversos autores é a possibilidade do teletrabalho melhorar a relação entre vida profissional e vida familiar.

42 International Telework Association \& Council 1999 telework research results International Telework Association \& Council - 2000 
Chomiak $^{43}$ (1998) relacionou dados entre horas envolvidas no teletrabalho, flexibilidade e balanço entre vida profissional e vida familiar. A autora encontrou que aqueles que desenvolvem teletrabalho não demonstraram um ganho significativo na relação vida profissional e vida familiar, destacando que quanto mais tempo se passa envolvido no teletrabalho, são consumidas mais horas de trabalho efetivo.

Pratt (1999) tem uma posição conflitante a esta encontrada por Chomiak (1998), afirmando que a relação trabalho/família é beneficiada com o teletrabalho, e Cree ${ }^{44}$ (1998) em pesquisa baseada em teletrabalhadores que desenvolvem suas atividades com uma certa constância de freqüência e duração apresentaram maior satisfação em relação ao balanço entre a vida profissional e a vida familiar, concluindo que a chave para o benefício desta relação está na manutenção de uma regularidade e do controle para que as horas de trabalho sejam similares entre as dos trabalhadores convencionais e as dos teletrabalhadores.

Os conflitos entre trabalho e família têm origem nas horas em que se passa desenvolvendo atividades de trabalho, incompatibilidades de horários, demandas e autonomia do emprego, divisão do trabalho doméstico e cuidados com os filhos que, segundo Ellison (1999) estão atrelados à questão tempo de tempo e de local.

Quando as questões de tempo e espaço são dirimidas, no caso com o teletrabalho, os empregados tem a possibilidade de organizar os conflitos entre trabalho e família.

\footnotetext{
${ }^{43}$ Chomiak, A.A. Work/life balance and job flexibility: does teleworking make a difference? The State University of New Jersey - Doctoral Dissertation - 1998

${ }^{44}$ Cree, L.H. Work/family balance of telecommuters California School of Professional Psychology- 
Schreiber ${ }^{45}$ (1999) e Coveyduck (1997) também concluem que o teletrabalho tem um papel importante na redução deste conflito, porém, para De Lay (1995), homens que desenvolvem atividades de teletrabalho tem um nível de conflito menor que os trabalhadores convencionais e as mulheres que teletrabalham têm um nível de conflito entre trabalho e família maior do que os homens nessas atividades, e ainda, a idade das crianças cujos pais desenvolvem teletrabalho também é apontada como um fator de conflito.

"...teletrabalho não parece ser um sistema de trabalho mágico que permite aos empregados resolverem todos os conflitos entre vida profissional e vida familiar, mas a estrutura com longas horas de trabalho impostas aos trabalhadores e que causam desequilíbrio e interferências da vida profissional na vida familiar também não é a resposta."

Essa critica colocada por McCloskey (1998), ilustra não só o quanto o modelo de trabalho interfere na vida familiar, mas conclui que o teletrabalho é uma possibilidade de alternativa para a melhoria destas relações, mas isoladamente não resolve totalmente esta questão.

O local de trabalho oferece a possibilidade de interações e comunicações informais que não apenas colaboram com troca de informações que ajudam no desenvolvimento do trabalho como promovem o convívio social.

45 Schreiber, P.J. The nature of career development for women who telecommute. University of Georgia- 
Algumas pesquisas tratam sobre o tema do isolamento do profissional quando confinado ao desenvolvimento de suas atividades afastado da empresa.

Gainey (1999) concluiu que o isolamento afeta diretamente na percepção de conforto, satisfação e comprometimento com a empresa e Sturgill (1998) encontrou respostas similares, onde os teletrabalhadores sentem que fazem sacrifícios quando abdicam do contato com os demais funcionários da empresa e que acreditam que horas na empresa melhoram e estimulam as comunicações e relacionamentos profissionais.

Fireman ${ }^{46}$ (1999) acredita que a falta das relações sociais do escritório e a falta de uma supervisão direta são os maiores motivadores para que empregados deixem as atividades de teletrabalho.

As atuais condições oferecidas pelas tecnologias de informação e comunicação permitem que o isolamento dos teletrabalhadores seja reduzido e, embora não exista o contato físico, a troca de idéias e informações pode ser feita em tempo real, o que já havia sido observado na linha de pensamento das pesquisas de Lowry ${ }^{47}$ (1996), onde afirma que nem a quantidade nem a qualidade da comunicação entre empregador e empregado está relacionada com a distância que os separa.

\footnotetext{
${ }^{46}$ Fireman, S.M. A model of telecommuting withdrawal: employee predicting the reduction or stopping of telework. University of Washigton - Doctoral Dissertation - 1999

${ }^{47}$ Lowry, T. Alternative work arrangements: the effects of distance and media use on the supervisor/subordinate relationship. Rice University - 1996
} 
A questão do isolamento também resvala nas dificuldades do comparativo entre as pesquisas, pois algumas tratam de teletrabalhadores em tempo integral, e outras de funcionários que desenvolvem o teletrabalho apenas alguns dias na semana.

As oportunidades de carreiras também são freqüentes no universo do teletrabalho e existem estudos a respeito de seus efeitos sobre satisfação e desenvolvimento de carreira, onde profissionais optam pela redução destas oportunidades em troca de outras prioridades pessoais.

Ainda que o teletrabalho seja uma alternativa para aqueles que decidiram abdicar do tempo de trabalho em detrimento de uma atenção maior a outros aspectos da vida pessoal, Khaifa \& Davidson ${ }^{48}$ (2000) afirmam que o teletrabalho compromete o desenvolvimento profissional de maneira negativa, embora Schreiber (1999) pesquisou mulheres que tiveram sucesso em suas áreas ainda que desenvolvendo o teletrabalho, cujas carreiras não foram afetadas por terem adotado o trabalho à distância.

Os estudos na área do gerenciamento do teletrabalho são escassos, porém alguns trabalhos sobre o tema podem ser destacados com o objetivo de formar um pensamento a respeito de como o sucesso de um programa de teletrabalho depende do modelo de gestão. 
Para Klayton ${ }^{49}$ (1994) o gerenciamento que não usa

ferramentas diferenciadas para a avaliação do desempenho entre trabalhadores convencionais e teletrabalhadores pode comprometer a continuidade de um programa de teletrabalho, assim como Reinsch ${ }^{50}$ (1999) explica que existem empregados que trabalham à distância que necessitam que seus supervisores compartilhem informações em tempo real, que reajam a resultados negativos de maneira construtiva e que demonstrem alto grau de lealdade para com seus subordinados.

Conner ${ }^{51}$ (1986) acredita que a continuidade de um programa de teletrabalho dependa mais da satisfação do corpo gerencial com o programa do que com o próprio estilo de gerenciamento, e Speeth ${ }^{52}$ (1992) complementa que o nível de experiência, efetividade e treinamento do corpo gerencial estão diretamente relacionados com o sucesso de um programa de teletrabalho.

Como visto, o teletrabalho é o modelo de trabalho onde o trabalhador desenvolve suas atividades à distância da empresa, ou seja, em local diferente da sua área física.

A opção pelo teletrabalho vem de encontro às necessidades de empresas, cada vez mais empenhadas em manter sua competitividade em um mercado de economia globalizada, e às necessidades dos trabalhadores que procuram atender a outras prioridades de suas vidas.

\footnotetext{
49 Klayton, M.A. The impact of telecommuting on the supervisory performance appraisal process. Virginia Commonwealth University - Doctoral Dissertation - 1994

50 Rainsch, N.L. Selected communication variables and telecommuting workers. The Journal of Business Communications, $36-1999$

51 Conner, C.C. The effect of management style on manager's satisfaction with telecommuting. University of Tennessee - Doctoral Dissertation - 1986

52 Speeth, L.M. The attributes of successful managers of telecommuters and successful telecommuting programs. Golden Gate University - Doctoral Dissertation - 1992
} 
Essas necessidades geraram novas relações de trabalho onde a flexibilidade de horários e locais de trabalho foram sendo adotadas pelas organizações.

Segundo Harvey ${ }^{53}$ (1998), a flexibilidade está presente em diferentes campos do trabalho, envolvendo os novos processos, mercados de trabalho, tecnologias e padrões de consumo.

A flexibilidade permite que se proponham novos modelos de relações de trabalho, alterando o panorama do trabalho tradicional, como apresentado por Lannes ${ }^{54}$ (1998).

\section{Quadro 01}

\begin{tabular}{ll} 
Modelo tradicional & Novas Tendências \\
\hline Permanência & Temporariedade \\
\hline Crescimento populacional & Diminuição populacional \\
\hline Força de trabalho monolítica & Força de trabalho flexível \\
\hline Empregados em tempo integral & Trabalho em meio período \\
\hline Valorização da lealdade & Valorização do desempenho \\
\hline Paternalismo & Autoconfiança e responsabilidade \\
\hline Compromisso com a empresa & Compromisso pessoal \\
\hline Segurança de emprego & Desenvolvimento e realização \\
\hline Carreira linear & Carreiras múltiplas \\
\hline Aprendizado estagnado & Aprendizado constante \\
\hline Relação vitalícia & Empregabilidade \\
\hline
\end{tabular}

Quadro 1-Modelo tradicional de trabalho e novas tendências

Fonte : Lannes - 1998

Das várias modalidades de teletrabalho, destacam-se os Home Offices, tema central desta tese, que apresenta um modelo de trabalho onde as atividades profissionais compartilham a mesma infraestrutura das atividades domésticas.

53 Harvey, D. Condição Pós Moderna - São Paulo: Loyola, 1998

${ }^{54}$ Lannes, L.S. Equipes autogerenciáveis e a forma de organização do trabalho. Universidade de São Paulo - Faculdade de Economia e Administração - Monografia - 1998 
Segundo a enciclopédia livre Wikipédia ${ }^{55}$ (2006), este novo conceito de trabalho é conhecido pela sigla SOHO, do inglês Small Office and Home Office que pode ser traduzido como Pequeno Negócio e Escritório Residencial, sendo que esse conceito, pode abranger atividades de pequeno e médio porte e que podem conter de 01 a 10 trabalhadores.

Segundo o Serviço Brasileiro de Apoio a Micro e Pequenas Empresas - SEBRAE ${ }^{56}$ (2006), esta modalidade cresce em esfera mundial, em decorrência da globalização da economia e das novas relações de trabalho decorrentes das novas necessidades de competitividade das empresas.

O SEBRAE aponta ainda, que é cada vez maior o número de pequenas empresas que iniciam suas atividades em domicílios, alavancando o setor de micro e pequenas empresas, responsável por $52 \%$ do Produto Interno Bruto do País.

Deve-se porém entender que para alguns autores existe a diferença entre trabalhar "em" casa e trabalhar "a partir" de casa.

A diferença pode parecer sutil, mas como colocam Lister \& Harnish (2009), as pesquisas até hoje realizadas não fazem distinção entre proprietários que têm suas empresas ou pequenos negócios que trabalham "em" casa, dos profissionais contratados por empresas que desenvolvem atividades para estas empresas "a partir" de casa.

Wikipédia - Enciclopédia Livre - Home Office - Disponivel em http://en.wikipedia.org/wiki/Small_office/home_office

56 Serviço Brasileiro de Apoio a Micro e Pequenas Empresas SEBRAE - Home Office - disponível em: http://www.sebrae.com.br/br/parasuaempresa/tiposdenegocios_64.asp 
As pesquisas realizadas no Brasil pelo IBGE, também são abrangentes e não distinguem aqueles trabalhadores que possuem pequenos negócios em seus domicílios, daqueles que estão prestando serviços a empresas.

Assim sendo, conceituar e definir o Home Office requer uma abordagem que vai além das definições das atividades realizadas nestes ambientes.

O Conceito, segundo Sternberg ${ }^{57}$ (2000) é a unidade fundamental do processo simbólico, ou seja, a idéia sobre alguma coisa, e o estudo teórico preocupa-se com os conceitos, particularmente em função das palavras como bases do conceito.

A tradução literal de Home Office, apresenta duas palavras, identificando-se dois conceitos: "casa" e "escritório".

Para Holanda $5^{8}$ (1993), o conceito da palavra "casa" está relacionado a habitação, lar, família e o direito constitucional brasileiro, apresentado por Ferreira ${ }^{59}$ (1989), define alguns conceitos de legalidade para o domicílio:

- Qualquer compartimento habitado;

- Aposento ocupado de habitação coletiva, pensões, hotéis, casas de pousada;

- Dependências de casas, sendo cercadas, gradeadas, muradas.

Portanto, pode-se perceber que o conceito de "casa" está relacionado ao descanso e lazer, informalidade e atividades não remuneradas, Guérin ${ }^{60}$ (2001).

\footnotetext{
57 Sternberg, R.J. Psicologia cognitiva - Porto Alegre: Artes Médicas, 2000

58 Holanda, A.B. Dicionário da Língua Portuguesa - Rio de Janeiro: Nova Fronteira, 1993

59 Ferreira, P. Comentários à Constituição Brasileira - São Paulo: Saraiva, 1989

${ }^{60}$ Guérin, F. Compreender o trabalho para transformá-lo - São Paulo: Edgard Blücher, 2001
} 
Em relação ao verbete "escritório", o dicionário eletrônico Houaiss $^{61}$ (2001) define como compartimento ou cômodo de um imóvel destinado à leitura e ao ato de escrever e ainda sala ou conjunto de salas em que se administram negócios.

Já o conceito de "escritório" apresenta características de trabalho remunerado, rede de contatos profissionais e relacionamentos formais em ambientes destinados à produtividade.

A fusão destas duas palavras concebe a criação de um terceiro conceito, onde as características particulares de cada um dos conceitos iniciais podem ser excludentes ou não compatíveis, proporcionando interferências de ordem cultural para o entendimento do novo conceito formado, o Home Office, como coloca Sternberg (2000):

- SE a casa é um ambiente de descanso, ENTÃo o escritório em casa não pode ser produtivo.

- SE o trabalho em casa não é remunerado, ENTÃO o trabalho no escritório em casa pode representar menorvalor.

- SE a casa possui aspecto de informalidade, ENTÃO o serviço prestado em casa pode não ser convencional ou padrão.

- SE a casa é considerada um invólucro inviolável, ENTÃO a presença de pessoas consideradas fora do círculo familiar significa a perda de privacidade pessoal e pode gerar constrangimento.

- SE casa é sinônimo de estrutura personalizada, ENTÃO o trabalho em casa pode pressupor um trabalho amador ou de baixa qualidade. 
As relações acima descritas podem representar situações paradoxais, porém a realidade mostra que estas são as bases de um novo modelo de trabalho, onde a flexibilidade de tempo e espaço assume o ambiente doméstico como sua forma de expressão.

Portanto, como definição para esta tese de doutoramento, o Home Office é o local, ambiente ou posto de trabalho, inserido no ambiente doméstico onde são desenvolvidas atividades de escritório, que se utilizam de equipamentos e tecnologias de informação e comunicação e são considerados como Home Officers, aqueles indivíduos cujas atividades englobem desenvolvimento de trabalho de escritório, com utilização de equipamentos e tecnologias de informação e comunicação, inseridas no ambiente da habitação, não diferenciando a condição de proprietário de empresa, profissional liberal ou funcionário, ou seja, a tese tem como foco as condições do ambiente l posto de trabalho, o Home Office, e não a relação trabalhista de quem desenvolve a atividade. 
O cenário mundial foi pauta de discussões dos trabalhos realizados quando da elaboração da dissertação de mestrado do autor, em 2005.

Retomar o tema após alguns anos parece ser apropriado e relevante, pelo fato de diversas alterações e evoluções terem ocorrido no período tanto em relação ao teletrabalho como ao avanço do uso da Internet que, segundo a Internet World Stats ${ }^{62}$, o crescimento da penetração à população mundial foi de $380,3 \%$ entre 2005 e 2009.

\subsubsection{O Cenário da Americano do Norte}

Impulsionado pelos Estados Unidos, os países da América do Norte dispõem de uma penetração do uso da internet pela população acima dos $74 \%$, bem acima da média mundial de $23 \%$, com a maioria das conexões efetuadas pelo sistema digital, segundo a Internet World Stats, fator importante para o desenvolvimento do trabalho à distância. Gráfico 1

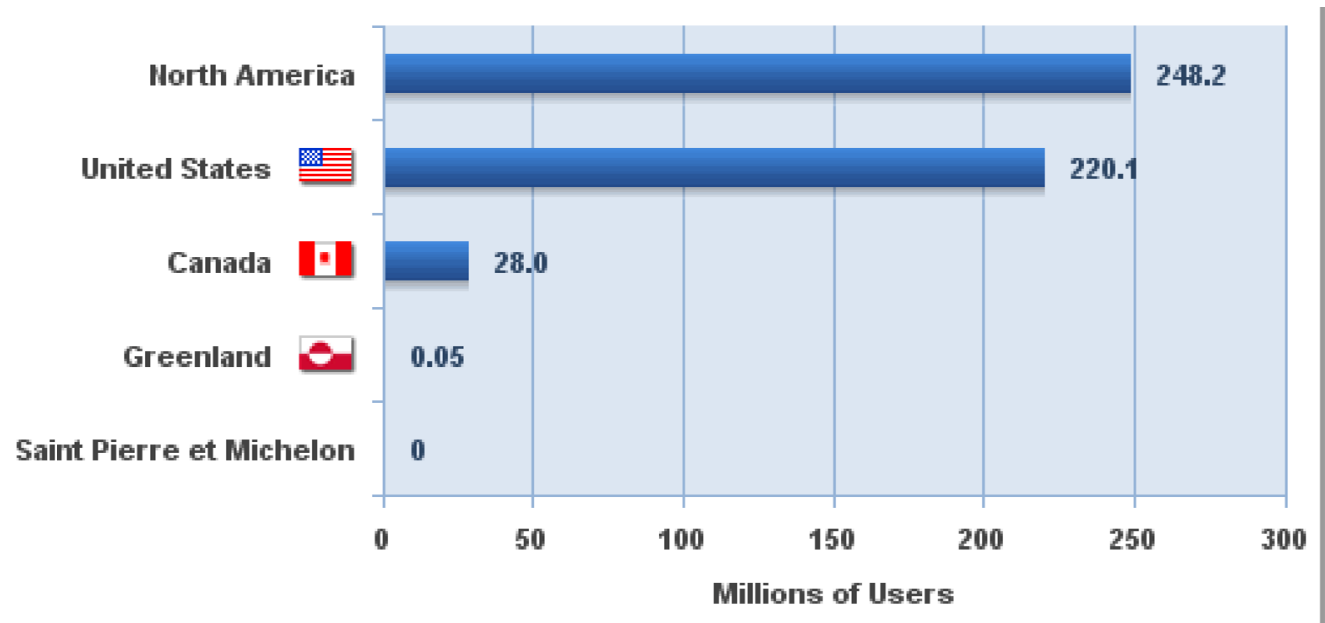

${ }^{62}$ Internet World Stats Disponivel em http://www.internetworldstats.com 
Em pesquisa realizada pela empresa WorldatWork W3 $^{63}$ (Telework Trendlines, 2009), logo em sua introdução destaca:

"[...] quando os preços da gasolina chegam aos $U \$ 3,00 \quad e, \quad e m$ algumas regiões ultrapassam os $U \$ 4,00$ por galão em meados de 2008, ambos, patrões e empregados saem em busca de alternativas... o teletrabalho, claro, surge rapidamente como resposta viável, pela sua relativa facilidade de implementação[...]"

Ainda na introdução, a pesquisa expõe que existe uma nuance tecnológica existente nas décadas de 1980, 1990 e início da década de 2000 onde, no passado, a tecnologia estava um passo atrás das reais necessidades requeridas pelo teletrabalho e nos dias atuais, onde a proliferação da conectividade em alta velocidade e os diversos dispositivos de comunicação móvel permitiram que essa modalidade seja de fato uma alternativa viável.

A pesquisa realizada apresenta um crescimento de $39 \%$ no biênio 2007-2008 (e 74\% de crescimento desde 2005) de trabalhadores americanos que desenvolvem seu trabalho, ou parte dele, à distância.

Em 2006, aproximadamente $8 \%$ da força de trabalho americana era ocupada por teletrabalhadores sendo que, em 2008, os dados apontaram para um total de $11 \%$ desta população.

${ }^{63}$ Worldatwork - Telework Trendlines 2009 Disponivel em http://www.workingfromanywhere.org/ 
Houve também um crescimento de cargos de gerência e diretoria, além de profissionais liberais e proprietários de pequenas empresas que passaram a adotar o teletrabalho.

Ainda que os dados revelem que o número de teletrabalhadores que praticam a atividade diariamente tenha decrescido, o número de trabalhadores que passaram a trabalhar nessa modalidade em alguns dias da semana cresceu, sendo que em 2003 existiam 23.5 milhões e em 200833.7 milhões de teletrabalhadores, um crescimento de $43 \%$.

A tabela abaixo demonstra a freqüência com que os teletrabalhadores americanos desenvolvem suas atividades.

Tabela 3

\begin{tabular}{|l|l|l|l|l|}
\hline Teletrabalhadores & $\mathbf{2 0 0 6}$ & TT 2006 & $\mathbf{2 0 0 8}$ & TT 2008 \\
\hline Pelo menos 1 vez por mês & $100 \%$ & 28.7 milhões & $100 \%$ & 33.7 milhões \\
\hline Pelo menos 1 vez por semana & $77 \%$ & 22 milhões & $72 \%$ & 24.2 milhões \\
\hline Quase diariamente & $51 \%$ & 14.7 milhões & $40 \%$ & 13.5 milhões \\
\hline
\end{tabular}

Tabela 3 - Teletrabalhadores Americanos - Freqüência da Atividade

Fonte : Wolrdatwork, 2009

Um conjunto de dados importante e relevante é o local de onde o teletrabalhador americano conduz suas atividades. Ressalta-se o aumento percentual que a habitação apresentou entre 2006 e 2008 , de $76 \%$ para $87 \%$ como local indicado e ainda a variação das atividades desenvolvidas a partir do local de trabalho do cliente ou consumidor que em 2006 apresentou $28 \%$ e em 2008 passou a $41 \%$.

Outras evoluções podem ser vistas na tabela abaixo:

Tabela 4 


\begin{tabular}{|l|c|c|}
\hline LOCAL & 2006 & 2008 \\
\hline Casa & $76 \%$ & $87 \%$ \\
\hline Local de trabalho do cliente & $28 \%$ & $41 \%$ \\
\hline Carro & $38 \%$ & $37 \%$ \\
\hline Café ou restaurante & $31 \%$ & $23 \%$ \\
\hline Hotel & $26 \%$ & $26 \%$ \\
\hline Estacionamentos ou espaços abertos & $19 \%$ & $14 \%$ \\
\hline Avião, ônibus ou metrô & $13 \%$ & $21 \%$ \\
\hline Aeroportos, terminais de ônibus ou metrô & $16 \%$ & $23 \%$ \\
\hline Biblioteca & $16 \%$ & $10 \%$ \\
\hline Filiais "satélites" & $3 \%$ & $7 \%$ \\
\hline Centros de teletrabalho (lan-house) & $5 \%$ & $8 \%$ \\
\hline Nenhuma das anteriores & $12 \%$ & $4 \%$ \\
\hline Em férias & $18 \%$ & $23 \%$ \\
\hline
\end{tabular}

Tabela 4 - Teletrabalhadores americanos - Local da Atividade

Fonte: Wolrdatwork, 2009

Outra pesquisa importante realizada nos Estados Unidos foi apresentada em fevereiro de 2009, e realizada pelo Governo Federal junto a suas 78 "agências" ou Secretarias de Estado do Governo Federal, entre janeiro e dezembro de 2008.

Os principais resultados foram seguem abaixo relacionados:

- 102.900 (de um total de 1.962.975) trabalhadores desenvolvem suas atividades por teletrabalho, cerca de $5,24 \%$ dos trabalhadores.

- 61\% das 78 agências relataram que houve um crescimento no número de teletrabalhadores

- $64 \%$ dos empregados utilizam o teletrabalho em média 3 dias por semana. 
- Custos operacionais e controles de manutenção são consideradas as maiores barreiras para implementação do teletrabalho, seguidas pela resistência do corpo gerencial, cultura da organização e segurança das informações.

- Dentre as questões positivas na implementação, os ganhos morais em qualidade de vida e equilíbrio vidatrabalho dos empregados apresentou-se como o mais apontado, seguidos do aumento de produtividade e ganho de tempo em deslocamentos.

- comparativamente com o ano anterior, 2008 apresentou um crescimento de $8,72 \%$ em relação a 2007 , ou seja, 8.257 trabalhadores passaram a desenvolver atividades pelo teletrabalho.

- Para sobrepor as principais barreiras apontadas para a implementação do teletrabalho, algumas agências ofereceram treinamento aos gerentes e diretores, treinamento aos empregados e ainda implantaram sistemas de controle e segurança da informação.

Uma breve análise nestes dados apresentados pode nos mostrar que o crescimento da modalidade de teletrabalho no cenário Norte Americano é evidente, porém, vale ressaltar que, de maneira divergente ao que se apresentou na dissertação de mestrado, quando a modalidade de trabalho à distância era oferecida como uma bonificação e incentivo para atrair ou conservar os bons profissionais da empresa, hoje se apresenta com um forte viés econômico, onde o Home Office surge como resposta aos indicadores de custos operacionais crescentes. 
Conforme pesquisado no trabalho anterior, a questão canadense para o teletrabalho se resume não apenas à questão econômica, mas também a um estilo de vida, devido ao clima de inverno rigoroso e baixa densidade demográfica as novas tecnologias de comunicação e informação passam a ser imprescindíveis para o país, segundo a Canadian Telework Association ${ }^{64}$.

Para além destas questões, o Canadá ainda possui um grande percentual de residências com acesso à internet de alta velocidade, (acima dos 78\%), sendo, ao lado da Austrália um dos países onde o custo deste acesso é um dos mais baixos do mundo.

Ainda existem mais dois fatores econômicos que ajudam a promover o crescimento do teletrabalho, o alto custo de realocações de trabalhadores para outras cidades e ainda a redução do absenteísmo. 


\subsubsection{O Cenário Europeu}

O Cenário Europeu também sofreu mudanças significativas sobre o comportamento da força de trabalho em relação ao trabalho a partir de casa.

Os primeiros dados a serem abordados são aqueles apresentados pela Confederation of British Industry - $C B I^{65}$ em novembro de 2009, que mostra o crescimento de empresas que disponibilizam a opção do trabalho à distância para seus funcionários. A tendência de crescimento pode ser visualizada pelo comparativo dos dados de 2004 , onde $11 \%$ das empresas proporcionavam esta opção, seguidos dos dados de 2007 , com $46 \%$ das empresas e em 2009 passamos para o patamar de $66 \%$ das empresas britânicas.

A pesquisa ainda aponta o fator econômico, provocado pela recessão provocada pelo mercado financeiro em setembro de 2008, como um dos principais motivos para o crescimento desta modalidade de trabalho, impulsionada pela pré-disposição dos trabalhadores a uma flexibilização de horários e disponibilidade a trabalhar a partir de suas residências.

Esses dados vêem de encontro com o apresentado no estudo de 2005, onde mais de 30\% dos trabalhadores britânicos entrevistados mostraram-se interessados no teletrabalho, porém o número de empresas que disponibilizavam esta modalidade de trabalho era reduzido. 
O European Working Conditions Observatory - EWCO ${ }^{66}$, tem realizado pesquisas que tratam da experiência do teletrabalho, porém a última grande avaliação sobre o tema foi realizada em 2005, sendo prevista uma nova pesquisa em 2010, onde 30.000 trabalhadores dos 27 países da União Européia e ainda Turquia, Croácia, Noruega e Suíça serão entrevistados.

Apesar dessa defasagem, a investigação de 2005, divulgada em maio de 2007, mostra um panorama dos trabalhadores que na época desenvolviam suas atividades de trabalho a partir de casa, com a utilização de um computador pessoal, e mostra-se grande a variação entre os países pesquisados, conforme vemos no quadro abaixo. Gráfico 2

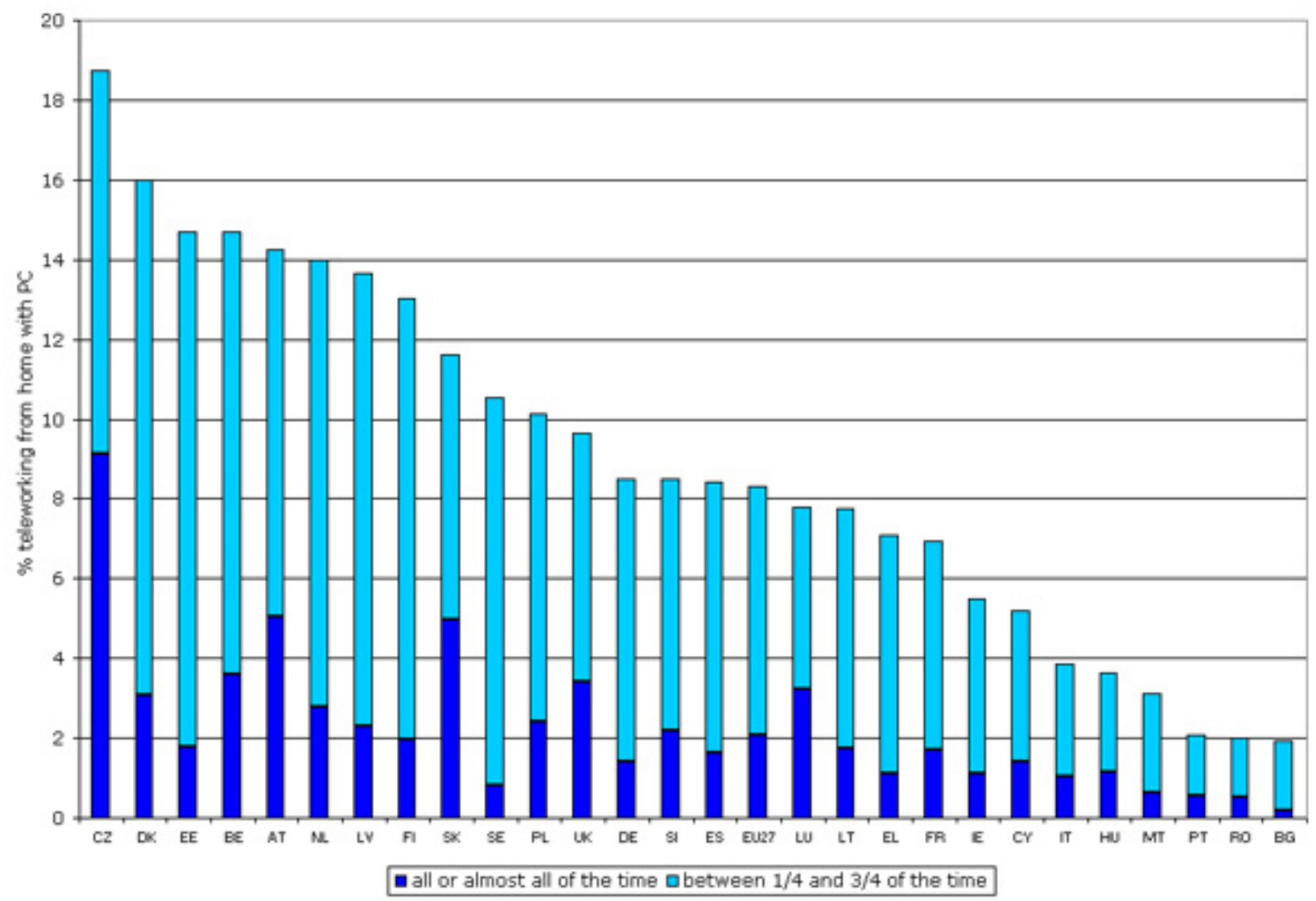

Gráfico 2 - Teletrabalhadores Europeus - Freqüência da Atividade Fonte : EWCO, 2005 
As grandes variações também se mostram quando investigadas as faixas etárias que exercem o teletrabalho em cada país, setor de atividade ou nível de trabalho.

A flexibilidade do trabalho foi o foco da pesquisa realizada pela Dynamic Markets, a pedido da Avaya, intutulada "Flexible Working $2009 " 67$.

Nesta pesquisa, o teletrabalho é apontado como um dos caminhos para o equilíbrio entre a vida profissional e a vida familiar e ainda contribui positivamente para o aumento da produtividade.

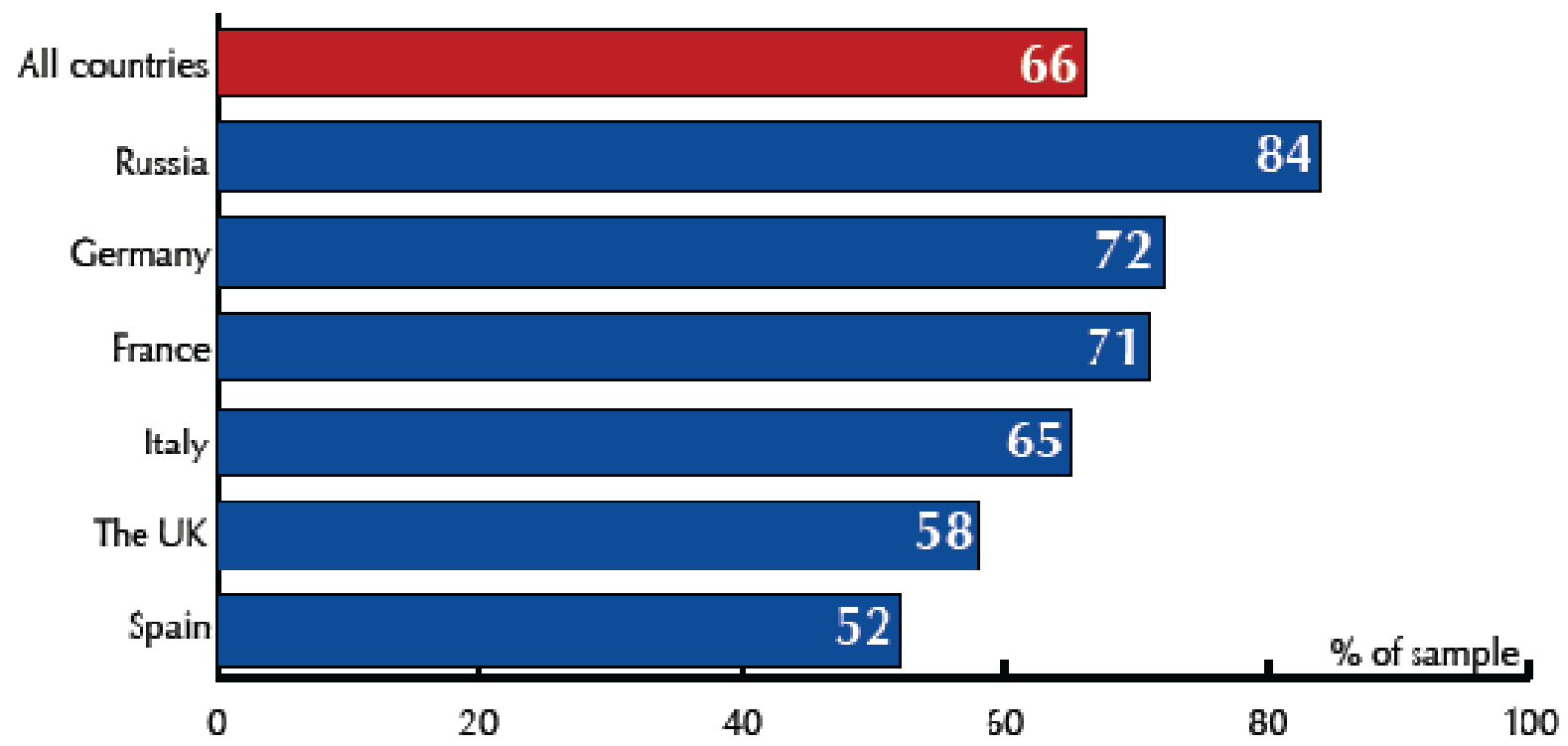

Gráfico 3 - Flexible Working 2009 - Flexibilidade do trabalho na Europa e Rússia Fonte : Dynamic Markets. abril 2009.

A pesquisa mostra que $66 \%$ dos trabalhadores europeus e russos desenvolvem algum modelo de trabalho à distância ou adotam horários flexíveis de trabalho, sendo que a maior ocorrência aparece em cargos administrativos (gerências e diretorias) e com funcionários com maior experiência (senior managers). Gráfico 3 
A disponibilidade de trabalhar em períodos noturnos ou finais de semana apontadas na pesquisa demonstra a possibilidade de utilização do ambiente doméstico para o desenvolvimento das atividades profissionais. Tabela 5

\begin{tabular}{|l|c|}
\hline Situação & Flexibilidade \\
\hline Período Noturno & $44 \%$ \\
\hline Final de Semana & $37 \%$ \\
\hline $\begin{array}{l}\text { Enquanto fora da empresa em } \\
\text { treinamento }\end{array}$ & $34 \%$ \\
\hline No deslocamento casa-trabalho & $30 \%$ \\
\hline Em período de convalescência & $28 \%$ \\
\hline A caminho de reuniões & $25 \%$ \\
\hline Em feriados & $12 \%$ \\
\hline Nenhuma situação & $7 \%$ \\
\hline
\end{tabular}

Tabela 5 - Flexible Working 2009 - Disponibilidade para Flexibilização Fonte : Dynamic Markets. abril 2009.

Embora exista a reivindicação por uma legislação específica para trabalhadores que adotem algum tipo de sistema de trabalho flexível - cerca de $25 \%$ dos entrevistados, principalmente nas empresas de grande porte - $75 \%$ dos trabalhadores admitem considerar a redução do pacote de remuneração em troca da diminuição dos deslocamentos casa-trabalho, desenvolver mais atividades de trabalho a partir de suas casas e ter um ganho de flexibilidade em suas vidas. 
O tempo estimado de deslocamentos casa-trabalho-casa nos países pesquisados aponta uma média de 74 minutos diários.

96\% dos trabalhadores que adotam algum sistema de trabalho flexível confirmam que possuem um ganho de 'tempo' em suas vidas, o que Ihes permite uma agenda de atividades com a família, atividades culturais, atividades físicas ou simplesmente um ganho de tempo para o relaxamento.

Apesar de Portugal estar entre os três países que menos desenvolvem atividades de teletrabalho, segundo a pesquisa EWCO(2005), demonstrada no gráfico 1 , a pesquisa do LNEC | FAUUSP aplicada em Lisboa em 2007, que buscava informações sobre as funções e atividades da habitação, obteve os seguintes resultados nas questões sobre o "Trabalho na Habitação":

- $39,5 \%$ desenvolvem trabalhos em casa

- $55,0 \%$ trabalham em casa diariamente

- $55,0 \%$ utilizam o dormitório para a atividade

- 76,0\% utilizam computador

- $60,0 \% \quad$ utilizam notebook

- $40,0 \% \quad$ utilizam desktop

- 36,0\% gostariam de ter um escritório na residência 


\subsubsection{O Cenário Australiano}

Devido as condições continentais do país, a Austrália se posiciona como um dos principais países cuja população se utiliza das tecnologias de informação e comunicação.

Nesse sentido, o governo promove pesquisas regulares sobre o tema, onde destacamos os resultados do "The Sensis Business Index", que traça informações sobre as pequenas e médias empresas do país desde 1993.

A última pesquisa divulgada se deu em julho de 2009 e foram ouvidos 1800 empregadores de pequenas e médias empresas por todo o território australiano, em diversos segmentos do mercado.

A média de empresas que adotam o teletrabalho é de $24 \%$ e, na capital chega a $29 \%$ e, quanto maior a empresa, sobe o número de incidência de teletrabalhadores.

A pesquisa também contemplou perguntas sobre o local a partir do qual os teletrabalhadores desenvolvem suas atividades quando não estão nas dependências da empresa, e o resultado apontou que a grande maioria tem a residência como base de teletrabalho. Gráfico 4 


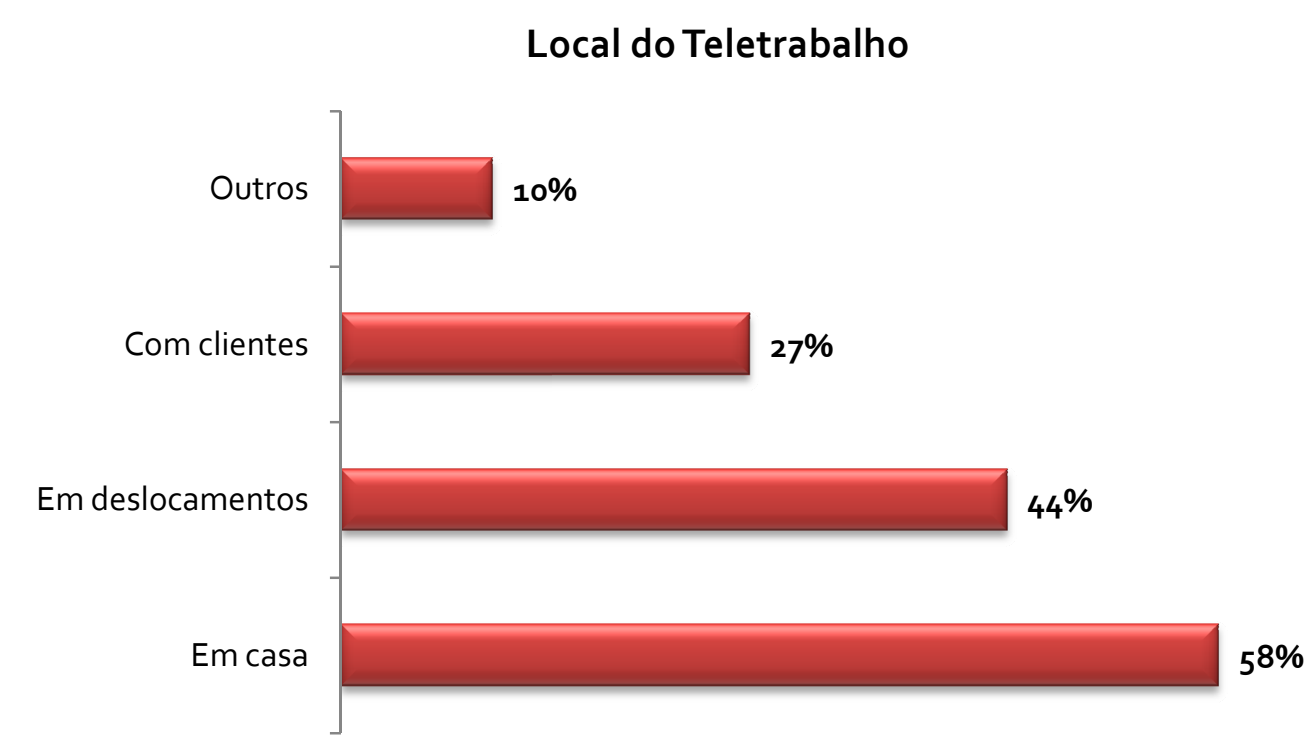

Em relação ao tipo de atividades, os serviços administrativos, financeiros, atendimento e suporte ao cliente são as principais atividades apontadas na pesquisa. Gráfico 5

\section{Principais Tarefas do Teletrabalho - 2009}

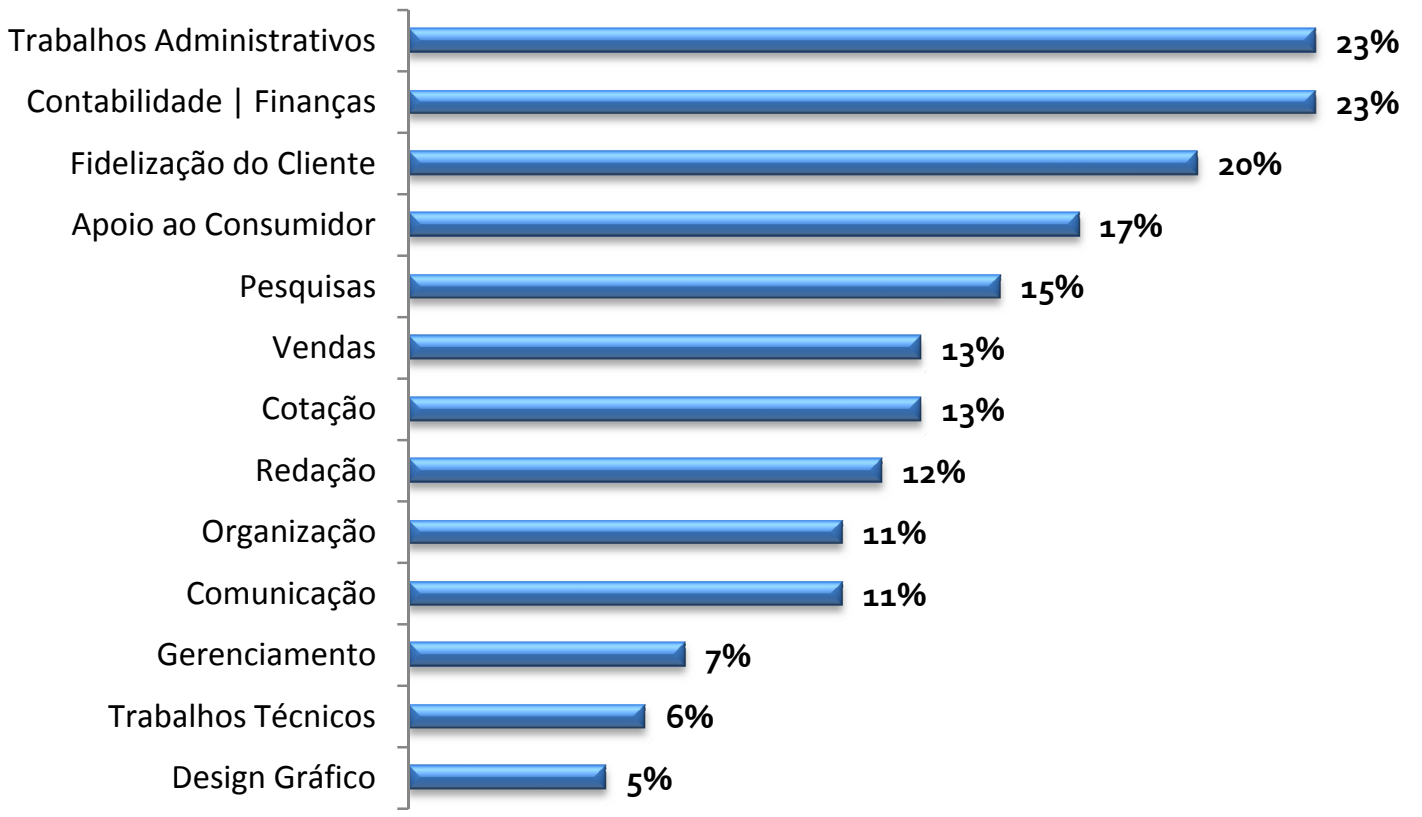


A pesquisa apresenta ainda a porcentagem de funcionários que se utilizam do teletrabalho para realização de suas atividades, chegando a uma media de $60 \%$ dos empregados das empresas consultadas.

\section{Gráfico 6}

\section{Porcentegem de Empregados que Teletrabalham}

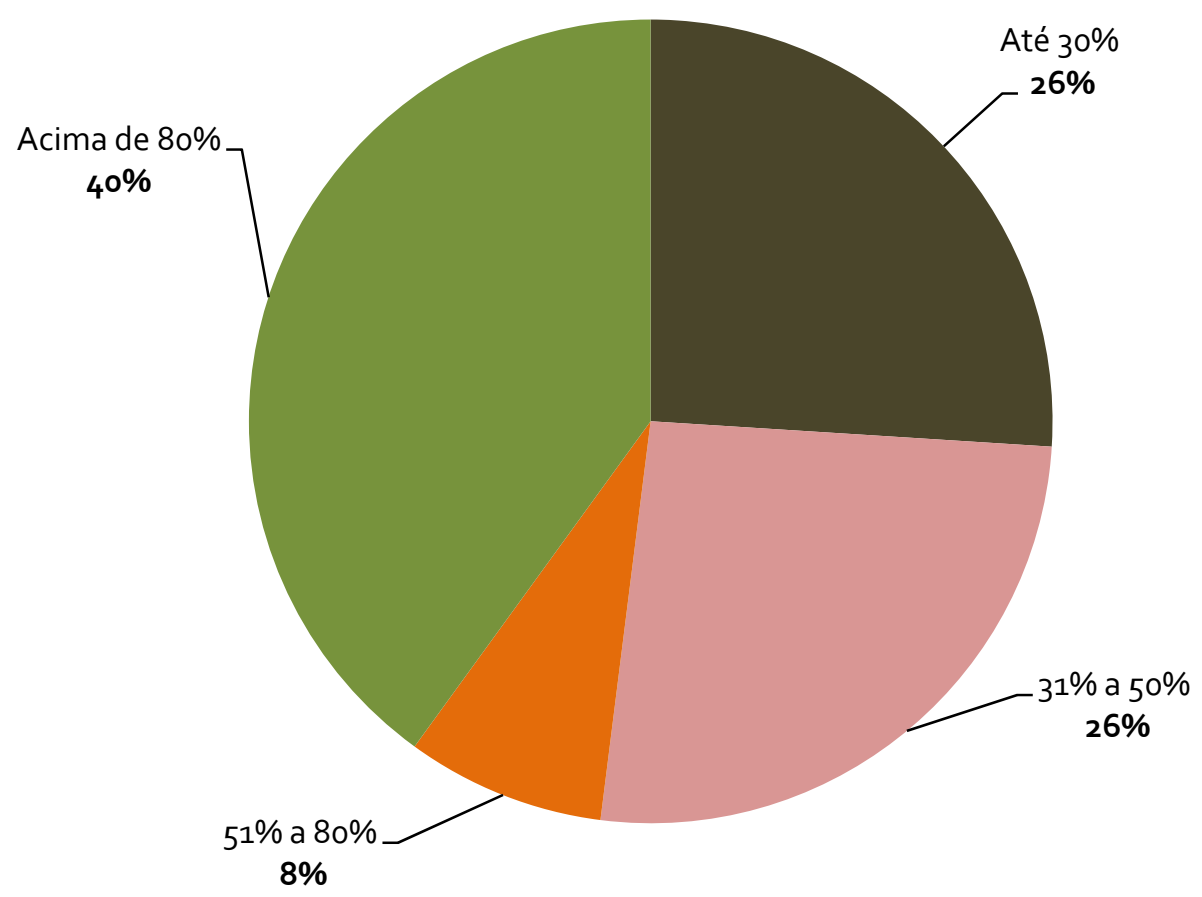

Mais um dado importante é o tempo que cada trabalhador se ocupa em atividades de teletrabalho, onde a média ficou em 17 horas semanais. Gráfico 7 


\section{Tempo em Teletrabalho}

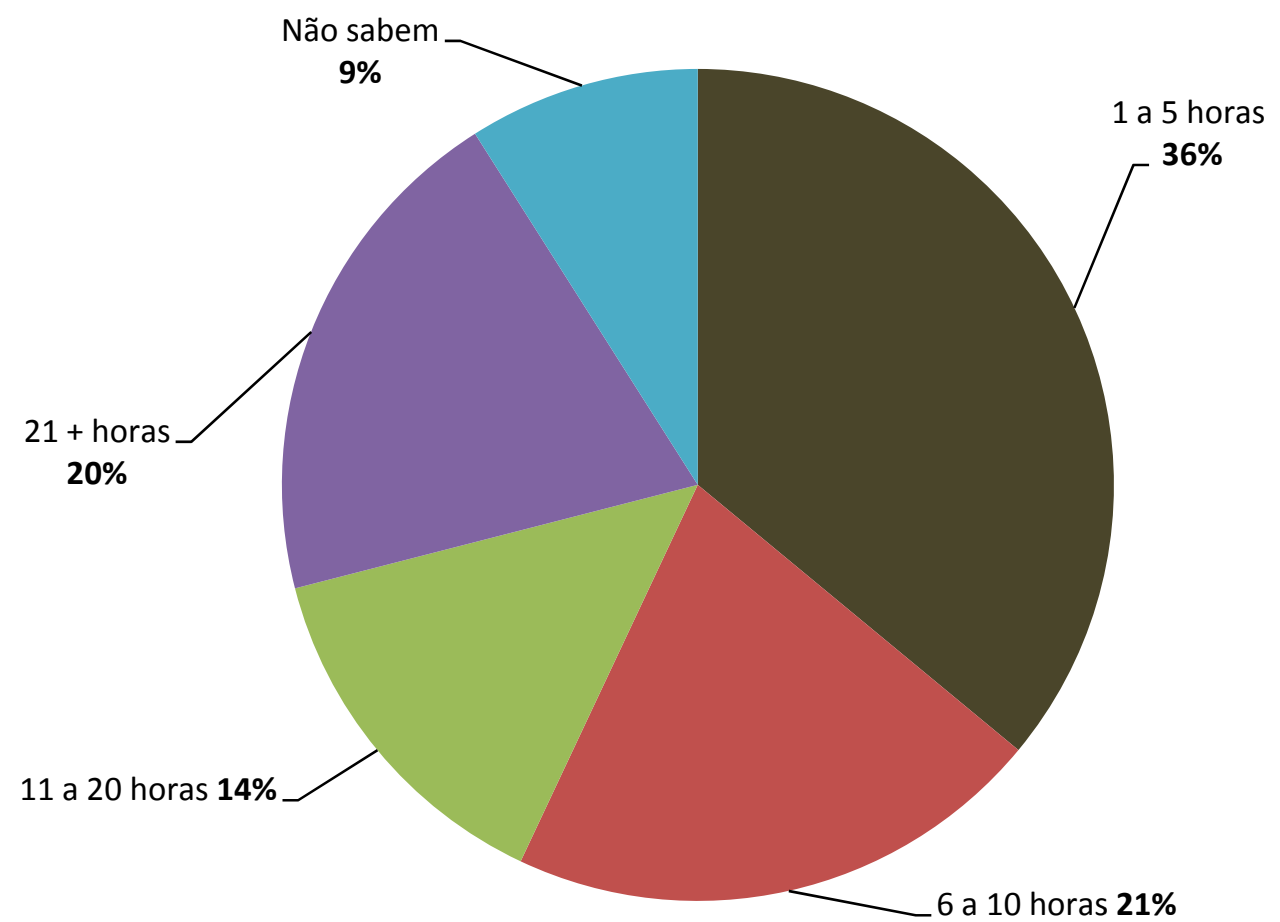

Ao traçar um comparativo entre as pesquisas de 2005 e 2009, pode-se verificar o crescimento de duas ferramentas no desempenho das atividades de teletrabalho: o computador portátil e a conexão de banda larga, enquanto a telefonia celular apresentou uma retração. Gráficos 8 e 9

A pesquisa revela ainda que $82 \%$ das empresas consideraram que os impactos do teletrabalho em seus negócios foi positivo. 


\section{Equipamentos e Infraestruturas utilizados \\ para o Teletrabalho - 2009}

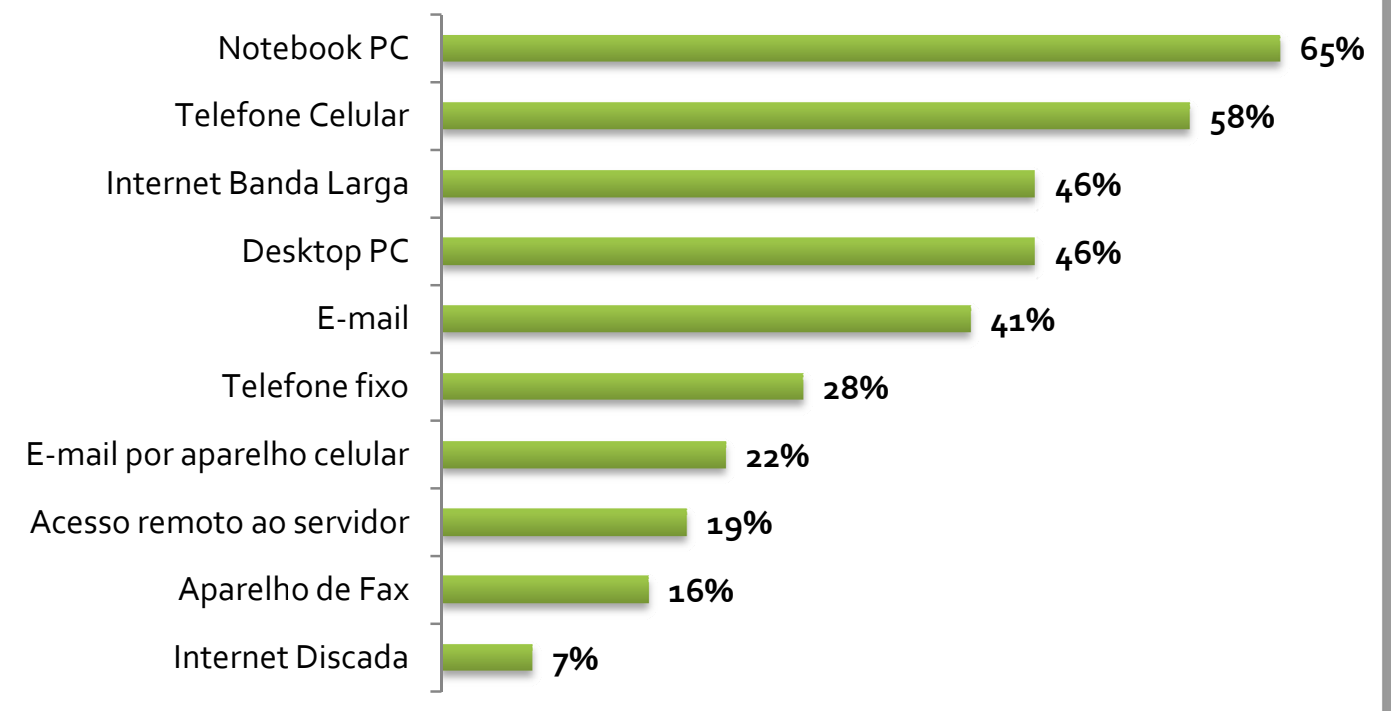

\section{Equipamentos e Infraestruturas utilizados para o \\ Teletrabalho - 2005}

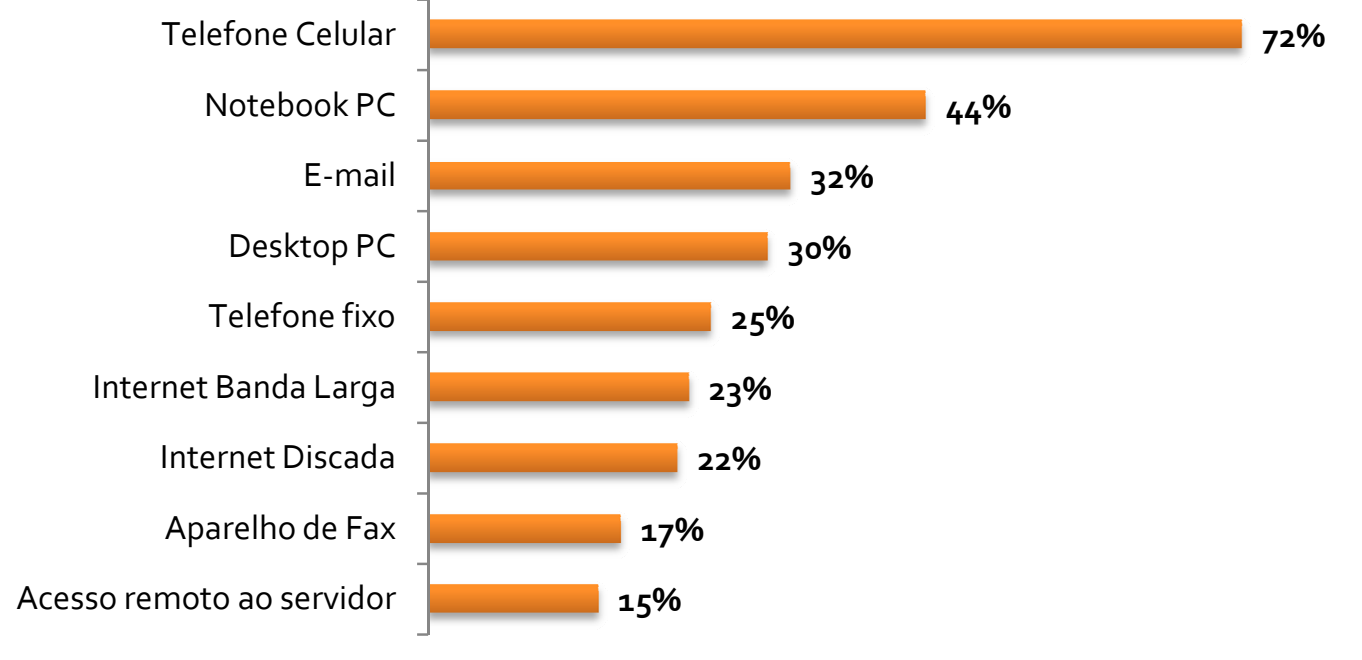




\subsubsection{Os Cenários Asiático, Africano e Oriente Médio}

Apesar da Ásia apresentar o maior número de usuários da internet com $42,6 \%$ do total mundial, segundo a Internet World Stats (2009), a penetração média na população asiática é de apenas 19,4\%. Gráfico 10

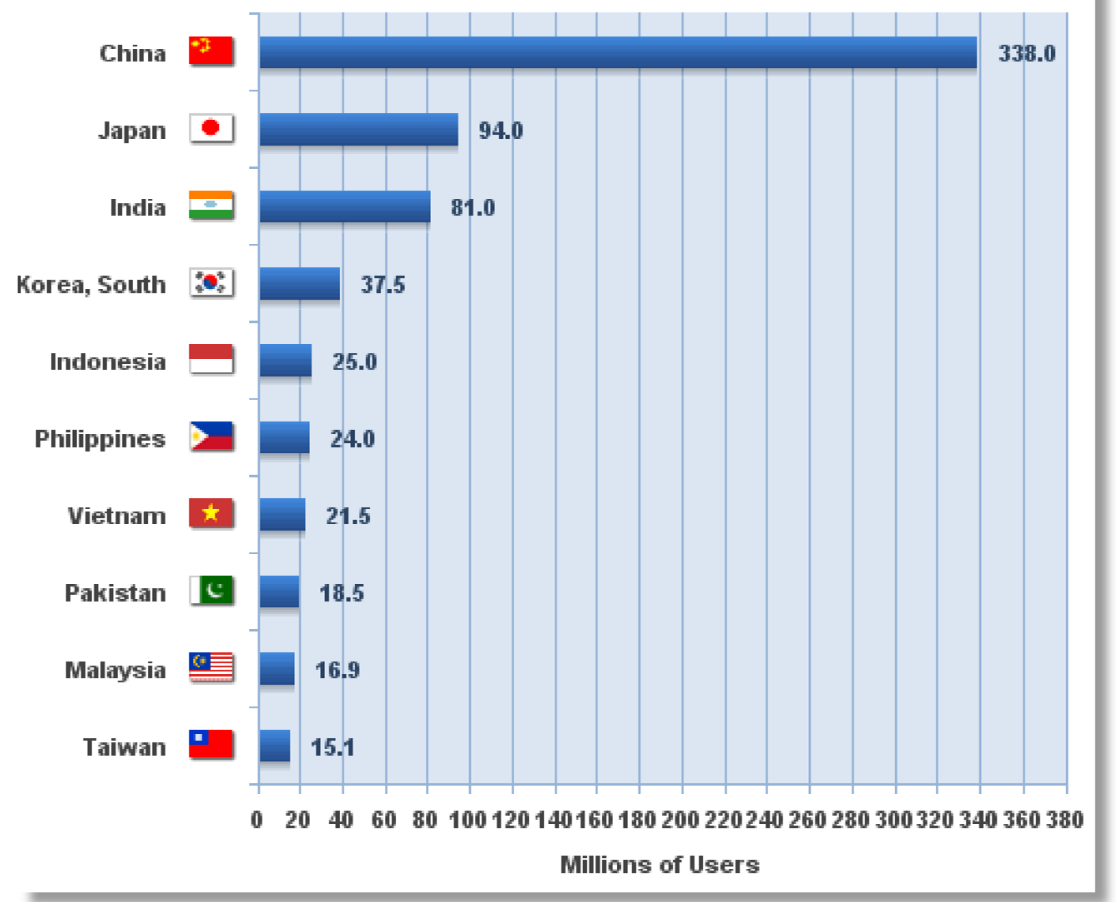

As pesquisas sobre teletrabalho são escassas, apenas destacando-se o trabalho de Saloma-Akpedonu et al. ${ }^{68}$ (2004), onde estuda as condições das mulheres que trabalham em seus domicílios e têm acesso às tecnologias de informação e comunicação na Indonésia, Malásia e Tailândia.

68 Saloma-Akpedonu, C.; Ching, C.S.; Tan, A. Homeworkers and ICTs in Southeast Asia. Ateneo de Manila 
Os principais resultados foram as necessidades de legislações nestes países que regulem e reconheçam o trabalho à distância, realizado em sua grande maioria por mulheres de baixa renda, permitindo acesso a assistências oferecidas a micro e pequenas empresas que possibilitem investimentos em equipamentos e treinamentos adequados para que as oportunidades naqueles países sejam mais justas.

Nos casos do Oriente Médio e África, existem apenas os dados de uso da internet, os quais possuem as menores representatividades no contexto mundial, com 3,95 e 3,3\% do total de usuários segundo a Internet World Stats (2009). 


\subsection{O Cenário Brasileiro, Empresas Nacionais e Legislação}

\subsubsection{O Cenário Brasileiro}

O Brasil conta hoje com mais de 10 milhões de trabalhadores que desenvolvem suas atividades profissionais em locais que não estão inseridos na área física da empresa utilizando-se das tecnologias de informação e comunicação. Este universo contempla todos os setores e áreas de produção e serviços, incluindo trabalhadores formais e informais que se utilizam de todos os dispositivos e meios de comunicação à distância.

Estes dados, apresentados pela SOBRATT(2008), em uma primeira análise podem conflitar com os dados do IBGE(PNAD2008) que apontam para um universo de 208 mil trabalhadores com e sem carteira assinada que desenvolvem atividades remuneradas à partir de suas residências.

Deve-se, porém, entender que se trata de universos diferentes, onde, no primeiro consideram-se todos os trabalhadores envolvidos com teletrabalho e, no segundo caso, somente aqueles que desenvolvem atividades remuneradas à partir de suas residências, e que apenas uma parcela desse total são "home-officers". 
O Comitê Gestor da Internet no Brasil - CGI, cujas atribuições são a coleta e disseminação de informações sobre serviços de Internet, desde 2005 vem colaborando com o IBGE e a ANATEL no acompanhamento, monitoramento e avaliação do uso e impactos sócioeconômicos das TICs no Brasil, bem como permitir a comparabilidade brasileira com a de outros países.

A pesquisa 'TIC - Domicílio', apresentada pela CGI em 2009, referente ao ano de 2008 , mostrou vários indicadores sobre o uso da Internet brasileira e o perfil de seus usuários.

A Região Sudeste aparece como a região com maior acesso às TICs, com $43 \%$ do total nacional, dado relevante pelo fato deste trabalho de doutoramento ter como foco de investigação o município de São Paulo. Gráfico 11

\section{Distribuição do Acesso às TICs}

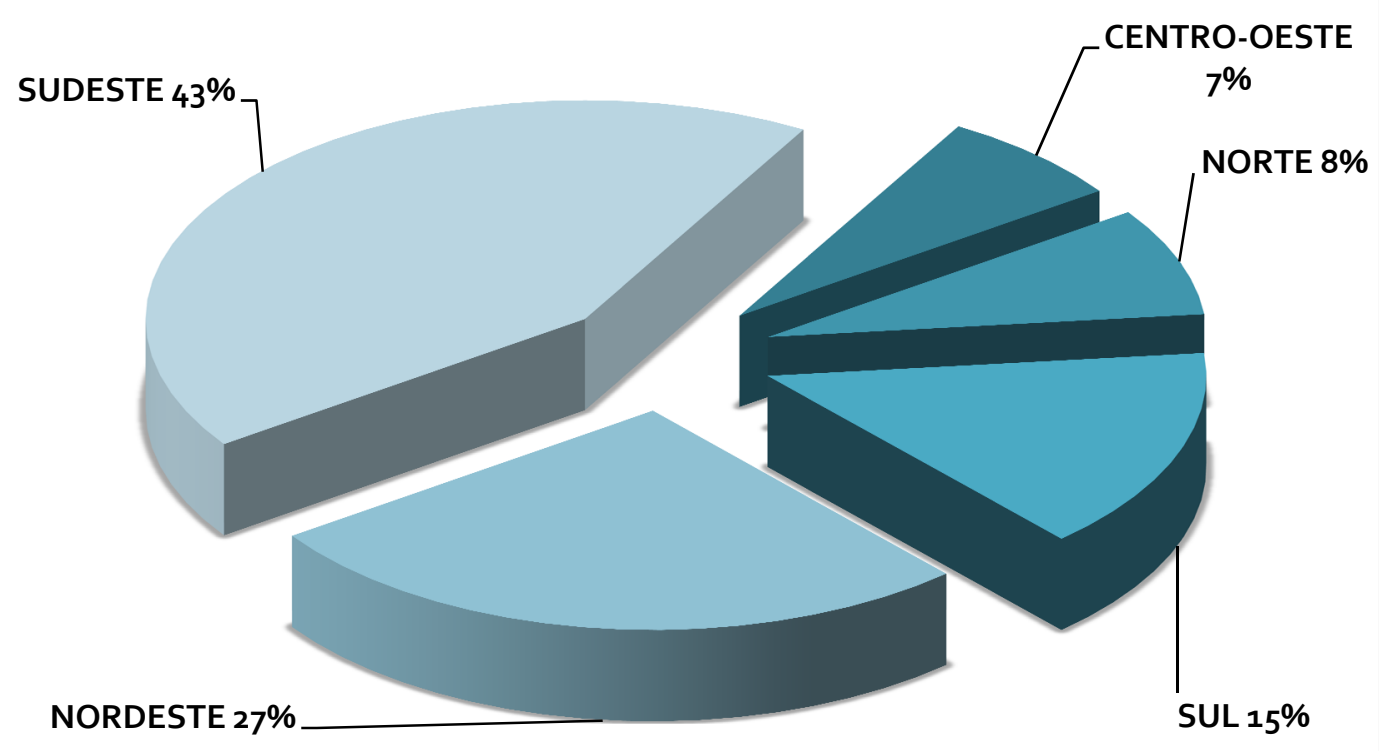


Sobre a faixa etária que acessa a Internet, pode-se verificar três faixas de relevância: Gráfico 12

$51 \%$ tem entre 10 e 34 anos

$55 \%$ tem entre 16 e 44 anos

$55 \%$ tem entre 25 e 59 anos

\section{Faixa Etária}
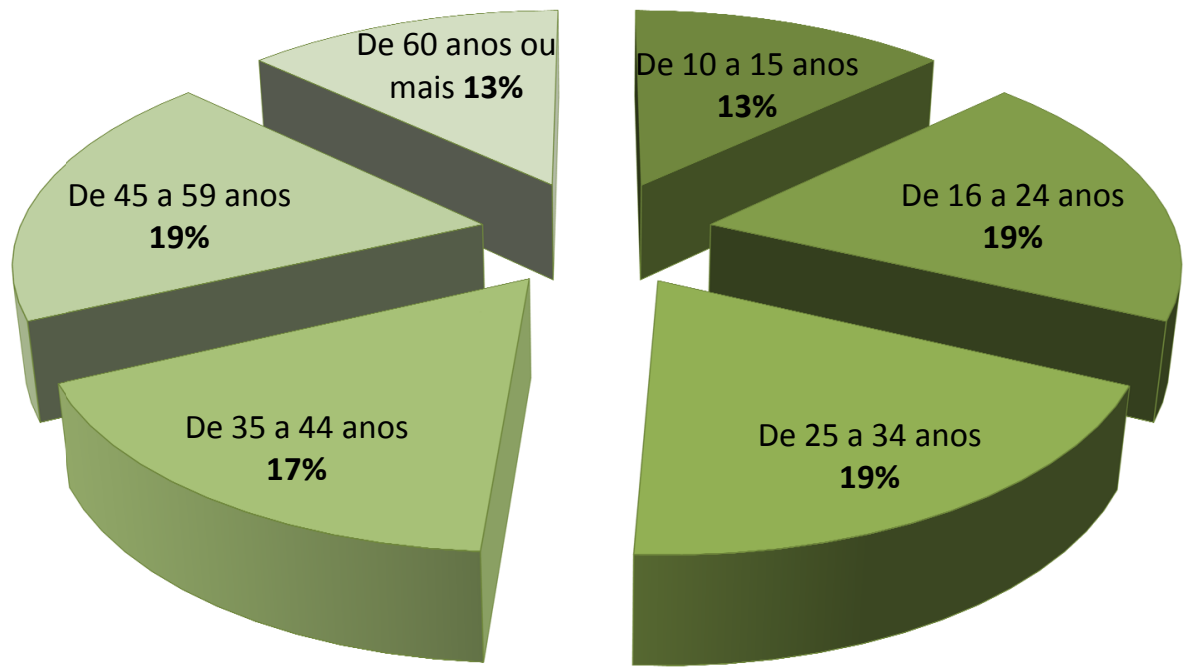

Em relação aos locais de acesso à Internet, a pesquisa mostra que as Lan-Houses (Centros Públicos de Acesso pagos) são os locais mais procurados, seguidos das residências. Neste caso, se somados os dados dos acessos "Em casa" e "Na casa de outra pessoa", temos o total de $65 \%$ de acessos à partir das habitações, superando os acessos públicos pagos. Gráfico 13 


\section{Evolução dos Locais de Acesso à Internet - Brasil}

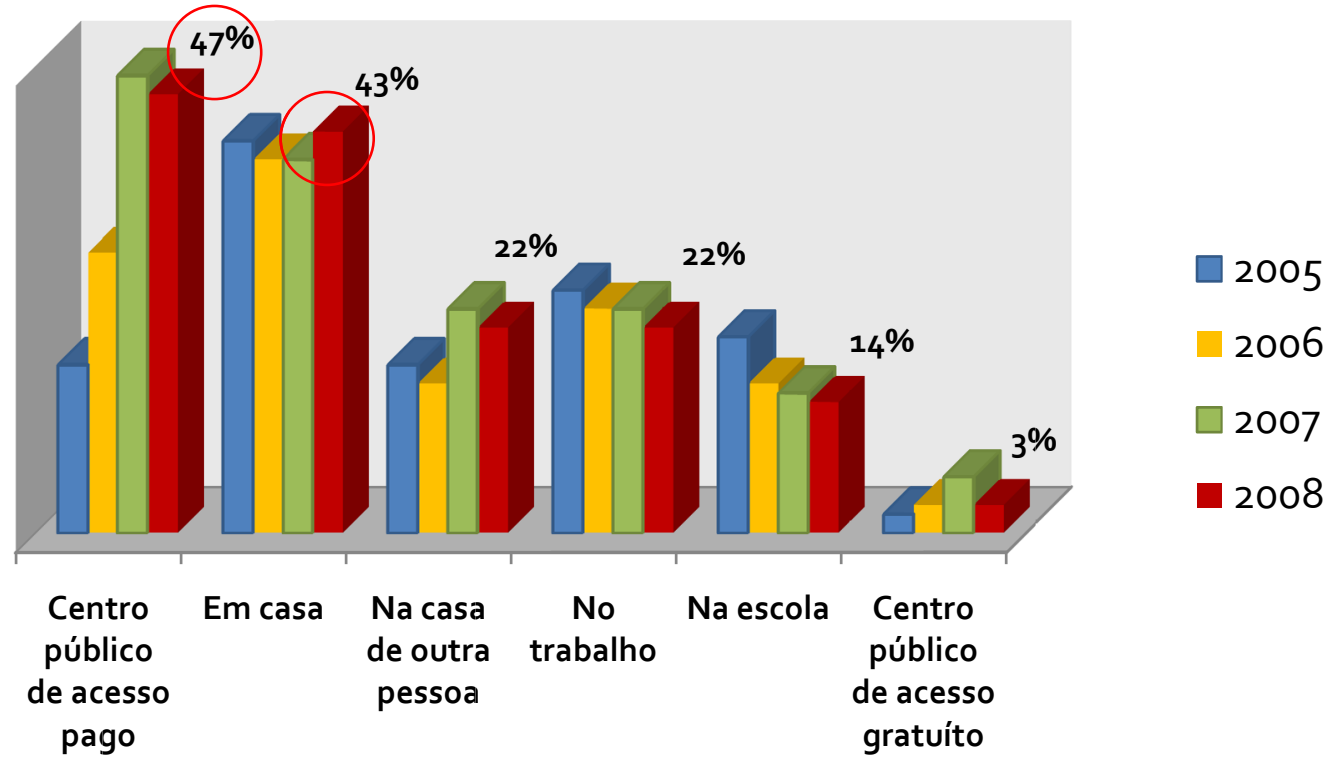

Pode-se verificar no gráfico abaixo a maior porcentagem de acessos via residência quanto maior for o grau de instrução, faixa etária mais elevada e classes sociais mais abastadas.Gráfico 14

Comparação dos principais locais de acesso: casa vs lanhouse revelam perfis complementares quanto a classe social, grau de instrução e faixa etária.

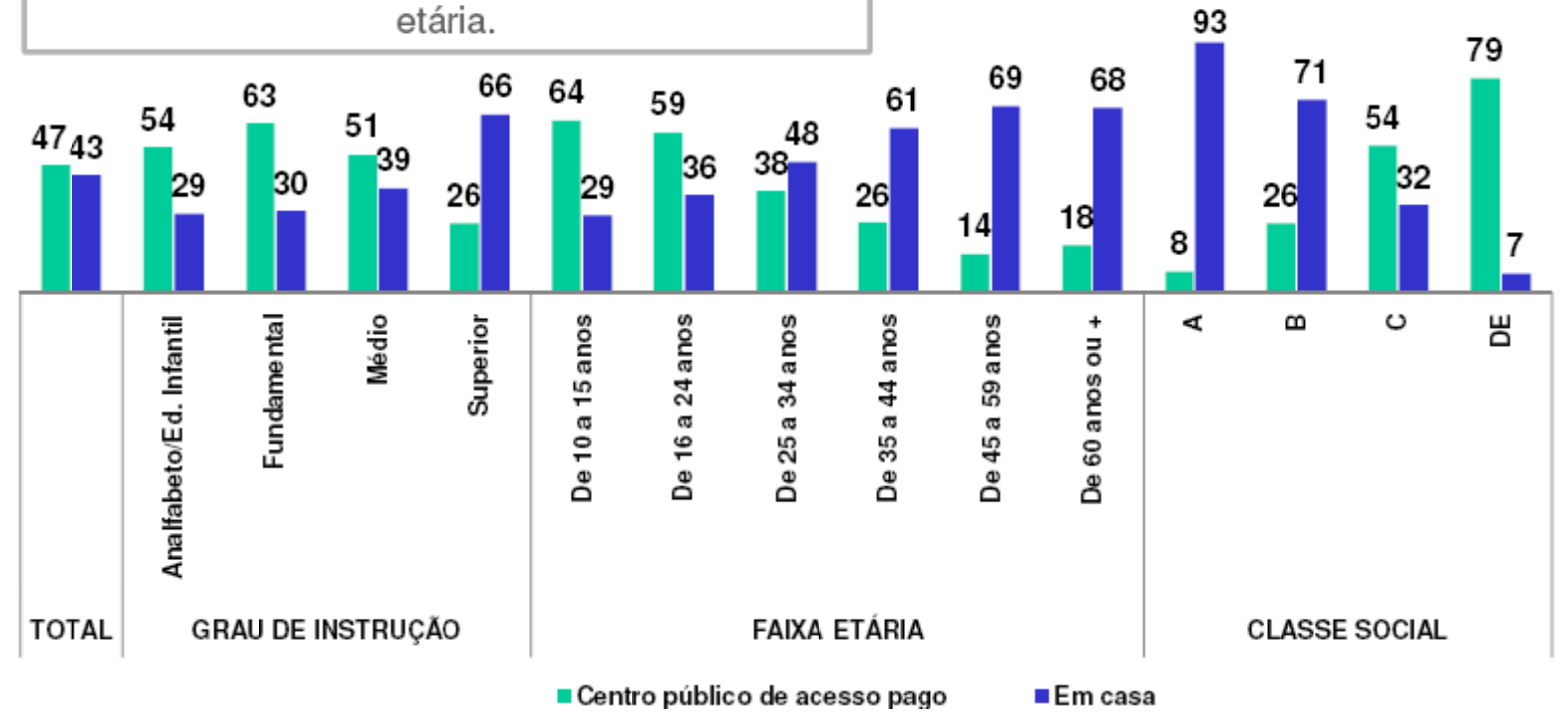


A grande utilização dos centros públicos de acesso pago por camadas de menor poder aquisitivo e menor instrução pode ser explicada pela questão financeira, onde a pesquisa mostrou que $74 \%$ dos usuários de computadores não possuem o equipamento em casa, $54 \%$ dos usuários não possuem acesso à Internet a partir de suas residências e $48 \%$ acessa de suas casas pelo sistema discado e não possui banda larga, pelo fato de que estes itens estão acima de suas capacidades financeiras.

O relatório da CGI apresenta a proporção de equipamentos TICs presentes nos domicílios brasileiros pesquisados, sendo que, para este trabalho, deve-se manter o foco nos itens de computadores de mesa e portáteis, com $27 \%$ e $3 \%$ de domicílios, respectivamente. Gráfico 15

\section{Porcentagem de Domicílios que possuem equipamentos TIC}
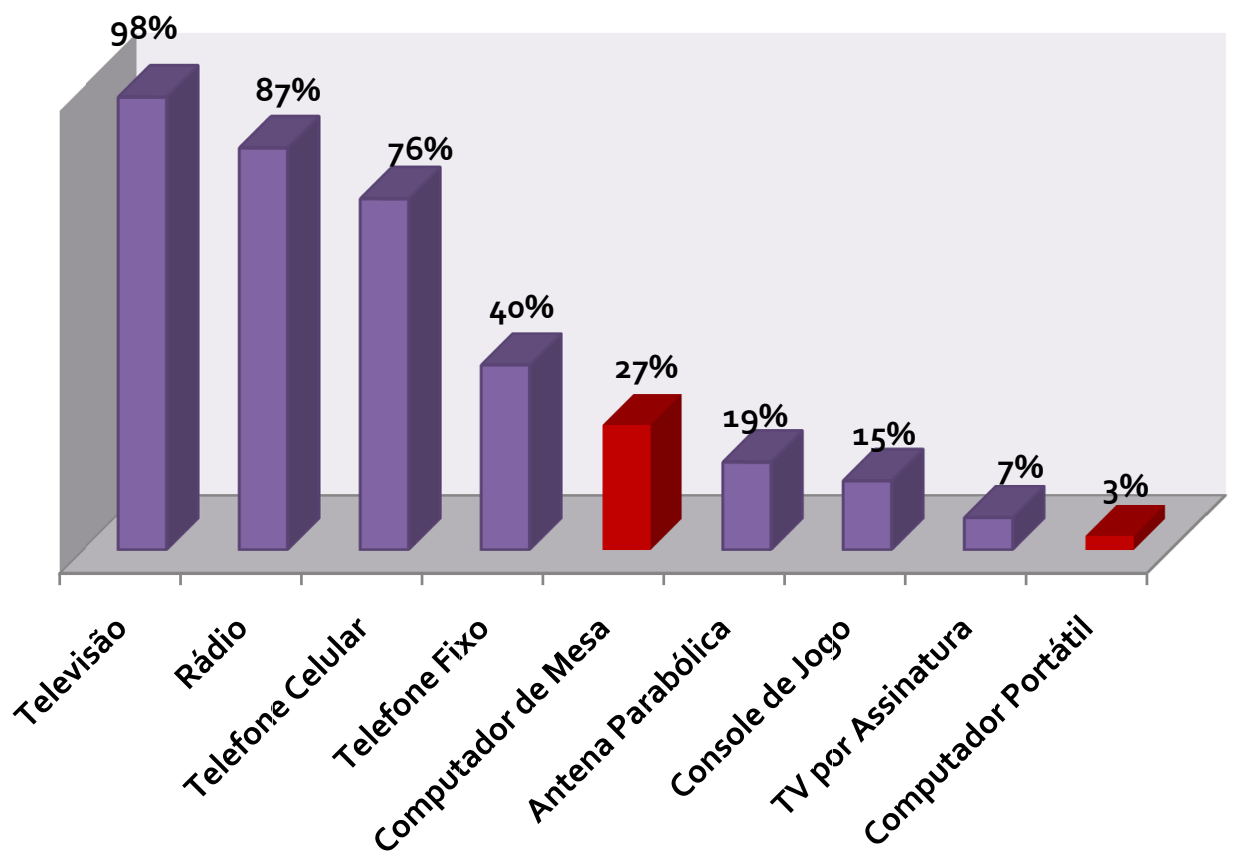
Pode-se ainda verificar a evolução de 2005 a 2008 da penetração destes equipamentos nos lares brasileiros, observando-se uma clara tendência de aumento. Gráfico 16

Evolução da Posse de Computadores em Domicílios - Brasil

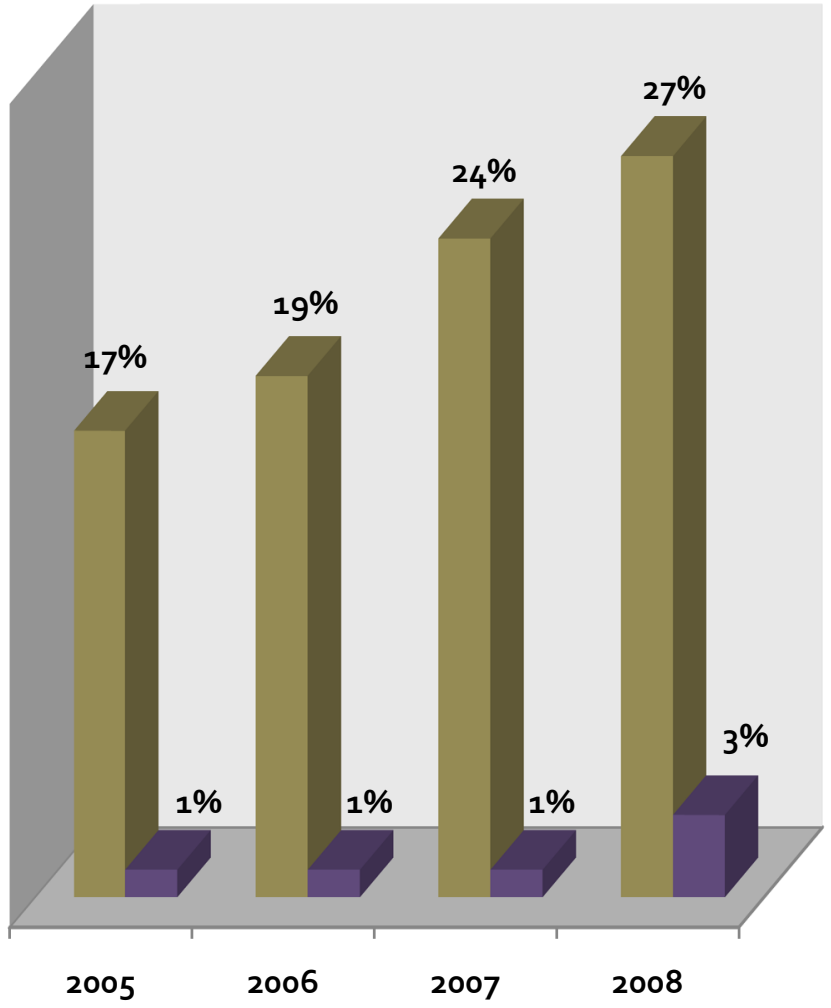

Computador de Mesa

- Computador Portátil

Houve também um crescimento tanto na porcentagem de domicílios com computadores quanto de domicílios com acesso à Internet, observando-se que no primeiro caso o avanço foi maior. Gráfico 17 


\section{Comparativo da Evolução entre Domicílios com Computador}

e Domicílios com Acesso à Internet

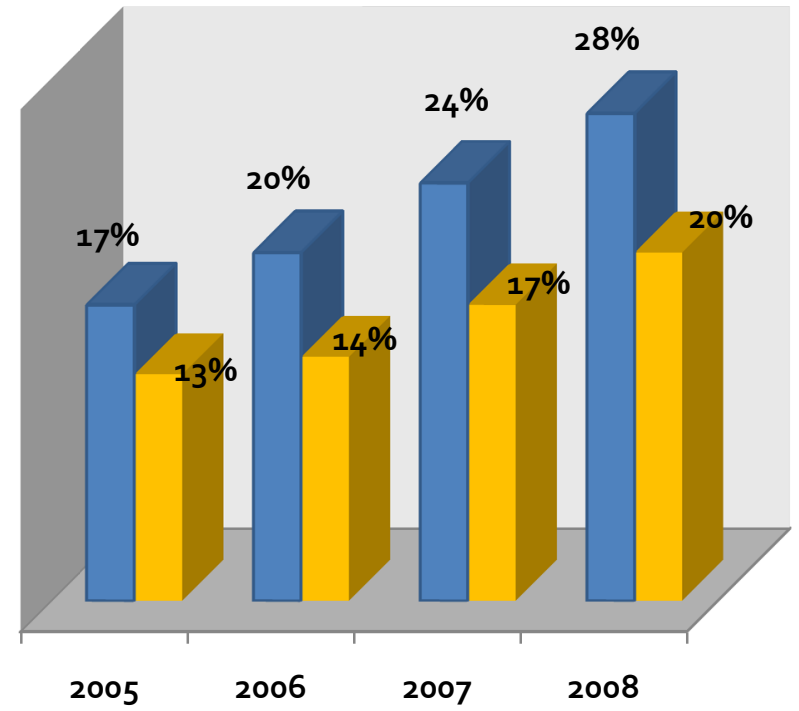

Domicílios com

Computador

Domicílios com

Computador e Acesso

à Internet

Outro comparativo importante é o crescimento do número de usuários de computadores e também do número de usuários da Internet, mostrando que houve uma redução dessa diferença, onde o crescimento de usuários da Internet no período foi maior do que o crescimento dos usuários de computador. Gráfico 18

\section{Comparativo da Evolução entre Usuários de Computador e Usuários de Internet}

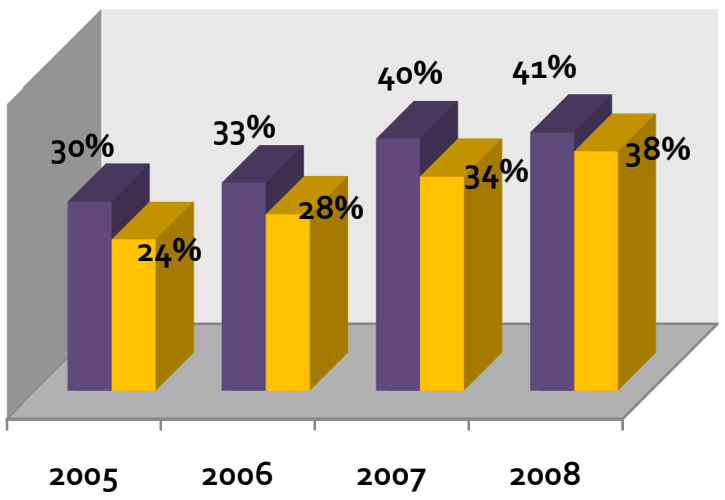

- Usuário Computador

- Usuário Internet 
Observa-se ainda o avanço do acesso de alta velocidade (Banda Larga) em relação ao decrescente uso do acesso discado. Nesse quesito o crescimento ainda está vinculado não apenas ao fator econômico, mas também da viabilidade técnica de algumas regiões que não dispõem desta tecnologia para o usuário residencial. Gráfico 19

\section{Comparativo da Evolução das Modalidades de Acesso à Internet}

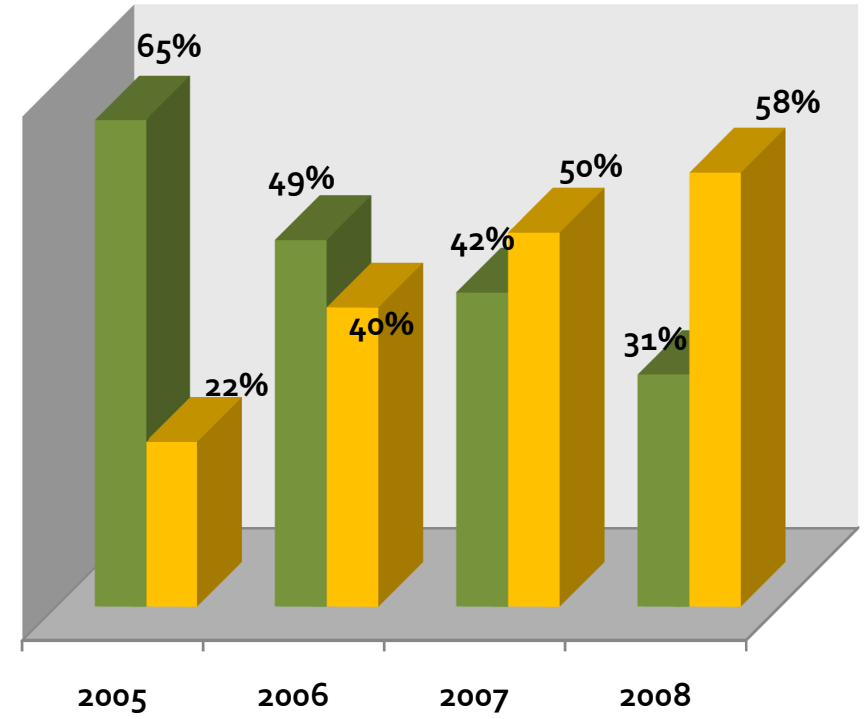

Acesso Discado Acesso Banda Larga

O Governo Brasileiro estuda um Plano de Banda Larga Nacional, apresentado em novembro de 2009, que prevê a 'massificação' deste tipo de acesso até o ano de 2014.

A meta para os acessos fixos individuais é de 30 milhões e para a banda larga móvel de 60 milhões. O texto do plano prevê ainda acesso à internet de banda larga a 100\% dos órgãos do governo, incluindo a totalidade das unidades da administração federal, estadual e municipal, escolas, unidades de saúde, órgãos de segurança pública e $100 \mathrm{mil}$ novos telecentros comunitários. 
Em se tratando do Município de São Paulo, em novembro de 2009 o IBGE divulgou dados sobre a capital paulista, que apresentava em 2008, 2,39 milhões de residências conectadas à Internet, o que equivale a um número superior que as Regiões Norte e Nordeste somadas.

Outra iniciativa dos órgãos governamentais, neste caso do Governo do Estado de São Paulo, em dezembro de 2009, foi a elaboração de um plano de isenção de ICMS para conexões de até $1 \mathrm{Mbps}$, reduzindo o valor do acesso em banda larga da Internet, beneficiando principalmente a população de baixa renda.

As iniciativas governamentais, além de terem como objetivo a inclusão digital da população brasileira tornando as TICs acessíveis a parcelas cada vez maiores desta população, pode-se acreditar que também serão estímulos para que o trabalho à distância possa cada vez mais ser inserido no contexto urbano das cidades brasileiras. 
O desenvolvimento do teletrabalho e sua disseminação não apenas depende da disponibilidade do trabalhador, mas também, e de maneira tão necessária quanto, depende da estratégia do setor de recursos humanos das empresas.

Os benefícios apontados pelos trabalhadores para o desenvolvimento do trabalho à distância, especificamente em suas residências, já são conhecidos e estudados, como a flexibilidade de horários, organização pessoal do tempo, balanço entre vida profissional e vida familiar, dentre outros, porém, para que o conceito de trabalho à distância seja de fato incorporado na vida das empresas, estas têm que vislumbrar quais os benefícios ou impedimentos que esta modalidade de trabalho pode gerar.

Taveras $^{69}$ (1998) explorou o impacto do teletrabalho nas atitudes comportamentais na cultura das empresas e concluiu que o trabalho à distância não interfere de maneira estatisticamente significante na percepção da organização da empresa, na satisfação do trabalho, comprometimento e outras variáveis culturais do comportamento.

A pesquisa apresentada pela Dynamic Markets - The Flexible Working 2009 - trouxe à luz alguns dos benefícios apontados pelos empregadores europeus sobre o sistema de trabalho à distância desenvolvido por suas empresas.

69 Taveras, L.E. The effects of telecommuting on attitudinal and behavioral characteristics of organizational culture. University of Sarasota - Doctoral Dissertation - 1998 
$45 \%$ dos dirigentes acredita que um plano de horário flexível, com adoção de trabalho à distância se traduz na contratação de melhores profissionais, pois estes se vêm atraídos pelos ganhos proporcionados pela flexibilidade de horários.

$55 \%$ dos empregadores entendem que a produtividade de seus funcionários aumenta com a flexibilização de horários, e este fato é corroborado pelo dado que $60 \%$ do tempo ganho pelo funcionário por não se deslocar para a empresa são voltados ao trabalho a distância e somente os $40 \%$ restantes são ocupados com atividades pessoais.

Pode-se apontar ainda, embora não existam dados confiáveis de pesquisas, que o deslocamento do funcionário das dependências da empresa acarreta em diminuição de gastos com equipamentos, manutenção e necessidade de área física para este trabalhador, e pode-se especular que estes gastos reduzem os custos operacionais da empresa, ainda que esta empresa de alguma maneira assuma os gastos extras que o funcionário terá em seu domicílio.

Os aspectos legais ao lado da confiabilidade e segurança das informações da empresa são as maiores barreiras para a implementação do teletrabalho.

Ainda que existam dispositivos de controle de presença e gerenciadores de informação eletrônica, a resistência nesse sentido ainda é grande por parte dos empregadores, céticos de que o sistema de trabalho à distância permita o mesmo controle de empregados e informações que dispõem no sistema convencional de trabalho. 
No Brasil, algumas empresas de capital nacional e outras multinacionais com sede no país disponibilizam a parte de seus funcionários a oportunidade de desenvolverem suas atividades à distância.

Ruppel ${ }^{70}$ (1995) desenvolveu pesquisas nas áreas relacionadas à adoção do teletrabalho em organizações, cultura organizacional e gerenciamento do teletrabalho, comparando empresas que adotaram programas de teletrabalho com as que mantêm apenas o sistema convencional.

As empresas onde a não houve a adoção têm como motivo básico as implicações negativas do teletrabalho na sua cultura organizacional, enquanto o segundo grupo apresenta as seguintes características comuns:

- Atuam em mercados mundiais

- Atuam em mercados altamente competitivos

- Possuem legislação de trabalho específica

- Algo grau de profissionalismo nas equipes da empresa

- Decisões centralizadas

- Corpo gerencial treinado para os benefícios do teletrabalho

- Disponibilização de sistemas de comunicação on line

- Existência de sistemas de segurança da informação

- Suporte da empresa ao teletrabalhador 
Estas empresas, além dos fatores positivos e negativos para funcionários e empresas, visam ganhos ambientais e sociais, a exemplo da redução de viagens e emissão de polventes.

Um estudo realizado pela CISCO internacional(2009), uma das empresas multinacionais que incentiva o teletrabalho, mostrou que em 2008 os deslocamentos evitados com o trabalho à distância de seus funcionários evitou a emissão de 47 mil metros cúbicos de gases agressivos à camada de ozônio e uma economia de US\$10.3 milhões em combustível.

A SOBRATT disponibiliza em sua página na Internet as principais empresas brasileiras que possuem o sistema de flexibilidade de trabalho, as quais estão relacionadas abaixo:

- AT \& T Brasil

- CISCO Brasil

- IBM Brasil

- DELL do Brasil

- ERNEST \& YOUNG

- HP Brasil

- MARRY LYNCH

- MERCK Brasil

- NATURA

- NORTEL

- POLYCOM Brasil

- SEMCO

- SERPRO

- SHELL do Brasil 
- SONIWALL

- SYMANTECH

- TELEJOB

- TICKET

- VIRTUAL CALL

As empresas que possuem suas sedes ou escritórios na capital paulista foram contatadas e, ainda que exista uma forte resistência ao acesso ao setor de recursos humanos e muitas delas não se mostraram disponíveis para fornecer algumas informações sobre seus programas, fato recorrente nas pesquisas sobre o tema conforme McCloskey \& Igbaria ${ }^{71}$ (1998) outras se mostraram voluntariosas e colaboraram com o desenvolvimento desta tese de doutoramento, conforme relatos a seguir. 
No ano de 2000, a Cisco do Brasil, uma empresa do ramo de sistemas de comunicações, chegou ao Brasil com a proposta tradicional de ocupação de espaços de escritórios em centros financeiros da capital paulista, onde cada funcionário tinha seu posto de trabalho na empresa.

Com a evolução tecnológica que a própria Cisco ajudou a desenvolver, a filosofia de postos fixos passou a ser questionada e a empresa passou a adotar uma política diferenciada de ocupação dos espaços do escritório, e voltar recursos para viabilizar a mobilidade de seus funcionários.

Hoje, os conceitos de "paperless" e "full mobility" (sem papel e mobilidade total), são os norteadores dos responsáveis pela distribuição dos postos de trabalho e organização espacial da empresa.

O processo começa na contratação, onde apenas 25 dos 370 funcionários da sede da empresa em São Paulo são trabalhadores chamados "tradicionais", ou seja, são aqueles que possuem cadeira cativa no ambiente da empresa, tratando-se daqueles responsáveis basicamente pela manutenção predial, segurança e dos sistemas internos dos escritórios.

Os demais funcionários são chamados "mobile" (móveis), que não possuem postos de trabalho fixos, são funcionários que podem tanto atuar dentro da empresa como externamente a ela, e podem ser contratados tanto pelo regime da CLT, como por Pessoa Jurídica. 
Cada funcionário tem suas obrigações, deveres e responsabilidades e onde vão produzir suas atividades para atingir os objetivos da empresa fica a cargo de cada um.

Para os funcionários, que aprovam e elogiam o sistema, a mobilidade permite um planejamento de vida e de horários mais confortáveis, $83 \%$ citam a residência como local prioritário de trabalho, sentem-se valorizados com a confiança da empresa e retribuem com a responsabilidade dos resultados esperados.

Para a empresa, além da satisfação dos funcionários, existe a redução das faltas, a redução das taxas de ocupação dos escritórios, reduzindo as necessidades de espaço físico, e a não personalização dos postos de trabalho tem como conseqüência o uso mais cuidadoso de materiais, mobiliário e equipamentos.

Os custos de equipamento e sua manutenção dos funcionários, bem como gastos de conexões e telefonia são arcados pela Cisco. 
Desde 2003 a IBM do Brasil oferece a parte de seus funcionários a opção do teletrabalho, estimulando o desenvolvimento de suas atividades a partir de suas casas.

A empresa tem por filosofia não interferir na organização do posto de trabalho na habitação, porém reembolsa todos os gastos da implantação, incluindo mobiliário e equipamentos, e ainda cobre as despesas com manutenção, como gastos com telefonia e conexão de alta velocidade.

Esta opção, segundo a empresa, é baseada na confiança e responsabilidade, oferecendo ao trabalhador as condições que ele julga serem as melhores para ele, quer seja por estar mais próximo à família, quer seja para economizar tempo e gastos com deslocamentos da casa para a empresa.

Uma avaliação do setor de Recursos Humanos aponta para um índice de satisfação de quem aderiu à modalidade de trabalho à distância superior a $75 \%$.

Observa ainda, que a questão predominante para aqueles que não aderiram à opção e preferiram continuar a trabalhar no ambiente da empresa foi a cultura do relacionamento presencial, muito forte e arraigada nos hábitos dos profissionais. 
Em 2006, em decorrência das necessidades comerciais da empresa, a Ticket, uma das empresas do grupo Accor do segmento de convênios e serviços, promoveu uma reestruturação com objetivos de redução de gastos e de se manter como uma das empresas de alto rendimento do mercado.

A estratégia adotada foi a redução gradual e posterior encerramento das atividades de suas 25 filiais, que compunham $15 \%$ do efetivo de funcionários da empresa.

O setor de Recursos Humanos desenvolveu ações específicas para que a transição dos 120 funcionários das filiais para o modelo de trabalho à distância, especificamente para o Escritório Residencial.

A primeira ação foi garantir aos funcionários as mesmas cláusulas contratuais mantendo as contratações como funcionários regulares da empresa, com os mesmos direitos e benefícios daqueles que desenvolviam suas atividades nos escritórios da empresa.

Toda a implantação dos postos de trabalho nas residências foi acompanhada e os gastos correram por conta da Ticket (mobiliário, computadores, telefones).

Foi adotada uma ação educativa, elaborando um material para as famílias onde são ressaltados a confiabilidade e senso de responsabilidade do funcionário, sua importância para a empresa e ainda a importância do papel da esposa e filhos na colaboração e apoio à adaptação do trabalhador à nova situação. 
Foi mantido um ritual de reuniões programadas na empresa

a fim de atenuar os efeitos do distanciamento e isolamento daqueles que foram transferidos para suas residências.

Os principais resultados apontados pela Ticket após a implantação do sistema de Escritórios Residenciais foram:

- Economia de 3 milhões de reais no período de dois anos, gastos anteriormente com manutenção das estruturas das filiais.

- Ganho na qualidade de vida dos funcionários transferidos.

- Aumento de $40 \%$ no período de dois anos em vendas de novos produtos.

- Redução do tempo do funcionário com tarefas burocráticas

- Redução do tempo de deslocamento dos funcionários da casa para a empresa.

- Aumento do tempo do funcionário no atendimento ao cliente, resultando no crescimento média de vendas por carteira de clientes em $76 \%$.

- Aprovação de $93 \%$ dos funcionários transferidos com o novo modelo de trabalho. 


\subsubsection{Virtual Call}

Em 2007, a Virtual Call iniciou suas atividades no segmento de call center com um diferencial: os operadores desenvolveriam suas atividades a partir de suas residências, e não mais nos tradicionais centros de atendimento que caracterizam o setor.

Após dois anos de experiência nesse sistema, a empresa voltou suas atenções a outro nicho de mercado, as pessoas com necessidades especiais e as empresas que devem atender às cotas mínimas de contratação dessa força de trabalho.

Baseados nas normas de call centers, a NR17, com treinamentos que duram de 7 a 20 dias e reuniões mensais em sua sede, a empresa atende 5 empresas, com mais de 40 pessoas atuando a partir de suas residências.

A aprovação dos trabalhadores é superior a 95\%, e a Virtual Call se responsabiliza pela estrutura fornecendo computador, manutenção e custos da conexão de alta velocidade.

O regime de trabalho depende da empresa que contrata o funcionário, mas a supervisão do serviço sempre é da Virtual Call, onde o trabalhador deve respeitar um total de 6 horas e vinte minutos diários no máximo, com intervalos regulares.

O controle de presença é feito por meio de sensor biométrico e o controle de operação é feito por programa próprio da empresa que monitora os atendimentos e o uso da internet. 
As exigências básicas impostas para o trabalhador adotar esta modalidade de escritório residencial é disponibilizar um local reservado na residência, com iluminação e ventilação adequadas, não pode haver a presença de crianças e animais de estimação que produzam ruídos e, como a utilização dos equipamentos é livre, o mau uso ou navegação que acarretem em danos ou problemas ao equipamento ou programas é de responsabilidade do trabalhador.

A maior barreira encontrada pela empresa para que existe uma maior penetração de mercado deste sistema é a disponibilidade de conexão de alta velocidade que garanta a transmissão de dados e voz com eficiência e confiabilidade.

O problema se apresenta em duas vertentes: a primeira pela falta de confiabilidade no fornecimento pois, segundo o diretor da Virtual Call, as empresas operadoras deste serviço, pela Lei de Concessão da ANATEL, são obrigadas em contratos a fornecer um mínimo de apenas $10 \%$ da velocidade de transmissão de dados contratada, o que permite uma variação muito grande para o usuário final.

A segunda questão é a disponibilidade de acesso à conexão de alta velocidade em localidades mais distantes da região central da cidade, onde justamente existe a maior disponibilidade de mão de obra para este tipo de trabalho.

As operadoras podem até possuir a rede instalada na região, mas via de regra os canais de transmissão estão operando com sua capacidade máxima, não permitindo mais o atendimento a novos usuários. 


\subsubsection{Legislação}

Além dos desafios operacionais da implantação do Escritório Residencial, quer seja pela composição dos gastos e custos de manutenção, quer seja pela relutância dos funcionários ao se verem afastados meio físico da empresa - que tem sido a cultura predominante das relações de trabalho, ou ainda pela insegurança das chefias em não ter o controle presencial de seus comandados, existem ainda algumas questões legais cuja evolução e discussão parecem permanecer estagnadas nos seus devidos fóruns.

Atualmente existe o projeto de lei 3129 de 2004 que está em tramitação na esfera federal, já passou pela Câmara dos Deputados e aguarda análise do Senado Federal.

O projeto de lei tem como único fim equiparar o trabalho realizado no domicílio do trabalhador, o trabalho realizado a distância e aquele realizado no estabelecimento do empregador.

Entretanto a CLT não impede o trabalho remoto em domicílio, uma vez que a redação atual do artigo $6^{\circ} \mathrm{diz}$ que:

"Não se distingue entre o trabalho realizado no estabelecimento do empregador e o executado no domicílio do empregado, desde que esteja caracterizada a relação de emprego."

Com o projeto em tramitação, este artigo passa a ter uma nova redação, evitando a restrição de um único modelo de trabalho à distância, que seria a residência do empregado, sendo apresentado o seguinte texto: 
"ART $6^{\circ}$ - Não se distingue entre o trabalho realizado no estabelecimento do empregador e o executado no domicílio do empregado $E$ O REALIZADO 'A DISTÂNCIA, desde que estejam caracterizados os pressupostos da relação de emprego".

E ainda:

$$
\begin{aligned}
& \text { "Parágrafo Único - Os meios telemáticos e } \\
& \text { informatizados de comando, controle e } \\
& \text { supervisão se equiparam, para fins de } \\
& \text { subordinação jurídica, aos meios pessoais e } \\
& \text { direitos de comando, controle e supervisão } \\
& \text { do trabalho alheio." }
\end{aligned}
$$

O Artigo 651 prevê que:

"A competência das Juntas de Conciliação e Julgamento é determinada pela localidade onde o empregado, reclamante ou reclamado, prestar serviços ao empregador, ainda que tenha sido contratado noutro locar ou no estrangeiro."

e o parágrafo $3^{\circ}$ desse artigo afirma também que:

"Em se tratando de empregador que promova a realização de atividades fora do lugar de contrato de trabalho, é assegurado ao empregado apresentar reclamação no foro da celebração do contrato ou no da prestação dos respectivos serviços." 
Portanto, se analisada a atual legislação, pode-se observar que há espaço para se incluir legalmente o teletrabalho nas rotinas da empresa.

Todavia, entendemos ser previdente e importante celebrar um adendo ao contrato de trabalho especificando as novas condições em que os serviços serão prestados, de maneira a dar credibilidade às ações da empresa e estimular o comprometimento do trabalhador.

No Município de São Paulo, entretanto, a Lei de Zoneamento possibilita o trabalho em casa sem o uso de licença específica, mesmo que seja realizado em uma Zona Exclusivamente Residencial - ZER.

Antes desta regulamentação, era exigida uma licença de funcionamento para aqueles que mantinham atividades profissionais no endereço residencial, e não havia uma regulamentação bem definida a esse respeito.

A legislação atual, que entrou em vigor em fevereiro de 2005, explicita que:

"...são permitidos trabalhos simples, de pequeno impacto, que não gerem movimento de veículos e que usem apenas papel, caneta, computador e telefone."

O modelo proposto por São Paulo tem várias das características da legislação americana, onde a atividade não pode alterar o padrão residencial da região, sendo vetado o uso de placas, letreiros ou luminosos, a atividade não pode gerar tráfego de veículos ou de pessoas, nem produzir odores ou barulho. 
Deverão ser respeitadas as eventuais regras condominiais, que podem restringir a atividade caso esta esteja proporcionando algum incômodo junto aos vizinhos, porém o trabalho intelectual não poderá ser vetado. 
Enquanto a adoção do teletrabalho lentamente encontrava seus caminhos no início da década de 1980, a década que se seguiu mostrou um avanço nas tecnologias de informação e comunicação que permitiram um crescimento considerável nas formas alternativas das relações de trabalho e flexibilização dos horários e locais de seu desenvolvimento, e foram foco de pesquisas como as de Doherty et al. $^{72}$ (2000), Bailey \& Kurland ${ }^{73}$ (2002), Robertson $^{74}$ (2005) e CTA ${ }^{75}$ (2006).

Embora contabilizar de maneira fidedigna o número exato de teletrabalhadores devido às divergências em suas definições entre autores e coordenadores de pesquisas sobre o tema, onde a freqüência, duração e outros aspectos relevantes sejam abordados de maneiras distintas, Yen ${ }^{76}$ (2000) e Sohn et al. ${ }^{77}$ (2003) concluem que os avanços tecnológicos e a evolução no setor de serviços e economia baseada na informação proporcionaram o crescimento de posições de trabalho que permitiam o teletrabalho e, conforme as pesquisas de Mokhtarian ${ }^{78}$ (1991) e Mokhtarian et al. ${ }^{79}$ (2004), no final do século $X X$, acima de $3 \%$ da força de trabalho americana e européia desenvolvia algum tipo de teletrabalho, com grandes variações nas taxas de penetração dos modelos de teletrabalho entre os países e regiões pesquisados, com maior proporção de adoção do teletrabalho nos Estados Unidos do que na Europa.

\footnotetext{
72 Doherty S.; Andrey, J.; Johnson, L. The economic and social impacts of telework. US Department of Labor conference on telework and new workplaces - 2000

${ }^{73}$ Bailey, D.; Kurland, N. A review of telework research: finding, new directions, and lessons for study of modern work. Journal of Organization H=Behavior, $23-2002$

74 Robertson, K. How telework in changing the traditional corporate office. - 2005 Disponivel em http://klr.com/articles/how_telework_changing_office.pdf

${ }^{75}$ Canadian Telework Association - CTA Canadian telework scene 2006 Disponivel em http;//www.ivc.ca/canadianscene.html

${ }^{76}$ Yen, J. Interpreting employee telecommuting adoption: an economic perspective. Transportation, 27 2000

77 Sohn, J.; Kim, T.; Hewings, G. Information technology and urban spatial structure: a comparative analysis of the Chicago and Seoul regions. Annals of Regional Science, $37-2003$

${ }^{78}$ Mokhtarian, P. Defining telecommuting. Transportation Research Record, $1305-1991$

79 Mokhtarian, P.; Collantes, O.; Gertz, C. Telecommuting, residential location, and commute-distance traveled. Environment and Planning, 36910) - 2004
} 
Em outro estudo, Mokhtarian et al. ${ }^{80}$ (2005), encontra evidências que o crescimento do teletrabalho na América apresentou-se mais lento do que o esperado, contudo e embora o teletrabalho seja realizado por uma parcela ainda pequena da força de trabalho, o potencial de crescimento é evidente bem como sua aceitação em todos os setores produtivos, e os estudos dos modelos de teletrabalho poderão contribuir para o reconhecimento de sua importância nas questões da sustentabilidade no contexto urbano.

Até o presente, segundo Bailey \& Kurland (2002), o entendimento das implicações do teletrabalho na sustentabilidade é limitado devido as pesquisas procurarem focar na implantação, crescimento e programas de teletrabalho sendo necessária uma visão mais ampla sobre - tema e suas inter-relações para proporcionar novas percepções e esclarecimentos sobre estas implicações.

O desenvolvimento sustentável pode fornecer uma estrutura detalhada para o estudo do teletrabalho. O conceito de desenvolvimento sustentável, lançado pela International Union for the Conservation of Nature - IUCN ${ }^{81}$ (1980), envolve a melhoria da qualidade da vida social e aprimoramento do processo econômico sem o esgotamento e degradação dos recursos naturais e meio ambiente, onde - teletrabalho tem um grande potencial para afetar de maneira benéfica vários aspectos de sustentabilidade.

\footnotetext{
${ }^{80}$ Mokhtarian, P.; Salomon, I.; Choo, S. Measuring the measurable: why can't we agree on the number of telecommuters in the US? Quality and Quantity, 39 - 2005

81 International Union for the Conservation of Nature - IUCN World conservation strategy: living resources conservation for sustainable development. Gland: IUCN, 1980
} 
Autores como Mariani ${ }^{82}$ (2000) e Atkyns et al. ${ }^{83}(2002)$ reconhecem que os programas de teletrabalho são geralmente motivados pela redução de custos e aumento da produtividade das empresas ou pelo otimismo de funcionários que entendem que a prática do teletrabalho pode de alguma maneira trazer melhorias à sua qualidade de vida e, raramente, o aspecto de sustentabilidade e atenção ao meio ambiente são fatores determinantes para a adoção do programa.

Embora a conservação ambiental e sustentabilidade não sejam foco prioritário dos investigadores do teletrabalho, os modelos de trabalho à distância freqüentemente trazem em suas promoções, como fatores de benefício social, seu potencial para a redução do uso do automóvel e redução dos impactos no transporte coletivo, segundo Harpaz ${ }^{84}$ (2002), porém, alguns autores, como Kithou \& Horvath ${ }^{85}$ (2003) questionam os reais efeitos que a redução destes deslocamentos e uso de transporte individual podem trazer à questão ambiental.

Esta mesma questão foi abordada pelo Finnish Environment Institute - SYKE ${ }^{86}$ (2004), em associação com a Universidade de Helsinque e o Ministério dos Transportes que também investigou a questão do crescimento das manchas urbanas, onde o estudo se concentrou em determinar se existe uma relação entre a freqüência de deslocamentos e a distância a ser percorrida.

\footnotetext{
${ }^{82}$ Mariani, M. Telecommuters. Occupational Outlook Quarterly, 4 - 2000

83 Atkins, R.; Blazek, M.; Roitz, J. Measurement of environmental impacts of telework adoption amidst change in complex organizations. Resources, Conservation and Recycling, 36 - 2002

${ }^{84}$ Harpaz, I. Advantages and disadvantages of telecommuting for individual organization and society. Work Study, 51 - 2002

${ }^{85}$ Kithou, E.; Horvath, A. Energy-related emissions from telework. Environmental Science \& Technology, $37-2003$

${ }^{86}$ Finnish Environment Institute - SYKE Statistics Finland 2004 University of Helsinki, 2004
} 
A Finlândia aparece como um dos países da comunidade européia com uma das mais elevadas taxas de penetração das novas tecnologias de informação e comunicação na população, segundo a Internet World Stats, com número elevado de trabalhadores atuando no setor da informação, o que ajuda a elevar o potencial para o teletrabalho.

Como resultados obtidos, observou-se que é irrelevante o fator distância para determinar a freqüência de deslocamentos e alguma percepção de variação em distâncias entre 70 e $100 \mathrm{~km}$, porém a variação foi considerada irrelevante.

Também observou-se ser questionável e não conclusiva a redução do tráfego na capital Helsinque em função das pessoas que trabalham em seus domicilios e ainda, sobre a expansão urbana, não se comprova também a hipótese da pesquisa, pois o deslocamento ocorre mesmo dos locais mais remotos, portanto, o planejamento de bairros afastados baseados na suposição de que as pessoas não irão se deslocar fica inválido.

A pesquisa conclui que, embora o teletrabalho tenha um elevado potencial para contribuir nas questões ambientais, de planejamento, mobilidade urbana e sustentabilidade, o estágio atual não apresenta resultados determinantes e significativos nestas questões.

Para Devuyst \& Van Volsen ${ }^{87}$ (2001) as conseqüências do teletrabalho nos padrões de uso do solo, comportamento de consumo e geração de resíduos não foram ainda detalhadas nem esclarecidas e o processo de reeducação de comportamento não foi bem compreendido.

${ }^{87}$ Devuyst, D.; Van Volsen, S. How green is the city? Sustainable assessment and the management of urban environments - New York: Columbia University Press - 2001 
Como as alterações do estilo de vida são pontuais e descontínuas, deve existir uma coordenação das ações onde as combinações de decisões podem resultar em reais mudanças e sem uma avaliação completa das conseqüências ambientais, os efeitos das ações permanecerão incertos.

Uma ferramenta que pode ser utilizada para vencer o desafio de mensurar e avaliar as questões ambientais criada por Wackernagel \& $\operatorname{Rees}^{88}$ (1996), denominada "Ecological Footprint", traduzida para a língua portuguesa como "pegada ecológica", tem sido amplamente adotada por sua abrangência e capacidade de relacionar o consumo à sustentabilidade.

$$
\begin{aligned}
& \text { "esta ferramenta nos permite estimar o } \\
& \text { consumo de recursos e a produção de resíduos } \\
& \text { de uma determinada população ou economia e } \\
& \text { fazer a correlação com uma determinada área } \\
& \text { de terra produtiva." }
\end{aligned}
$$

Completando esta colocação dos criadores da ferramenta, Chambers et al. ${ }^{89}$ (2000), analisaram o total de terras produtivas disponíveis no planeta e concluíram que a produção agregada da população humana está prestes a exceder a capacidade produtiva do planeta e existe o risco de todo o sistema entrar em colapso.

Ainda que a ferramenta receba críticas por sua metodologia, a exemplo de Van Den Bergh \& Verbruggen ${ }^{90}$ (1999), que coloca em seu trabalho:

${ }^{88}$ Wackernagel, M.; Rees, W. Our ecological footprint: reducing human impact on the Earth - British Columba: New Society, 1996

${ }^{89}$ Chambers, N.; Simmons, C.; Wackernagel, M. Sharing nature's interest: ecological footprints as an indicator of sustainability - London: Earthscan, 2000

${ }^{90}$ Van Den Bergh, J.; Verbruggen, H. Spatial sustainability, trade and indicators: an evaluation of the ecological footprint. Ecological Economics, 29 - 1999 


\begin{abstract}
"Seu conceito e procedimento de cálculo podem ser criticados sob diversos aspectos, e isso conclui que a 'Ecological Footprint' não é uma ferramenta de planejamento transparente $e$ compreensível como pretende ser..."
\end{abstract}

a "Ecological Footprint", tem sido utilizada para estudar os impactos ambientais de atividades específicas e medir a evolução das medidas ambientais adotadas por diversos países e regiões, como nos estudos de Holden ${ }^{91}$ (2004), e também sendo desenvolvidas aplicações para estudos pontuais e de pequena escala, a exemplo de Wood \& Lenzen ${ }^{92}$ (2003).

Enquanto os acadêmicos devotaram considerável atenção às questões de qualidade de vida, métodos de teletrabalho e trabalho à partir de casa, , o mesmo não se pode dizer sobre as questões potencialmente impactantes ao meio ambiente devido à modalidade de teletrabalho.

Hopkinson et al. ${ }^{93}$ (2002), categorizaram as impactantes freqüentemente utilizadas pelas análises da "Ecological Footprint" e as relacionaram com o teletrabalho, quais sejam:

- Transporte

- Residência

- Energia

- Bens

91 Holden, E. Ecological footprints and sustainable urban form. Journal of Housing and the Built Environment, $19-2004$

${ }_{92}$ Wood, R.; Lenzen, M. An application of a modified ecological footprint method and structural path analysis in a comparative institutional study. Local Environment, $84-2003$

93 Hopkinson, P.; James, P.; Maruyama, T. Sustainable teleworking: identifying and evaluating the economic, environmental and social impacts of teleworking. Disponivel em http://www.sustel.org/documents/deliverable_conceptual520paper520v2b.rtf 
- Serviços

- Alimentação

- Resíduos

$\mathrm{Na}$ perspectiva ambiental, o transporte é a preocupação primordial devido seu impacto aparente, conforme coloca Choo et al. ${ }^{94}$ (2005):

"... os quilômetros percorridos pelos veículos são substancialmente reduzidos por aqueles que desenvolvem trabalho à distância, nos dias em que não se deslocam.."

Corroborado pelos estudos de Wood $^{95}$ (2003) que confirma que existe a redução do uso de automóvel associados ao teletrabalho.

Além do transporte e deslocamentos, o teletrabalho pode contribuir na distribuição da ocupação residencial urbana, conforme EURESCOM ${ }^{96}$ (2001), onde as pesquisas sugerem que individuos relacionam a flexibilidade do teletrabalho com a escolha do local de moradia, fato também observado nos estudo de Lake97 (2005), apresentando que os agregados familiares envolvidos com o teletrabalho podem deslocar-se para áreas afastadas dos centros urbanos.

\footnotetext{
94 Choo, S.; Mokhtarian, P.; Salomon, I. Does telecommuting reduce vehicle-miles traveled? An aggregate time series analysis for the U.S. Transportation, $32-2005$

${ }^{95}$ Wood, G. Modeling the ecological footprint of green travel plans using network analysis: from metaphor to management tool? Environment and Planning, B30 - 2003

${ }^{96}$ EURESCOM Project 904 - The impacts of telework on sustainable social development and quality of life. Disponivel em http://www.eurescom.de/ pub/deliverables/documents/p900-series/p904/p904_brochure.pdf 2001

Lake, A. Planning in the
http://flexibility.co.uk/issues/modgov/planning.htm -2005

information age. Disponivel em
} 
Porém, destaca-se uma vez mais a falta de consistência entre as pesquisas pelas limitações de aferição do exato número de teletrabalhadores, podendo-se concluir apenas que o teletrabalho aparentemente pode reduzir o número de deslocamentos intra urbanos e com isso reduzir os impactos ambientais, embora de maneira modesta, segundo Andrey et al. ${ }^{98}$ (2005).

Outro impacto ambiental em potencial é a questão das alterações associadas ao crescimento do uso da energia no setor residencial com a introdução do trabalho nos domicílios.

Hopkinson et al. (2002) conclui que a atividade de trabalho em domicílio acarreta em mudanças de hábitos, de consumo e de atividades no ambiente doméstico, sendo que o fator mais representativo e que concentrou maiores atenções nas pesquisas foi o aumento da demanda do consumo de energia nas residências, no entanto, existe a constatação da transferência deste consumo, que reduz a demanda nas empresas e passa para o setor residencial, todavia o montante destes valores não foi aferido.

O mesmo ocorre com equipamentos e consumo de insumos de escritório, cuja demanda é deslocada das organizações para os domicílios em que o teletrabalho é executado, considerando-se apenas o dado que nas residências a troca e atualizações de equipamentos é realizada com mais freqüência que nas empresas, constata Hopkinson et al. (2002).

Portanto, conclui-se que basicamente a questão da sustentabilidade relacionada ao teletrabalho fica restrita ao transporte e consumo de energia como os elementos cujo potencial podem levar a impactos ambientais relevantes.

98 Andrey, J.; Burns, K.; Doherty, S. Toward sustainable transportation: exploring transportation decisions making in telework households in a mid-sized Canadian city. Canadian Journal of Urban Research, $13-$ 2005 


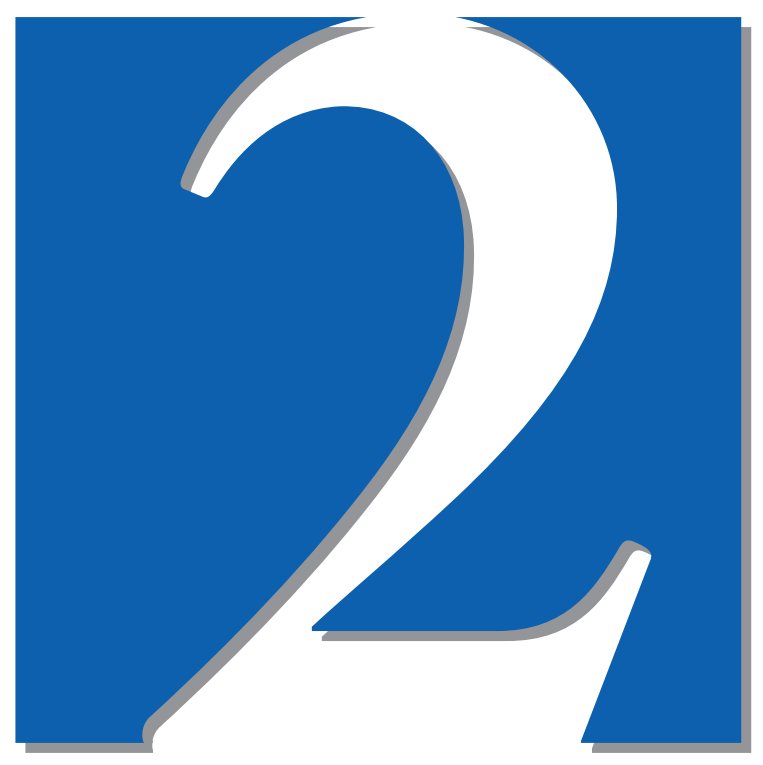

\section{Metodologia}


CAPÍTULO 2.

METODOLOGIA

\subsection{Considerações Preliminares}

Como visto no capítulo anterior, o tema desta tese de doutoramento são os Escritórios Residenciais onde foram abordadas as questões de relevância, enquadramento temporal, um breve histórico sobre a evolução destes ambientes, como a questão está sendo administrada por países como Estados Unidos, Canadá e membros da União Européia e quais os objetivos e questões que se pretende responder com o estudo.

Este capítulo apresenta a metodologia empregada para a realização desta tese de doutoramento.

Nesse sentido, são traçados os passos e as seqüências que envolveram todo a pesquisa.

O processo se deu de maneira investigativa, buscando dados quantitativos e qualitativos, partindo da revisão bibliográfica, objetivando o embasamento teórico para contextualizar o problema dentro do panorama históricocultural, delineando os caminhos a serem traçados para a confirmação ou não da hipótese proposta nesta tese.

O método e procedimento de pesquisa se iniciam pelo modelo clássico de pesquisa científica de levantamento, desdobra-se na análise comparativa entre os dados processados, posterior revisão, avaliação e consolidação dos dados estudados, sendo dividido pelas seguintes etapas de trabalho com seus respectivos detalhamentos: 
- Etapa 1. Levantamento de dados secundários.

- Etapa 2. Levantamento de dados primários.

- Etapa 3. Tabulação dos dados levantados.

- Etapa 4. Análise e diagnóstico das informações levantadas.

- Etapa 5. Verificação de comprovação das hipóteses

- Etapa 6. Conclusões, Reflexões, Recomendações e Novas Pesquisas

O fluxograma a seguir representa as etapas do processo de trabalho do desenvolvimento da tese: 


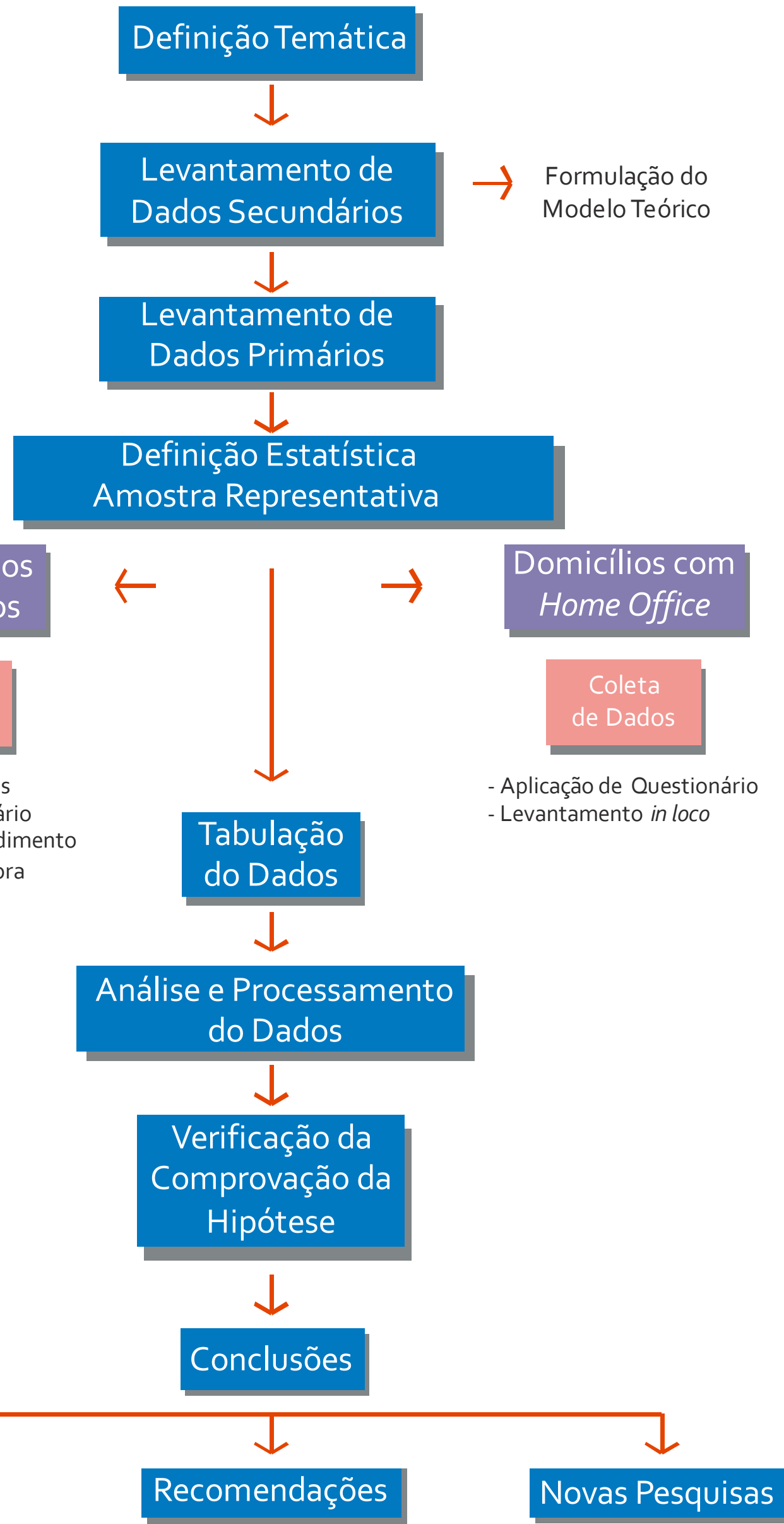

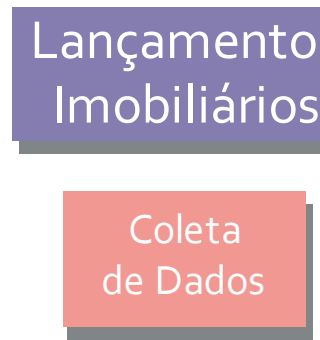

- Plantão de Vendas

- Material Publicitário

- Site de Empreendimento

- Site de Construtora
Definição Temática

Dados Secundários Dados Primários 


\subsection{Etapas do Desenvolvimento do Trabalho}

2.2.1 Etapa 1. Levantamento de dados secundários

Após a definição temática, no caso os "Home Offices", o objetivo desta etapa consiste na reunião das informações que estejam direta e indiretamente ligadas ao tema proposto a fim de proporcionar a fundamentação teórica e referenciar a tese para os métodos de investigação e coleta de dados, bem como ampliar a gama de fontes e assuntos correlatos que venham a contribuir de maneira positiva no conteúdo dos estudos e análises.

Para tanto são propostas as seguintes atividades:

- Levantamento e fichamento das referências bibliográficas;

- Análise e arquivamento das informações básicas pertinentes aos assuntos estabelecidos para o estudo nesta etapa.

Os assuntos pesquisados se concentram nos seguintes temas:

- O desempenho de edifícios habitacionais em relação ao conforto e à ergonomia;

- A evolução dos ambientes de trabalho na habitação;

- A evolução das tipologias das relações trabalhistas;

- Legislações pertinentes ao trabalho nas habitações;

- Projetos habitacionais que incorporam o ambiente para o trabalho com atividades de escritório. 


\subsubsection{Etapa 2. Levantamento de Informações de Campo}

Nessa etapa, o estudo envolve a busca investigativa dos dados e informações quantitativas e qualitativas relevantes ao conhecimento do tema e que farão parte das análises e verificações e que irão colaborar para a comprovação ou não da hipótese.

O primeiro passo foi a determinação do universo da pesquisa.

Como área de investigação, foi escolhido o município de São Paulo, cujas dimensões urbanas a fazem uma das maiores cidades do mundo, com um mercado imobiliário que, segundo o SECOVI(2009), no período de 2006 a 2009 lançou mais de 1200 empreendimentos habitacionais, com estimativa de ma e onde se encontra a maior concentração de população economicamente ativa no país, segundo o IBGE (2009).

A partir desta definição, a pesquisa é direcionada em dois sentidos.

\subsubsection{Parte A - Inclusão de Home Offices em lançamentos imobiliários}

\section{a) Universo de estudo}

Consiste na busca e cadastramento dos lançamentos imobiliários em São Paulo.

Para o recorte temporal, os lançamentos imobiliários foram coletados a partir de 2006, ano em que, também de acordo com a EMBRAESP(2008), o mercado residencial voltou a apresentar uma recuperação quanto a tendência de retração que vinha sendo apresentada nos anos anteriores. 
Neste período, segundo relatório anual EMBRAESP(2008) e complementados pelos dados do SECOVI(2009), que consideram os projetos aprovados pela Prefeitura do Município de São Paulo, foram lançados 1263 empreendimentos residenciais.

\section{b) Definição estatística}

Conhecido o universo a ser pesquisado, os 1263 lançamentos imobiliários residenciais, foi determinada a amostragem segundo os seguintes critérios.

Conforme um levantamento prévio realizado pelo autor em 2007, 38\% das plantas verificadas na época apresentaram a opção de "Home Offices", portanto, este será o valor adotado para a proporção da população a ser investigada.

Utilizando a equação apresentada por Levine ${ }^{99}$ para determinação da amostra temos:

$$
\mathbf{n}=\frac{\left(Z_{\alpha / 2}\right)^{2} \cdot p \cdot(1-p)}{E^{2}}
$$

Onde:

$\mathbf{n}$ = número de amostras

$Z_{\alpha / 2}=$ valor crítico que corresponde ao grau de confiança desejado (tabela 6)

$\mathbf{p}=$ proporção populacional de elementos que pertencem a categoria a ser estudada

$\mathrm{E}=$ erro máximo de estimativa

99 Levine, D.M.; Berenson, M.L.; Stephan, D. - "Estatística: teoria e aplicações"- LTC - Rio de Janeiro2000. 


\begin{tabular}{ccc}
\hline Grau de Confiança & $\alpha$ & Valor $\mathrm{Critico}_{\alpha / 2}$ \\
\hline $90 \%$ & 0,10 & 1,645 \\
$95 \%$ & 0,05 & 1,96 \\
$99 \%$ & 0,01 & 2,575 \\
\hline
\end{tabular}

Tabela 6 - Grau de confiabilidade estatística

Fonte: Levine - 2000 .

Portanto, para a aplicação da fórmula foi considerado:

Grau de Confiança $=95 \%$, o que representa um Valor Crítico $\left(Z_{\alpha / 2)}\right.$ de 1,96 .

Proporção populacional $(p)=38 \%$

Erro máximo de estimativa $(\mathrm{E})=\mathbf{5 \%}$

Aplicando-se a fórmula:

$$
n=\frac{(1 \cdot 96)^{2} \cdot 0,38 \cdot(1-0,38)}{0,05^{2}}
$$

Resultando em 361,88 casos, ou seja, o número de amostras representativas deste universo é de $\mathbf{3 6 2}$ casos, ou plantas.

\section{c) Determinação da amostragem representativa}

Para a determinação da amostragem foi utilizado o método de "amostragem sistemática", onde os elementos do universo estão pré classificados. 
Os principais agentes responsáveis pela produção imobiliária são os escritórios de arquitetura, incorporadores e construtoras.

Entendendo que vários lançamentos fazem parte do portfólio de dois ou até mesmo dos três agentes, o levantamento se concentrou nas construtoras, e a partir deste segmento buscou os elementos da amostragem.

Para esta determinação, foram consideradas as principais empresas construtoras levando em consideração a classificação da EMBRAESP - "Ranking das Construtoras | Incorporadoras - Ano Base 2008".

As empresas escolhidas foram as onze primeiras classificadas em função do total de metros quadrados lançados no ano de 2008 , sendo que este recorte atinge a representatividade de $33 \%$ do total de área construída dos empreendimentos lançados no período. Quadro 3 
10 ieven

$2^{\circ}$ GOLDFARB

$3^{\circ}$

$4^{\circ}$

$5^{\circ}$

$6^{\circ}$

$7^{\circ}$

$8^{\circ}$

$9^{\circ}$

$10^{\circ}$

$11^{\circ}$ GYPEZL A

ROSS
Even Construtora e Incorporadora S.A.

Goldfarb S.A.

Cyrela Empreendimentos Imobiliários S.A.

Gafisa S.A.

MRV Engenharia

Construções e Comércio Camargo Corrêa

Trisul S.A. Construtora e Incorporadora

Tecnisa Construtora e Incorporadora

AGRE Construtora e Incorporadora S.A.

$2.36 \%$

Rossi Residencial S.A.

$2.31 \%$

$1.95 \%$

$33.03 \%$

Brookfield Incorporações S.A.

$3.02 \%$

$2.55 \%$

$2.40 \%$

$2.39 \%$

$2.38 \%$

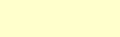

TOTAL

$\underset{\text { Brcorporaçós }}{\text { Brookf }}$

$+1$

O passo seguinte foi identificar a proporção de lançamentos residenciais de cada tipologia em relação a o número de dormitórios. Quadro 4

\begin{tabular}{ll} 
Tipologia & Porcentagem \\
\hline 1 dormitório & $24 \%$ \\
2 dormitórios & $30 \%$ \\
3 dormitórios & $36 \%$ \\
4 dormitórios & $24 \%$ \\
\hline
\end{tabular}

26 a 2008) 
Com estes dois dados, a representatividade das empresas e as tipologias, os 362 casos foram distribuídos proporcionalmente para cada empresa, por tipologia, determinando o número de amostras a serem selecionadas para cada uma. Quadro 5

\begin{tabular}{llcccc} 
Empresa & \% & 1 dorm & 2 dorm & 3 dorm & 4 dorm \\
\hline Even & 5.00 & 7 & 18 & 21 & 15 \\
Goldfarb & 4.43 & 6 & 16 & 18 & 13 \\
Cyrela & 4.24 & 6 & 16 & 17 & 13 \\
Gafisa & 3.02 & 3 & 11 & 13 & 8 \\
MRV & 2.55 & 3 & 9 & 10 & 7 \\
Camargo & 2.40 & 3 & 9 & 9 & 7 \\
Corrêa & & & & 9 & 7 \\
Trisul & 2.39 & 3 & 9 & 9 & 7 \\
Tecnisa & 2.38 & 3 & 9 & 9 & 7 \\
AGRE & 2.36 & 3 & 9 & 9 & 7 \\
Rossi & 2.31 & 3 & 7 & 8 & 5 \\
Brookfield & 1.95 & 2 & 9 & 9 & 7 \\
\hline
\end{tabular}

Quadro 5 - Distribuição das Amostras Elaborado pelo autor

A partir da determinação destas empresas e o número de amostras de cada uma, foram pesquisados os empreendimentos que disponibilizaram material de comercialização impresso ou mídia eletrônica com as plantas do apartamento tipo e suas variantes, e ainda foram visitados pontos de venda dos empreendimentos.

As páginas na internet das empresas incorporadoras e das construtoras informam sobre seus lançamentos e geralmente disponibilizam os projetos ou caminhos para as páginas dos empreendimentos que oferecem as informações necessárias ao público consumidor. 
Além da mídia eletrônica, as empresas trabalham com material de divulgação impresso, e também disponibilizam este material ao público, realizando a distribuição junto aos plantões de venda, localizados no terreno onde os lançamentos serão edificados.

Eventualmente, algumas empresas não apresentaram a disponibilidade total ou parcial de tipologias necessárias sendo que, nesses casos, foram selecionados empreendimentos e plantas das empresas subseqüentes para completar a amostragem.

$\mathrm{Na}$ composição final da amostragem, devido à variação do número de opções de plantas de cada empreendimento, foram selecionados 251 empreendimentos (19,8\% do universo da pesquisa), perfazendo um total de $\mathbf{4 0 0}$ plantas levantadas.

\section{d) Informações Pesquisadas}

A investigação foi desenvolvida segundo algumas determinantes a serem mapeadas junto aos lançamentos e as seguintes informações foram o foco dos levantamentos:

i. Nome da Construtora|Incorporadora Identifica a empresa responsável pelo empreendimento.

ii. Nome do Empreendimento

É a identificação primária do produto investigado.

iii. Localização: Zona|Bairro Identifica o local do empreendimento na cidade. 
iv. Opção de Projeto

Geralmente os lançamentos imobiliários permitem que a unidade habitacional possa sofrer variações de ocupação dos espaços, permitindo ao usuário certa flexibilidade para que o produto melhor se adapte às suas necessidades, para tanto, além do apartamento "tipo", são disponibilizadas algumas opções de projeto para o mesmo lançamento.

v. Tipologia da Unidade Habitacional

É a classificação das unidades habitacionais em número de dormitórios, utilizada pelo mercado imobiliário - 1, 2, 3 ou 4 dormitórios.

vi. Área da Unidade Habitacional Identifica a "área privativa principal" da unidade autônoma.

vii. Área do Ambiente Identifica a área física onde as atividades de trabalho de escritório tendem a ser desenvolvidas.

viii. Ambiente Identifica onde as atividades de trabalho de escritório tendem a ser realizadas na unidade habitacional investigada, de acordo com o mobiliário apresentado nos panfletos promocionais. 
ix. Setor do Ambiente na Habitação

Identifica se o local das atividades de trabalho de escritório está inserido no setor social, intimo ou de serviço da unidade habitacional investigada.

$x$. Ambiente que cedeu espaço ao Home Office Identifica qual ambiente da unidade habitacional cedeu espaço, ou foi adaptado para a implantação do escritório residencial, observando-se o local da implantação do mobiliário pertinente às atividades de escritório ou realizando a comparação entre a planta "tipo" com a variante que oferece a opção de Home Office.

xi. Tipologia de Implantação

Identifica qual o tipo de implantação foi utilizada para atender ao Home Office, quais sejam:

- Ambiente Projetado: é identificado quando o Home Office é apresentado no projeto do apartamento "tipo", ou quando todas as opções de projeto apresentam o ambiente pré-estabelecido para este uso;

- Ambiente Adaptado: é identificado quando existe a opção de uso como escritório residencial, mas não é apresentado no projeto do apartamento "tipo"; 
- Parte do Ambiente: é identificado quando o mobiliário | equipamento destinado às atividades de escritório encontram-se junto a outros itens que sugerem um compartilhamento do ambiente para outras atividades além daquelas destinadas ao Home Office.

xii. Porcentagem da área do Home Office Identifica qual a porcentagem de área que o Home Office ocupa em relação à área privativa principal da unidade autônoma.

As plantas selecionadas foram catalogadas em forma de fichas, onde os dados pesquisados são organizados para facilitar sua visualização.

Figura 6 


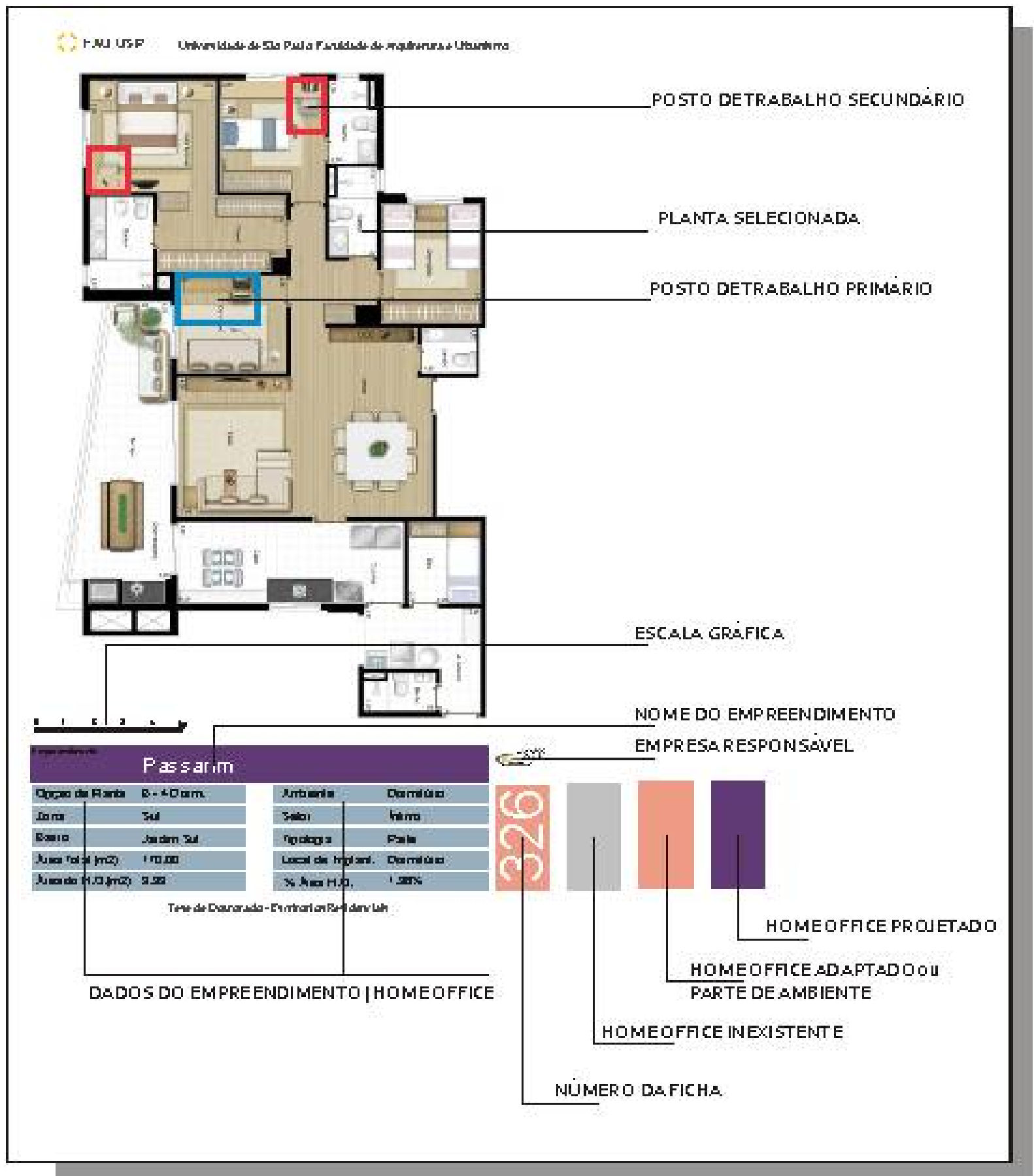

Figura 6 - Ficha Cadastral das Plantas Selecionadas Elaborado pelo autor 
Observa-se que a legenda de cores na numeração das fichas representa três situações:

a. Cinza: plantas onde não existe representação de ambiente ou posto de trabalho para atividades de escritório

b. Rosa: plantas onde existe o Home Office adaptado, ou postos de trabalho que fazem parte de um ambiente

c. Roxo: plantas onde o Home Office projetado é representado.

Há casos de plantas em que o posto de trabalho é inserido como parte de um ambiente e compartilha deste com outras funções da habitação, sendo representado mais de um local onde existe a possibilidade de realização de atividades de escritório.

Nestes casos, foi adotado o seguinte critério:

a. Posto de Trabalho Primário: Aquele que representa a área onde o Home Office foi projetado ou representado para esta determinada função. Ainda, quando existe mais de uma representação de áreas para o desenvolvimento de atividades de escritório, a área que está mais próxima ao setor social, ou, a maior área para esta finalidade, nesta ordem. 
b. Posto de Trabalho Secundário: um ou mais locais representados para o desenvolvimento de atividades de escritório que não são o posto de trabalho Primário.

Como algumas plantas são apresentadas sem dimensionamento dos compartimentos, ou em escalas não convencionais, a compatibilização da escala gráfica das plantas foi realizada no programa AutoCAD ${ }^{\circledR}$ da AutoDESK, adequando as plantas à escala 1:100, permitindo o cálculo das áreas necessárias ao desenvolvimento da tese.

O conjunto das 400 plantas pesquisadas são apresentados no VOLUME ANEXO I desta tese de doutoramento. 


\section{a) Universo de estudo}

O universo a ser pesquisado são as habitações unifamiliares do município de São Paulo que apresentam ambientes ou postos de trabalho que possibilitem o desenvolvimento de atividades de escritório.

Neste caso, houve apenas o recorte espacial - o Município de São Paulo - sendo considerados tanto casas como apartamentos, não sendo também considerada qualquer restrição de tempo de início das atividades do trabalhador em sua residência, desde que no período da investigação estivesse em desempenho destas atividades.

Segundo o IBGE (2008), cerca de 208 mil trabalhadores brasileiros, com e sem carteira assinada, desenvolvem atividades remuneradas a partir de suas residências.

Para o Município de São Paulo, o IBGE (2008) aponta para um número de 12 mil trabalhadores, porém, não existe a informação detalhada das proporções de cada atividade desenvolvida no domicílio, ou seja, neste universo estão incluídas todas as atividades que vão desde pequenos negócios, como cabeleireiros ou oficinas mecânicas, como pequenos produtores de alimentação, costureiras, empregadas domésticas e, inclusive, os trabalhadores que desenvolvem atividades de escritório.

Não existe portanto, nenhum dado a respeito da quantidade de domicílios que são utilizados para a realização de atividades profissionais, apenas o número de pessoas que desenvolvem estas atividades no ambiente doméstico. 
Segundo o IBGE (2000), existiam cerca de 3 milhões de domicílios particulares permanentes no Município de São Paulo no censo realizado em 2000, e 4,6\% da população economicamente ativa realizava atividades profissionais em seus domicílios.

\section{b) Definição estatística}

Como não existem dados oficiais sobre o universo de domicílios que abrigam atividades de escritório, a determinação da amostra considerou as informações disponíveis e, a que mais se aproxima das necessidades da tese, é aquela que afirma que $4,6 \%$ da população economicamente ativa do Município de São Paulo desenvolve atividades profissionais em seus domicílios IBGE(2000), ainda que, como já mencionado, este dado englobe não apenas as atividades de escritório, mas toda e qualquer atividade profissional desenvolvida pelo morador na sua residência, portanto, este será o valor adotado para a proporção da população a ser investigada.

Utilizando a equação apresentada por Levine(2000) para determinação da amostra temos:

$$
n=\frac{\left(Z_{\alpha / 2}\right)^{2} \cdot p \cdot(1-p)}{E^{2}}
$$

Onde:

$\mathbf{n}$ = número de amostras

$Z_{\alpha / 2}=$ valor crítico que corresponde ao grau de confiança desejado (vide tabela $X$ ) 
$\mathbf{p}=$ proporção populacional de elementos que pertencem a categoria a ser estudada

$E$ = erro máximo de estimativa

\begin{tabular}{ccc}
\hline Grau de Confiança & $\alpha$ & Valor Critico $Z_{\alpha / 2}$ \\
\hline $90 \%$ & 0,10 & 1,645 \\
$95 \%$ & 0,05 & 1,96 \\
$99 \%$ & 0,01 & 2,575 \\
\hline
\end{tabular}

Portanto, para a aplicação da fórmula foi considerado:

Grau de Confiança $=95 \%$, o que representa um Valor Crítico $\left(Z_{\alpha / 2)}\right.$ de 1,96.

Proporção populacional $(p)=4,6 \%$

Erro máximo de estimativa $(E)=5 \%$

Aplicando-se a fórmula:

$$
n=\frac{(1 \cdot 96)^{2} \cdot 0,046 \cdot(1-0,046)}{0,05^{2}}
$$

Resultando em 67,4 casos, ou seja, o número de amostras representativas deste universo é de 68 casos, ou unidades habitacionais. 


\section{c) Determinação da amostragem representativa}

Para a determinação da amostragem foi utilizado o método de "amostragem aleatória simples", onde os elementos do universo são escolhidos aleatoriamente, onde os indivíduos da população têm chances iguais de serem selecionados.

Por meio do relacionamento profissional e pessoal do autor, foram feitas pré entrevistas, com cerca de 550 pessoas residentes no Município de São Paulo.

A pré entrevista englobou cidadãos das classes $A, B, C, D$ e E pela classificação do IBGE, englobando também os setores Norte, Sul, Leste, Oeste e Centro do município.

As questões permitiram a formação de um grupo de indivíduos que possibilitou a determinação da amostragem.

As questões foram seqüenciais, onde as respostas negativas eram eliminadas do processo, abaixo descrito:

- Questão 1 - Existe computador na habitação? - $80 \%$ de respostas afirmativas (442 casos)

- Questão 2 - Existe um local específico para o uso do computador na habitação? - 70\% de respostas afirmativas (310 casos)

- Questão 3 - Existe o desenvolvimento de trabalho de escritório no uso do computador? - 90\% de resposta afirmativas (279 casos) 
Este grupo de 279 casos foi selecionado para a determinação da amostragem.

Destes casos, aleatoriamente, foram sorteados 100 casos, com 17 reposições devido a indisponibilidade para a aplicação do questionário e levantamentos in loco.

\section{d) Informações Pesquisadas}

Foram consultadas bibliografias específicas nas questões de composição de questionários e investigações para pesquisas nas áreas de arquitetura e marketing as quais auxiliaram na elaboração do questionário e formatação das perguntas, e ainda o auxílio do pesquisador João Branco Pedro, investigador do Núcleo de Arquitetura do Laboratório Nacional de Engenharia Civil - LNEC, cujo contributo foi de grande valia nesta etapa de desenvolvimento dos trabalhos.

O pré teste de aplicação do questionário foi proposto a um grupo de 10 casos, que permitiu dirimir dúvidas, revisão e aprimoramento das questões.

O questionário aplicado, após a elaboração inicial, sofreu alterações tanto no quesito seqüencial, onde a ordem das questões foi sendo ajustada para desempenho da pesquisa, como a própria organização visual das páginas, facilitando a leitura e o entendimento.

Após os testes iniciais do questionário, concluiu-se que a aplicação do mesmo seria mais eficaz com a participação do autor e permitiu que em uma única visita ao local pesquisado produzisse as informações necessárias ao desenvolvimento dos trabalhos. 
A investigação foi desenvolvida segundo algumas determinantes quantitativas e qualitativas a serem mapeadas junto às habitações e as seguintes informações foram o foco dos levantamentos.

i. Caracterização do Imóvel

São as informações básicas a respeito do imóvel:

- tipologia

- número de dormitórios

- zona | região

ii. Caracterização do Usuário

São os dados sobre os residentes do imóvel:

$-\operatorname{sexo}$

- idade

- vínculo com o chefe da habitação

- escolaridade

- atividade ramo | tipologia

- limitações físicas

iii. Caracterização do Uso do Ambiente | Posto de trabalho

São os dados pertinentes ao uso do posto de trabalho:

- usuários

- freqüência de uso

- duração de uso

- atividade de uso 
iv. Caracterização do Ambiente | Posto de Trabalho

São os dados pertinentes às questões de conforto:

- mobiliário

- equipamentos

- instalações

- armazenamento

v. Caracterização da Implantação

São as informações sobre as características da tipologia da implantação do posto de trabalho

- responsável pela implantação

- tipologia da implantação

- setor da habitação onde foi implantado

- fatores que promovem a implantação

- fatores que desmotivam a implantação

- condições negativas do ambiente / posto de trabalho

vi. Lay-out da Implantação

Fotos e croqui básico do ambiente I posto de trabalho implantado.

Para a coleta dos dados in loco, foi utilizada trena metálica, máquina fotográfica e luxímetro modelo LD-200 fabricado e aferido pela Instrutherm - Instrumentos de medição Ltda.

O questionário-base é apresentado nas páginas a seguir e o conjunto dos cem casos pesquisados são apresentados no VOLUME ANEXO II desta tese de doutoramento. 


\section{Habitação}

\begin{tabular}{|l|r|r|r|r|r|r|r|r|}
\hline 1. Tipologia da Habitaçä̃o & Apto & & Casa & & \multicolumn{5}{|l|}{} \\
\hline 2. Número de Dormitórios & 1dorm & & 2 dorm & & 3 dorm & & 4 dorm & 5 dorm \\
\hline 3. Região & Centro & & Norte & & Sul & & Leste & Oeste \\
\hline
\end{tabular}

\begin{tabular}{|c|c|c|c|c|c|c|c|c|c|}
\hline \multicolumn{2}{|c|}{ USUÁRIOS DA HABITAÇÃO } & U1 & U2 & U3 & U4 & U5 & U6 & U7 & U8 \\
\hline 4. Idade & & & & & & & & & \\
\hline \multirow{2}{*}{ 5. Sexo } & Masculino & & & & & & & & \\
\hline & Feminino & & & & & & & & \\
\hline \multirow{8}{*}{$\begin{array}{l}\text { 6. Parentesco } \\
\text { com o chefe da } \\
\text { habitação }\end{array}$} & Chefe & & & & & & & & \\
\hline & Cônjugè & & & & & & & & \\
\hline & Filho & & & & & & & & \\
\hline & Neto & & & & & & & & \\
\hline & Irmão & & & & & & & & \\
\hline & Avô & & & & & & & & \\
\hline & Amigo & & & & & & & & \\
\hline & Outro & & & & & & & & \\
\hline \multirow{5}{*}{ 7. Escolaridade } & Não possui & & & & & & & & \\
\hline & Ensino Fundamental & & & & & & & & \\
\hline & Ensino Médio & & & & & & & & \\
\hline & Ensino Superior & & & & & & & & \\
\hline & Pós-Graduado & & & & & & & & \\
\hline \multirow{7}{*}{ 8. Atividade } & Patrão / Prof Liberal & & & & & & & & \\
\hline & $\begin{array}{l}\text { Trabalhador } \\
\text { Registrado }\end{array}$ & & & & & & & & \\
\hline & Trabalhador Informal & & & & & & & & \\
\hline & Desempregado & & & & & & & & \\
\hline & Aposentado & & & & & & & & \\
\hline & Do Lar & & & & & & & & \\
\hline & Estudante & & & & & & & & \\
\hline \multirow{6}{*}{ 9. Limitaçöes } & Não Possui & & & & & & & & \\
\hline & Movimento & & & & & & & & \\
\hline & Visual & & & & & & & & \\
\hline & Auditiva & & & & & & & & \\
\hline & Obeso & & & & & & & & \\
\hline & Outro & & & & & & & & \\
\hline \multirow{2}{*}{\multicolumn{10}{|c|}{$\begin{array}{l}\text { 10. Ramo de } \\
\text { Atividade }\end{array}$}} \\
\hline & & & & & & & & & \\
\hline \multirow{2}{*}{$\begin{array}{l}\text { 11. É usuário do } \\
\text { espaço de } \\
\text { Trabalho? }\end{array}$} & Sim & & & & & & & & \\
\hline & Não & & & & & & & & \\
\hline $\begin{array}{l}\text { 12. Quem } \\
\text { Implementou o } \\
\text { Posto de } \\
\text { Trabalho? }\end{array}$ & Empresa & & lário & & & & & & \\
\hline
\end{tabular}


Uso do Equipamento | Posto de Trabalho

\begin{tabular}{|c|c|c|c|c|c|c|c|c|c|c|c|c|c|c|c|c|c|c|c|c|c|c|c|c|c|c|c|c|}
\hline Dias & Segl & unda & & & Terç & & & & Qua & & & & Qui & inta & & & Sex & & & & Sáb & bado & & & Don & hing & & \\
\hline $\begin{array}{l}\text { Períodos } \\
\text { Usuários }\end{array}$ & 署 & & & & 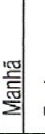 & & & 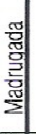 & 器 & 寄 & & 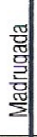 & 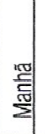 & 흠 & 产 & 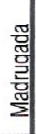 & 高 & 밈 & $\frac{9}{5}$ & 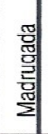 & & 产 & : & $\begin{array}{l}\text { 웜 } \\
\text { 㐙 } \\
\text { 产 }\end{array}$ & & 운 & & $\begin{array}{l}\text { 몀 } \\
\text { 홀 } \\
\text { 욜 }\end{array}$ \\
\hline U1 & & & & & & & & & & & & & & & & & & & & & & & & & & & & \\
\hline U2 & & & & & & & & & & & & & & & & & & & & & & & & & & & & \\
\hline U3 & & & & & & & & & & & & & & & & & & & & & & & & & & & & \\
\hline U4 & & & & & & & & & & & & & & & & & & & & & & & & & & & & \\
\hline U5 & & & & & & & & & & & & & & & & & & & & & & & & & & & & \\
\hline
\end{tabular}

\begin{tabular}{|c|c|c|c|c|c|c|}
\hline & & U1 & U2 & U3 & U4 & U5 \\
\hline \multirow{4}{*}{$\begin{array}{l}\text { 13. Tempo de Uso } \\
\text { Diário }\end{array}$} & até $1 \mathrm{~h}$ & & & & & \\
\hline & de 2 a 4 hs & & & & & \\
\hline & de 5 a 8 hs & & & & & \\
\hline & mais de 8 hs & & & & & \\
\hline \multirow{6}{*}{$\begin{array}{l}\text { 14. Atividade } \\
\text { pode haver mais } \\
\text { de uma resposta } \\
\text { por usuário }\end{array}$} & $\begin{array}{l}\text { Trab. Principal } \\
\text { Remunerado }\end{array}$ & & & & & \\
\hline & Trab. Complementar & & & & & \\
\hline & Trab. não remunerado & & & & & \\
\hline & Estudo / Pesquisa & & & & & \\
\hline & Lazer / Entretenimento & & & & & \\
\hline & Comunicação & & & & & \\
\hline
\end{tabular}

Mobiliário (preencher o mobiliário existente, se possivel indicando largura, profundidade, altura e tipo de material)

\begin{tabular}{|c|c|c|c|c|c|c|c|}
\hline 15. CADEIRAS & \multicolumn{2}{|c|}{ Cadeira 1} & \multicolumn{2}{|c|}{ Cadeira 2} & \multicolumn{2}{|c|}{ Cadeira 3} & Não Possui \\
\hline \multicolumn{7}{|l|}{ Material } & \\
\hline Fixa (sem rodízios) & Sim & Não & Sim & Não & Sim & Não & \\
\hline Giratória & Sim & Não & Sim & Não & Sim & Não & \\
\hline Com apoio de braços & Sim & Não & Sim & Não & Sim & Nắ0 & \\
\hline Com regulagem de altura & Sim & Nāo & Sim & Não & Sim & Não & \\
\hline
\end{tabular}

\begin{tabular}{|c|c|c|c|c|c|}
\hline \multicolumn{2}{|c|}{ 16. Mesas / Bancadas } & Mesa 1 & Mesa 2 & Mesa 3 & Não Possui \\
\hline \multicolumn{5}{|l|}{ Material } & \\
\hline Largura & (cm) & & & & \\
\hline Profundidade & (cm) & & & & \\
\hline Altura & (cm) & & & & \\
\hline
\end{tabular}




\begin{tabular}{|c|c|c|c|c|}
\hline 17. Armários / Estantes & Armário 1 & Armário 2 & Armário 3 & Não Possui \\
\hline \multicolumn{4}{|l|}{ Material } & \\
\hline Largura & & & & \\
\hline Profundidade & & & & \\
\hline Altura & & & & \\
\hline 18. Gaveteiros & Gaveteiro 1 & Gaveteiro 2 & Gaveteiro 3 & Não Possui \\
\hline \multicolumn{4}{|l|}{ Material } & \\
\hline Largura & & & & \\
\hline Profundidade & & & & \\
\hline Altura & & & & \\
\hline Número de Gavetas & & & & \\
\hline
\end{tabular}

\begin{tabular}{|c|c|c|c|c|c|c|}
\hline \multicolumn{5}{|c|}{ COMPUTADOR / PERIFÉRICOS } & \multicolumn{2}{|c|}{ OBSERVAÇŌES } \\
\hline 19. Tipologia & \multicolumn{2}{|c|}{ Desktop } & \multicolumn{2}{|c|}{ Notebook / Laptop } & & \\
\hline 20. Monitor & $14^{\prime \prime}$ & $15^{\prime \prime}$ & $17^{\prime \prime}$ & $21^{\prime \prime}$ & Tubo & LCD / Plasma \\
\hline 21. CPU & \multicolumn{2}{|c|}{ Sobre a mesa } & \multicolumn{2}{|c|}{ No piso } & & \\
\hline 22. Teclado & \multicolumn{2}{|c|}{ Sobre a mesa } & \multicolumn{2}{|c|}{ Em nível abaixo } & & \\
\hline 23. Impressora & Nấo possui & Marca & & & Modelo & \\
\hline 24. Scanner & Não possui & Marca & & & Modelo & \\
\hline 25. Multifuncional & Năo possui & Marca & & & Modelo & \\
\hline 26. Telefone & Não possui & Marca & & & Model0 & \\
\hline 27. Secretária Eletrônica & Não possui & Marca & & & Model0 & \\
\hline 28. Aparelho de FAX & Não possui & Marca & & & Modelo & \\
\hline 29. Copiadora & Não possui & Marca & & & Modelo & \\
\hline
\end{tabular}

\begin{tabular}{|c|c|c|c|c|c|c|}
\hline \multicolumn{5}{|c|}{ INSTALAÇŌES do Posto de Trabalho } & \\
\hline 30. Energia & $110 \mathrm{v}$ & $220 v$ & \multicolumn{2}{|c|}{ Numero de Tomadas } & \multicolumn{2}{|c|}{ OBSERVAÇŌES } \\
\hline 31. Telefonia & Não Possui & Fixa & Celular & Rádio & & \\
\hline 32. Internet & Não Possui & Discada & Banda Larga & & & \\
\hline 33. TV a cabo & Não Possui & Possui & & & & LUX \\
\hline 34. Ponto de Luz no Forro & Não Possui & $N^{0}$ Ptos & Lâmpada Fria & Incan & cente & Total de Watts \\
\hline 35. Arandela & Não Possui & $\mathrm{N}^{0} \mathrm{Plos}$ & Lâmpada Fria & Incan & & Total de Watts \\
\hline 36. Luminária de Mesa & Não Possui & $N^{0}$ Ptos & Lâmpada Fria & Incan & cente & Total de Watts \\
\hline
\end{tabular}




\begin{tabular}{|c|c|c|c|c|}
\hline \multicolumn{3}{|c|}{ ARMAZENAMENTO (onde os produtos abaixo são armazenados) } & \multicolumn{2}{|c|}{ OBSERVAÇŌES (complementos necessários) } \\
\hline 37. Material de Escritório & gaveteiro & armário & estante & \\
\hline 38. Mat Consulta / Livros & gaveteiro & armário & estante & \\
\hline 39. Arquivo Morto & gaveteiro & armário & estante & \\
\hline
\end{tabular}

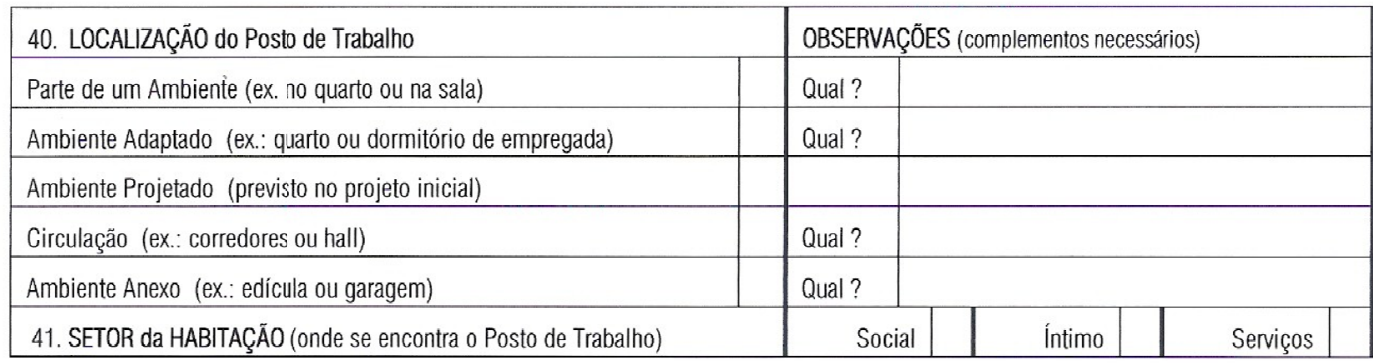

42. Classifique de 1 a 5 , partindo do mais importante, os principais motivos para o trabalho de escritório na habitação: Evita o deslocamento casa / trabalho / casa

Permite maior tempo com a família

Reduz os investimentos com compra, aluguel, manutenção e gastos gerais em outro local

Permite a organização e administração do tempo pessoal

Evita impactos ambientais para a cidade como um todo

43. Classifique de 1 a 5 , partindo do mais importante, os principais pontos negativos para o trabalho de escritório na habitação: Isolamento pessoal e profissional Falta de privacidade e informalidade Condiçốes inadequadas de espaço físico, mobiliário e equipamentos Necessidade de gastos na implantação e manutenção Interferências da vida doméstica na vida profissional

44. Classifique de 1 a 5 , partindo do mais importante, os pontos negativos do CONFORTO do seu posto de trabalho na habitação: Falta de Espaço Físico Falta de lluminação Natural | Artificial Falta de Ventilação Excesso de Ruído

Mobiliário | Equipamentos inadequados

\begin{tabular}{|l|}
\hline OBSERVAÇÕES GERAIS (alguma informaçāo ou sugestão) \\
\hline \\
\hline
\end{tabular}


Lay-out (representar o Posto de Trabalho com desenho ou fotos)

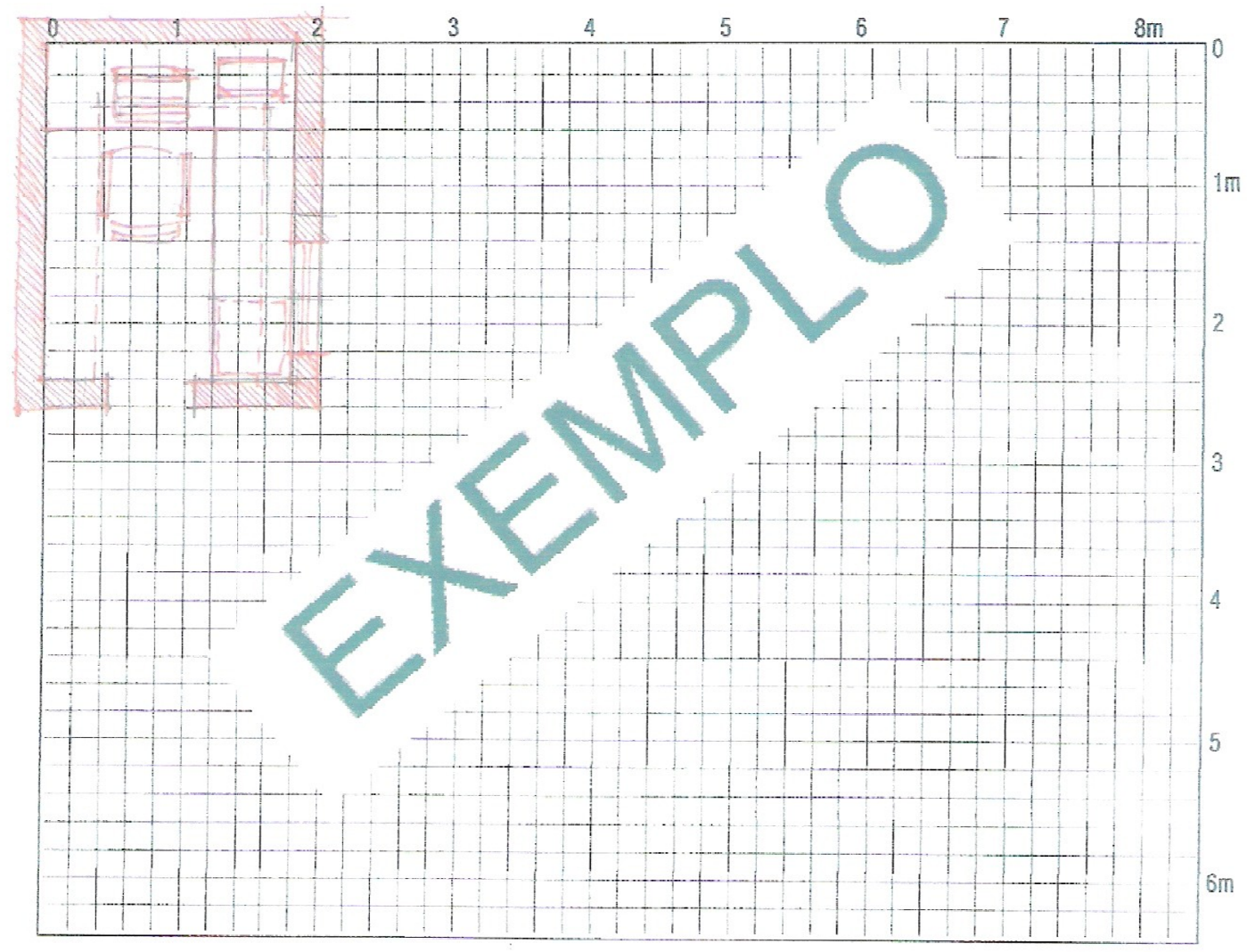


Registro Fotográfico

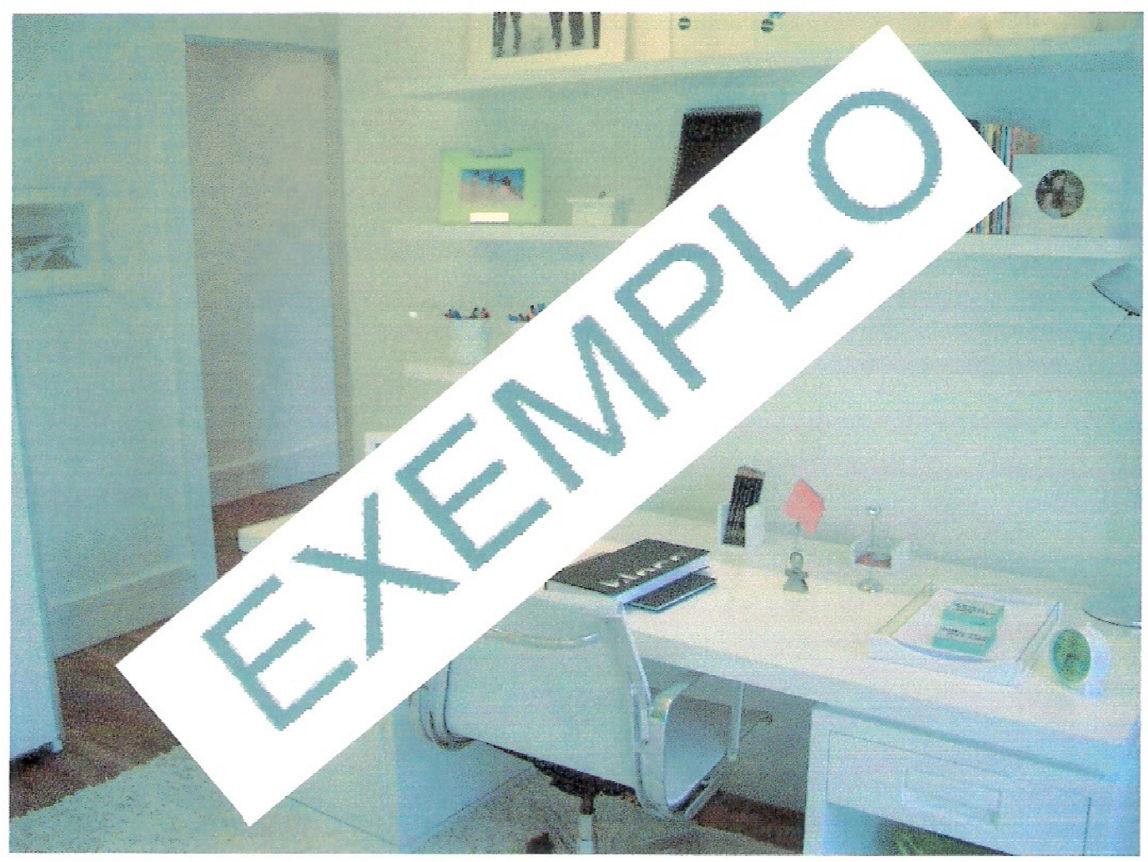




\subsubsection{Etapa 3. Tabulação das Informações Pesquisadas}

Para a tabulação e processamento dos dados da Etapa 2 Levantamento das Informações de Campo, tanto para a Parte A (Inclusão de Home Offices em lançamentos imobiliários), como para a Parte B (O uso de ambientes da habitação para atividades de escritório), foi utilizado o programa Excel ${ }^{\circledR}$ da Microsoft, que permite a utilização de filtros das informações, facilitando a visualização, produção de gráficos e análise dos dados.

Os casos foram distribuídos em linhas e as colunas representam as informações pesquisadas.

Os resultados foram apresentados em forma de gráficos e tabelas, seguidos do diagnóstico e análises que permitiram conclusões pertinentes à validação da hipótese proposta.

\subsubsection{Etapa 4. Análise e Diagnóstico das Informações} Levantadas

Com as informações organizadas de maneira sistemática na etapa anterior, é feito o diagnóstico dos dados à luz dos parâmetros, requisitos e critérios apresentados no Capítulo 3 deste trabalho.

Este diagnóstico permite uma análise aprofundada do objeto de estudo e se constitui na fundamentação básica do conhecimento gerado no desenvolvimento desta tese de doutoramento. 


\subsubsection{Etapa 5. Verificação e Comprovação da Hipótese}

Tendo concluído e organizado as informações levantadas, processados os dados e elaborado as leituras, esta fase tem como objetivo verificar a hipótese levantada e validar, ou não, o que foi conclusivo de maneira afirmativa.

\subsubsection{Etapa 6. Conclusões, Reflexões, Recomendações e} Pesquisas Futuras

A última etapa do processo conclui o trabalho com observações do autor sobre os resultados obtidos e ainda discute sobre as questões relevantes abordadas durante a elaboração da tese, apontando as eventuais situações em que existam não conformidades de quaisquer naturezas e proporciona recomendações para que estas desconformidades possam ser estudadas e posteriormente solucionadas.

Nesta fase também são propostos estudos seqüenciais, que poderão complementar esta pesquisa. 2 


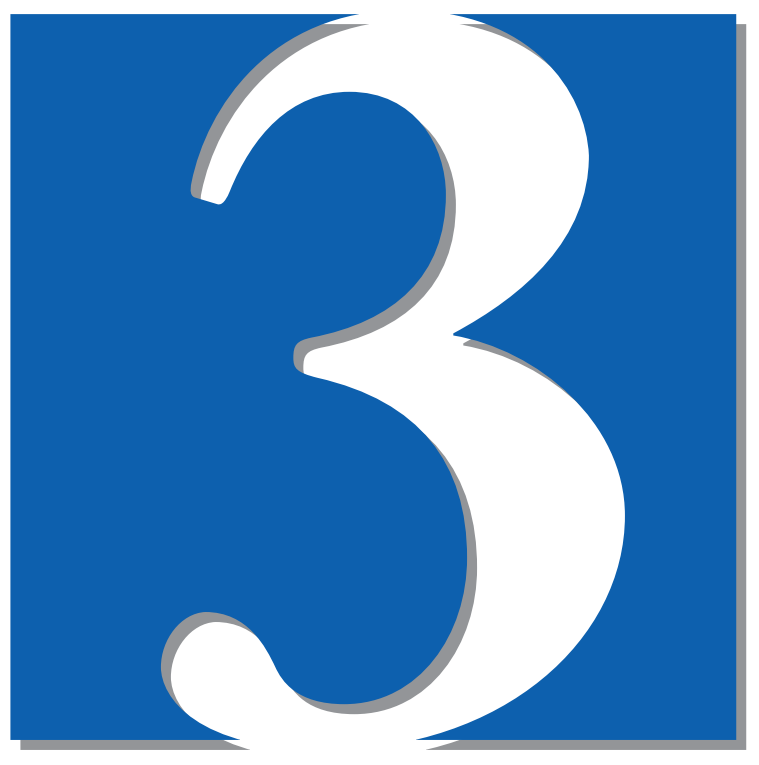

\section{Parâmetros}

Ergonômicos e Indicadores 


\section{CAPÍTULO 3. PARÂMETROS ERGONÔMICOS E INDICADORES}

\subsection{Considerações Preliminares}

O estudo das condições de conforto e segurança nos ambientes construídos vem sendo tema de diversos trabalhos acadêmicos e de pesquisas nos setores envolvidos no processo de projeto e edificação destes espaços, corroborando com a Organização Internacional do Trabalho - OIT ${ }^{100}$, na área da medicina do trabalho, que tem as seguintes recomendações básicas:

- Assegurar a proteção dos trabalhadores contra todo o risco que prejudique a sua saúde e que possa resultar de seu trabalho ou das condições em que este se efetue;

- Contribuir à adaptação física e mental dos trabalhadores, em particular pela adequação do trabalho e pela sua colocação em lugares de trabalho correspondentes às suas aptidões;

- Contribuir ao estabelecimento e manutenção do nível mais elevado possível do bem-estar físico e mental dos trabalhadores

Da mesma maneira, na área da arquitetura, o ambiente em que o usuário desenvolve suas atividades de escritório deve ser estudado sob este prisma, principalmente quando este encontra-se inserido no universo da habitação, onde variantes relacionadas à vida doméstica interferem diretamente nas condições destes ambientes. 
Este capítulo tem por objetivo elencar os parâmetros, requisitos e critérios de ergonomia e conforto que serão adotados nesta tese de doutoramento para as análises comparativas e diagnósticos dos dados levantados na pesquisa.

Para compreender os ambientes que são utilizados para atividades de escritório dentro da habitação, se faz necessário um estudo das condições que estes ambientes proporcionam aos seus usuários e esta questão pode ser entendida como o grau de conforto que o ambiente oferece.

Quando se trata de ambientes da habitação e das atividades de trabalho de escritório que neles são desenvolvidas, vale lembrar que a rotina doméstica tem uma grande influência no desempenho do ambiente pois nessa rotina existem comportamentos e fatores alheios ao universo do trabalho.

Portanto, a caracterização de conformidade de um ambiente para essas atividades requer a definição de parâmetros que sejam capazes de direcionar uma avaliação e permitir uma análise que englobe os principais aspectos dos requisitos de uso para o desempenho das tarefas propostas.

Nesse sentido, o estudo deve realizar a "Análise da Tarefa", que compreende o estudo do usuário e suas relações com o posto de trabalho, suas dimensões, mobiliário, equipamentos e condições ambientais.

Coloca-se aqui uma questão em relação a algumas terminologias e conceitos que parece oportuno salientar. 
Segundo lida ${ }^{101}$ (1992), um dos principais estudiosos e profissional atuante na área ergonômica, esta é a definição para o termo "ERGONOMIA":

"[... Ergonomia é o estudo do
relacionamento entre o homem e seu
trabalho, equipamento e ambiente,
particularmente a aplicação dos
conhecimentos de anatomia, fisiologia e
psicologia na solução de problemas surgidos
desse relacionamento."

Seguindo esta definição, pode-se entender que a ergonomia abrange um conjunto de fatores que vai além do que poderse-ia chamar de "Conforto Dimensional", ou adaptação de equipamentos e mobiliário ao corpo humano.

A relação se faz entre o homem e seu trabalho, envolvendo todos os elementos que participam deste ato, torna-se, portanto, pertinente entender que o conforto visual, acústico, condições higrotérmicas e de salubridade do ar, estejam relacionados aos elementos estudados na Ergonomia, bem como os quesitos relacionados à segurança no ambiente de trabalho.

Portanto, a ergonomia envolve um grupo de conhecimentos sobre as habilidades, limitações e outras características humanas que são relevantes para o projeto, no objetivo de adaptar o ambiente ao homem, como apresentado no quadro abaixo: Quadro 6 


\section{Aplicação da Ergonomia no Projeto de Arquitetura e Urbanismo}

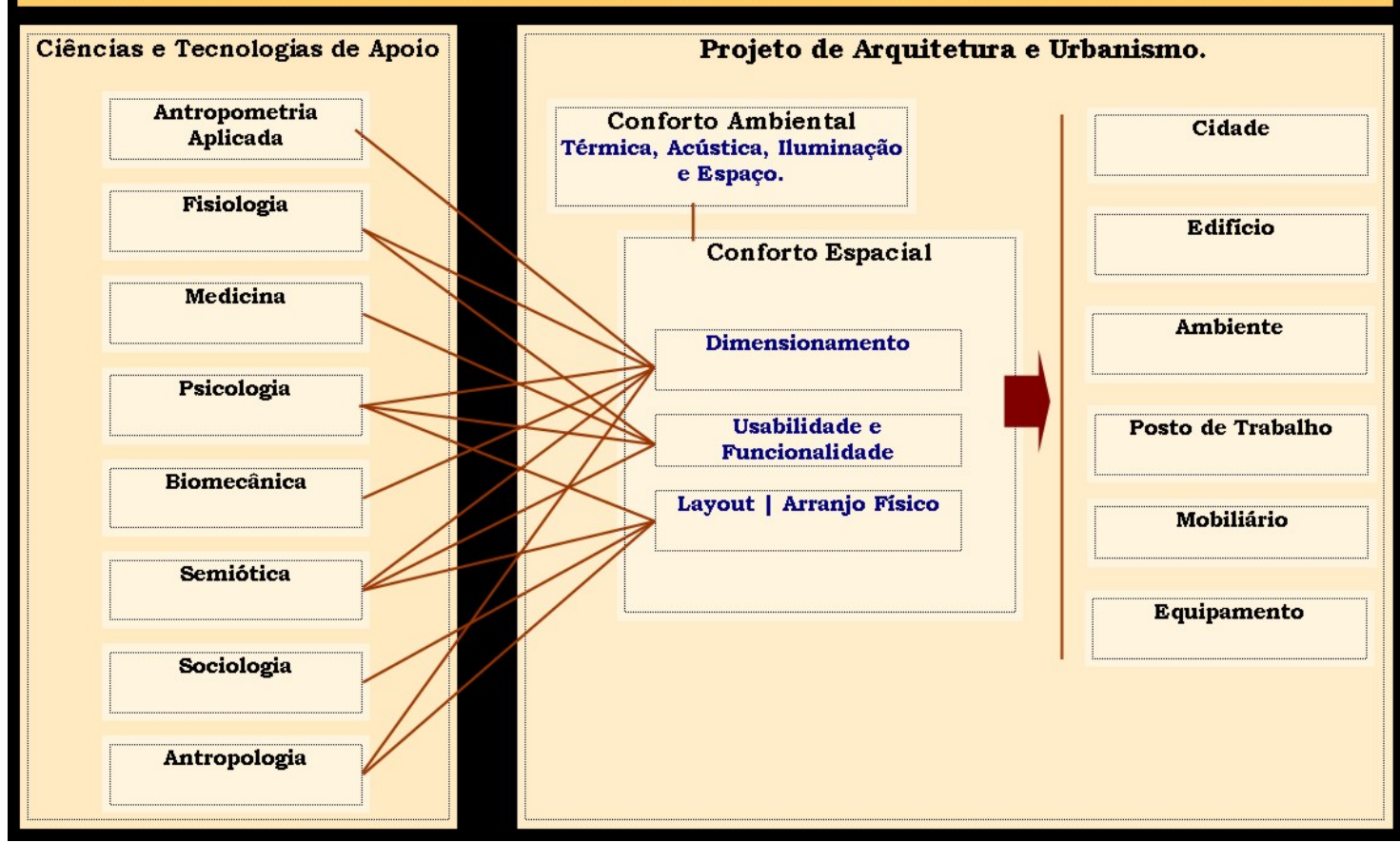

Quadro 6 -Aplicações da Ergonomia na Arquitetura

Fonte: Boveri, J. Livre Docência. 2004

Segundo Kroemer \& Kroemer ${ }^{102}$ (2001), há quase trezentos anos que o homem, inserido no escritório, é tema de estudos, iniciado com Bernardo Ramazzini ${ }^{103}$ (1713), médico italiano considerado o pai da medicina ocupacional, que em 1713 publicou "De Morbis Artificum Diatriba" - (Doenças do Trabalho), escreveu:

$$
\begin{aligned}
& \text { "É certo que nos dias de hoje, muitas } \\
& \text { pessoas em vilas e cidades ainda ganham } \\
& \text { sua vida com a escrita. As doenças que } \\
& \text { afetam estas pessoas são provocadas pelos } \\
& \text { seguintes fatores: primeiro, o tempo que } \\
& \text { permanecem sentadas; segundo, o constante } \\
& \text { movimento das mãos da mesma maneira; e } \\
& \text { terceiro, a atenção e aplicação da mente..." }
\end{aligned}
$$

\footnotetext{
102 Kroemer, K\& Kroemer, A. Office Solutions - New York: Taylor \& Francis Inc. - 2001

103 Ramazzini, B. Diseases of Workers - From the latin text of 1713 , revised with translate and notes by Wright, W.C. - Chicago: University of Chicago Press, 1940
} 
Com o advento do microcomputador, problemas músculoesqueleto com as mãos, região lombar e olhos passaram a ser preocupações constantes para aqueles que trabalham e projetam postos de trabalho, sendo que estes problemas foram apontados pelo Ministério da Previdência Social no "Anuário Estatístico de Acidentes do Trabalho - 2008"104 como uma das principais causas do afastamento de trabalhadores das suas atividades profissionais por doenças do trabalho, sendo que as notificações de doenças osteomuscular - nas quais se incluem as Lesões por Esforços Repetitivos - LER, e que representam $84,7 \%$ do total de doenças empregatícias, aumentaram 512\% no período de 2 anos, induzindo um crescimento de $134 \%$ nas enfermidades ocupacionais.

A partir do momento que as atividades de escritório são incorporadas ao ambiente doméstico, as mesmas preocupações passam a existir neste ambiente, agravadas com a possibilidade dos espaços destinados a estas atividades na habitação não estarem devidamente adaptados.

Esta preocupação é tema de questões legais, pois não está claramente determinado de quem é a responsabilidade em prover as condições adequadas de trabalho ao profissional que desenvolve suas atividades no ambiente doméstico - do contratante ou do contratado, do empregador ou do empregado. 
O elemento principal do ambiente ou um posto de trabalho é o seu usuário, ou seja, o homem, portanto, o conhecimento de suas necessidades, dimensões e limites são de fundamental importância para que o ambiente esteja adequado às atividades que nele serão desenvolvidas.

O objetivo final da ergonomia, como já citado, é adaptar o ambiente e o posto de trabalho às tarefas do usuário a partir de recomendações derivadas de um completo diagnóstico do ambiente e da atividade e, para tanto, devem ser estudadas as questões que envolvam estes tópicos.

\subsection{Análise da Atividade}

A Análise da Atividade é o conjunto de informações que são coletadas pelo estudo e observação de como o usuário desempenha suas tarefas, suas posturas, esforços, e toda inter-relação com o ambiente do posto de trabalho, mobiliário e equipamentos.

Boveri ${ }^{105}$ (2004) propõe um roteiro da análise da atividade, onde são considerados vários aspectos que envolvem itens relevantes à composição do diagnóstico e recomendações ergonômicas e será adotado como fio condutor deste estudo, como segue: Quadro 7 


\section{Análise Ergonômica da Atividade e do Uso do Espaço}

$1^{\circ}$. Identificar Objeto e Local de Estudo

$2^{\circ}$. Identificar Funções do Objeto de Estudo

$3^{\circ}$. In formações do Usuário

$4^{\circ}$. In formações da Atividade e Uso

$5^{\circ}$. In formações do Espaço

$6^{\circ}$. Identificação dos Requisitos de Uso

$7^{\circ}$. Diagnóstico Ergonômico

$8^{\circ}$. Recomendações Ergonômicas para o Projeto de Arquitetura e Urbanismo

Quadro 7-Roteiro de Análise da Atividade

Fonte: Boveri, J. Livre Docência. 2004

A partir desta seqüência, inicia-se a composição de um quadro genérico que irá abrigar o conjunto de recomendações ergonômicas, embasadas nas especificações e normas técnicas, que serão a base de avaliação das pesquisas e levantamentos de campo e a estruturação das informações para análise dos ambientes na redação da tese. 


\subsubsection{Objeto e local de estudo}

Neste caso, podem ser identificados como objeto ou local de estudo tanto o ambiente como o posto de trabalho para o desenvolvimento de atividades de escritório inseridas no ambiente doméstico, porém como o Escritório Residencial pode ser instalado em um ambiente existente que seja utilizado para outras finalidades e por outros usuários, adotar o Posto de Trabalho como objeto de estudo pode ser mais adequado, sendo, o ambiente, uma decorrência destas necessidades.

\subsubsection{Funções do objeto de estudo}

- Função Básica: é abrigar atividades de escritório, como ler (em papel ou monitor), escrever, digitar, operar microcomputador e periféricos, telefonar, enviar/receber fax. Deve-se lembrar que pela atual Lei de uso e Ocupação do Solo do Município de São Paulo, as atividades de escritório incorporadas em edificações de Uso Residencial (categorias $R_{1}, R_{2}$ ou $R_{3}$ ), devem ser de pequeno impacto e não devem gerar tráfego de veículos.

- Função Secundária: armazenar insumos e materiais de escritório, livros e abrigar mobiliário e equipamentos para estes fins. 


\subsubsection{Informações do usuário}

Aqui devem ser definidas as características do usuário ou usuários que irão efetivamente desenvolver atividades no ambiente ou posto de trabalho, como sexo, idade, e dados antropométricos a exemplo da figura abaixo. Figura 7

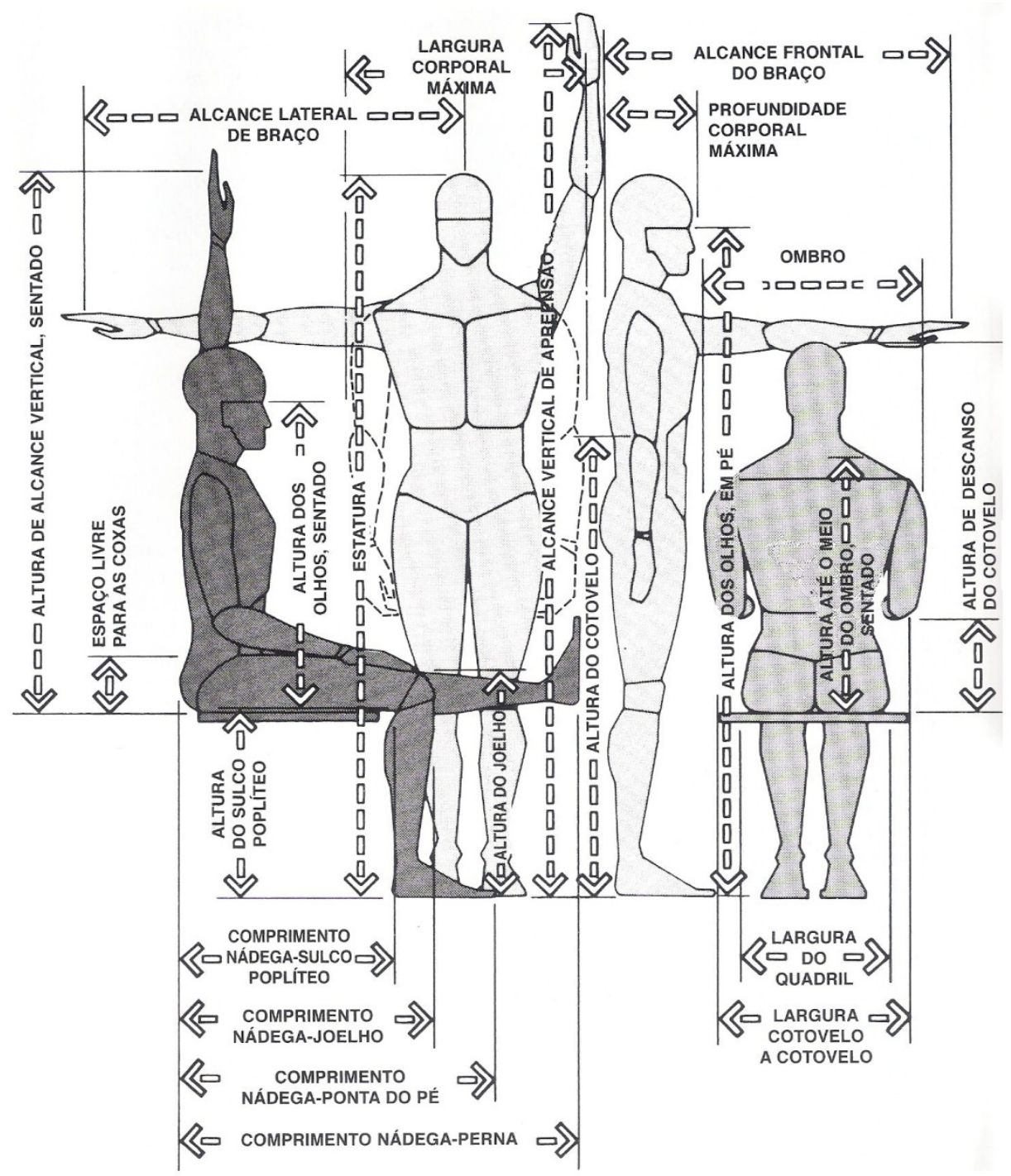

Figura 7-Dimensões Corporais

Fonte: Panero, J. \& Zelnik, M. Dimensionamento Humano para Espaços Interiores Barcelona: Gustavo Gili, 2002. Ilustração 
Devem ser enumeradas todas as atividades e usos que serão desenvolvidos pelo usuário no objeto de estudo e verificadas as formas de contato e as posturas que o corpo humano assume ao desenvolvê-las, com o objetivo de entender quais os requisitos de uso necessários.

Conforme apresentado em Mendonça (2005), temos:

As formas de contato podem ser divididas em contatos sensoriais e contatos psico-fisiológicos. Tabela 7

\begin{tabular}{|l|}
\hline Contatos Sensoriais \\
\hline Visual \\
\hline Tátil \\
\hline Auditivo \\
\hline Odor e Paladar \\
\hline
\end{tabular}

\begin{tabular}{l}
\hline Contatos Psico-fisiológicos \\
\hline Esforço Físico \\
\hline Precisão dos Movimentos \\
Repetição dos Movimentos, Ritmo de Execução e \\
Duração da Tarefa \\
\hline Percurso realizado para a execução da tarefa \\
\hline Pressão psicológica para a execução da tarefa \\
\hline
\end{tabular}

Tabela 7-Formas de Contato

Fonte: Mendonça, M. Dissertação de Mestrado-Escritórios Residenciais - São Paulo:FAUUSP, 2005

No caso das posturas das atividades a serem desenvolvidas, devem ser listadas e observadas cada uma destas atividades e analisadas cada postura na interação com mobiliários, equipamentos e com o ambiente.

O objetivo destas análises é verificar quais partes do corpo humano serão mais solicitadas e qual espaço será necessário para cada uma delas, a fim de colaborar com as recomendações ergonômicas. 
Para o Escritório Residencial podem ser citadas as

seguintes atividades de uso e suas respectivas posturas:

Figuras 8,9 e 10

\begin{tabular}{|l|l|l|l|}
\hline Mesa & Posturas \\
\hline Leitura & Escrita & \\
\hline Apoio de objetos & & \\
\hline Telefonar & \\
\hline Receber I Enviar Fax
\end{tabular}

Figura 8 - Postura - Uso da Mesa

Elaborado pelo autor

\begin{tabular}{|l|l|}
\hline $\begin{array}{l}\text { Microcomputador } \\
\text { e Periféricos }\end{array}$ & Posturas \\
\hline Leitura em monitor & \\
\hline Digitação & \\
\hline Uso do mouse & \\
\hline Uso da impressora do Scanner & \\
\hline
\end{tabular}

Figura 9-Postura - Uso de Microcomputador e Periféricos Elaborado pelo autor

\section{Armazenamento}

Armário|Prateleira|Gaveteiro

Guardar

Retirar

Abrir|Fechar gavetas

\section{Posturas}

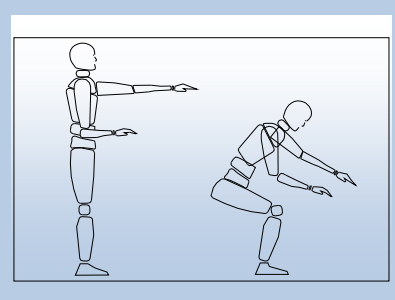

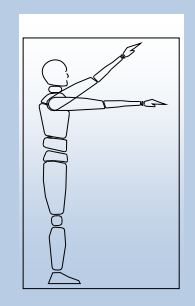

Figura 10 - Postura - Armazenamento

Elaborado pelo autor

Braços, cabeça-pescoço e tronco são as partes do corpo mais utilizadas nestas atividades, sendo que as pernas, na maior parte do tempo encontram-se em posição de repouso. 


\subsubsection{Informações da área física}

O espaço aqui deve ser entendido como o ambiente onde será implantado o posto de trabalho e, para tanto, todas as informações pertinentes e relevantes devem ser levantadas, como:

- Dimensões de largura, comprimento e altura;

- Localização de portas e janelas;

- Localização de pontos de instalação de rede elétrica - tomadas, arandelas e pontos de luz no forro;

- Localização de pontos de rede de telefonia;

- Localização de pontos de rede lógica;

- Identificação e localização em planta ou croqui de todo e qualquer elemento do ambiente, quer seja componente, mobiliário ou equipamento que farão parte do conjunto cuja utilização esteja relacionada às atividades de escritório;

- Identificação de materiais, cores e padrões de revestimento de piso, parede e forro.

\subsubsection{Informações dos requisitos de uso}

Para que o Posto de Trabalho - Escritório Residencial possa proporcionar um desempenho satisfatório ao usuário, alguns pré-requisitos devem ser considerados e são divididos em dois conjuntos em Requisitos Obrigatórios e Requisitos Desejáveis, conforme segue: Tabela 8 
- Requisitos Obrigatórios: O requisito obrigatório na utilização do Posto de Trabalho - Escritório Residencial refere-se ao conhecimento prévio ou treinamento adequado para a utilização dos equipamentos Microcomputador e Periféricos, e ainda uma adequação do mobiliário ao usuário.

- Requisitos Desejáveis: Os Requisitos Desejáveis são itens que devem fazer parte das considerações preliminares quando da implantação de um Escritório Residencial.

\begin{tabular}{|l|}
\hline Requisitos Obrigatórios \\
\hline Requisitos Funcionais \\
\hline Requisitos Anatômicos \\
\hline \\
\hline
\end{tabular}

Tabela 8 - Requisitos de Uso

Fonte: Mendonça, M. Dissertação de Mestrado-Escritórios Residenciais-São Paulo:FAUUSP, 2005

\section{Requisitos Desejáveis}

Requisitos Dimensionais

Requisitos de Qualidade

Requisitos de Manutenção

Requisitos Estéticos

\subsubsection{Diagnóstico ergonômico}

Esta etapa da análise da atividade tem por finalidade indicar quais os eventuais problemas que podem ocorrer no desempenho das tarefas do profissional quando do uso do Posto de Trabalho.

Podem ser identificados problemas em relação às posturas e movimentos prejudiciais, decorrentes das inadequações do espaço em relação à atividade ou ainda problemas decorrentes da relação entre o usuário e o mobiliário, equipamentos e espaço, como: posição dos equipamentos, alcance, acessibilidade, campo de visão ou esforços adicionais. 


\subsubsection{Recomendações de conforto}

A adequação ergonômica de um ambiente ou posto de trabalho tem por finalidade a melhoria das condições de usabilidade do usuário, para que este possa desempenhar as tarefas que foram propostas para determinado espaço construído com o máximo de conforto e segurança que se possa atingir, lembrando que o objetivo final será sempre o conforto do usuário.

Para que esta adequação seja eficiente, deve-se observar alguns itens importantes do ambiente e analisá-los com o objetivo de levantar os eventuais pontos críticos, confrontar com as exigências mínimas determinadas por normas ou bibliografias especializadas e, finalmente, recomendar as ações para a adequação plena do espaço. 


\subsection{Conforto Ergonômico e Dimensional}

Embora a ergonomia trate das inter-relações entre o usuário, o mobiliário e equipamento, e o ambiente no qual se insere o posto de trabalho, neste momento serão abordadas apenas as questões de adaptabilidade do mobiliário | equipamento ao usuário.

\subsubsection{Cadeira}

Considerando que as atividades de escritório sejam desenvolvidas na maior parte do tempo na posição sentado, o desempenho da cadeira tem papel importante na situação de conforto ergonômico os seguintes recursos: Figura 11

- Os pés devem estar completamente apoiados;

- A altura do assento deve permitir a formação de um ângulo reto das coxas com as pernas;

- A região renal deve estar completamente apoiada no encosto;

- O assento deve apresentar depressões para evitar que o peso da perna pressione os vasos sanguíneos, estrangulando-os.

- O corpo deve contar com suporte pleno em qualquer posição sentada;

- As vértebras lombares devem ser suportadas em seus pontos estratégicos;

- As costas devem ser apoiadas até o topo, para evitar a tensão dos músculos

- Os cotovelos deverão estar apoiados, evitando a sobrecarga de esforço dos punhos. 


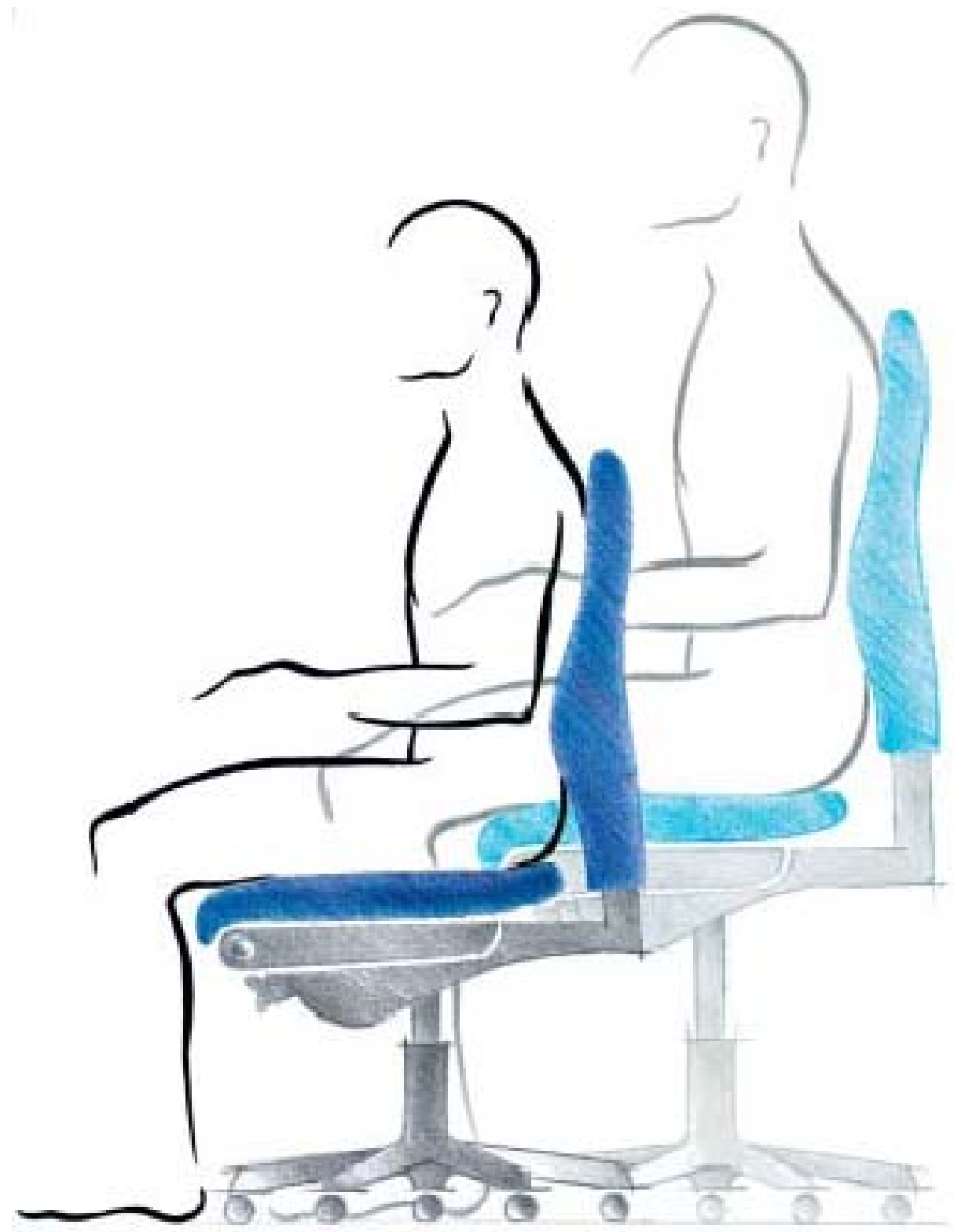

Figura 11 - Postura - Uso da Cadeira Fonte: Giroflex 
Para uma melhor adaptação aos vários biótipos de usuários, recomenda-se que as cadeiras sejam providas de sistemas de ajustes, giratórias e com rodízios. Figura 12
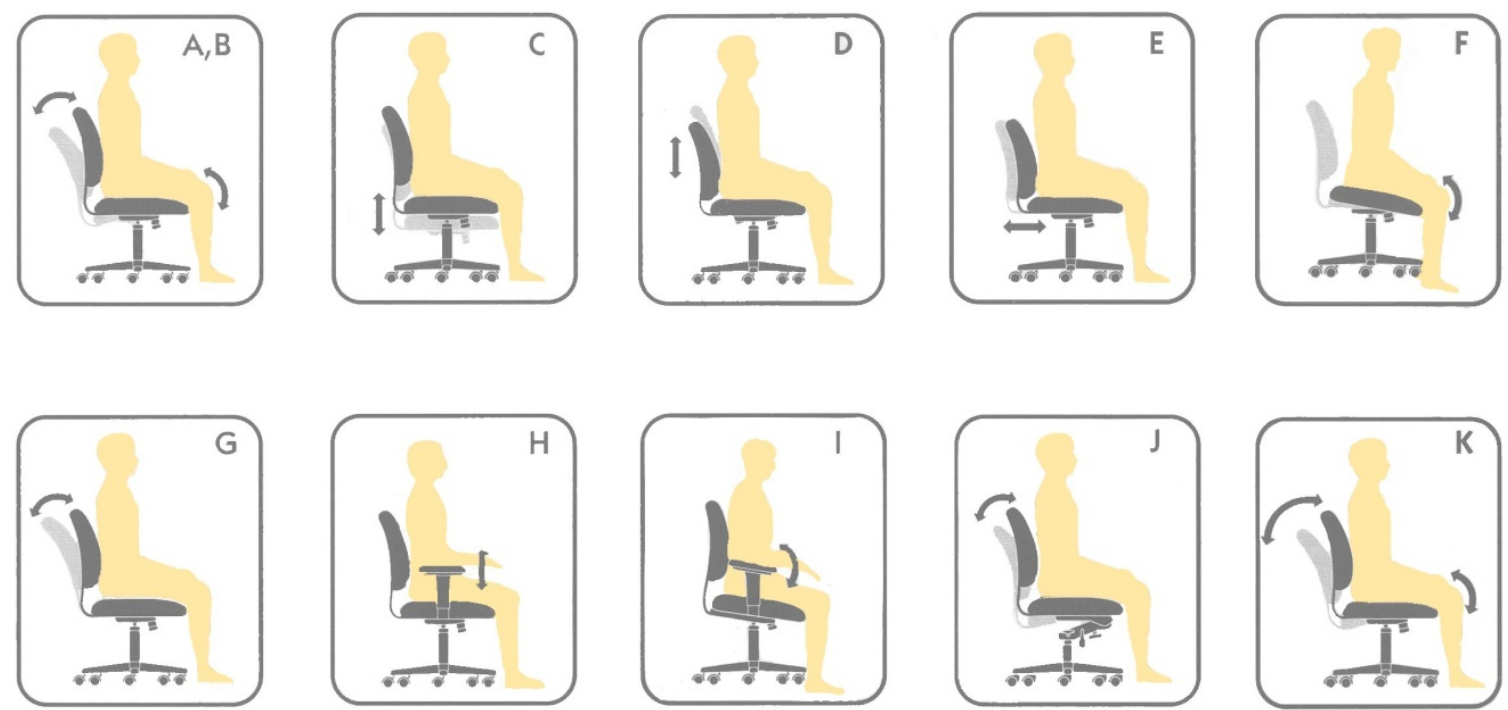

Figura 12 - Ajustes ergonômicos de Cadeiras

Fonte: Zimmerman, N. Home Office Design. 1996. Ilustração

\subsubsection{Mesa}

Também considerado como elemento essencial para as atividades de escritório, a mesa, além de permitir uma área de apoio para as necessidades do usuário, deve também atender as questões ergonômicas no tocante ao desempenho do material de acabamento, que deve proporcionar sensação de bem-estar quanto a sua temperatura (conforto tátil), e não possuir elementos agressivos, como bordas ou cantos que possam causar ferimentos ao usuário. Figura 13 
É recomendável também que a mesa possua dispositivos que permitam a regulagem de sua altura em relação ao piso, pois, em casos onde o posto de trabalho é utilizado por usuários de diferentes padrões antropométricos (ex: crianças e adultos), esse ajuste se fará necessário.

\subsubsection{Microcomputador e Periféricos}

Assim como a cadeira e a mesa, o conjunto microcomputador e os periféricos também serão considerados como elementos essenciais para o posto de trabalho que envolve as atividades de um escritório residencial, embora algumas atividades profissionais não necessitem destes equipamentos.

O conjunto de microcomputador será representado pela Unidade Central de Processamento - CPU, teclado, mouse e monitor; os periféricos considerados são a impressora, o scanner e telefone com aparelho para fax. Figura 13

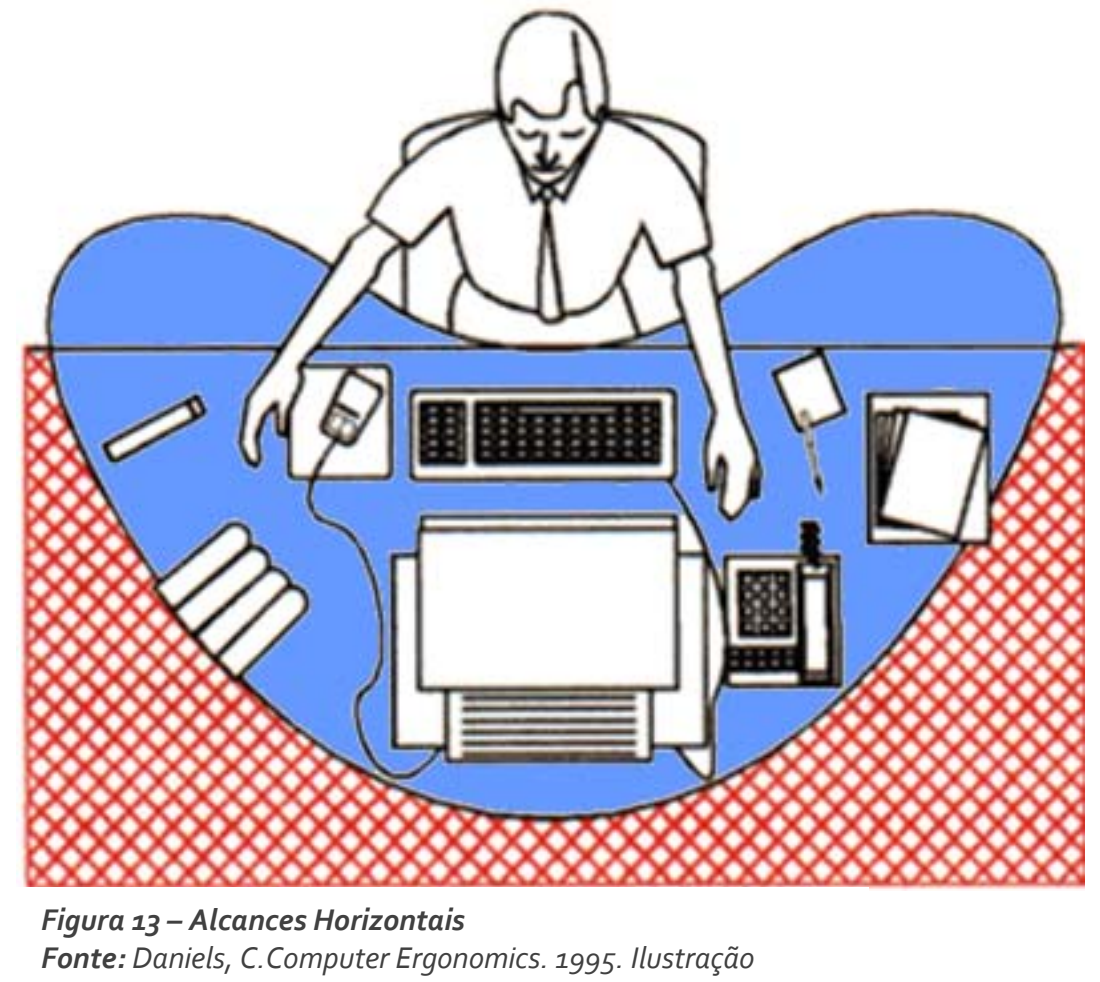

Tese de Doutorado - Escritórios Residenciais 
Neste caso, as recomendações estão ligadas principalmente à altura do teclado, à altura e inclinação do monitor, e às posições da CPU e periféricos em relação ao usuário.

Todos estes itens devem levar em consideração os alcances horizontal e vertical máximos dos usuários. Figura 14

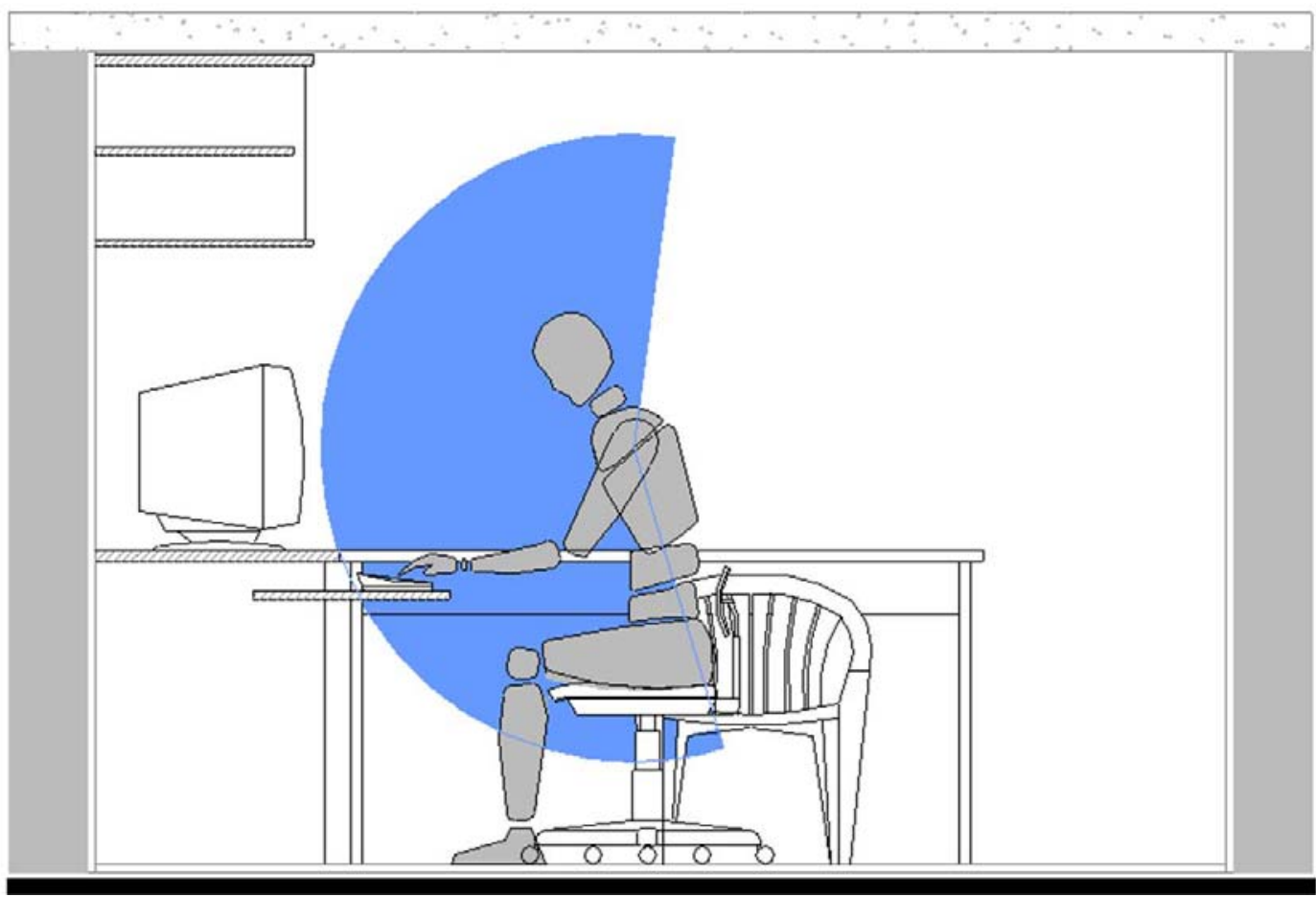

Figura 14 - Alcances Verticais

Fonte: Mendonça, M. Dissertação de Mestrado-Escritórios Residenciais São Paulo:FAUUSP, 2005. Ilustração 


\subsubsection{Conforto Dimensional}

Parte integrante da ergonomia, o Conforto Dimensional busca a relação usuário| ambiente, e suas necessidades de espaço físico para desenvolver suas atividades, referindo-se à composição dimensional do ambiente.

Um amplo estudo foi elaborado por Boveri (2004), onde os espaços de atividades dos equipamentos e mobiliário da habitação foram recomendados, e Mendonça (2005), complementou esse estudo com itens pertinentes ao escritório residencial.

O Conforto Espacial - aqui determinado como Conforto Dimensional, segundo Boveri (2004), é a condição apresentada pelo ambiente de proporcionar as dimensões necessárias para abrigar todo e qualquer elemento que seja parte integrante das atividades propostas para sua utilização, sem restrições ou interferências.

Com essas premissas, o estudo de uma matriz dimensional realizado pelo autor em 2005, concluiu determinadas composições, arranjos e áreas mínimas para implantação de postos de trabalho para atividades de escritório no ambiente doméstico, sendo a síntese apresentada a seguir que será utilizada como parâmetro dimensional para o posto de trabalho. Figura 15 


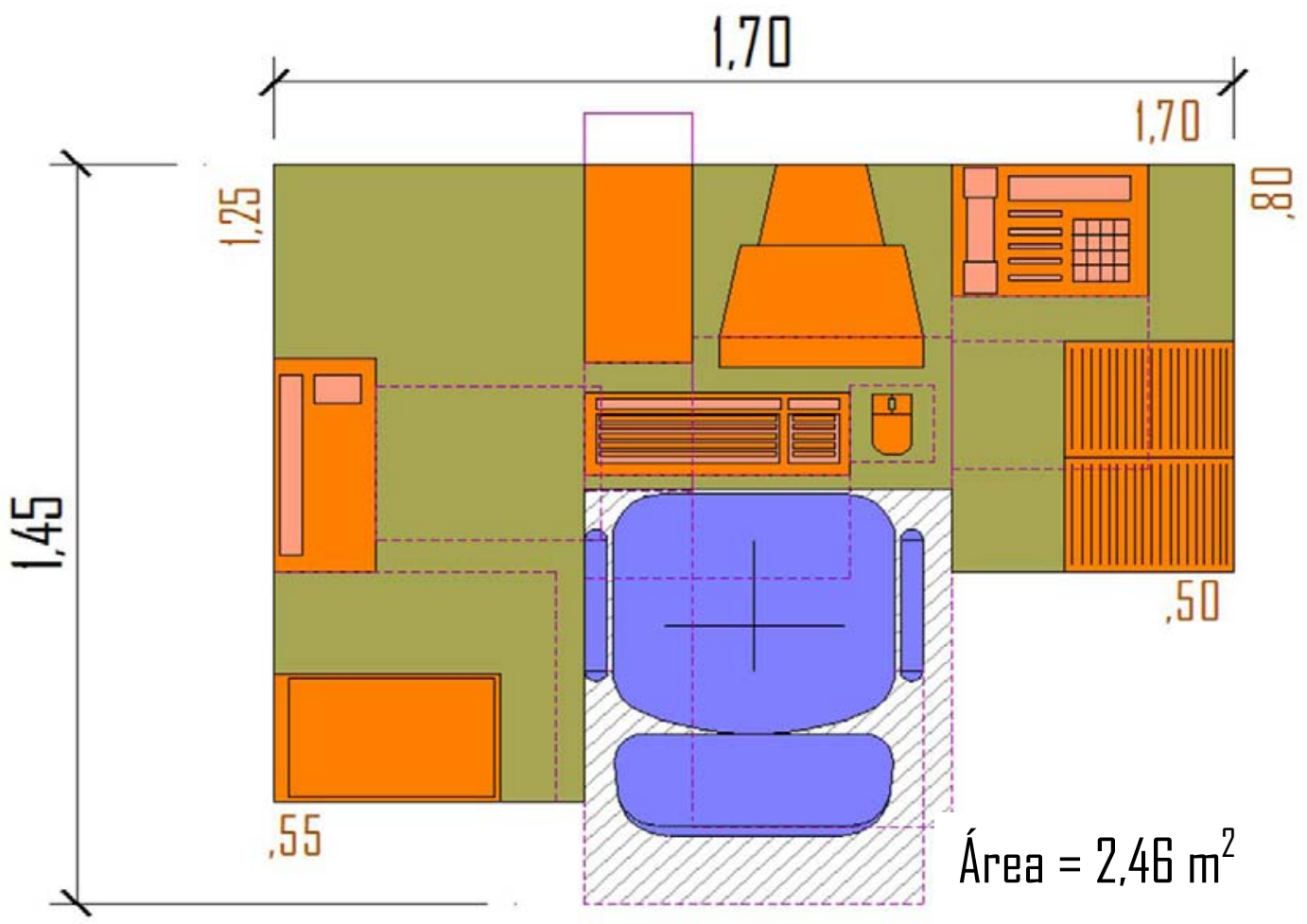

Figura 15- Arranjo Compacto

Fonte: Mendonça, M. Dissertação de Mestrado-Escritórios Residenciais São Paulo:FAUUSP, 2005. Ilustração

\subsection{Conforto Visual}

Segundo o Canadian Centre for Occupational Health and Safety - $\mathrm{CCOHS}^{106}$ - as pessoas recebem cerca de $85 \%$ das informações por meio da visão, daí a importância do controle dos elementos de iluminação no ambiente de trabalho para o bem-estar e a produtividade do usuário.

No Brasil, a Associação Brasileira de Normas Técnicas ABNT, publicou em 1992 a NBR $5413^{107}$ que regula a Iluminância de Interiores.

106 Canadian Centre for Occupational Health and Safety - CCOHS Disponível em http://www.ccohs.ca/ 107 Associação Brasileira de Normas Técnicas - ABNT NBR5413 lluminância de interiores - 1992 Disponível em http://www.labcon.ufsc.br/anexos/13.pdf 
A habilidade da visão no ambiente de trabalho pode estar ligada a outros fatores além da iluminação:

- O tempo de manutenção do foco no objeto, objetos que se movam rapidamente dificultam a visão;

- O tamanho do objeto, quanto menor o objeto, maior a dificuldade de enxergá-lo;

- Brilho, muita ou pouca reflexão de luz dificulta a visão do objeto e;

- Contraste entre o objeto e seu fundo próximo, pouco contraste dificulta a distinção entre objeto e fundo.

- Ofuscamento direto ou reflexivo, dificulta a visão do objeto;

No ambiente do escritório a iluminação deve permitir a plena visualização de documentos impressos, manuscritos ou no terminal de vídeo, com o cuidado de que a iluminação não atinja um nível de brilho que provoque o ofuscamento reflexivo, dificultando a visão.

A introdução dos microcomputadores nos escritórios nos anos 80 , em substituição às máquinas de escrever, resultou em alterações nas demandas visuais provocando mudanças nos projetos de iluminação.

A luz deficiente pode causar uma situação de perigo, por um erro de julgamento de posição, forma ou velocidade do objeto; ou ainda, quando a atividade requisitar uma tarefa de precisão, uma iluminação inadequada pode prejudicar a qualidade e a produtividade do trabalho, sendo que a inadequação pode ser causada pelos extremos - com muita ou pouca iluminação. 
A quantidade de luz necessária no ambiente pode variar de acordo com os seguintes itens:

- Tipo de atividade desenvolvida;

- Tipo da superfície de trabalho (em relação à reflexão ou absorção de luz)

- O ambiente de trabalho como um todo e;

- A capacidade visual de cada indivíduo.

A quantidade de iluminação incidente sobre o plano de trabalho é medida pela unidade chamada lux (que é igual à quantidade de lumens por metro quadrado de superfície) e, dependendo dos fatores acima identificados, pode variar, sendo que, segundo a IESNA - Iluminating Engineering Society of North America ${ }^{108}$, o valor apropriado para o posto de trabalho de um escritório encontra-se entre 500 e 1000 lux, medidos no plano a $76 \mathrm{~cm}$ do piso.

\subsection{Conforto Higrotérmico, Ventilação e Qualidade do Ar}

O ambiente construído, no qual o homem desenvolve suas atividades, deve proporcionar uma situação de bem-estar em vários aspectos e que podem definir o estado de conforto.

Já foram abordados o conforto espacial e visual, e agora o foco passa a ser o clima que envolve o ambiente de trabalho, as questões relativas ao conforto térmico, ventilação e qualidade do ar que envolvem o escritório residencial.

108 Iluminating Engineering Society of North américa-IESNA Disponível em http://www.iesna.org/ 
O ser humano faz parte do grupo de animais que mantém a temperatura interna do corpo por meio de mecanismos fisiológicos, os homeotérmicos, cuja temperatura interna tende a ser estável aos $37^{\circ} \mathrm{C}$, com pequenas variações entre $36,1^{\circ} \mathrm{C}$ e $37,2^{\circ} \mathrm{C}$, onde os limites inferior e superior para a sobrevivência são de $32^{\circ} \mathrm{C}$ e $42^{\circ} \mathrm{C}$, respectivamente.

O bem-estar das pessoas pode ser afetado pelas variações de calor, umidade e vento, afetando em seu desempenho, causando inquietação e perda de concentração.

Dependendo das perdas de calor que as condições ambientais proporcionam, o organismo reage na busca de reduzir as perdas e aumentar as combustões internas, no caso da sensação de frio; ou aumentando as condições de troca de calor entre o organismo e o ambiente, no caso da sensação de calor.

O calor produzido no corpo é determinado pelo nível de atividade da pessoa, sendo também variável com a idade e o sexo.

Existem quatro processos responsáveis pela troca calor no ambiente, são eles:

- Condução: a troca de calor acontece pela diferença de temperatura entre o corpo e outras superfícies e, no caso do processo de condução, a troca de calor ocorre pelo contato direto entre os elementos;

- Irradiação: similar à condução, onde a troca de calor se dá pela diferença de temperatura, porém, não existe o contato direto entre o corpo e a superfície, e a troca acontece apenas pela proximidade; 
- Convecção: neste processo, a velocidade do deslocamento da camada de ar próximo à pele e a temperatura do ar estimulam a troca de calor.

- Evaporação: já na evaporação as condições da umidade relativa do ar e sua velocidade promovem a troca de calor.

A Norma ISO $7730^{109}$, de 1994 abrange os conceitos para a determinação do conforto térmico, considerando que um ambiente apresenta este conforto quando não mais do que 10\% dos usuários demonstrem uma reação de desconforto, embora no caso dos Escritórios Residenciais esta porcentagem passa a ser irrelevante, pois geralmente são postos de trabalho e ambientes utilizados por apenas uma pessoa, eventualmente duas.

A norma ISO-7730 ainda faz algumas recomendações para o conforto térmico, relacionadas com os parâmetros de conforto, conforme segue:

- A assimetria da temperatura radiante de janelas ou outra superfície vertical fria deve ser inferior a $10^{\circ} \mathrm{C}$ (em relação a um plano vertical $0,6 \mathrm{~m}$ acima do chão);

- A velocidade do ar tem de ser no Inverno inferior a $0,15 \mathrm{~m} / \mathrm{s}$, com temperaturas entre 20 e $24^{\circ} \mathrm{C}$. No Verão inferior a $0,25 \mathrm{~m} / \mathrm{s}$, com temperaturas entre 23 e $26^{\circ} \mathrm{C}$

- A diferença de temperatura do ar entre 1,1 $\mathrm{m}$ e 0,1 m acima do chão não deve exceder $3^{\circ} C_{i}$

109 International Organization for Standardization ISO 7730 : 1994 - "Moderate Thermal Environments: Determinations of the PMV and PPD indices and specification of the Conditions for the Thermal Comfort". 
- A temperatura do chão deve situar-se entre 19 e $26^{\circ} \mathrm{C}$ exceto em pavimentos radiantes podendo atingir neste caso os $29^{\circ} \mathrm{C}$.

Outro elemento de estudo importante para o conforto do ambiente é a Qualidade do Ar, já que uma condição de ar insalubre, além da sensação de desconforto pode provocar distúrbios na saúde do usuário, como várias irritações de pele e alergias respiratórias.

Seguem os fatores que podem comprometer esta qualidade:

- Fatores Humanos: neste caso, os odores naturais do corpo humano, a emissão de vapor de água e o nível de dióxido de carbono da respiração podem empobrecer a qualidade do ar, inclusive o nível de oxigênio.

- Fatores Externos: são basicamente as micro partículas e microorganismos em suspensão no ar.

- Fatores Internos: odores provenientes de produtos de limpeza e dos próprios materiais que compõem o mobiliário e o equipamento, principalmente os revestimentos de base polimérica responsáveis pela emissão de compostos orgânicos voláteis VOCs; e ainda as emissões de fumaça de cigarros comprometem a qualidade do ar do ambiente.

Para garantir que não haja este comprometimento e o empobrecimento da qualidade do ar, é necessária a correta ventilação do ambiente a qual promove a renovação do volume de ar, levando em consideração o volume de ar renovado no ambiente por hora por pessoa. 
Como recomendação para escritórios, o volume de ar renovado por hora, por pessoa deve ser:

- $30 m_{3}$ - ambientes com não fumantes

- 40 m3 - ambientes com fumantes

\subsection{Conforto Acústico}

O ser humano tem a necessidade da sensação de envolvimento com seu entorno e saber que existe algum tipo de atividade ao redor é importante, mesmo em tarefas que exijam o máximo de concentração mental.

Nas empresas, vários são os ruídos que circulam pelos ambientes, conversas, sons de telefones tocando, impressoras, até pequenos ruídos como reatores de iluminação fluorescente, (tanto os eletrônicos como os comuns), equipamentos de ar condicionado e ainda alguma música de fundo, que pelo hábito podem deixar de serem percebidos.

Em um Escritório Residencial existem alguns outros tipos de ruídos que podem interferir nas atividades de trabalho; são ruídos do lar, produzidos por equipamentos de limpeza, crianças brincando, animais domésticos, enfim, uma série de sons que fazem parte da rotina doméstica e com os quais os usuários destes espaços terão que conviver. 
Todos estes ruídos não são caracterizados como fatores que comprometem o desempenho do trabalhador, porém, acima de determinado limite o nível de ruído pode vir a afetar este usuário de diversas formas.

De acordo com Kroemer \& Kroemer(2001), acima deste limite, a concentração em tarefas é afetada, o entendimento verbal fica prejudicado, cria sensações pessoais negativas, há interferência na capacidade sensorial do corpo e conseqüentemente a diminuição do desempenho para as tarefas.

Nos Estados Unidos, a Occupational Safety and Health Administration - OSHA ${ }^{110}$ - tem como regulamentação períodos de exposição diária ao ruído de 16 horas até $85 \mathrm{~dB}$, 8 horas até $90 \mathrm{~dB}$ e 4 horas para $95 \mathrm{~dB}$, contudo, estes limites variam, como o caso de alguns países europeus onde existe a permissão de 8 horas de exposição à $90 \mathrm{~dB}, 4$ horas a $93 \mathrm{~dB}$ e 16 horas a $87 \mathrm{~dB}$.

No Brasil, a norma NBR $10152^{111}$ - "Níveis de Ruído para Conforto Acústico", de 2000, apresenta como nível de conforto para escritórios $35 \mathrm{~dB}(\mathrm{~A})$ e o valor máximo de 45 $d B(A)$ como nível sonoro aceitável para o ambiente, porém, não apresenta o período de tempo que o usuário do ambiente poderia ser exposto a níveis mais elevados.

\footnotetext{
110 Occupational Safety and Health Administration - OSHA Disponivel em http://www.osha.gov/

111 Associação Brasileira de Normas Técnicas - ABNT NBR10152 Iluminância de interiores - 2000 Disponível em http://www.filecrop.com/NBR-10152.html
} 


\subsection{Conclusões}

Levantadas as necessidades e determinados os critérios de desempenho, tendo seguido o roteiro de análise da atividade, chega-se ao quadro resumo, onde estão dispostas as recomendações de conforto a serem consideradas como parâmetros na elaboração e possível avaliação de adequabilidade de um posto de trabalho para atividades de escritório inserido no ambiente residencial. Quadro 8

Outros itens de conforto devem ser analisados, porém não pode ser feita uma leitura direta que permita análise precisa ou que possa ser quantificada, pois tratam-se de questões não mensuráveis, como nível de satisfação quanto à privacidade, grau de interferência das atividades domésticas, grau de sociabilidade do usuário ou ainda conforto psicológico, portanto, para o desenvolvimento desta tese não se buscou parâmetros para estas questões. 


\begin{tabular}{|c|c|c|}
\hline CONFORTO & ITEM & RECOMENDAÇÃO \\
\hline \multicolumn{3}{|c|}{ Conforto Ergonômico e Dimensional $\quad$ área mínima $2.46 \mathrm{~m}^{2}$} \\
\hline \multirow[t]{7}{*}{ Cadeira } & Largura do assento & de 34.0 a $77.0 \mathrm{~cm}$ \\
\hline & Profundidade do assento & de 40.0 a $51.0 \mathrm{~cm}$ \\
\hline & Altura do assento & de 38.0 a $49.7 \mathrm{~cm}$ \\
\hline & Altura do apoio lombar & $\min .66 .0 \mathrm{~cm}$ \\
\hline & Altura do apoio de braço & de 56.1 a $69.3 \mathrm{~cm}$ \\
\hline & Giratória & Sim \\
\hline & Rodízios & Sim \\
\hline \multirow[t]{5}{*}{ Mesa } & Largura do tampo & de 65.0 a $142.2 \mathrm{~cm}$ \\
\hline & Profundidade do tampo & de 65.0 a $87.0 \mathrm{~cm}$ \\
\hline & Altura do tampo & de 73.7 a $76.2 \mathrm{~cm}$ \\
\hline & Material de revestimento & $\begin{array}{l}\text { Quentes } \\
\text { (madeira | plástico | couro) }\end{array}$ \\
\hline & Acabamento & Cantos boleados \\
\hline \multirow[t]{2}{*}{ Monitor } & Altura da base da tela & de 78.5 a $94.7 \mathrm{~cm}$ \\
\hline & Distância do observador & de 45.0 a $70.0 \mathrm{~cm}$ \\
\hline Teclado & Altura & de 63.7 a $66.2 \mathrm{~cm}$ \\
\hline CPU & Distância do operador & de 38.5 a $62.7 \mathrm{~cm}$ \\
\hline \multirow[t]{2}{*}{ Periféricos } & Alcance vertical & de 46.5 a $74.5 \mathrm{~cm}$ \\
\hline & Alcance horizontal & de 32.7 a $75.8 \mathrm{~cm}$ \\
\hline \multicolumn{3}{|c|}{ Conforto Visual } \\
\hline & Nível de iluminação no plano & de 500 a 1.000 lux \\
\hline & Direção do fluxo luminoso & Superior lateral \\
\hline \multicolumn{3}{|c|}{ Conforto Térmico, Ventilação e Qualidade do Ar } \\
\hline & Temperatura do ar no verão & de 20 a $24^{\circ} \mathrm{C}$ \\
\hline & Temperatura do ar no inverno & $21^{\circ} \mathrm{C}$ \\
\hline & Umidade Relativa do Ar - verão & de 40 a $60 \%$ \\
\hline & Umidade Relativa do $\mathrm{Ar}$ - inverno & $\min .30 \%$ \\
\hline & Velocidade do Ar & de 0.1 a $0.2 \mathrm{~m} / \mathrm{s}$ \\
\hline & Volume de Renovação do Ar & $30 \mathrm{~m}^{3} / \mathrm{h}$ - não fumantes \\
\hline & & $40 \mathrm{~m}^{3} / \mathrm{h}$ - fumantes \\
\hline \multicolumn{3}{|c|}{ Conforto Acústico } \\
\hline & \multirow[t]{2}{*}{ Nível de ruído } & 8h max. $90 \mathrm{~dB}$ \\
\hline & & $4 \mathrm{~h} \max .95 \mathrm{~dB}$ \\
\hline
\end{tabular}

Quadro 8 - Parâmetros e Critérios de Desempenho do Posto de Trabalho|Ambiente

Elaborado pelo autor 
Pode-se ainda considerar as instalações, ou conjunto de recursos disponíveis para a implantação do escritório como número de tomadas, bitola da fiação, fornecimento de energia, linhas de telefonia ou ainda tipologia de conexão com acesso à InterNet (rede mundial de computadores) - porém estes elementos estão diretamente relacionados com o conjunto de equipamentos a serem utilizados.

Da mesma maneira, o dimensionamento mínimo do ambiente ou do posto de trabalho depende do uso, onde variações são possíveis, inclusive com possibilidades de prover ambientes a serem utilizados por mais de um usuário ao mesmo tempo, cujas variantes foram estudas em Mendonça(2005). 

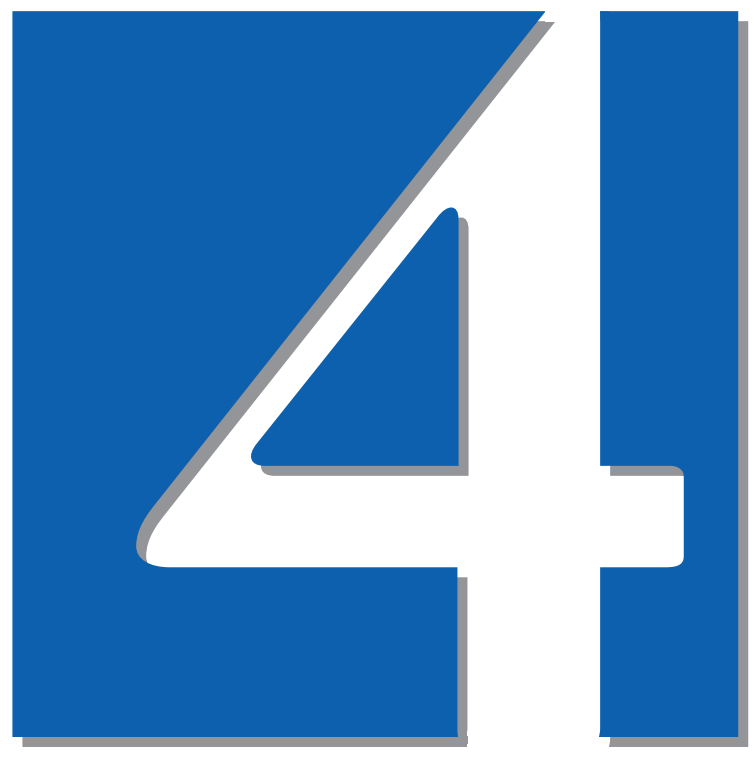

\section{A Inclusão de Escritórios Residenciais em Lançamentos Imobiliários}

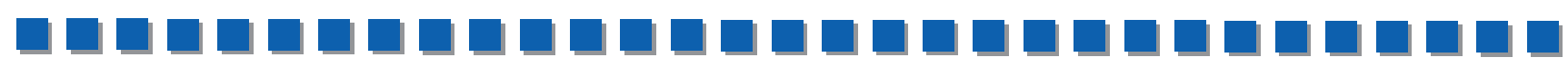




\section{CAPÍTULO 4. A INCLUSÃO DE ESCRITÓRIOS RESIDENCIAIS EM LANÇAMENTO IMOBILIÁRIOS}

\subsection{Considerações Preliminares}

Em função da hipótese colocada no início desta tese, se faz necessária a compreensão de duas questões elementares:

A primeira é estudar como os lançamentos imobiliários do Município de São Paulo estão incorporando espaços destinados ao desenvolvimento de trabalhos de escritório nas unidades habitacionais.

A segunda é estudar como os trabalhadores que desenvolvem atividades de escritório à partir de suas residências estão se apropriando de determinados espaços desta habitação para estas atividades.

Nesse sentido, duas pesquisas foram realizadas no decorrer do processo de elaboração deste estudo, e são apresentadas neste capítulo. 


\subsection{Introdução}

Quando se busca a compreensão de um determinado tema, estudam-se as mais variadas vertentes, sob prismas e focos diversos com o objetivo de trazer à luz a maior gama de informações que permitam gerar o conhecimento sobre o objeto de estudo.

O Escritório Residencial, ou Home Office, tem sido tema e objeto de estudo deste autor há sete anos, e no decorrer deste período já foram pesquisadas as condições ergonômicas e de conforto do ambiente, as possíveis opções de implantação na habitação, o perfil do usuário, as inter-relações entre as rotinas domésticas e as atividades de escritório, as legislações pertinentes que regem esta tipologia de trabalho, quais as interpretações que diferentes países deram para o tema, momentos históricos que determinaram a trajetória tanto para o sistema casaescritório, como para a trajetória do próprio trabalho e ainda as tecnologias que permitiram que este fenômeno estivesse presente na vida contemporânea das habitações.

O estudo ora proposto pretende investigar as opções que o mercado imobiliário do Município de São Paulo está disponibilizando para o público comprador de unidades habitacionais novas. 
Os elementos a serem investigados são os prospectos promocionais apresentados em impressos e também disponibilizados em mídia digital e ainda visitas ao pontos de vendas dos empreendimentos, porém, um passo anterior a este estudo se faz necessário, que é justamente o estudo de como os atores dessas promoções chegam ao produto final a ser disponibilizado para venda.

Neste caso, entende-se que o produto deverá ser consumido por um determinado grupo de usuários, e pressupõe-se que estudos da área de marketing devam ser realizados para a determinação desses consumidores e ainda, quais os fatores que incidem na decisão de compra de seus produtos, ou seja, o comportamento do usuário deve ser analisado para o direcionamento dos investimentos.

Portanto, a introdução deste estudo terá como foco algumas considerações a respeito do comportamento do consumidor e os fatores que influenciam em sua decisão de compra, sem a pretensão de um aprofundamento ou conclusões imutáveis, mas como uma visão das possíveis linhas de pensamento que regem este universo de consumo, baseados em textos e publicações que discorrem sobre o tema e que possam embasar a continuidade dos estudos dos Home Offices. 
Os esforços para entender ou interpretar o comportamento do consumidor podem ser facilmente percebidos nas inúmeras pesquisas que são realizadas sobre os mais diversos temas das mais variadas modalidades demonstrando que é importante saber o que cada consumidor busca no mercado para satisfazer suas necessidades e, no caso das habitações, cabe ao arquiteto projetista conhecer os requisitos relacionados à segurança e ao conforto que por muitas vezes são desconhecidos pelos usuários.

Quais serão, portanto, os fatores que influenciam este consumidor e seu ato de compra, quais as variantes que estão envolvidas na decisão e ainda, qual o processo pelo qual o consumidor será submetido até consumar a compra.

O dicionário eletrônico HOUAISS ${ }^{112}$ define assim o verbete "CONSUMIDOR":

"que ou aquele que adquire mercadorias, riquezas e serviços para uso próprio ou de sua família; comprador, freguês, cliente."

Para alguns autores, a definição de "consumidor" assume diferentes versões, Karsaklian ${ }^{113}$ define:

"Ser consumidor é ser humano. Ser consumidor é alimentar-se, vestir-se, divertir-se... é viver".

E Cobra ${ }^{114}$ coloca que:

"Cada consumidor reage de forma diferente sob estímulos iguais, e isso ocorre porque cada um possui uma 'caixa preta' diferente".

${ }^{112}$ Dicionário Eletrônico HOUAISS da Língua Portuguesa 1.0 - 2001 op. cit.

${ }^{113}$ Karsaklian, E. Comportamento do Consumidor - São Paulo: Atlas - 2000

${ }^{114}$ Cobra, M. Marketing Básico: uma abordagem brasileira - São Paulo: Atlas - 1997 
Dessa maneira, observa-se que as organizações que se dizem orientadas ao mercado - ou seja, aquelas que têm por princípio atender às necessidades ou demandas apresentadas por determinados grupos de indivíduos devem ter por prioridade vital a compreensão destes indivíduos e compreender que os fatores relacionados ao comportamento do consumo giram em torno das ações dos consumidores.

Os primeiros estudos sobre o comportamento do consumidor surgiram no final da década de 1960, influenciados por autores como Engel, Blackwell e Miniard ${ }^{115}$ e ainda Kotler e Amstrong ${ }^{116}$ que definiram alguns fatores que podem influenciar a tomada de decisão e comportamento do consumidor, quais sejam:

a. Motivações: os consumidores podem ser influenciados por necessidades que são divididas em fisiológicas (fome, sede, desconforto) e psicológicas (reconhecimento, auto-estima, relacionamento), mas muitas vezes estas necessidades não são fortes o bastante para motivar a pessoa a agir num determinado momento, ou seja, a pessoa necessita de um motivo maior para buscar sua satisfação.

\footnotetext{
${ }^{115}$ Engel, J.; Blackwell, R. D.; Miniard, P. W. - Comportamento do Consumidor-São Paulo: Cengage Learning - 2000

${ }^{116}$ Kotler, P.; Armstrong, G. Princípios de Marketing - Rio de Janeiro: Pearson Prentice Hall $-2003$
} 
b. Personalidade: É a personalidade de cada pessoa que vai determinar o seu comportamento no ato da compra, pois se refere a características psicológicas que conduzem uma resposta relativamente consistente no ambiente onde a pessoa está inserida, sendo que o conhecimento da personalidade pode ser de grande utilidade para analisar o comportamento do consumidor quanto a uma marca ou um produto.

c. Percepções: Considerada pelos autores como "processo pelo qual as pessoas selecionam, organizam e interpretam informações para formar uma imagem significativa do mundo"; estando a pessoa, desta forma, pronta para agir, influenciada pela sua percepção, determinando sua decisão de compra. Por meio destas influências os consumidores aprendem e diferenciam fatores sobre escolhas que farão durante as suas tomadas de decisões, tornando, assim, seu comportamento um poço mais previsível para os estudiosos desta área.

d. Classes Sociais: "As classes sociais são divisões relativamente homogêneas e permanecentes em uma sociedade, ordenadas com respeito a cada um e cujos membros compartilham dos mesmos valores, estilos de vida, interesses e comportamento.", e que está além do fator renda, sendo consideradas a ocupação, educação, riqueza e outras variáveis; desta maneira, os indivíduos de uma mesma classe social apresentam preferências distintas em relação a vestuário, imóveis, lazer e automóveis. 
Segundo Kotler ${ }^{117}$, as classes sociais podem ser definidas de acordo com o quadro abaixo, onde se observa que em cada um dos segmentos existem variantes para 0 comportamento: Quadro 9

\begin{tabular}{|c|c|c|}
\hline Tipo de Classe & Percentual & Características \\
\hline \multirow[t]{4}{*}{ Alta - alta } & \multirow[t]{4}{*}{ Menos de $1 \%$} & Representada pela elite social \\
\hline & & Consumo de jóias, antiquários, lazer \\
\hline & & Doa grandes somas para caridades \\
\hline & & Organiza bailes de debutantes \\
\hline \multirow[t]{4}{*}{ Alta - baixa } & \multirow[t]{4}{*}{ Aprox. $2 \%$} & Pessoas que ganham altas rendas \\
\hline & & Provém de classe média \\
\hline & & Adquirem símbolos de status para si e seus filhos \\
\hline & & Possuem imóveis de alto padrão, piscina, iates, etc... \\
\hline \multirow[t]{4}{*}{ Média - alta } & \multirow[t]{4}{*}{$12 \%$} & Preocupam-se com a carreira \\
\hline & & $\begin{array}{l}\text { Profissionais como advogados, médicos, cientistas, } \\
\text { professores universitários }\end{array}$ \\
\hline & & Gosta de tratar de idéias de arte e alta costura \\
\hline & & Procuram por uma vida doméstica agradável \\
\hline \multirow[t]{4}{*}{ Média - baixa } & \multirow[t]{4}{*}{$30 \%$} & Preocupam-se com a respeitabilidade \\
\hline & & $\begin{array}{l}\text { Possuem hábitos conscientes de trabalho e aderem a } \\
\text { normas e padrões culturais definidos }\end{array}$ \\
\hline & & O lar é importante: ter a casa arrumada e bonita \\
\hline & & $\begin{array}{l}\text { Representada em grande parte por "homens de } \\
\text { escritório", "funcionários" e "operários especializados" }\end{array}$ \\
\hline \multirow[t]{4}{*}{ Baixa - alta } & \multirow[t]{4}{*}{$35 \%$} & Levam uma existência de atividades permanentes \\
\hline & & $\begin{array}{l}\text { Homens trabalham em empregos manuais e mulheres em } \\
\text { casa }\end{array}$ \\
\hline & & Instrução escolar é apenas média \\
\hline & & $\begin{array}{l}\text { Ocasionalmente adquire artigo por impulso e compram a } \\
\text { mesma marca invariavelmente }\end{array}$ \\
\hline \multirow[t]{4}{*}{ Baixa - baixa } & \multirow[t]{4}{*}{$20 \%$} & Representa a camada mais baixa da sociedade \\
\hline & & $\begin{array}{l}\text { Pessoas desta classe são consideradas pelas outras classes } \\
\text { como moradores de favelas ou cortiços }\end{array}$ \\
\hline & & Tendem a ter instrução precária \\
\hline & & $\begin{array}{l}\text { Compram mais por impulso e é um grande mercado para } \\
\text { aparelhos de som e automóveis usados }\end{array}$ \\
\hline
\end{tabular}

Quadro 9-Classes Sociais

Fonte: Kotler, P. Administracão de Marketina. 1998

e. Variáveis Sociais: Segundo os autores Stoner e Freeman ${ }^{118}$, as variáveis sociais podem ser classificadas como: 
- Estilo de Vida: as mudanças no padrão de vida, como uniões instáveis, pessoas morando sozinhas, têm gerado um maior número de consumo, onde as pessoas procuram por produtos e serviços que lhes proporcionem maior conforto e tranqüilidade.

- Valores Sociais: os valores sociais são determinantes nas escolhas que as pessoas fazem na vida, sendo que um produto pode ter um determinado valor para uma pessoa e para outra não.

- Demografia: o fator crescente da população leva a observar que os padrões de consumo afetam o tamanho da oferta da mão-deobra e da localização no mercado de consumo.

As variáveis sociais podem ser observadas em situações onde as vontades pessoais ficam em segundo plano e a decisão de compra passa a ser influenciada por pressões do ambiente pessoal.

Kotler(1998) define dois grupos que podem influenciar neste tipo de situação: Quadro 10

\begin{tabular}{|l|l|}
\hline Grupos & Características \\
\hline \multirow{3}{*}{ Primários } & Existência de laços afetivos íntimos \\
\cline { 2 - 2 } & Comportamentos informais \\
\cline { 2 - 2 } & Família, amigos, vizinhos e colegas de trabalho \\
\hline & Relações mais formais e impessoais \\
\cline { 2 - 2 } & Grupo se dissolve a partir do momento que não for mais útil \\
\cline { 2 - 2 } & Associações fraternais e profissionais, organizações diversas \\
\hline
\end{tabular}


Define ainda que existam três maneiras de influência determinadas por estes grupos:

- Expondo a pessoa a comportamentos e estilos de vida alternativos;

- Influenciando as atitudes e o conceito próprio da pessoa, por causa de seus desejos de estar em sintonia com o grupo;

- Criando pressões para a submissão, que poderão afetar suas escolhas de produtos e marcas.

f. Variáveis Econômicas: o poder de compra está diretamente relacionado á variável econômica que, de certa maneira pode ser entendida como o instrumento regulador do mercado.

As mudanças ao impulso de compra das pessoas em relação ao consumo podem estar atreladas às variações do valor líquido das finanças individuais, ou seja, quando o balanço entre receita e gastos se encontra em um patamar que permita a pessoa refletir sobre um investimento esta passa a ter uma pré-disposição maior ao consumo.

Segundo Kotler(1998), os mercados não exigem apenas pessoas, mas também poder aquisitivo, os quais estão condicionados a quatro fatores: 
- Poupança

- Renda normal

- Preços

- Disponibilidade de financiamento

g. Variáveis Culturais: O fator comportamental, segundo Kotler e Armstrong(2003), é resultante do ambiente em que as pessoas nascem e crescem, e é esse ambiente que gera a formação de valores de uma determinada sociedade, a qual transmite para seus membros conceitos básicos, comportamentos e cultura que por sua vez influenciarão no comportamento enquanto consumidor.

Destacam-se ainda fatores relacionados ao ambiente de consumo, onde podem ser especuladas situações em que o conforto e o contexto agradável do ambiente podem influenciar na decisão de compra; os veículos de comunicação, mídias, estratégias direcionadas e todos os elementos externos que possam ser utilizados pelas organizações para obter um efeito significativo no comportamento da compra; e ainda formas de comportamento influenciadas por grupos dos quais não fazem parte, como identificação com personalidades esportivas, artistas e quaisquer outras que venham a direcionar de alguma maneira o comportamento do indivíduo.

Após elencadas as variantes que os autores destacam como sendo as principais fontes de influência no poder e decisão de compra, deve-se entender quais as etapas pelas quais o consumidor geralmente percorre no processo decisório. 
Blackwell(2000) destaca cinco estágios pelos quais os consumidores passam quando estão executando uma operação de compra:

- Reconhecimento do problema: é quando o consumidor percebe que existe uma necessidade a ser suprida;

- Busca de informações: é a procura por dados sobre o produto ou serviço, recorrendo a fontes diversas;

- Avaliação de alternativas: é o estágio que vai buscar informações e esclarecer problemas aos consumidores, onde sugerem critérios para orientar a compra, marcas que atendam os critérios estabelecidos e desenvolve as percepções de valor;

- Decisão de compra: neste momento o consumidor já tem definido o produto ou serviço que lhe atenderá aos critérios estabelecidos, devendo apenas considerar três aspectos - de quem comprar, como comprar e como pagar.

- Comportamento pós-compra, uso: é a satisfação, ou não, do usuário quando compara o desempenho do produto ou serviço em relação às expectativas e critérios pré-estabelecidos.

Embora essas etapas sejam descritas e estudadas, Blackwell(2000) coloca que, em uma situação de compra por impulso, alguns consumidores não percorrem todo o processo, pulando etapas e indo diretamente à ação de compra. 
Finalmente, uma última abordagem sobre características e comportamentos do consumidor está nos três papéis do cliente:

- Usuário: pessoa que consome ou utiliza o produto | serviço

- Comprador: é aquele que escolhe o produto | serviço no mercado

- Pagante: é a pessoa que financia a compra

Esses papéis podem ser desempenhados pela mesma pessoa ou por pessoas diferentes, dependendo da situação que envolve o processo.

Nesse sentido vale a colocação de Sheth, Mittal e Newman ${ }^{119}$ sobre o valor de mercado:

$$
\begin{aligned}
& \text { "valor de mercado é o potencial que um } \\
& \text { produto ou serviço tem de satisfazer às } \\
& \text { necessidades e aos desejos dos clientes". }
\end{aligned}
$$

Quando se diz que o produto deve satisfazer as necessidades do cliente, e, como colocado anteriormente, cada cliente tem uma necessidade diferente, fica evidenciado que um mesmo produto pode ser indexado com valores diferentes para cada pessoa.

Os autores classificam os valores de mercado em dois subitens: 
- Valores Universais: são aqueles que atendem as necessidades dos clientes

- Valores Pessoais: são aqueles que atendem os desejos dos clientes

Portanto, para cada um dos papéis desempenhados pelos consumidores existem as variantes quanto aos valores universais e pessoais e estes ainda subdivididos em valores específicos de grupos e valores específicos de indivíduos, conforme o quadro abaixo: Quadro 11

\begin{tabular}{|c|c|c|c|}
\hline & \multicolumn{3}{|l|}{ Papéis do Cliente } \\
\hline & Usuário & Pagante & Comprador \\
\hline Valores Universais & Desempenho & Preço & Serviço \\
\hline \multicolumn{4}{|l|}{ Valores pessoais } \\
\hline Específicos de Grupos & Valor Social & Valor de Cálculo & Valor de Conveniência \\
\hline Específicos de Indivíduos & Valor Emocional & Valor de Financiamento & Valor de Personalização \\
\hline
\end{tabular}

Pode-se assim perceber que as empresas, qualquer que seja o setor de atuação, têm a necessidade de conhecer profundamente o público para quem seus produtos estarão sendo oferecidos; e não haveria de ser diferente no setor imobiliário onde os imóveis são tratados como produtos e disponibilizados para a comercialização no mercado.

Os agentes da área de marketing imobiliário buscam oferecer aos consumidores produtos que satisfaçam suas necessidades e desejos, orientando cada produto a um público pré-determinado, consolidando as questões acima abordadas. 
As tipologias das unidades habitacionais variam de um a quatro dormitórios, e, excepcionalmente alguns empreendimentos possuem um número maior de dormitórios, sendo cada uma dessas tipologias direcionadas ao seu nicho de mercado, o que vale dizer que todo o processo envolvido na comercialização do produto está voltado ao atendimento deste usuário, desde a proposta do partido arquitetônico, o espaço Show Room até o panfleto publicitário e formas de financiamento.

Todo esse tratamento comercial, proporcionando um ambiente agradável, espaços com apartamentos decorados, maquetes dos edifícios, projetos apresentados em papéis grandiosos e toda uma gama de artefatos produzidos com a única intenção de gerar o impulso e confirmar o ato da compra pelo consumidor.

Tendo em vista estas premissas, de que os produtos devem estar alinhados às necessidades dos consumidores, podese então, de maneira precária e até intuitiva, concluir que os ambientes apresentados nos prospectos promocionais estejam, de alguma forma, atendendo a necessidades ou desejos do público a que se destinam.

Portanto, a existência dos ambientes destinados às atividades de escritório nos projetos, pelo menos a título de ser um componente que visa contribuir com o processo decisório de compra, vem demonstrar que essa necessidade é premente para um determinado grupo de indivíduos que atribui a esse ambiente um valor, quer seja universal ou individual, que the atenda a essas necessidades, podendo-se aí validar e justificar a intenção e a importância da pesquisa ora apresentada. 


\subsection{Desenvolvimento da Pesquisa}

Conforme apresentado no Capítulo 2 - Metodologia, item 2.2.2.1, o desenvolvimento do Levantamento das Informações de Campo, Parte A - Inclusão de Home Offices em Lançamentos Imobiliários, foi desenvolvido de acordo com a seqüência abaixo:

a. Objeto de Estudo: ambientes inseridos nas unidades habitacionais dos lançamentos imobiliários que são destinados às atividades de escritório;

b. Recortes da Pesquisa:

i. Recorte Geográfico - Município de São Paulo;

ii. Recorte Temporal: - Lançamentos Imobiliários residenciais entre 2006 e 2009 ;

c. Definição Estatística: 362 casos;

d. Determinação da Amostragem: 400 casos;

e. Levantamento de Dados de Campo: coleta de material e informações;

f. Processamento dos dados Pesquisados

g. Análise e Diagnóstico das Informações Levantadas 


\subsection{Processamento dos Dados Pesquisados}

Os dados levantados foram organizados em fichas e, posteriormente compilados no programa EXCEL ${ }^{\circledR}$ da Microsoft, cuja planilha completa é apresentada a seguir e, posteriormente, apresentam-se os gráficos elaborados a partir desta planilha. 
A seguir são listados os empreendimentos e as plantas, separados por tipologia da habitação.

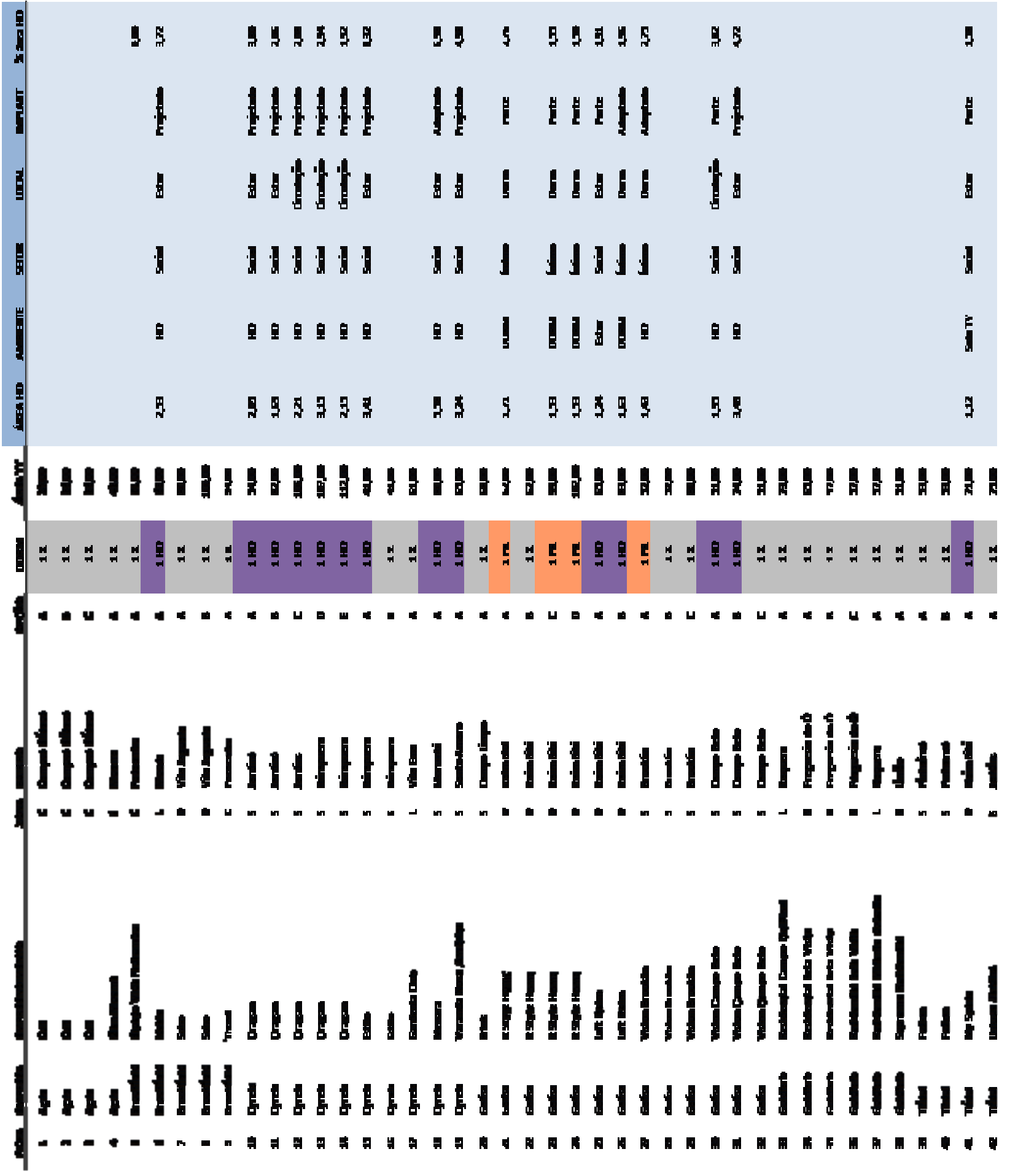




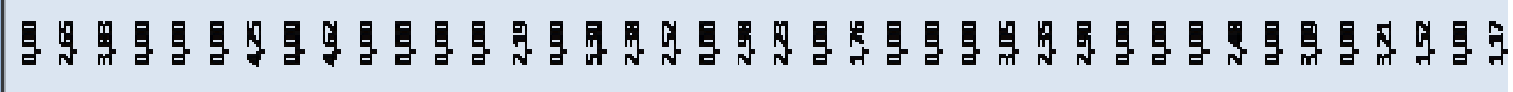

18

1 HI 11

ह

I I I I

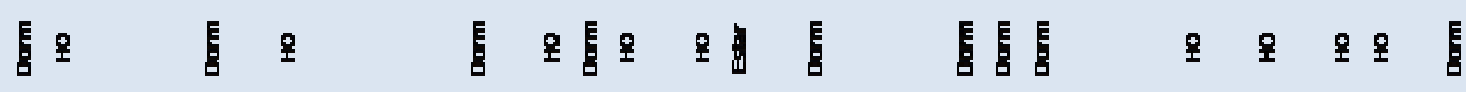

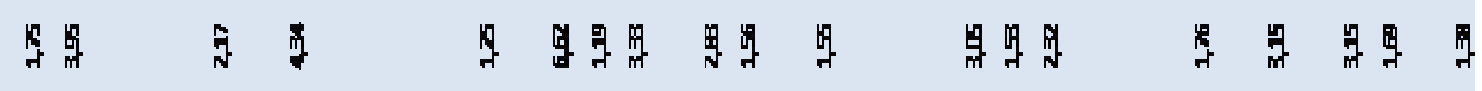

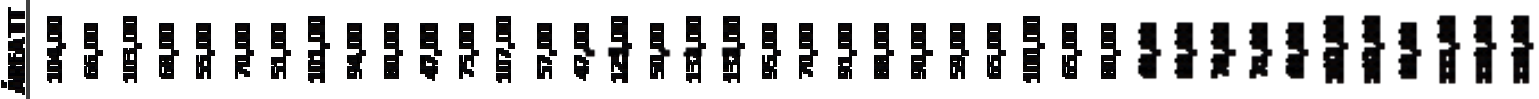

1

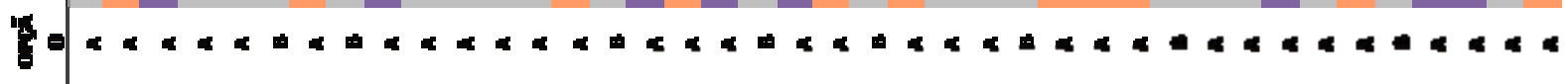

wothilmulnullunthint

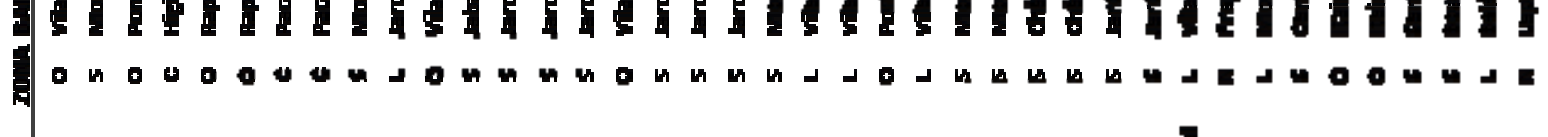

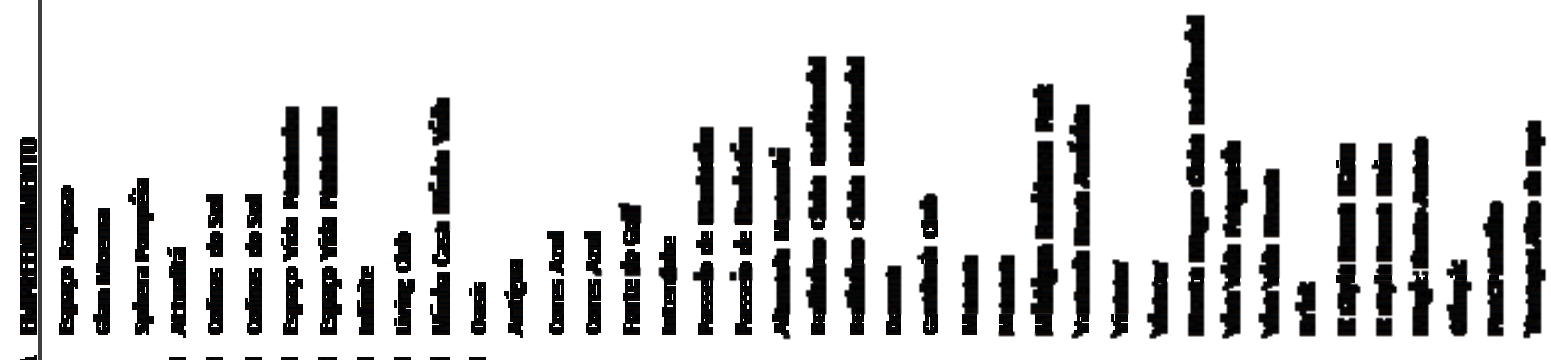

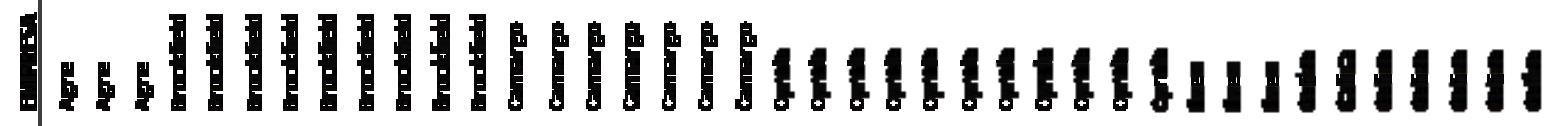

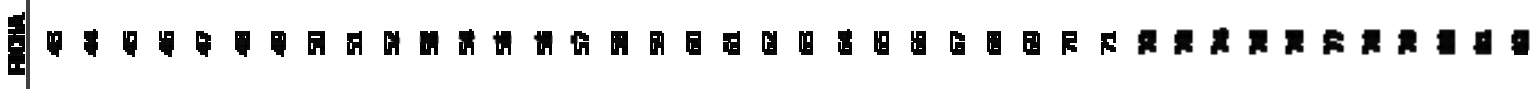




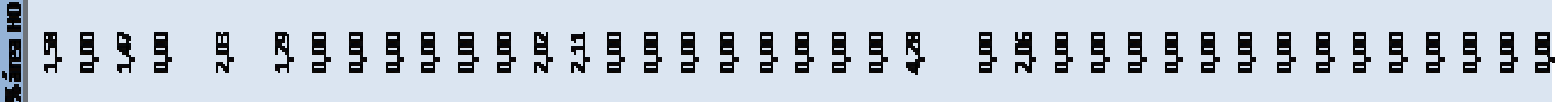

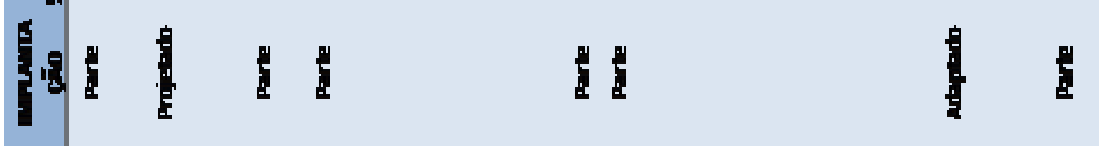

茴

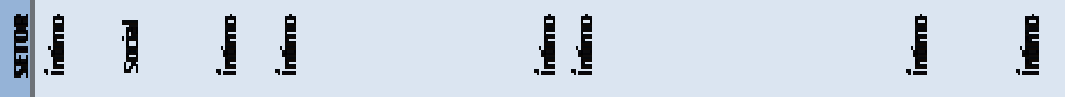

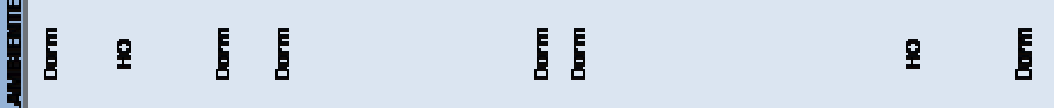

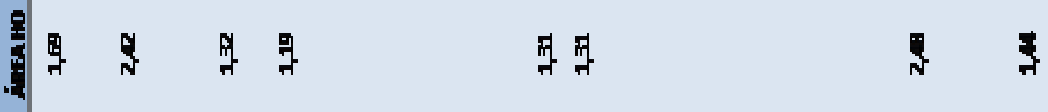

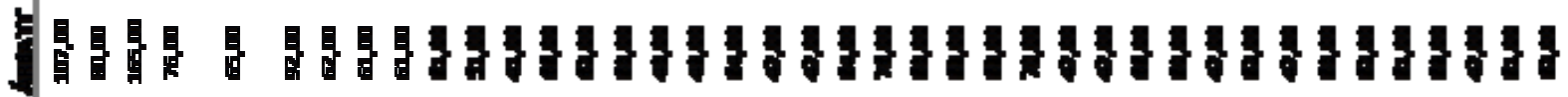

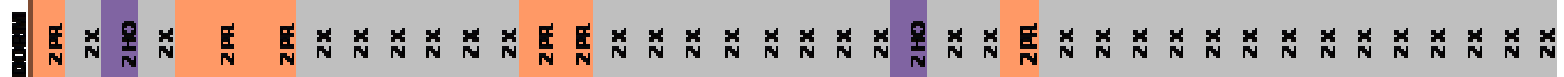

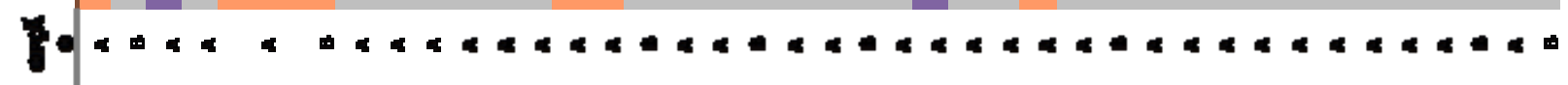

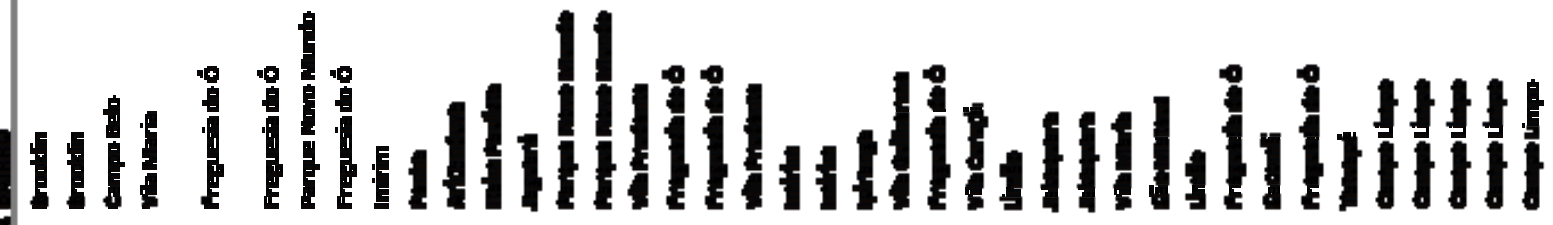
(...................................

แHแ

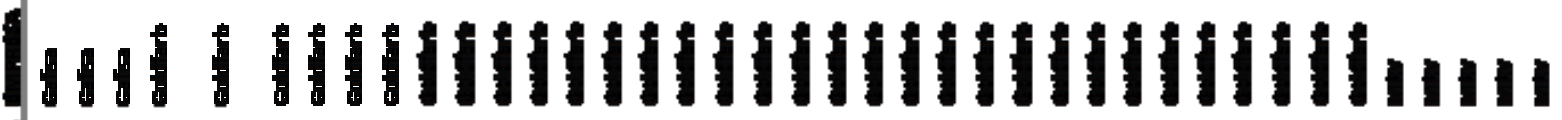

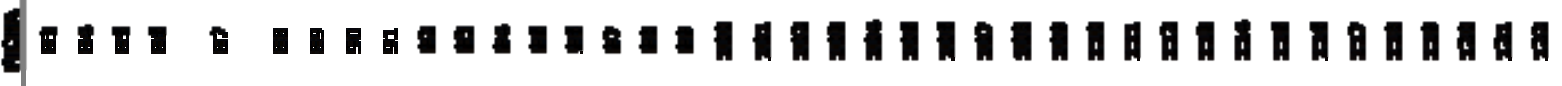




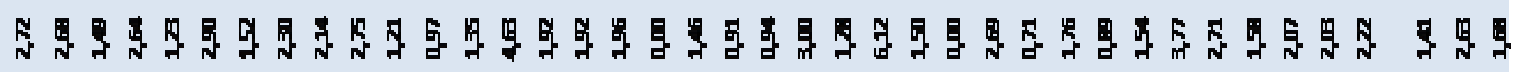

5.

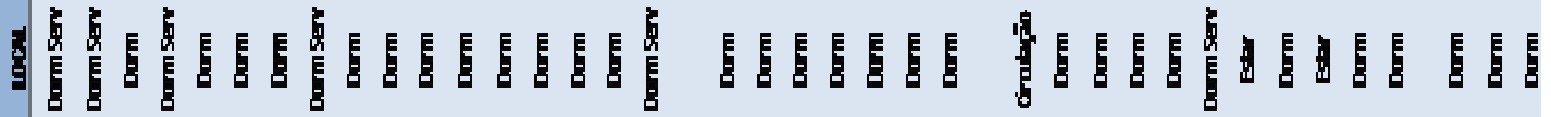

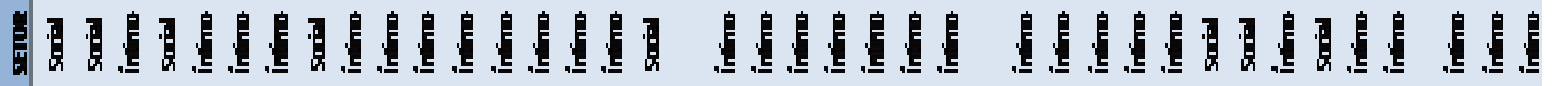
|29 \&

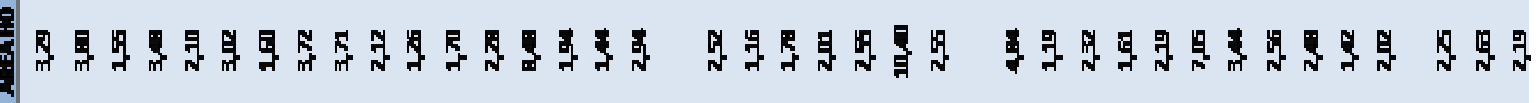

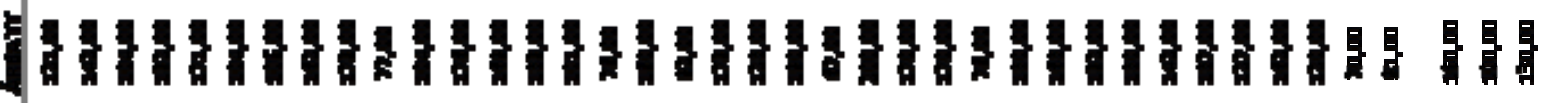

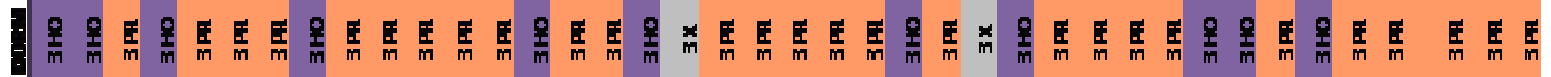

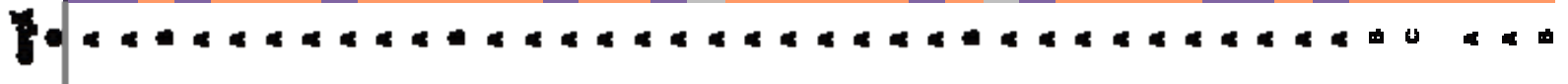

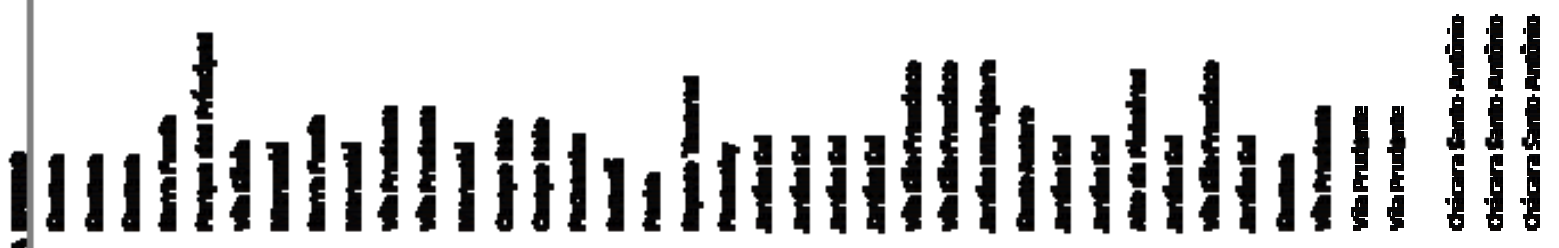
[...................................

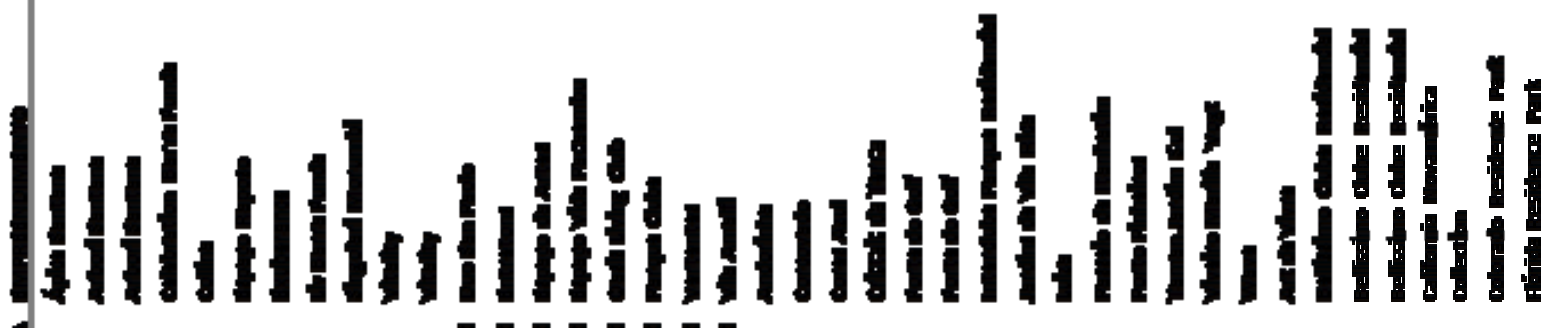
Lиm

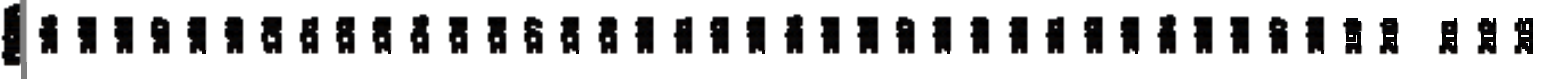




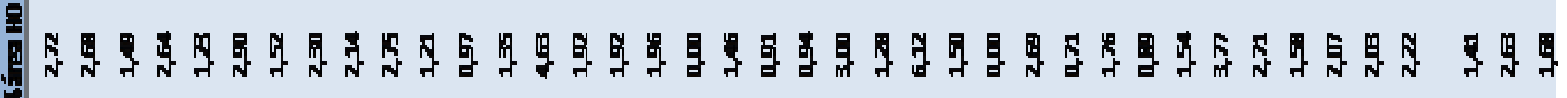
|8

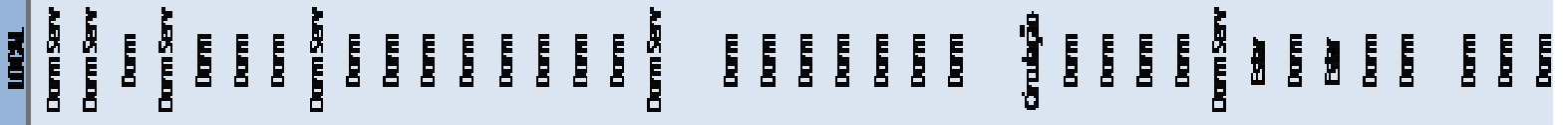
Q

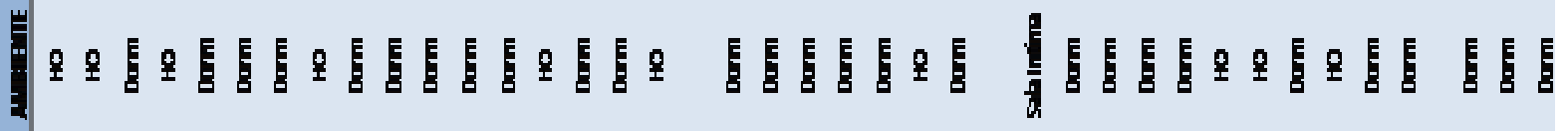

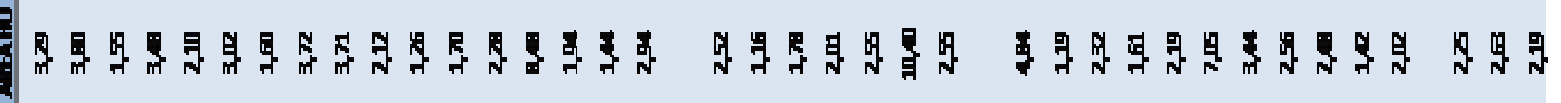

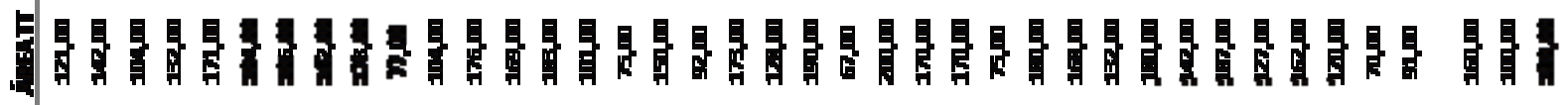

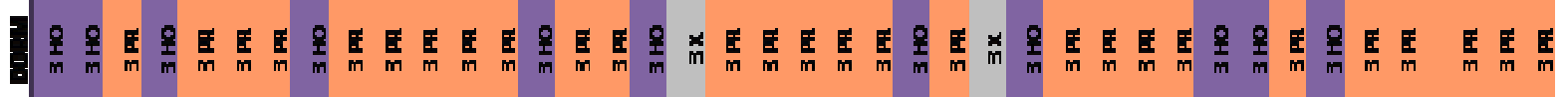

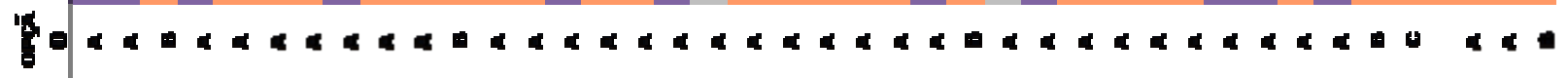

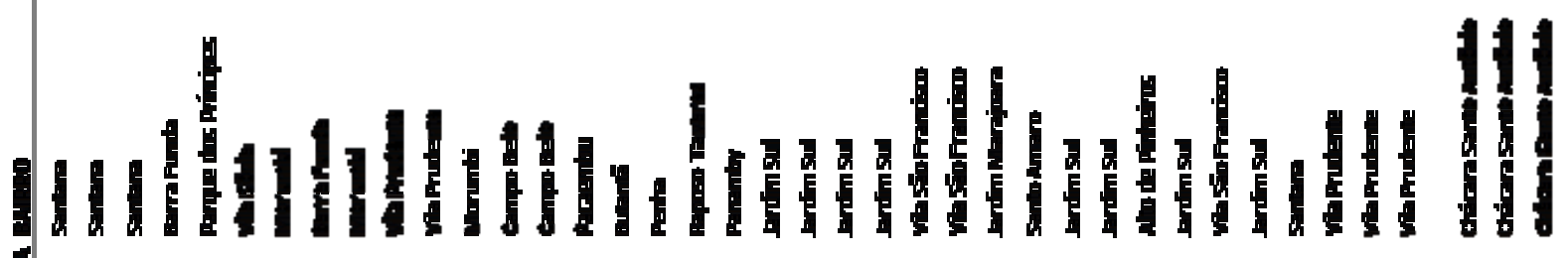
(1...0..................................

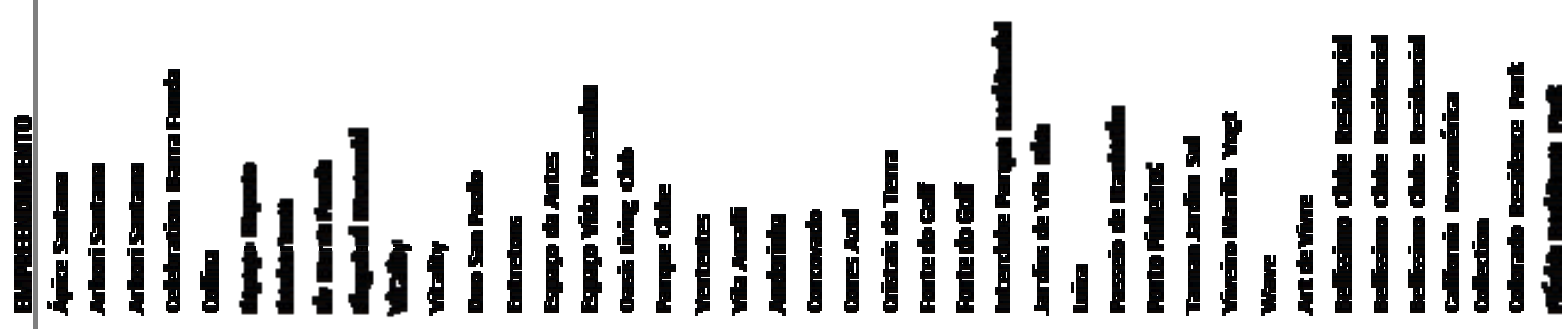

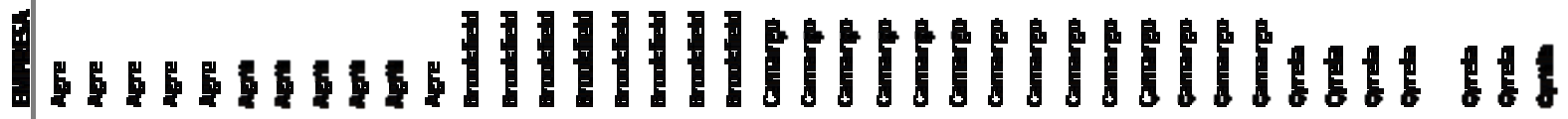

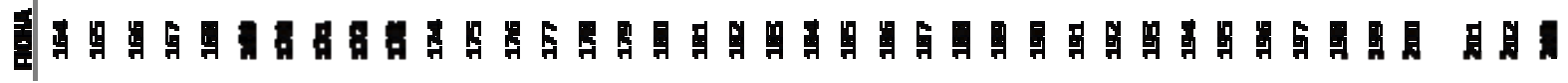




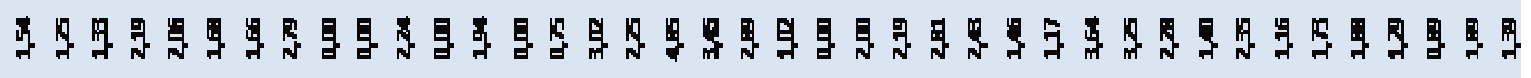

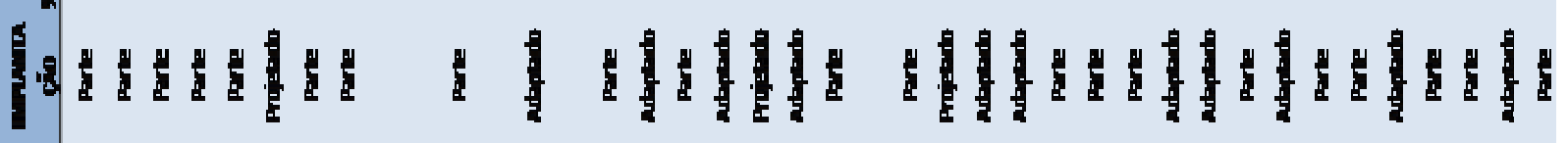

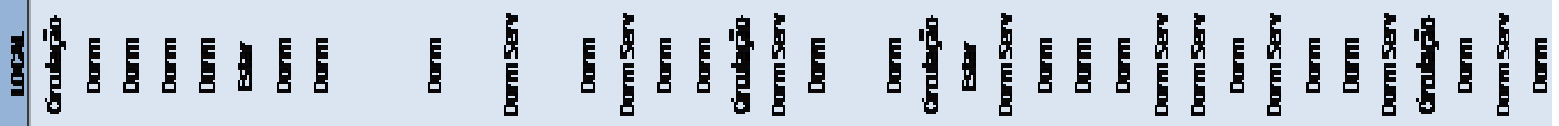

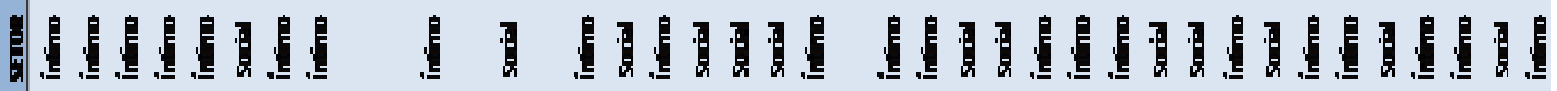

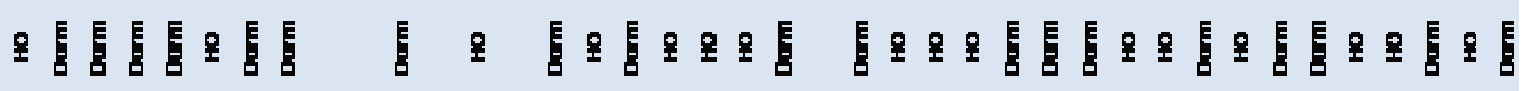

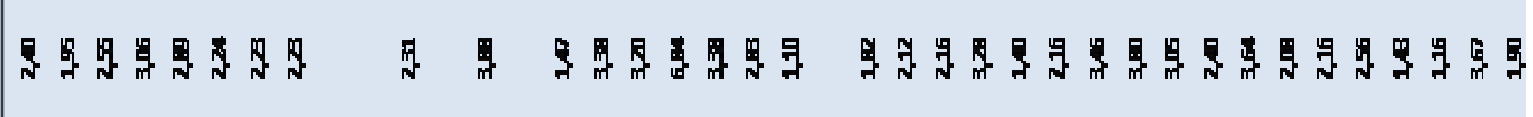

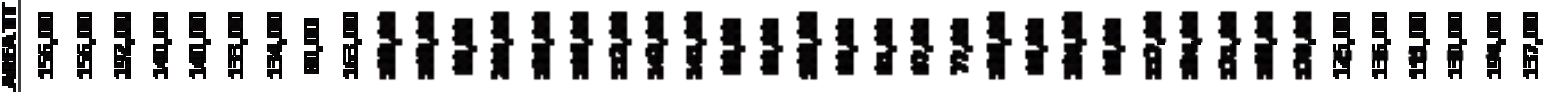

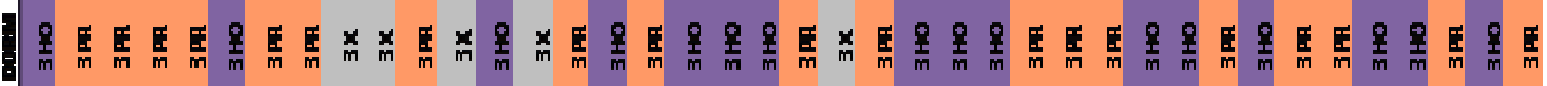

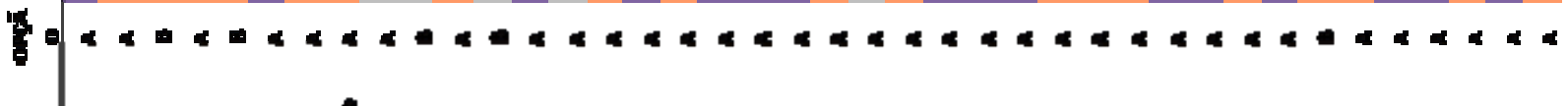

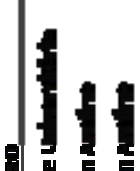

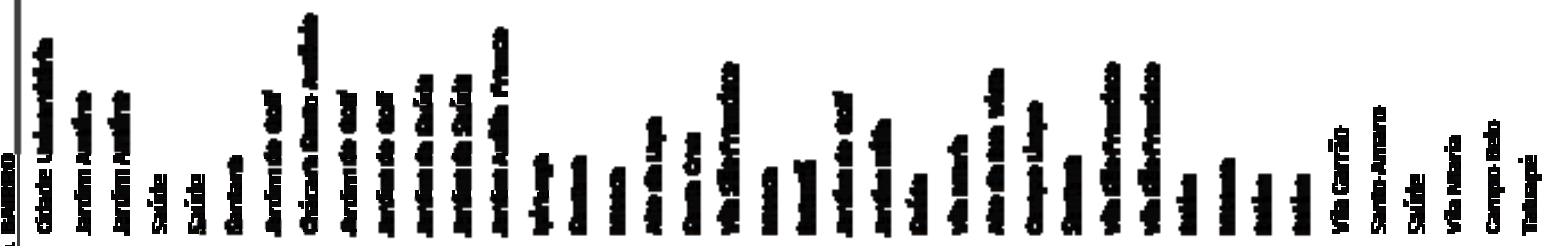

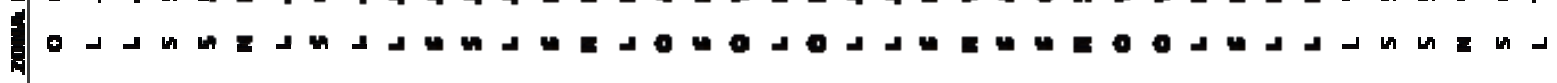

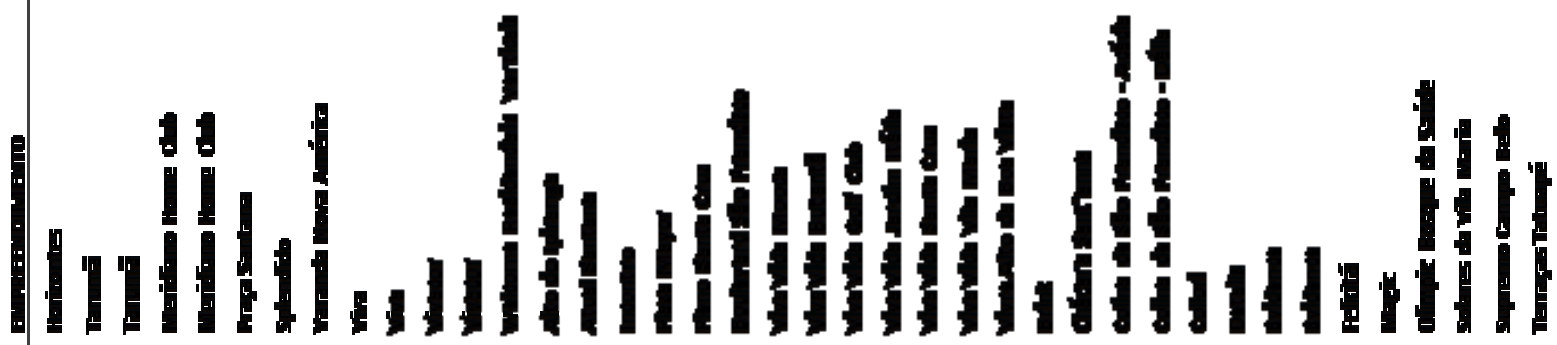

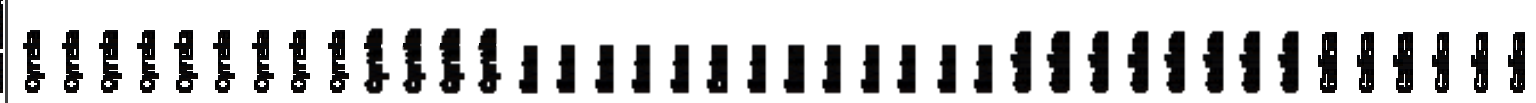

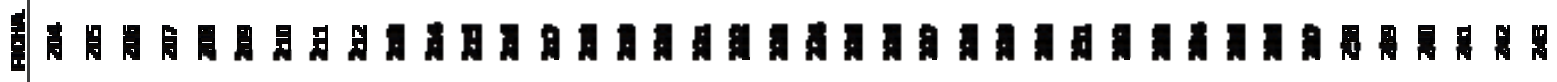




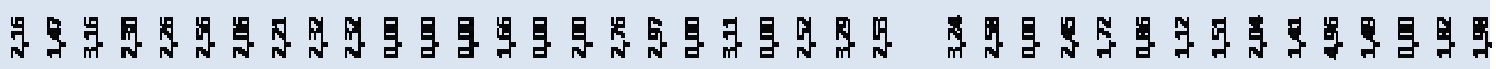

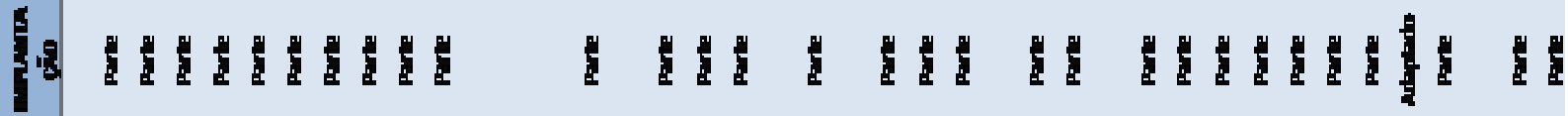
है

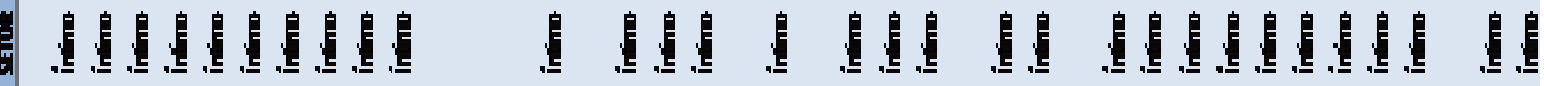

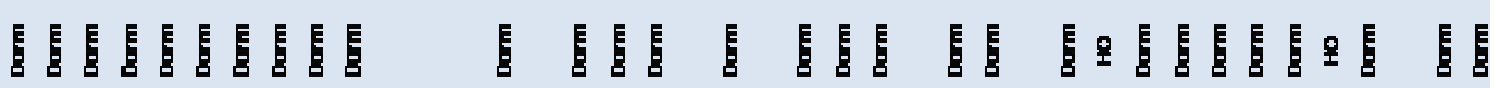

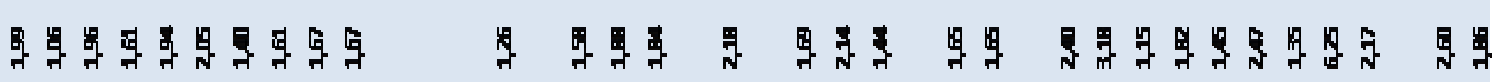

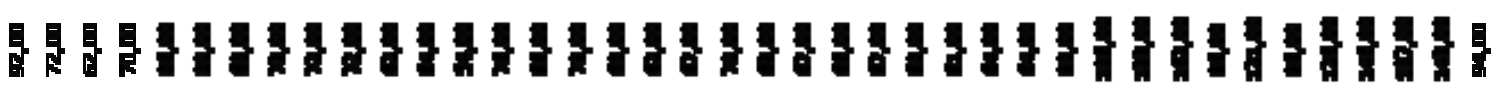

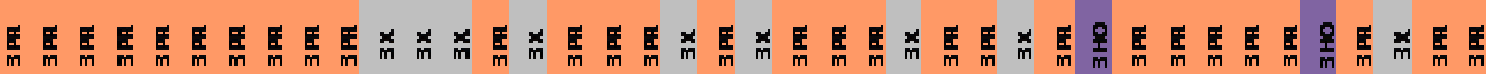

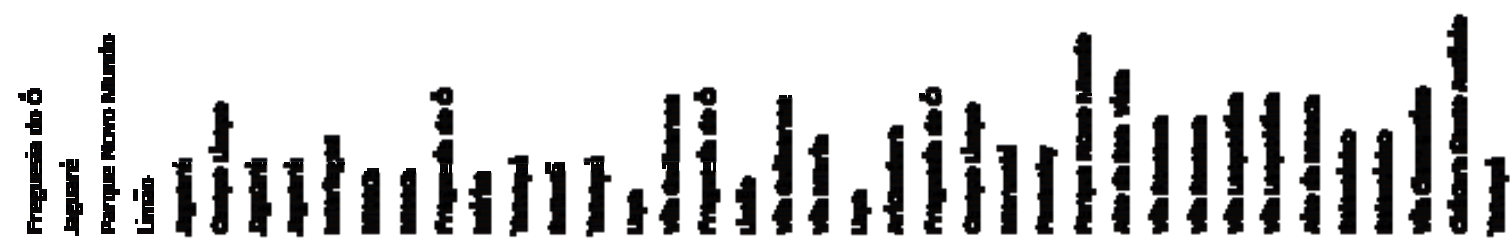

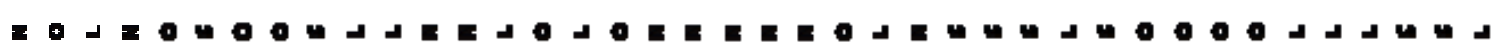

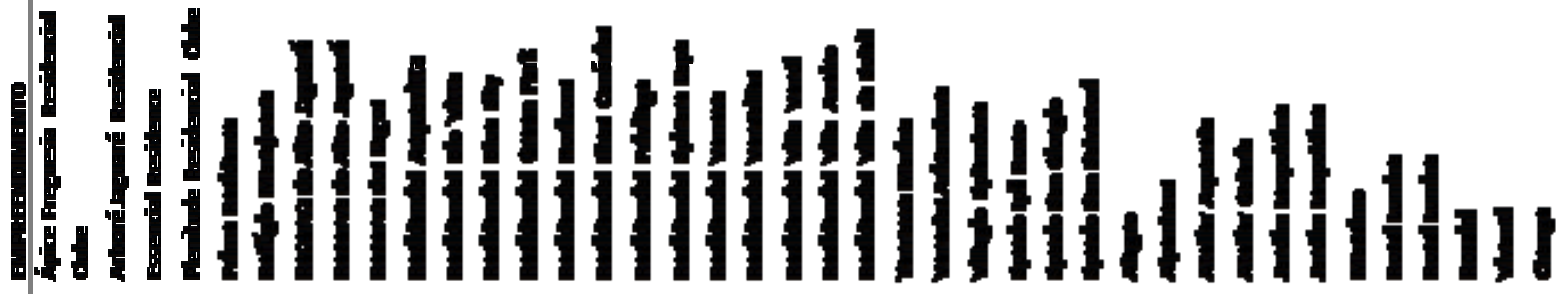

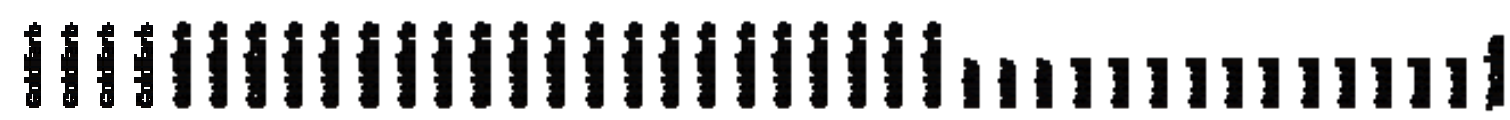
* \% 


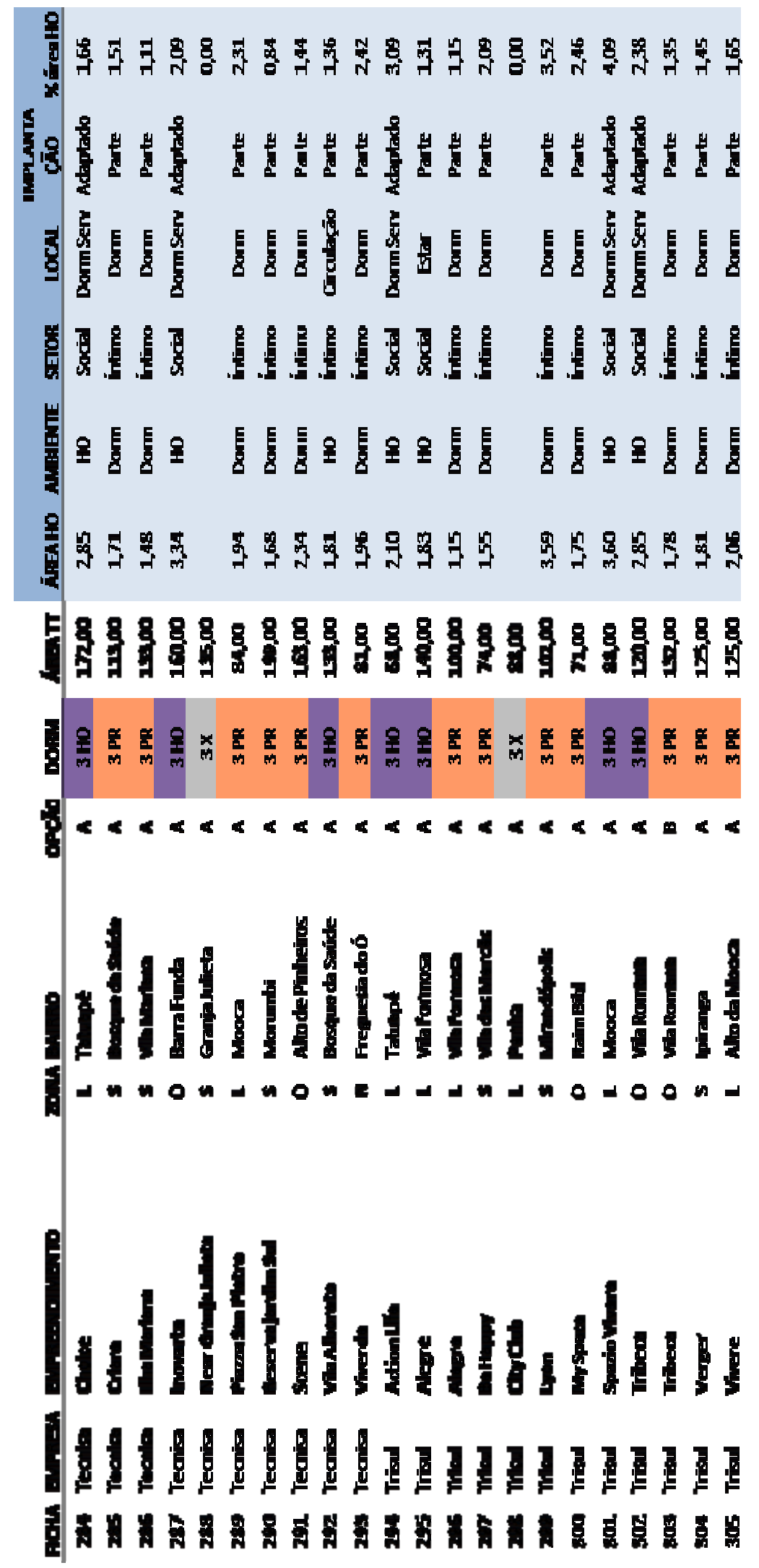




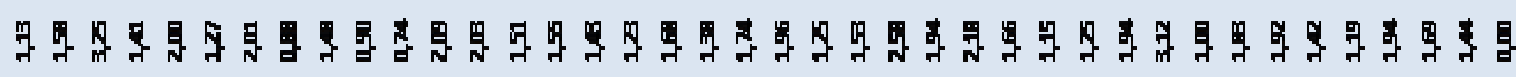

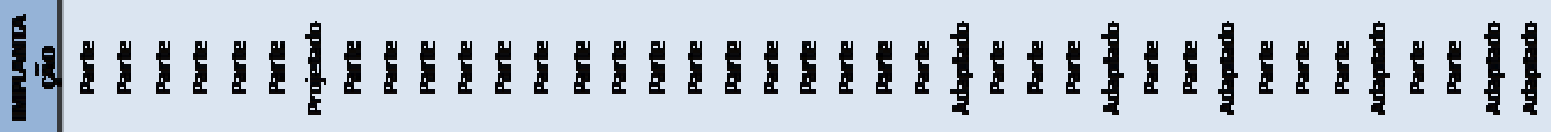

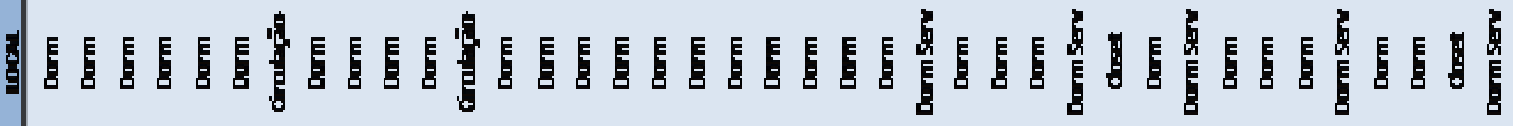

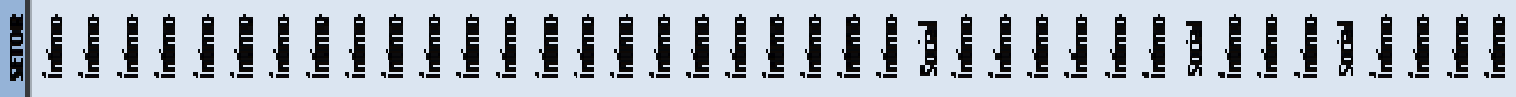

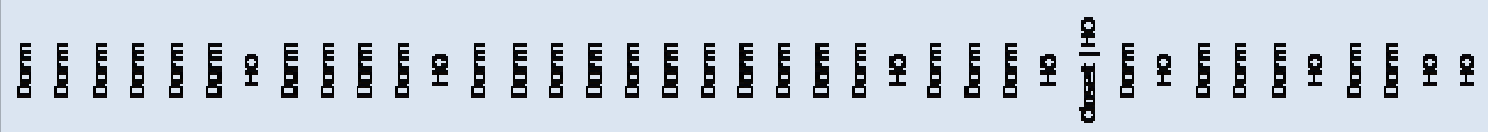

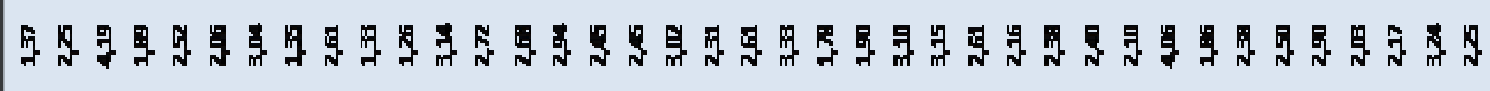

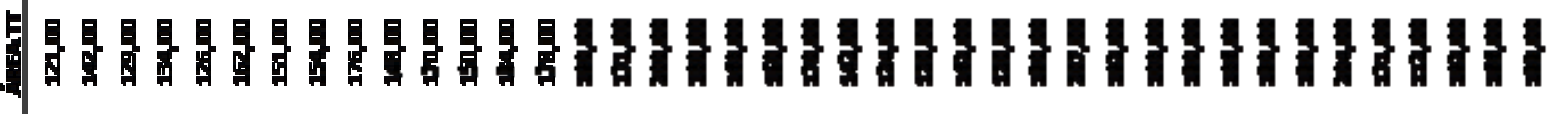

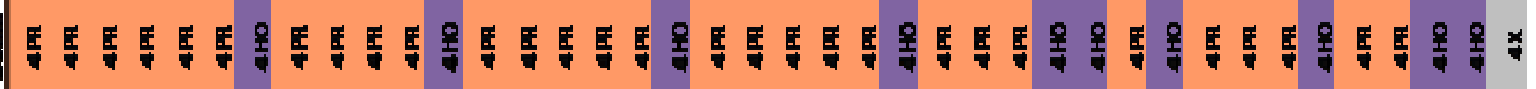
.

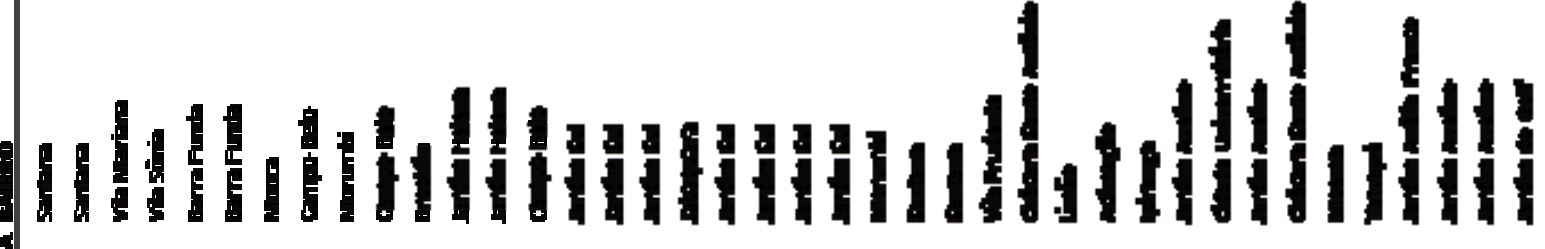
E E

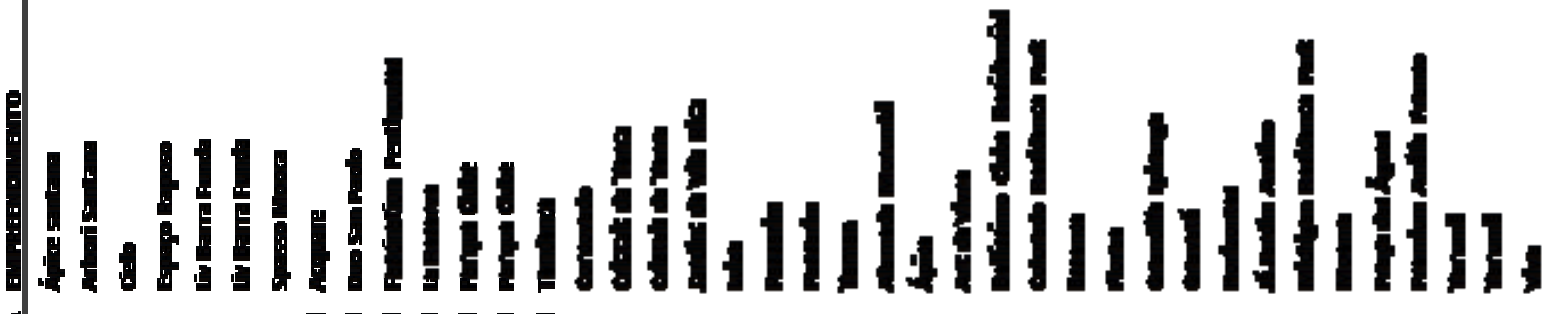

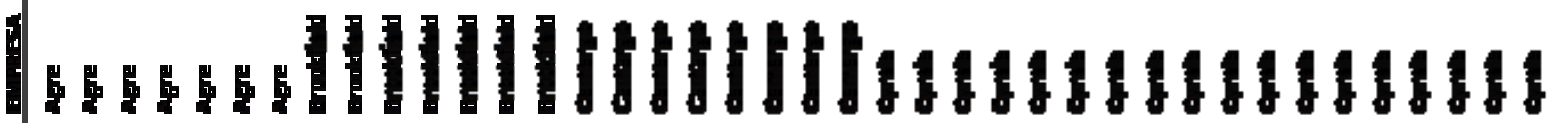

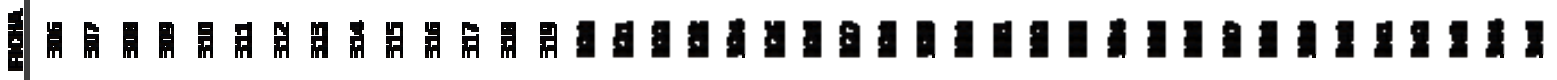




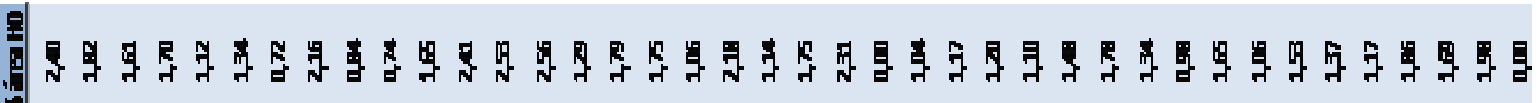

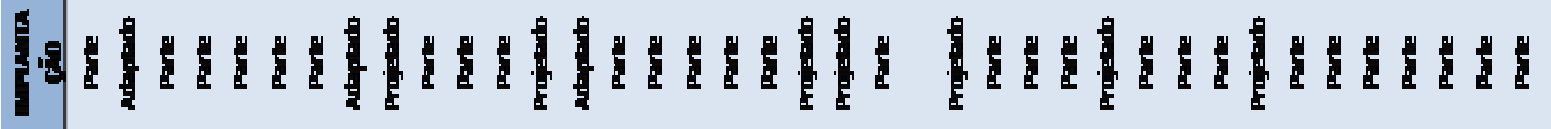

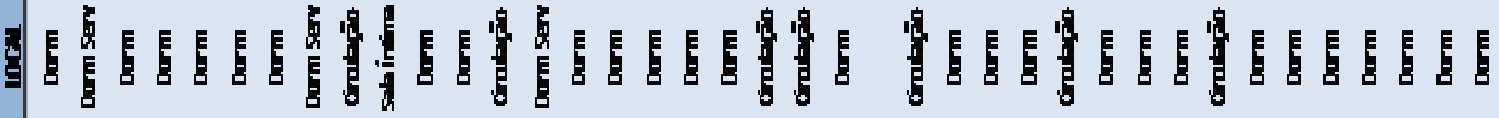

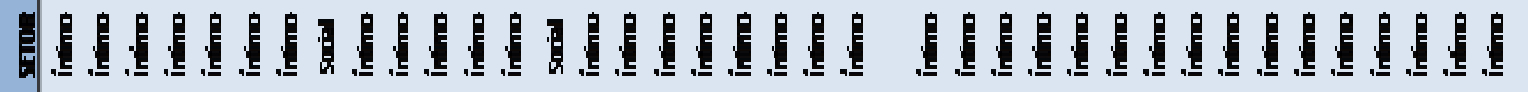
亭 9

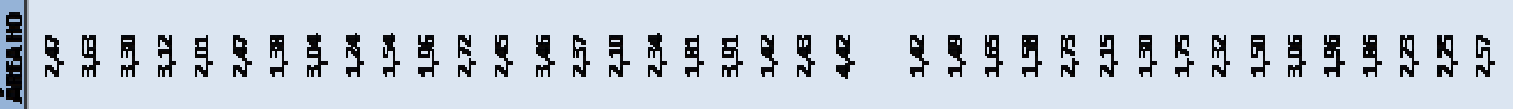

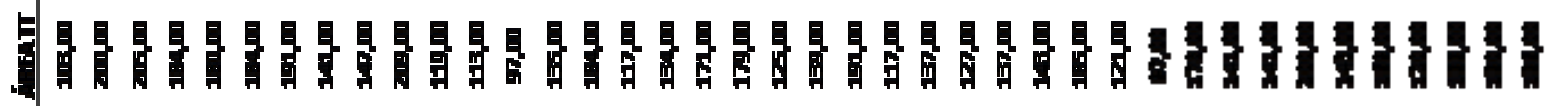

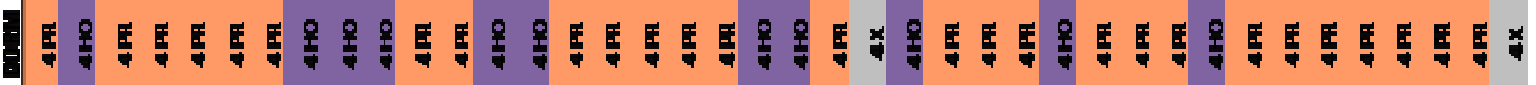
bo.

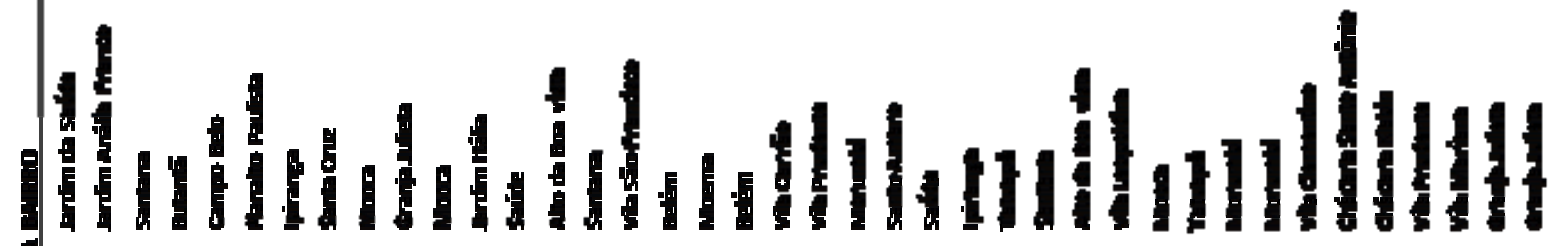

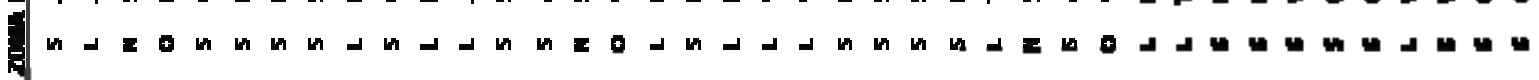

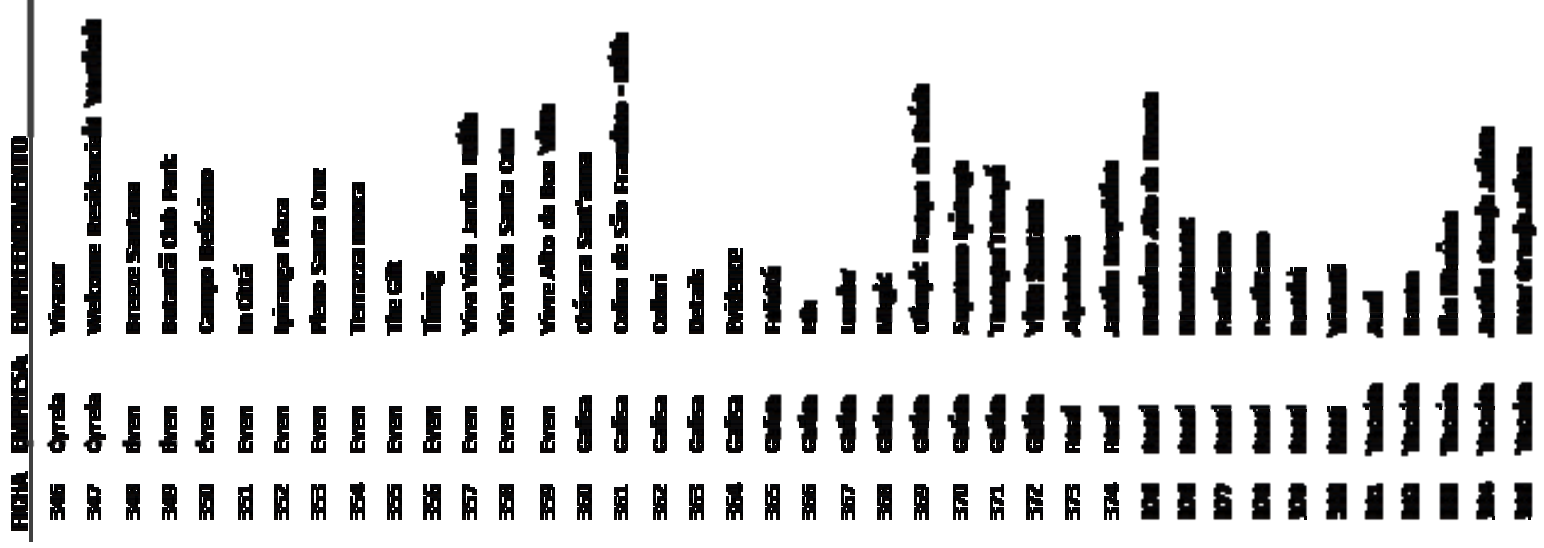




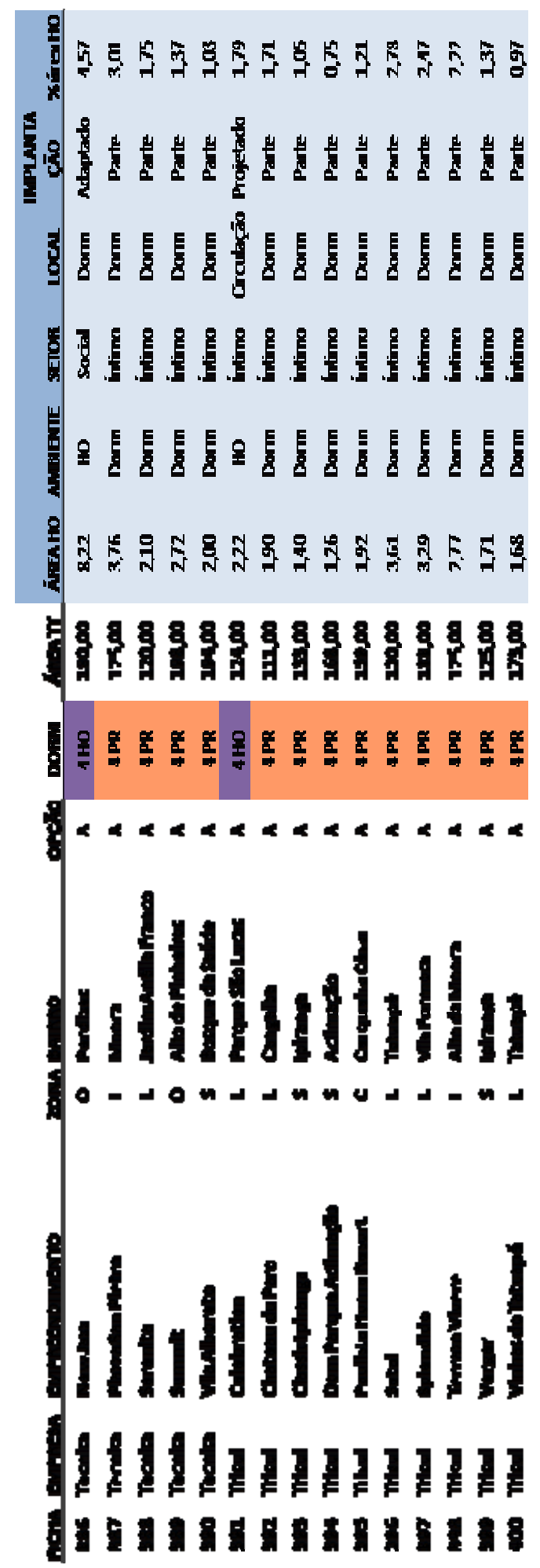


Os empreendimentos residenciais lançados no período de 2006 a 2009 pesquisados são apresentados pelas construtoras em cinco zonas do município, as quais divergem da nomenclatura usada pela Secretaria Municipal de Planejamento Urbano da Cidade de São Paulo. Figura 16

Portanto, segue a tabela de compatibilização entre a nomenclatura oficial da Prefeitura Municipal de São Paulo e aquela usada nas fichas desta tese: Quadro 12

\begin{tabular}{|c|c|c|}
\hline $\begin{array}{l}\text { Nomenclatura } \\
\text { Construtoras }\end{array}$ & Nomenclatura SEMPLA & \\
\hline Zona NORTE & $\begin{array}{l}\text { Zona NOROESTE } \\
\text { Zona NORDESTE }\end{array}$ & \\
\hline Zona SUL & $\begin{array}{l}\text { Zona SUL } \\
\text { Zona CENTRO SUL } \\
\text { Subprefeitura IPIRANGA }\end{array}$ & \\
\hline Zona LESTE & $\begin{array}{l}\text { Zona SUDESTE (exceto } \\
\text { Ipiranga) } \\
\text { Zona LESTE } 1 \\
\text { Zona LESTE } 2\end{array}$ & Sub \\
\hline Zona OESTE & Zona OESTE & \\
\hline Zona CENTRO & Zona CENTRO & \\
\hline
\end{tabular}

Quadro 12 - Compatibilização de Zonas da Cidade de São Paulo Elaborado pelo Autor 


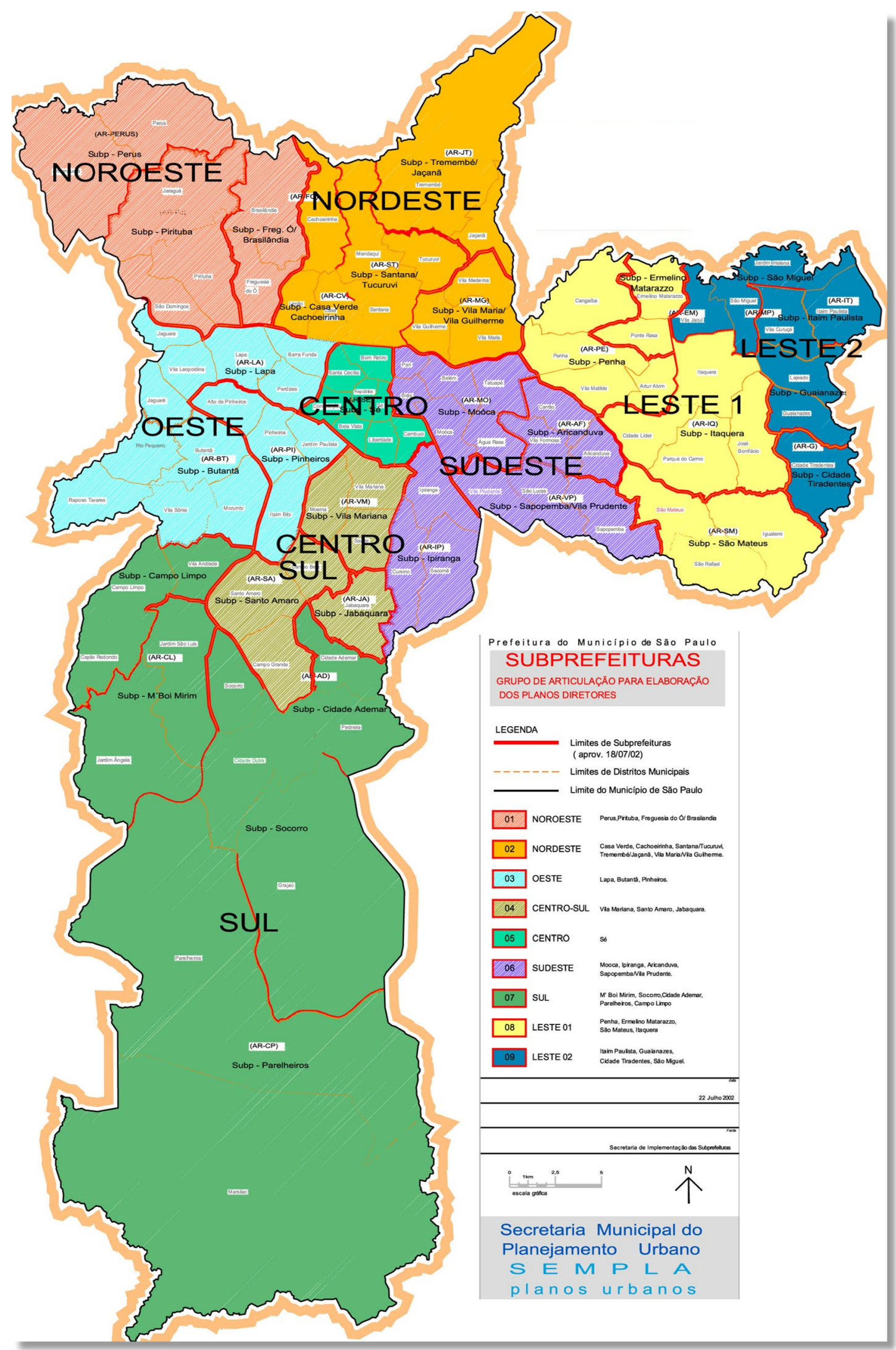




\begin{tabular}{|c|c|c|c|c|c|c|c|c|c|c|c|c|c|c|}
\hline CENTRO & $\pi$ & $\%$ & NORTE | Noroeste & $\pi$ & $\%$ & SUL | Sudeste & $\pi$ & 96 & LESTE & $\pi$ & $\%$ & OESTE & $\pi$ & $\%$ \\
\hline Campos Elíseos & 1 & 0,496 & Freguesia do ó & 9 & $3,6 \%$ & Aclimaçã̃o & 2 & $0,8 \%$ & Alto da Mooca & 3 & 1,296 & Alto da Lapa & 1 & 0,49 \\
\hline Cerqueira César & 1 & 0,496 & imirim & 2 & $0,8 \%$ & Alto da Boa Vista & 2 & $0,8 \%$ & Aricanduva & 4 & $1,6 \%$ & Alto de Pinheiros & 3 & 1,29 \\
\hline Higienópolis & 1 & 0,496 & Limão & 4 & $1,6 \%$ & Bosque da Saúde & 3 & $1,2 \%$ & Belém & 3 & 1,296 & Barra Funda & 3 & $1,2 \%$ \\
\hline \multirow[t]{29}{*}{ Pacaembu } & 2 & $0,8 \%$ & santana & 9 & $3,6 \%$ & Brooklin & 2 & $0,8 \%$ & Belenzinho & 1 & $0,4 \%$ & Butantã & 4 & $1,6 \%$ \\
\hline & & & Vila Guilherme & 2 & $0,8 \%$ & Campo Belo & 8 & $3,2 \%$ & Cangaiba & 2 & $0,8 \%$ & Cidade Universitári: & 1 & 0,49 \\
\hline & & & vila Maria & 2 & $0,8 \%$ & Campo Limpo & 5 & $2,0 \% 6$ & Itaim Paulista & 1 & 0,496 & Itaim Bibi & 4 & $1,6 \%$ \\
\hline & & & & & & Chácara Klabin & 1 & 0,496 & Itaquera & 3 & 1,296 & Jaguaré & 4 & $1,6 \%$ \\
\hline & & & & & & Chácara Santo Antô & 6 & 2,496 & Jardim Anália Franc & 3 & 1,296 & Lapa & 3 & 1,29 \\
\hline & & & & & & Cursino & 1 & $0,4 \%$ & Jardim Avelino & 3 & 1,296 & Parque dos Principe & 1 & 0,49 \\
\hline & & & & & & Granja Juileta & 3 & $1,2 \%$ & Jardim do Golf & 4 & $1,6 \%$ & Perdizes & 2 & 0,88 \\
\hline & & & & & & Guarapiranga & 1 & 0,496 & Jardim Helena & 1 & 0,496 & Pinheiros & 1 & 0,48 \\
\hline & & & & & & Ibirapuera & 2 & $0,8 \%$ & Jardim Itália & 1 & $0,4 \%$ & Pompéia & 2 & $0,8 \%$ \\
\hline & & & & & & Interlagos & 1 & 0,495 & Mooca & 11 & $4,3 \%$ & Raposo Tavares & 4 & $1,6 \%$ \\
\hline & & & & & & Ipiranga & 9 & $3,6 \%$ & Parque Novo Munde & 3 & 1,296 & Vila Jaguara & 2 & $0,8 \%$ \\
\hline & & & & & & Jabaquara & 3 & $1,2 \%$ & Parque São Lucas & 2 & $0,8 \%$ & Vila Leopoldina & 1 & 0,45 \\
\hline & & & & & & Jardim da Saúde & 2 & $0,8 \%$ & Penha & 3 & 1,296 & Vila Romana & 3 & 1,29 \\
\hline & & & & & & Jardim Marajoara & 2 & $0,8 \%$ & São Mateus & 1 & 0,496 & Vila São Francisco & 5 & 2,09 \\
\hline & & & & & & Jardim Sul & 11 & $4,3 \%$ & Sapopemba & 1 & 0,496 & Vila Sonia & 1 & 0,49 \\
\hline & & & & & & Jardins & 1 & 0,496 & Tatuapé & 12 & $4,7 \%$ & & & \\
\hline & & & & & & Mirandópolis & 1 & $0,4 \%$ & Vila Carrão & 1 & $0,4 \%$ & & & \\
\hline & & & & & & Moema & 3 & $1,2 \%$ & Vila Curuçá & 2 & $0,8 \%$ & & & \\
\hline & & & & & & Morumbi & 11 & $4,3 \%$ & Vila Ema & 1 & $0,4 \%$ & & & \\
\hline & & & & & & Panamby & 3 & $1,2 \%$ & Vila Formosa & 3 & $1,2 \%$ & & & \\
\hline & & & & & & Planalto Paulista & 1 & 0,496 & Vila Prudente & 7 & $2,8 \% 6$ & & & \\
\hline & & & & & & Sacomâ & 2 & $0,8 \%$ & & & & & & \\
\hline & & & & & & Santa Cruz & 1 & 0,496 & & & & & & \\
\hline & & & & & & Santo Amaro & 4 & $1,6 \%$ & & & & & & \\
\hline & & & & & & Saúde & 3 & 1,296 & & & & & & \\
\hline & & & & & & Vila Clementino & 1 & 0,496 & & & & & & \\
\hline & & & & & & Vila das Mercês & 1 & $0,4 \%$ & & & & & & \\
\hline & & & & & & Vila Mariana & 2 & $0,8 \%$ & & & & & & \\
\hline & & & & & & Vila Mascote & 1 & 0,496 & & & & & & \\
\hline
\end{tabular}

e São Paulo

Porcentagem de Empreendimendos Residenciais Lançados por Zona do Município de São Paulo

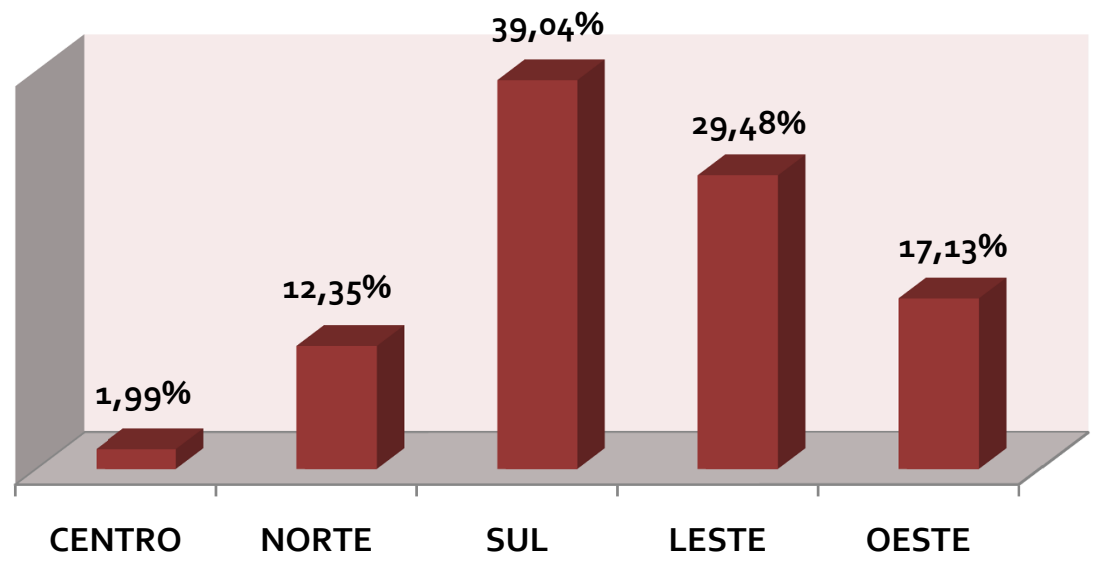

slo autor 
Porcentagem de Plantas Analisadas por

Tipologia da Habitação

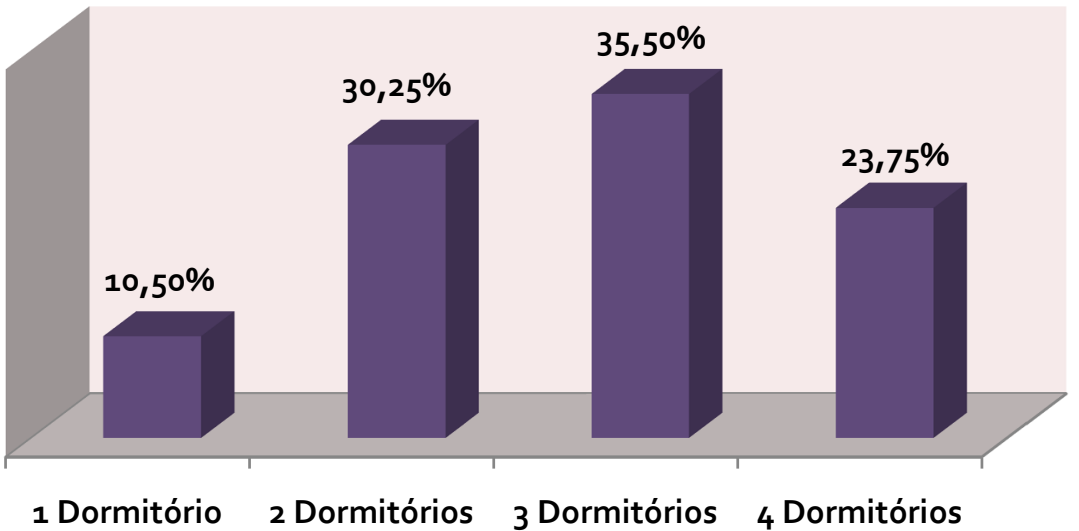

pelo autor

Área Média das Plantas Cadastradas por

Tipologia da Habitação (m2)

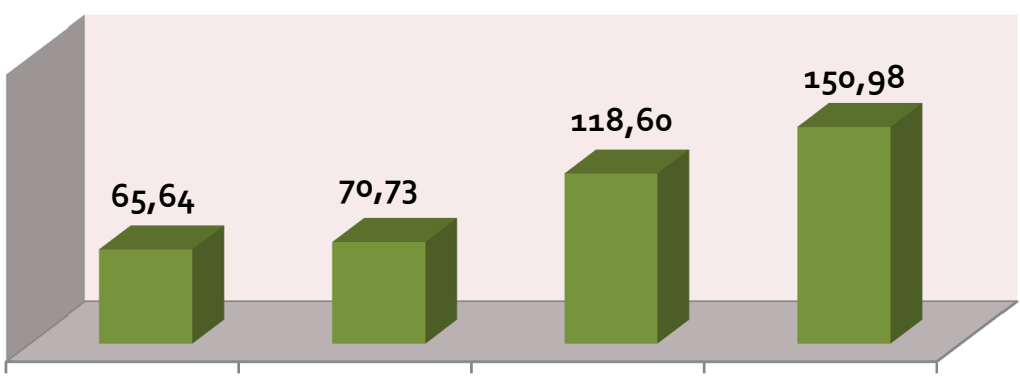

1 Dormitório 2 Dormitórios 3 Dormitórios 4 Dormitórios

pelo autor

Porcentagem de Plantas que Apresentam Ambientes para Home Office

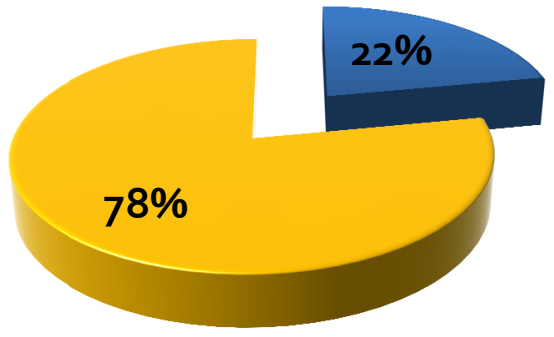

Plantas com ambientes Home Office

$\square$ Plantas sem ambientes Home Office 


\section{Porcentagem de Plantas que Apresentam}

Postos de Trabalho para Home Office

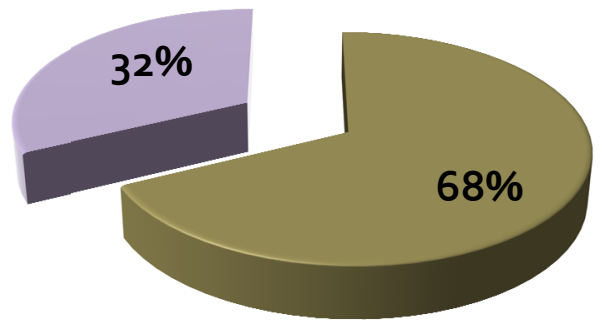

$\square$ Plantas com Postos de Trabalho para Home Office

घPlantas sem Postos de Trabalho para Home Office

Porcentagem de Empreendimentos Lançados com Home Office por Zona na Cidade

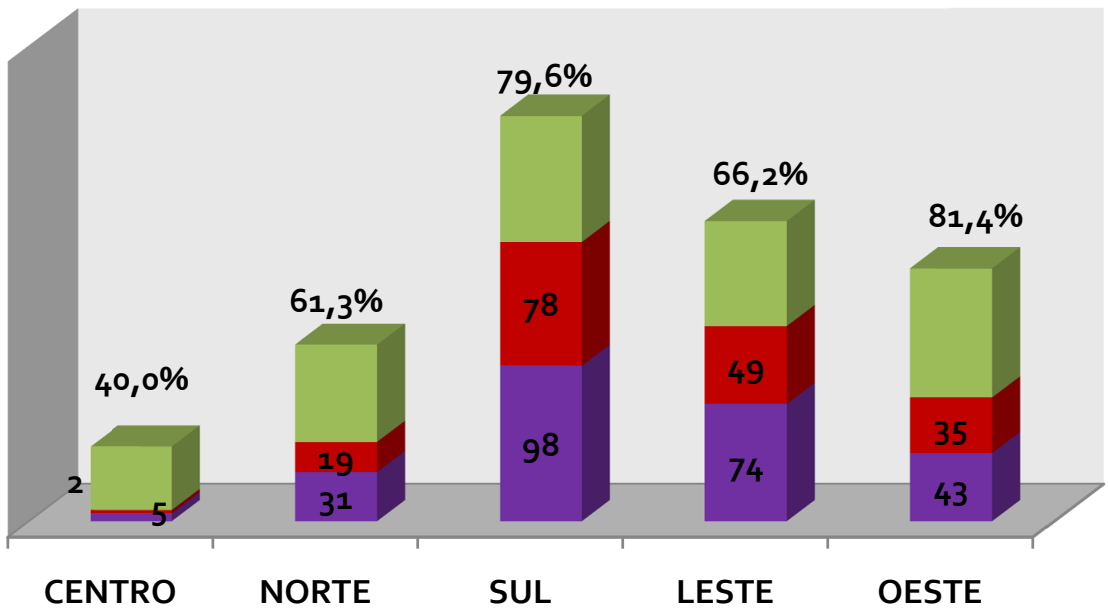

- Total de Empreendimentos

- Total de Empreendimentos com HO

- \% de Empreendimentos com HO por Zona 
Porcentagem de Plantas com Home Office por

Tipologia da Habitação

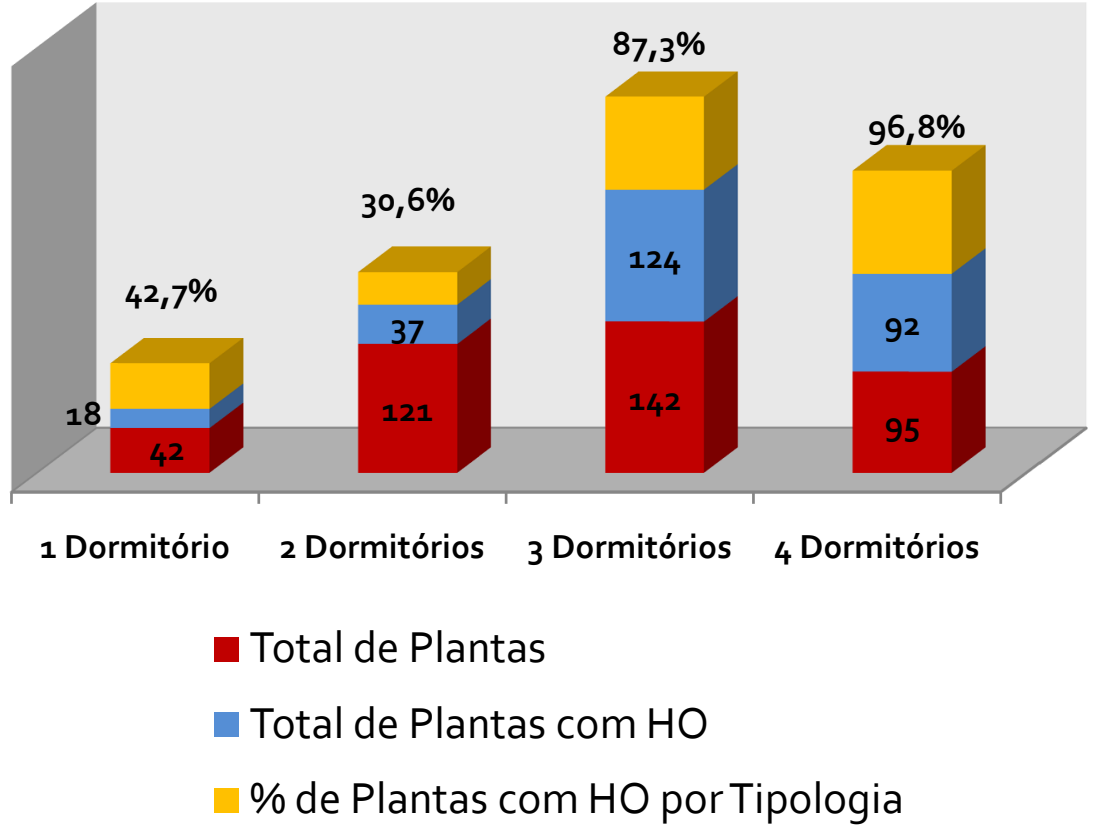

Área Média dos Home Offices e Porcentagem Média Ocupada por Tipologia da Habitação

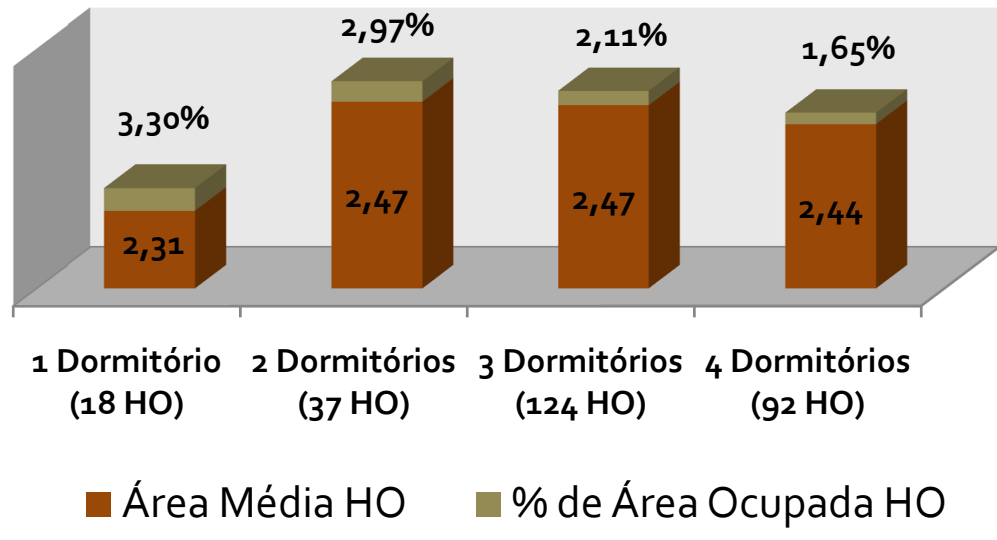

elo autor 
Porcentagem de Home Offices por Tipologia de Implantação

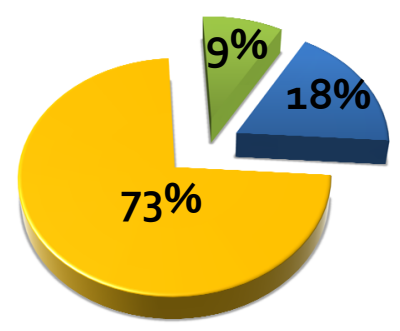

$\square$ Adaptado
$(48 \mathrm{HO})$
$\square$ Parte de Ambiente
$(198 \mathrm{HO})$
$\square$ Projetado
$(25 \mathrm{HO})$

lo autor

Área Média do Home Office por Tipologia de Implantação (m2)

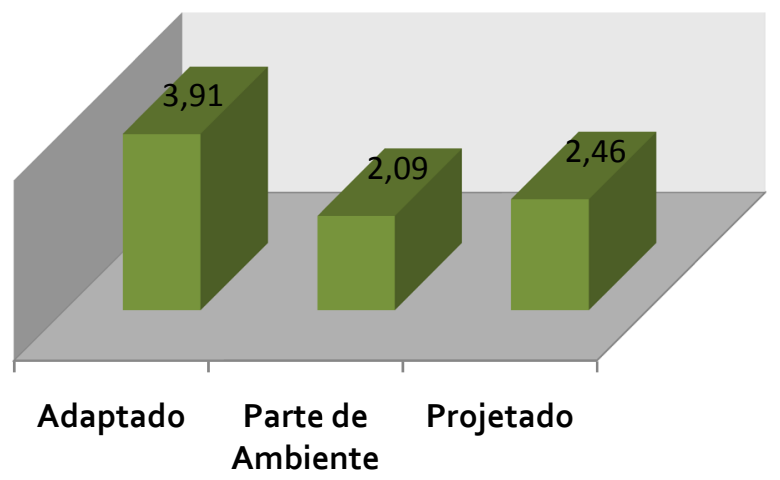

elo autor

Porcentagem de Tiplogia de Implantação por

Tipologia da Habitação

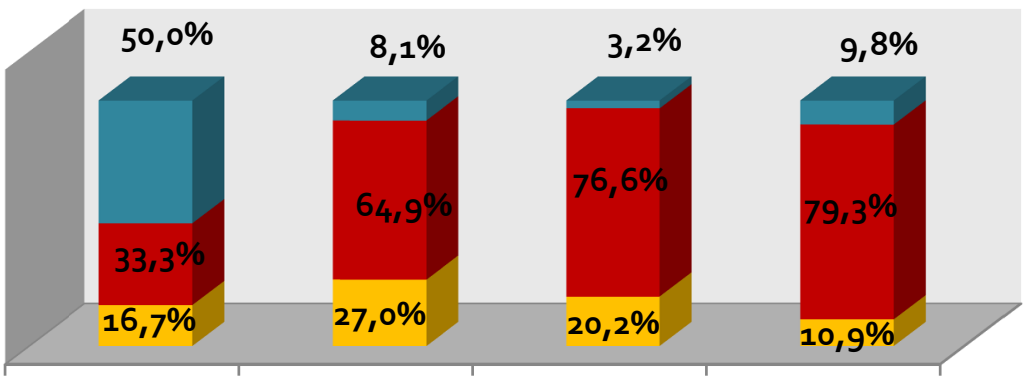

1 Dormitório 2 Dormitórios 3 Dormitórios 4 Dormitórios

Adaptado Parte de Ambiente $\quad$ Projetado 


\section{Porcentagem de Home Office por Setor da Habitação}

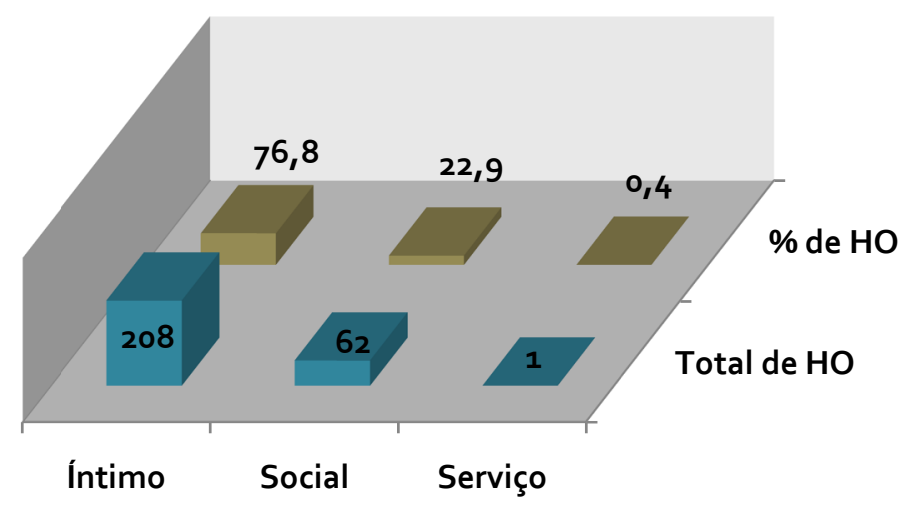

Total de $\mathrm{HO} \quad \%$ de $\mathrm{HO}$

elo autor

Porcentagem por Setor da Habitação por Tipologia da Habitação

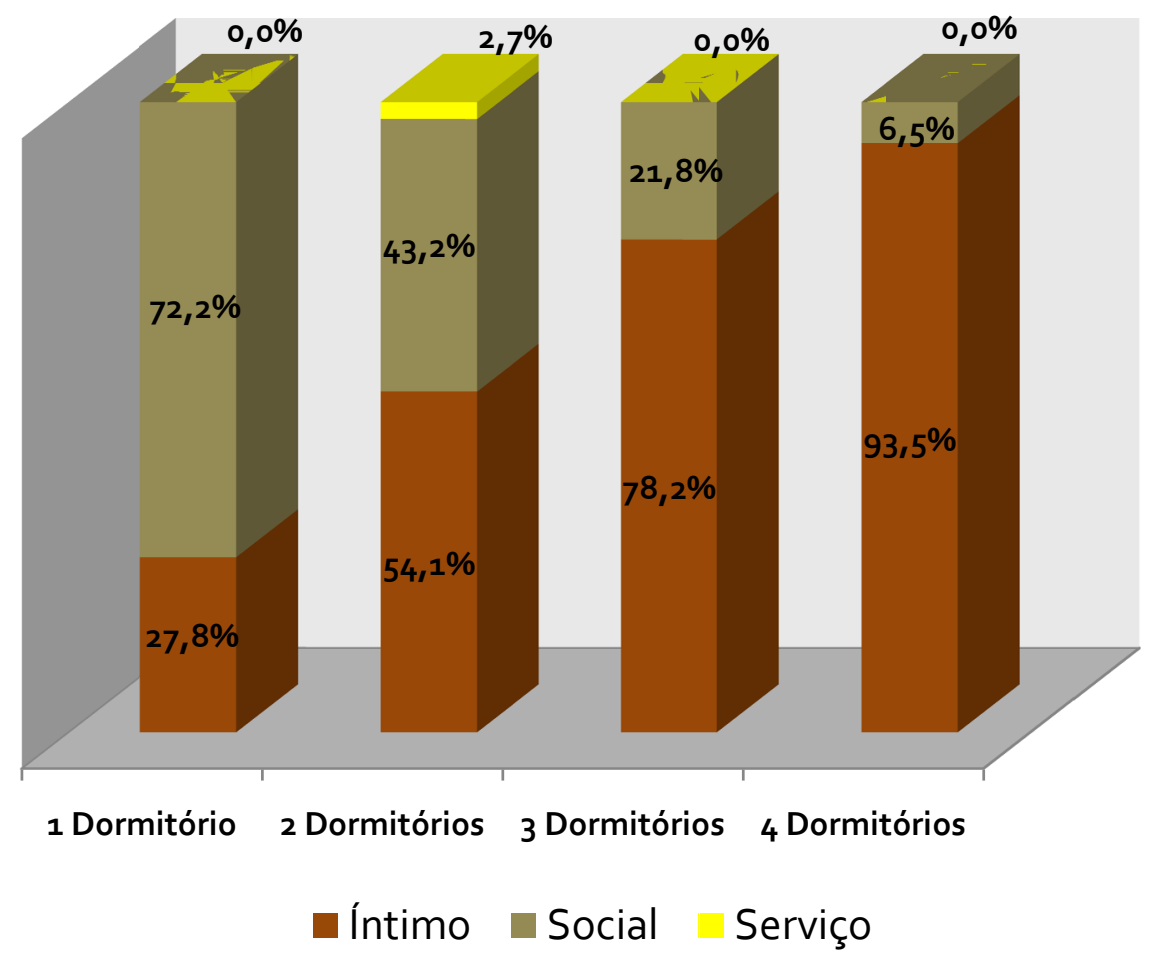

elo autor 
Porcentagem de Home Office implantado em cada Ambiente
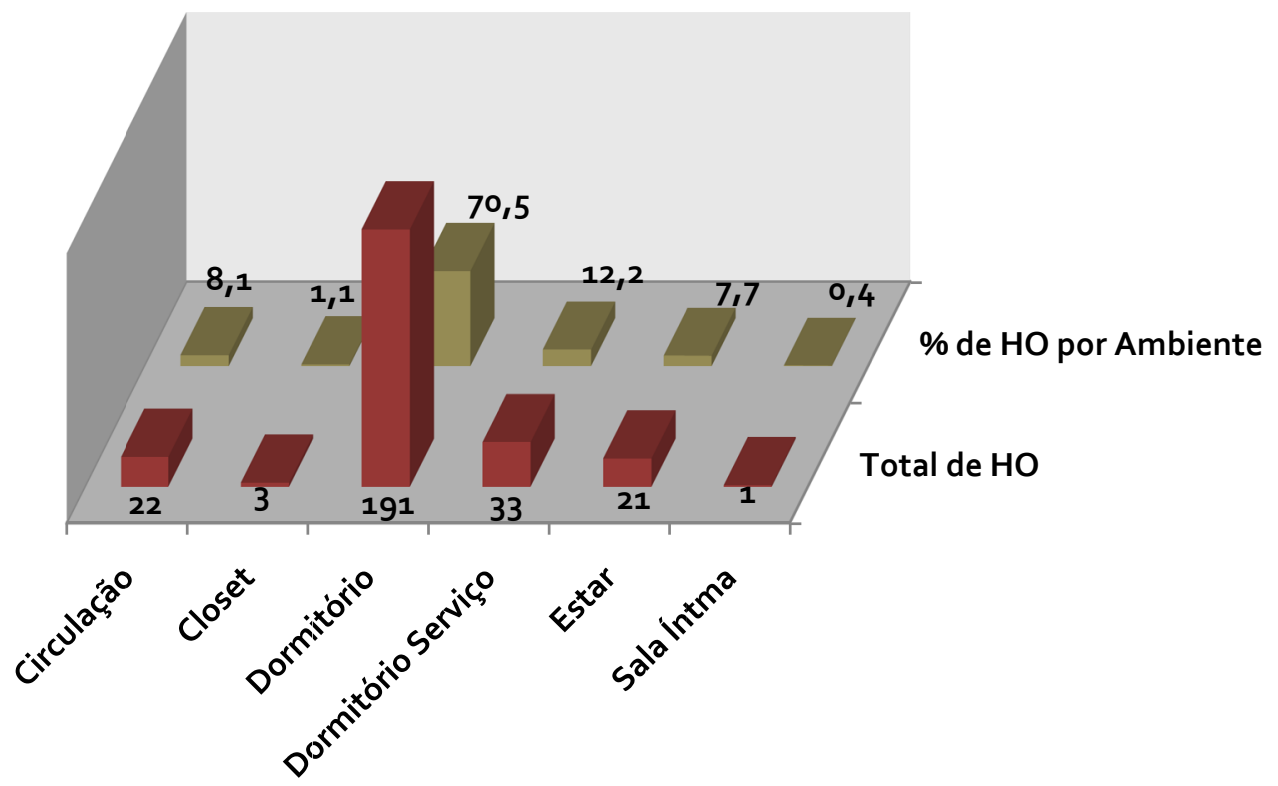

Total de $\mathrm{HO} \quad \%$ de $\mathrm{HO}$ por Ambiente

pelo autor

\section{Porcentagem de Implantações em Ambientes por}

Tipologia da Habitação

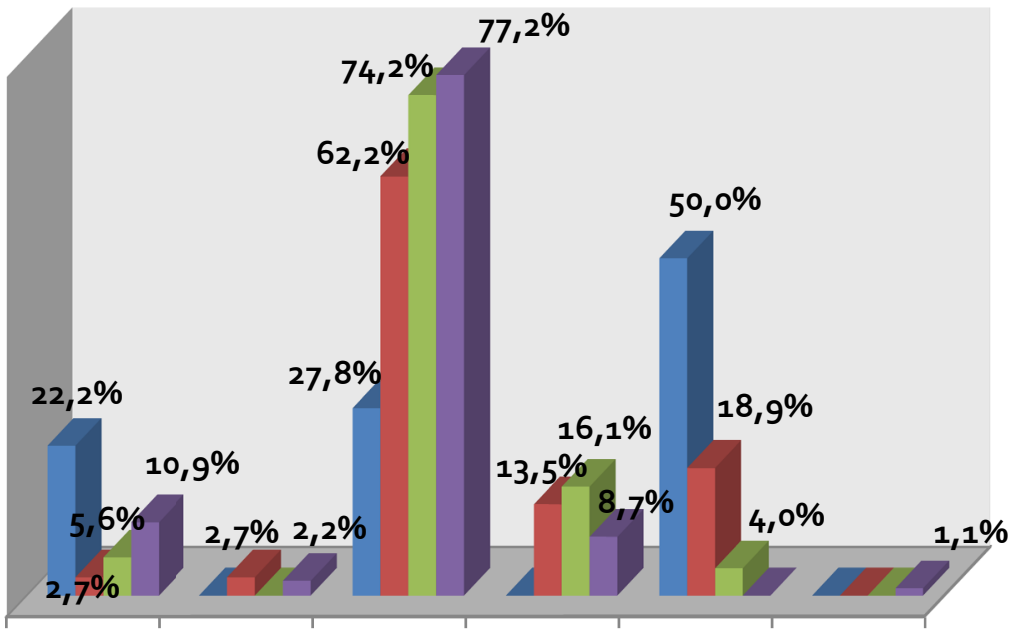

1 Dormitório

[ 2 Dormitórios

3 Dormitórios

4 Dormitórios
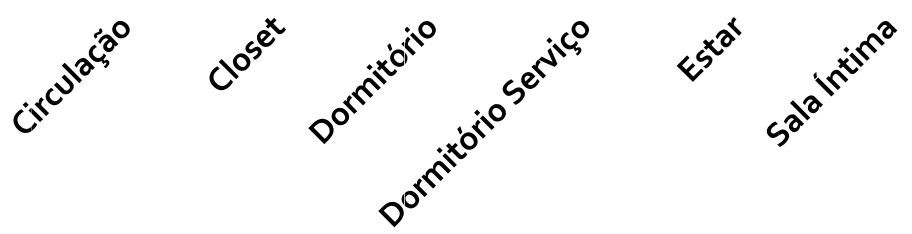


\subsection{Análise e Diagnóstico das Informações Levantadas}

Os dados tabulados devem permitir o cruzamento de algumas informações para que as leituras destes dados possibilitem as análises necessárias às conclusões e objetivos da pesquisa.

Nesse sentido, as seguintes leituras foram os objetivos das investigações:

- O total de empreendimentos imobiliários lançados cadastrados

- O total de plantas "tipo" e variantes de cada empreendimento

- O número e a porcentagem de empreendimentos lançados em cada zona da cidade

- O número de empreendimento lançados em cada bairro da cidade

- A área média dos imóveis cadastrados por tipologia da habitação

- A porcentagem de lançamentos cadastrados de cada tipologia da habitação

- A porcentagem de lançamentos que incluem Home Office.

- A porcentagem de lançamentos com Home Office para cada zona da cidade

- A porcentagem de lançamentos com Home Office por tipologia da habitação

- A área média ocupada pelos Home Office por tipologia da habitação 
- A porcentagem média de área ocupada pelos Home Office por tipologia

- A porcentagem de Home Office por tipologia de implantação

- A área média do Home Office por tipologia de implantação

- A porcentagem de tipologia de implantação por tipologia da habitação

- A porcentagem de implantação por setor da habitação

- A porcentagem de implantação por setor da habitação por tipologia da habitação

- A porcentagem de Home Office implantado em cada ambiente

- A porcentagem de implantações em ambientes por tipologia da habitação

- A porcentagem de Home Office com área igual ou superior a $2,46 \mathrm{~m}^{2}$.

O universo dos lançamentos imobiliários pode representar a resposta aos anseios e necessidades do mercado consumidor destes produtos, e nesse sentido que a investigação focada na busca de programas que apresentem ambientes ou postos de trabalho com a função de prover condições para o desenvolvimento de atividades no ambiente da habitação torna-se relevante justamente por permitir leituras que levem a estudos sobre o comportamento do mercado e concluir quais os vetores que deverão ser considerados pelos agentes promotores do mercado imobiliário. 
Em relação à localização dos empreendimentos, a Zona Sul apresenta o maior número de lançamentos, com 39,04\% dos casos investigados, seguido pela Zona Leste com $29.48 \%$.

Os bairros que receberam maiores lançamentos foram o Tatuapé e Mooca, na zona Leste e Morumbi e Jardim Sul na zona Sul, todos com aproximadamente $4,5 \%$ do total dos lançamentos pesquisados.

Na composição dos dados sobre a tipologia da habitação, os empreendimentos com unidades habitacionais de 3 dormitórios são a maioria, com 35,50\% dos casos, seguido pelo de 2 dormitórios com 30,25\%, somadas, estas tipologias representam $65,75 \%$ dos casos.

Acerca dos lançamentos imobiliários que incorporaram ambientes para atividades de escritório, a pesquisa apresentou que $27 \%$ dos 251 empreendimentos investigados têm a proposta para Home Office em ambiente exclusivo para esta atividade, tanto para ambientes projetados como para ambientes adaptados.

Considerando os empreendimentos que apresentam postos de trabalho para atividades de escritório, este número sobe para $78 \%$ dos empreendimentos residenciais lançados no período.

Ainda, dos 400 projetos que compõem esta pesquisa, $68 \%$ das opções de plantas oferecem o Home Office em seus programas, quer seja em ambiente exclusivo, quer seja em parte de ambiente. 
Considerando as zonas da cidade, a Oeste é aquela que apresenta maior porcentagem de empreendimentos com Home Office $-81,4 \%$, seguida da zona Sul com $79,6 \%$.

Em relação à tipologia da habitação, $96,8 \%$ das plantas com 4 dormitórios apresentam opções para atividades de escritório e as plantas de 2 dormitórios é que possuem menores índices, com apenas 30,6\% dos casos.

A área média aferida para as plantas que têm a opção de Home Office - projetados, adaptados ou parte de ambiente - é de $2,45 \mathrm{~m} 2$.

Acerca da tipologia de implantação, $73 \%$ das plantas cadastradas apresentam a área para atividades de escritório compartilhando um ambiente com outra função ou funções da habitação.

Pode-se verificar que em $18 \%$ dos casos a implantação do Home Office se deu pela adaptação de um ambiente projetado para uma determinada função e foi alterado para esta atividade.

Em 9\% das plantas, o Home Office aparece como ambiente projetado, pré-definido na planta do apartamento "tipo".

A área média do ambiente ou posto de trabalho para atividades de escritório varia conforme a tipologia de implantação. Quando o ambiente é adaptado para esta atividade, a área média é de 3,91 m2, seguida da tipologia de implantação projetada, com $2,46 \mathrm{~m} 2$ e finalmente daquelas implantações onde existe o compartilhamento do ambiente, com área média de 2,09m2. 
Os Home Offices projetados são $50 \%$ daqueles implantados em tipologias de 1 dormitório, sendo que nas outras tipologias da habitação, com 2, 3 e 4 dormitórios, ele está inserido como parte de um ambiente, com uma média de $71 \%$ dos casos.

Sobre o setor da habitação onde o Home Office foi introduzido, $76,8 \%$ está localizado no setor íntimo da habitação, $22,9 \%$ no setor social e praticamente não aparece no setor de serviços.

Este dado sofre apenas uma alteração quando observado da perspectiva das tipologias da habitação, onde as unidades com 1 dormitório apresentam $72,2 \%$ das áreas para atividades de escritórios incorporadas ao setor social. Nos demais casos o setor íntimo continua prevalecendo.

O ambiente que mais recebe a implantação de mobiliário para realização de atividades de escritório é o dormitório, com $70,5 \%$ das plantas estudadas, na maioria dos casos compartilhando as funções de dormitório e, por outras vezes sendo adaptado para a função de Home Office.

Observa-se ainda que o dormitório de serviço com 12,2\% dos casos e as circulações com $8,1 \%$ são também requisitadas para atender esta demanda de espaço.

Porém, estes dados referem-se à totalidade dos casos, contemplando todas as tipologias de implantação, porém, o panorama se altera quando existe a restrição para apenas as tipologias de implantação projetadas e adaptadas. 
Nestes casos, quando o Home Office é projetado, $56 \%$ é inserido na circulação e $44 \%$ no estar.

Já no caso em que é adaptado a um ambiente existente, $69 \%$ dos casos é o dormitório de serviço que é substituído para esta função e apenas $23 \%$ dos casos a adaptação ocorre em um dos dormitórios da unidade.

Finalmente, observa-se que $63,5 \%$ das áreas apresentadas em plantas para atividades de escritório têm menos que $2,46 \mathrm{~m}_{2}$. 

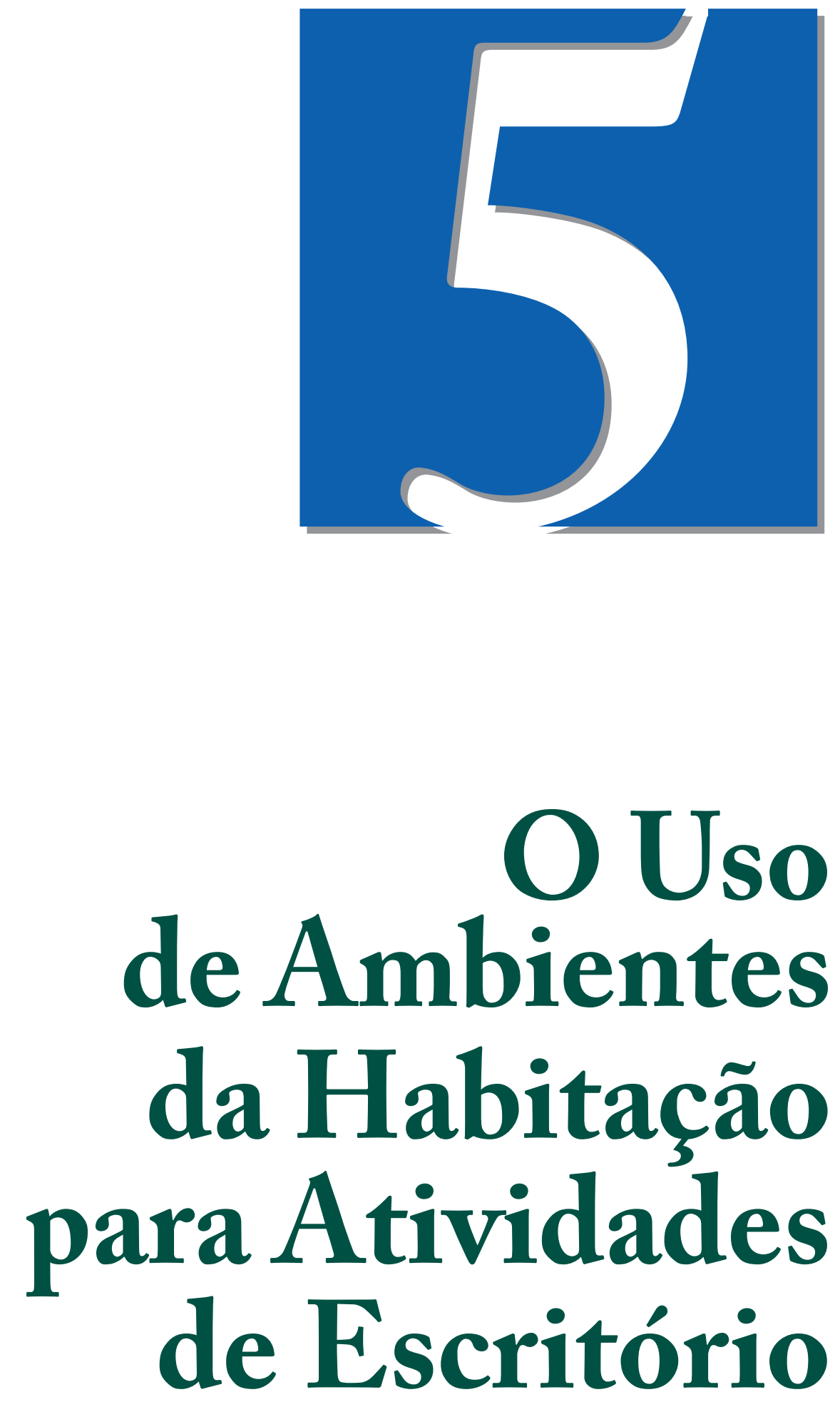

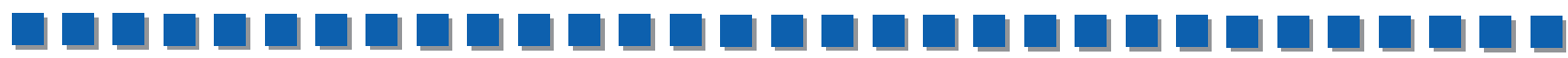

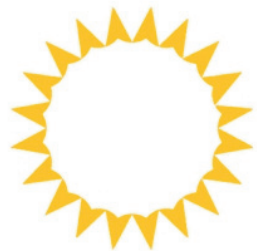




\section{CAPÍTULO 5. O USO DE AMBIENTES DA HABITAÇÃO PARA ATIVIDADES DE ESCRITÓRIO}

\subsection{Considerações Preliminares}

Esta etapa teve por objetivo investigar o uso de ambientes da habitação para a realização de atividades pertinentes ao trabalho de escritório.

Entendendo que existe uma lacuna nesta área de investigação, onde não existem elementos bibliográficos ou estatísticos disponibilizados em que sejam apresentados dados acerca desta tipologia de atividade na habitação, a pesquisa torna-se relevante não apenas pelo caráter do ineditismo, mas também pelo conteúdo a ser agregado aos estudos do doutoramento.

A investigação foi realizada no município de São Paulo, aplicadas aos moradores de habitações uni familiares, e que dispunham nestas habitações ambientes ou postos de trabalho que tivesse por função o atendimento de atividades pertinentes ao trabalho de escritório.

Dessa maneira, encontramos o perfil do usuário, períodos de uso do ambiente e algumas informações sobre as questões do conforto proporcionado ao usuário. 


\subsection{Introdução}

Habitar e trabalhar sempre fez parte das atividades humanas e por muito tempo essas atividades compartilharam de um mesmo espaço, ou seja, a habitação.

Como já estudado na dissertação de mestrado, o autor encontrou na bibliografia vários elementos que comprovam que trabalho e habitação conviveram harmoniosamente desde os primórdios da humanidade, apresentando projetos que demonstram que estas atividades faziam parte do programa da habitação.

Com a Revolução Industrial essas atividades sofreram a separação, e passaram a ocupar locais distintos: o trabalho nas empresas e fábricas e a habitação reservada apenas para a vida doméstica.

As pesquisas realizadas nas habitações européias após a segunda guerra mundial, apresentadas por Etiènne Grandjean (1973), deixam claro que a habitação era o espaço feminino onde se realizavam tarefas domésticas e raramente havia atividades relacionadas ao trabalho profissional de qualquer tipologia, contrastando com o que se podia encontrar nos períodos históricos que antecederam a revolução industrial, onde era comum o convívio das atividades domésticas como o trabalho de artesãos, escribas e calígrafos, e também atividades de armazenamento, comércio e pequenas produções de artefatos e utensílios. 
A evolução tecnológica a partir da segunda metade do século XX, notadamente nas áreas da comunicação e informática, aliada às novas formas de administração empresarial, permitiu a abertura de possibilidades para novos cenários e as funções gerenciais que não dependiam do fator presencial do funcionário passaram a estar desobrigadas de ocuparem um espaço fixo nas empresas, podendo ser deslocadas para ambientes e postos de trabalho inseridos em qualquer local.

Algumas opções surgiram como resposta a esta nova característica de gerenciamento e produção, como o conceito de escritórios não-territoriais e suas variações, os Hoteling, Free Address, Red Carpet Club e, os Home Office Escritórios Residenciais.

Além da suposta necessidade de desenvolver as atividades de escritório no ambiente doméstico, essa modalidade passou a ser reconhecida como uma nova alternativa de vida, adotada por trabalhadores e incentivada por empresas em várias culturas.

Vale salientar que os escritórios não-territoriais, particularmente os Home Offices, foram alternativas adotadas como resposta a questões que variam dependendo da cultura e do contexto em que está implantado. 
Exemplos desta colocação podem ser encontrados em pesquisas nos Estados Unidos, que revelam que a adoção das atividades de trabalho a partir da habitação vem como um privilégio concedido aos melhores profissionais, os quais podem desfrutar de um tempo maior com seus familiares; já para os canadenses, residentes em um país com um rigoroso inverno onde não raramente as nevascas interferem no deslocamento da população, o trabalho à distância representa uma alternativa eficaz que permite a continuidade das ações empresariais, e que independem do clima; já em nações européias, como Inglaterra, Alemanha e Holanda, a questão do deslocamento, produção de agentes polventes e suas interferências com o meio ambiente foram apontadas nas pesquisas como principais fatores que incentivam as atividades de trabalho a partir da habitação.

Qual seria, portanto, o agente motivador para este processo em cidades de países emergentes como o Brasil, em especial a cidade de São Paulo, em que fatores como o deslocamento intra-urbano, segurança pública, ao lado de uma rede tecnológica muito bem estruturada e base de grandes empresas nacionais e multinacionais, formam um cenário com elementos de desgaste e pujança entrelaçados a uma população composta por indivíduos de várias culturas e das mais diversas classes sócio-econômicas.

Além do agente motivador, não existe o conhecimento de quem é este trabalhador, quais atividades ele exerce, em quais períodos desenvolve as atividades e em quais condições estas atividades são realizadas. 
Com esta visão a pesquisa buscou investigar algumas habitações na cidade de São Paulo, pretendendo um primeiro esboço do que seria este universo, caracterizá-lo e a partir deste estudo preliminar identificar as bases para uma pesquisa mais abrangente, que responda às questões básicas sobre o tema proposto.

\subsection{Desenvolvimento da Pesquisa}

Conforme apresentado no Capítulo 2 Metodologia, item 2.2.2.1, o desenvolvimento do Levantamento das Informações de Campo, Parte B - O Uso de Ambientes da Habitação para Atividades de Escritório, foi desenvolvido de acordo com a seqüência abaixo:

a. Objeto de Estudo: ambientes inseridos nas unidades habitacionais que são destinados às atividades de escritório;

i. Recorte da Pesquisa: neste caso só existe o recorte geográfico que se refere ao Município de São Paulo;

b. Definição Estatística: 68 casos;

c. Determinação da Amostragem: 100 casos;

d. Levantamento de Dados de Campo: aplicação de questionários e levantamentos in loco.

e. Processamento dos dados Pesquisados

f. Análise e Diagnóstico das Informações Levantadas 


\subsection{Processamento dos Dados Pesquisados}

Os dados levantados pelos questionários foram organizados e, posteriormente compilados no programa EXCEL ${ }^{\circledR}$ da Microsoft, cujos resultados são apresentados a seguir em forma de gráficos elaborados a partir desta planilha.

\section{Tipologia da Habitação}

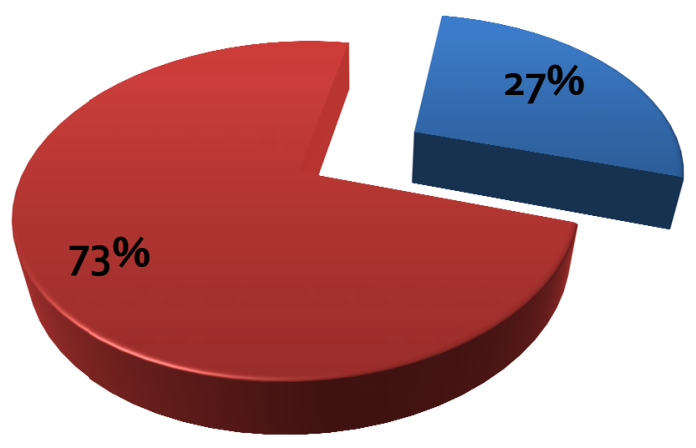

Casa

$\square$ Apartamento

Tipologia da Habitação por Número de Dormitórios

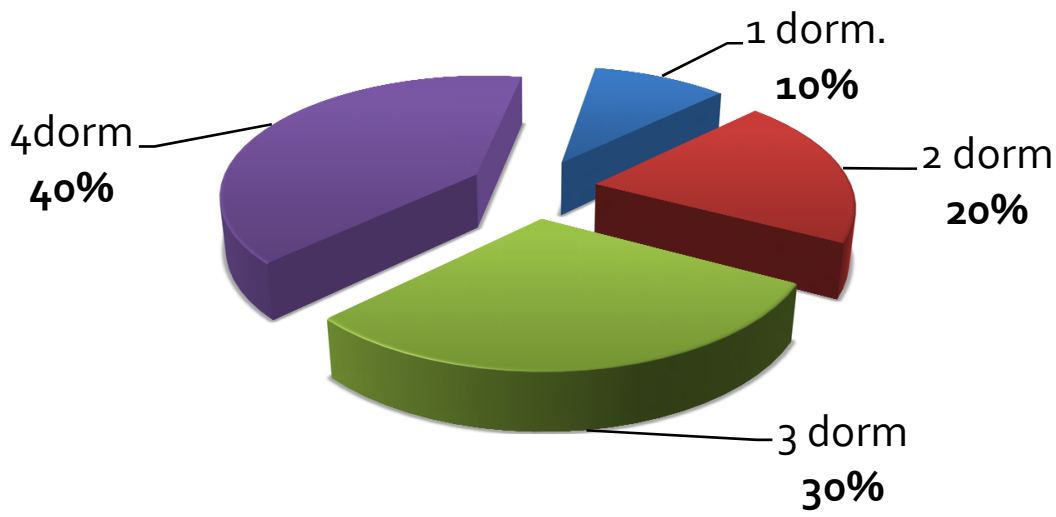


Porcentagem de Habitações por Zona na Cidade

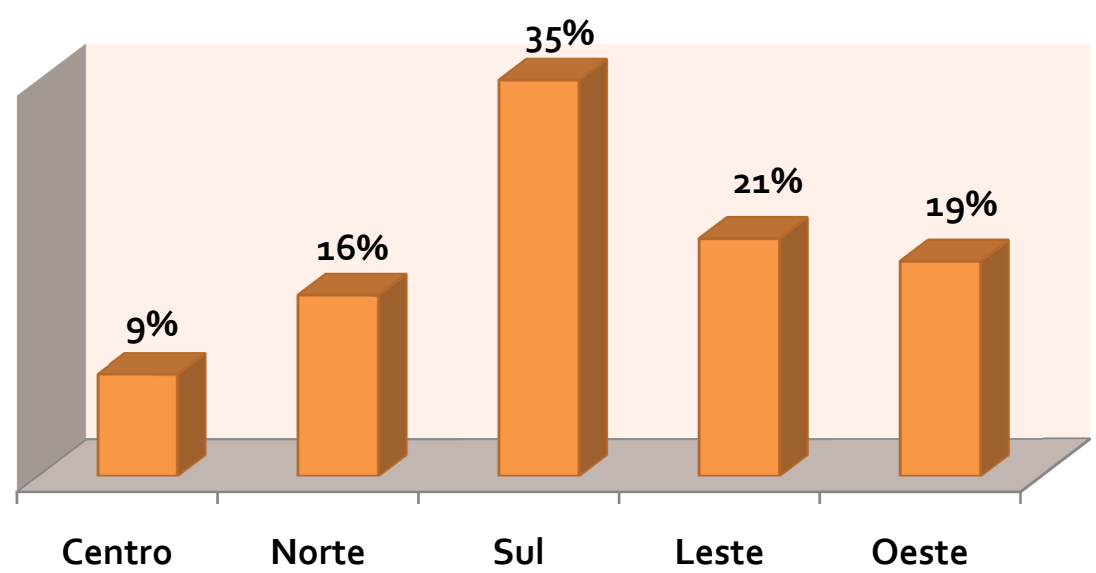

Porcentagem do Número de Habitantes por Unidade

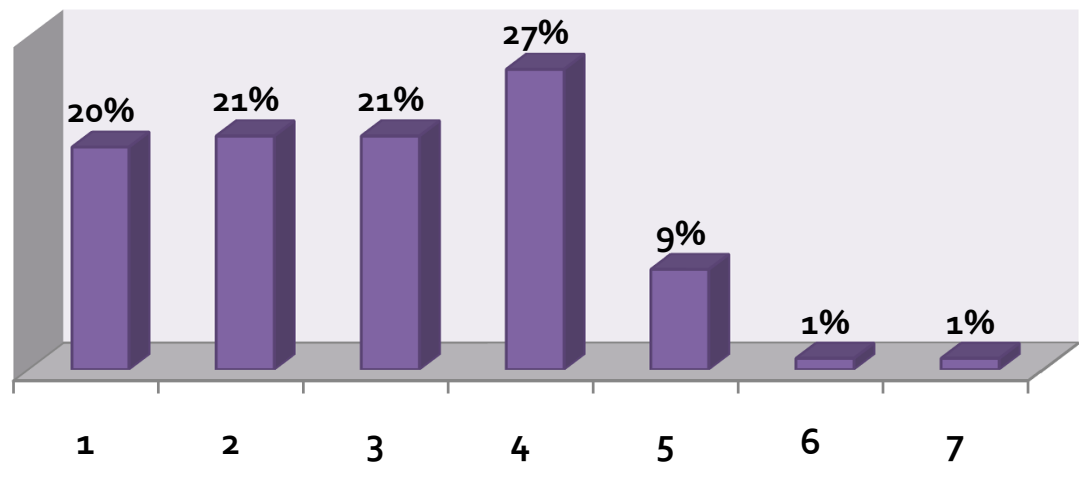

Porcentagem dos Habitantes por Sexo
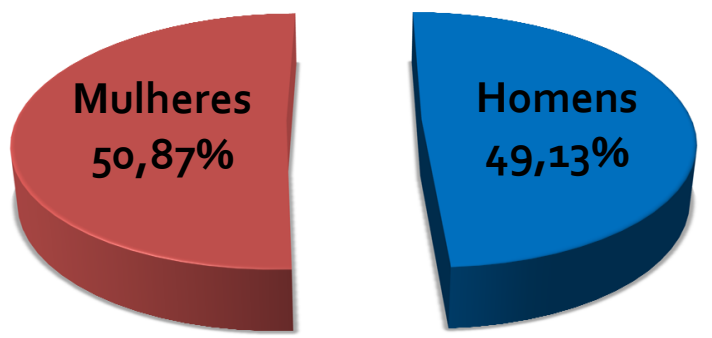
Porcentagem dos Habitantes por Escolaridade
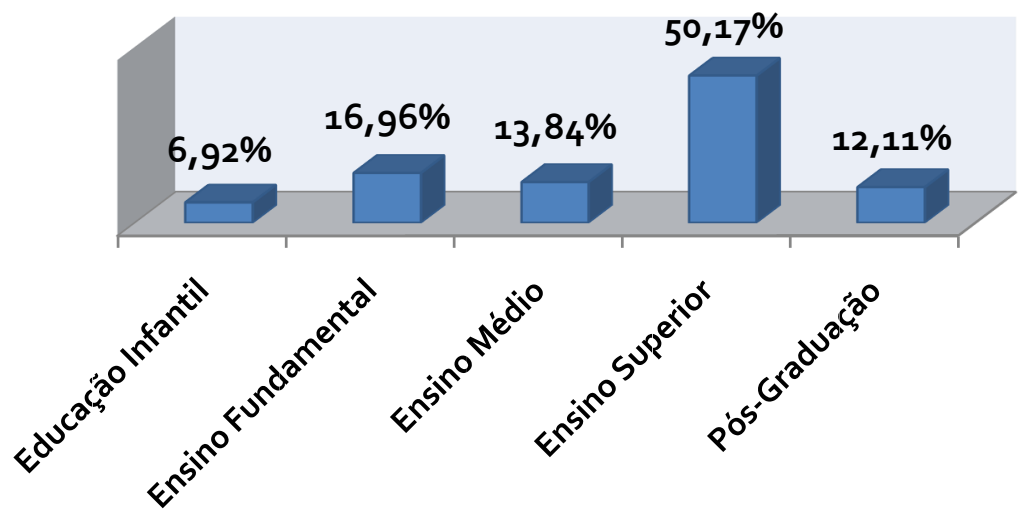

Porcentagem de Habitantes por Ocupação

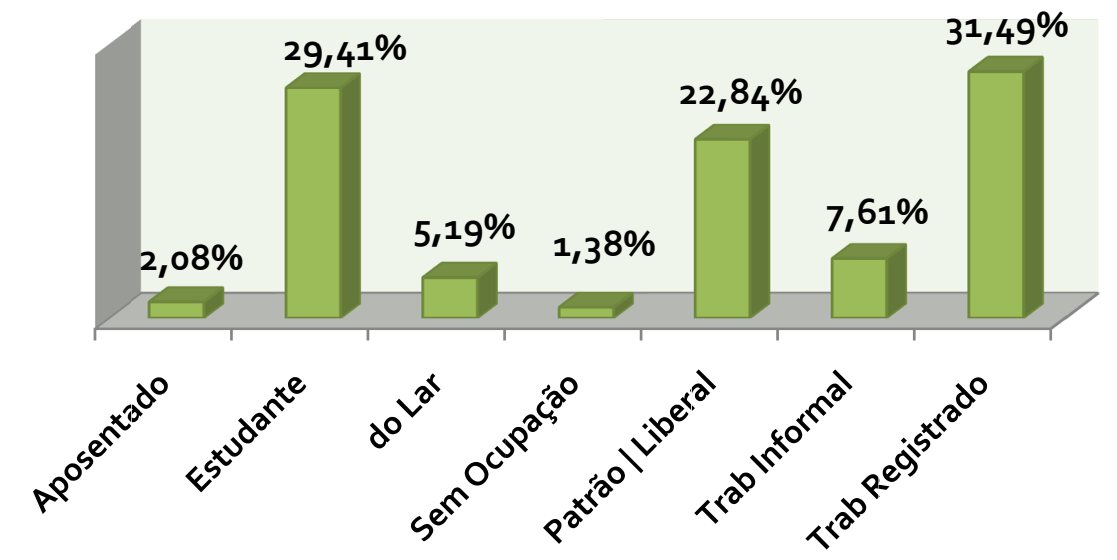

Porcentagem de Habitantes Usuários do Posto de Trabalho

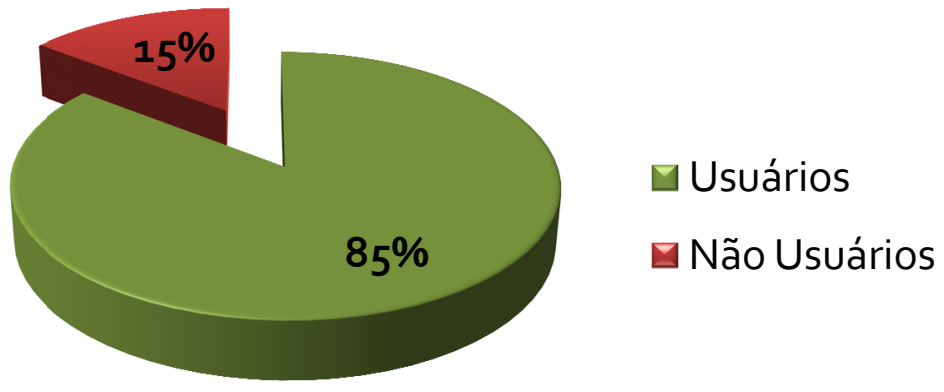




\section{Porcentagem de Usuários por Sexo}
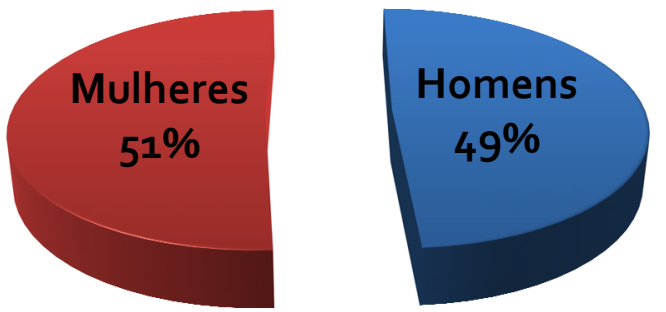

Porcentagem de Usuários por Ocupação

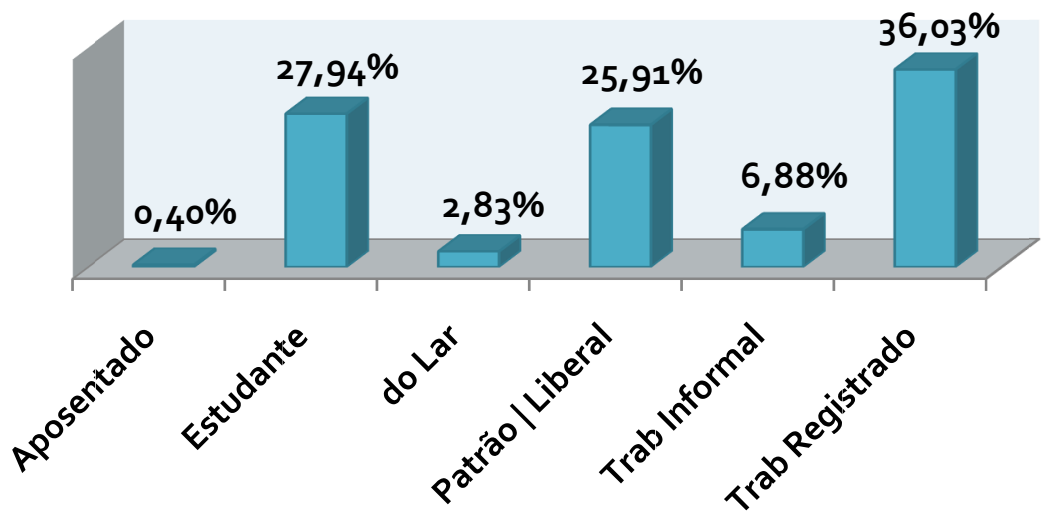

Porcentagem de Usuários com Atividades Profissionais

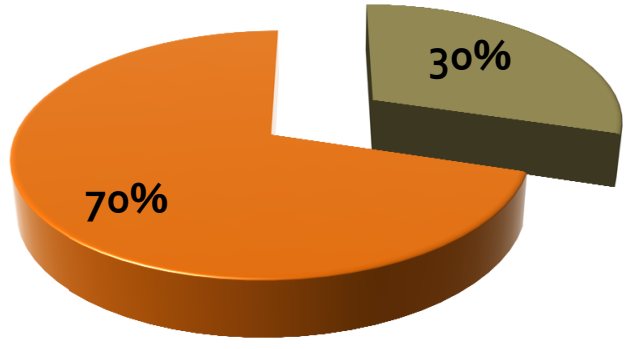

$\square$ Atividades Não Profissionais

$\square$ Atividades

Profissionais 


\section{Uso do Posto de Trabalho nos Dias da Semana}

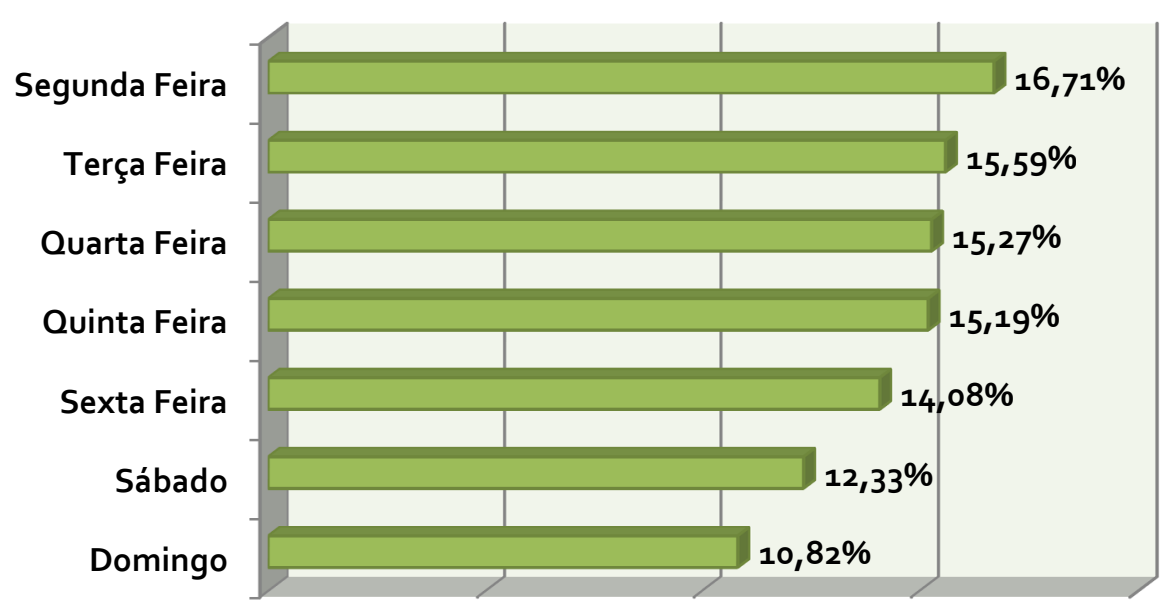

\section{Porcentagem do Uso por Período e Dia da Semana}

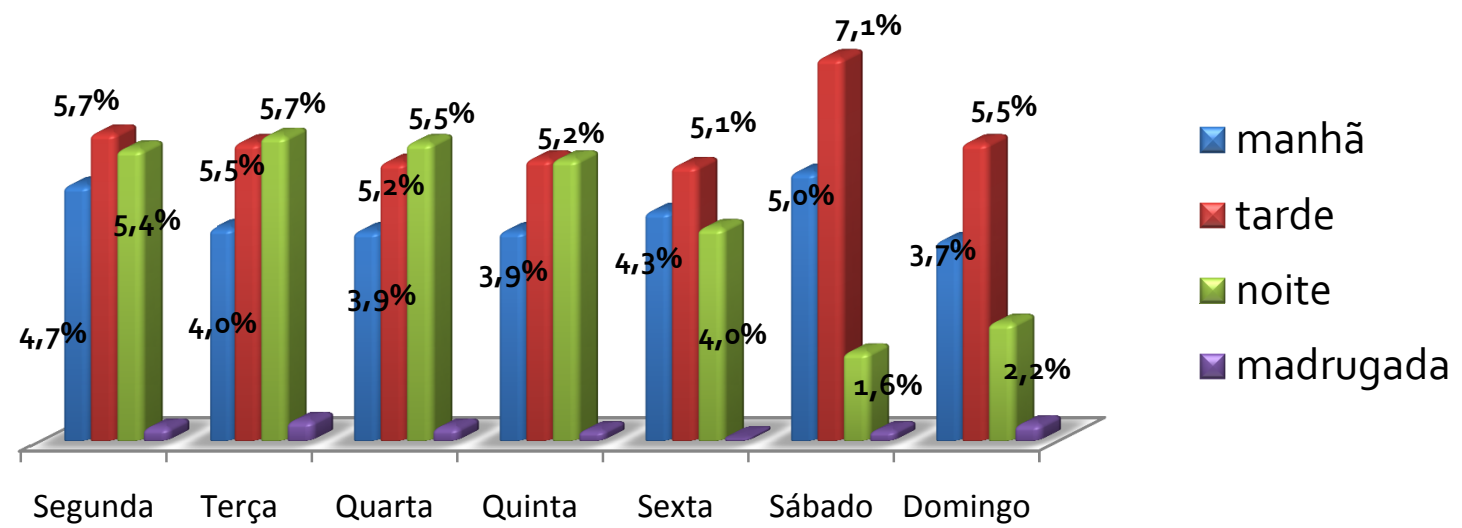


Porcentagem de Usuários por Ramo de Atividade

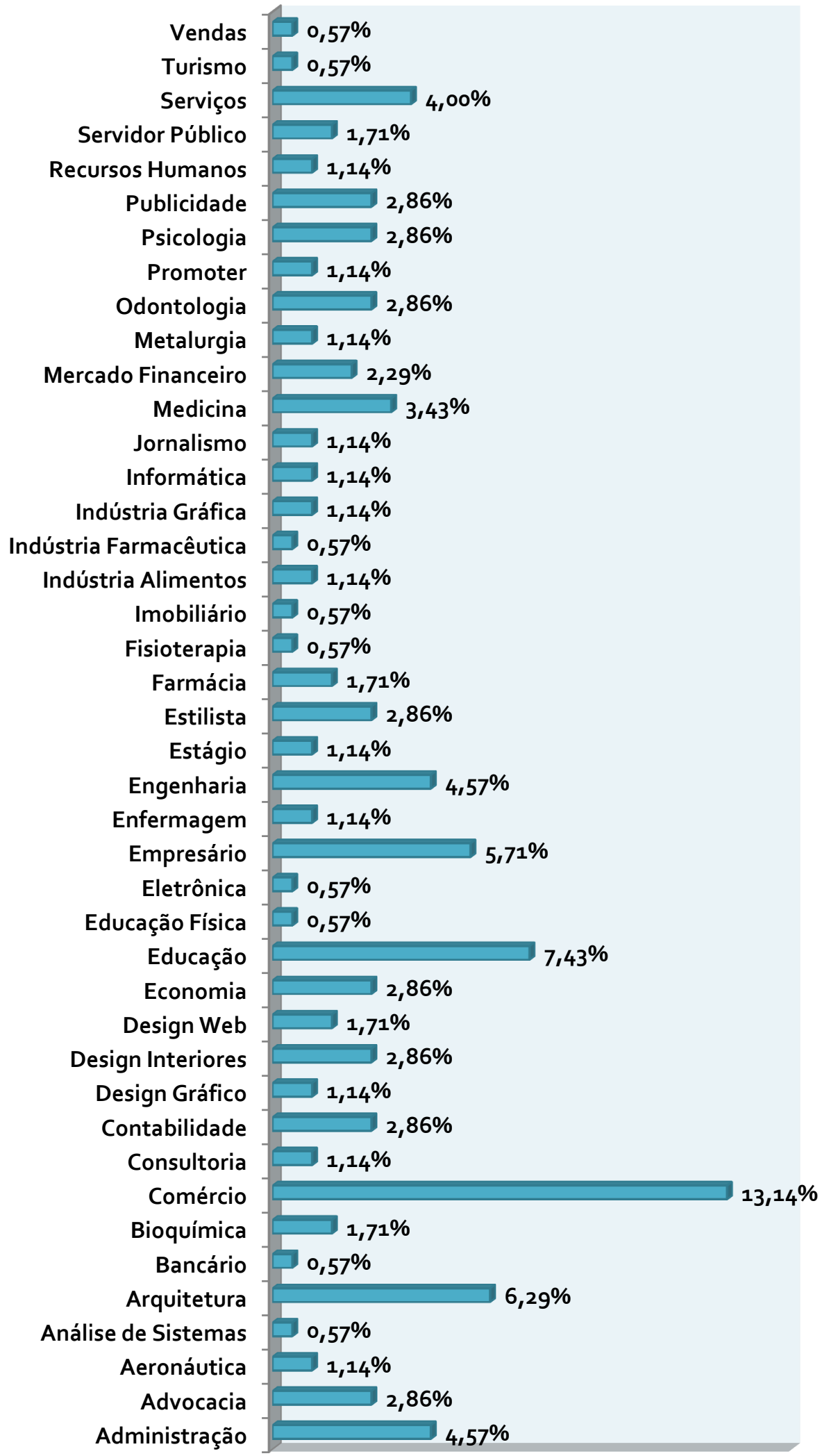




\section{Porcentagem de Uso por Período}
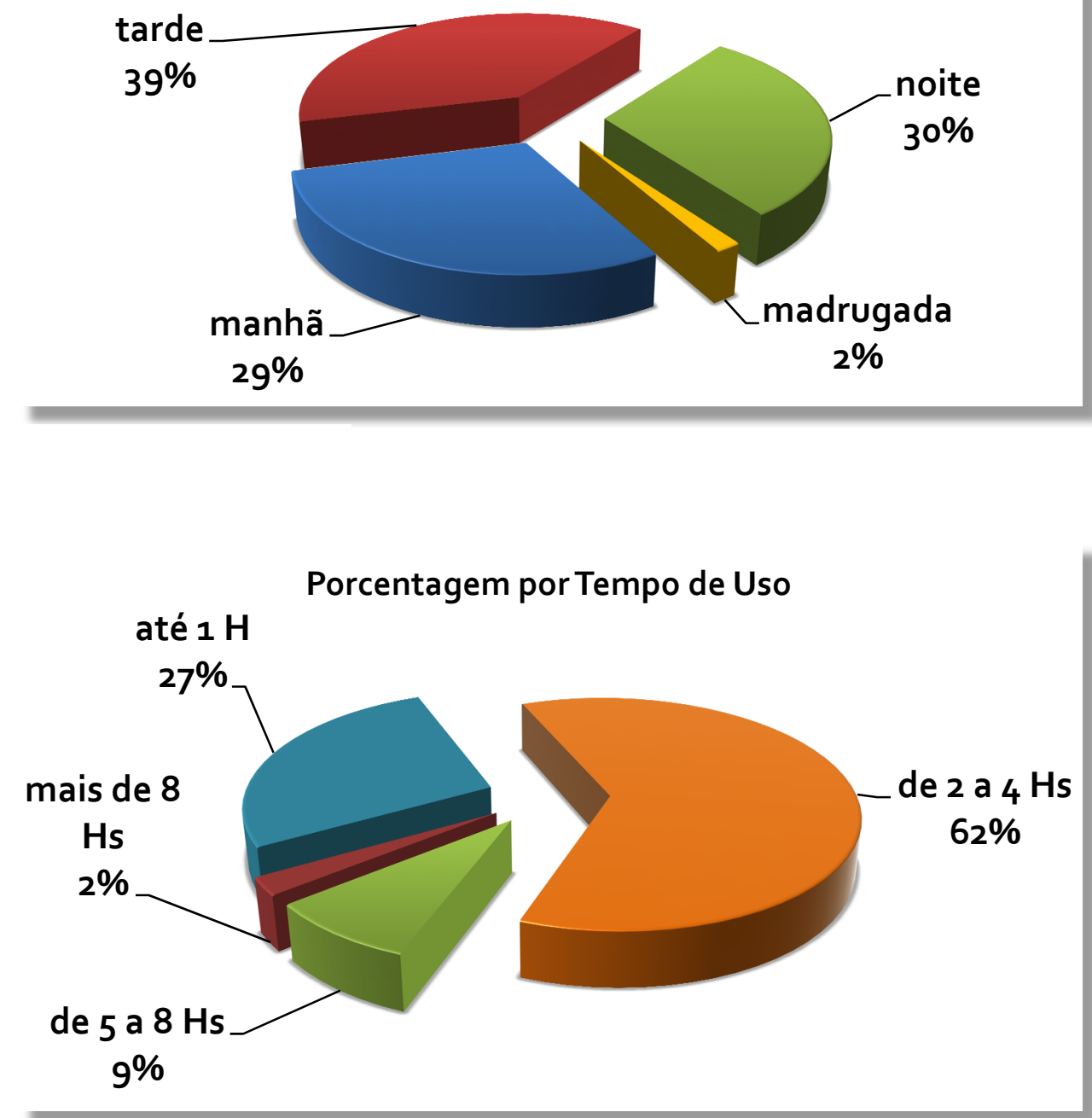

\section{Porcentagem segundo a Tipologia de Uso} Atividades Profissionais

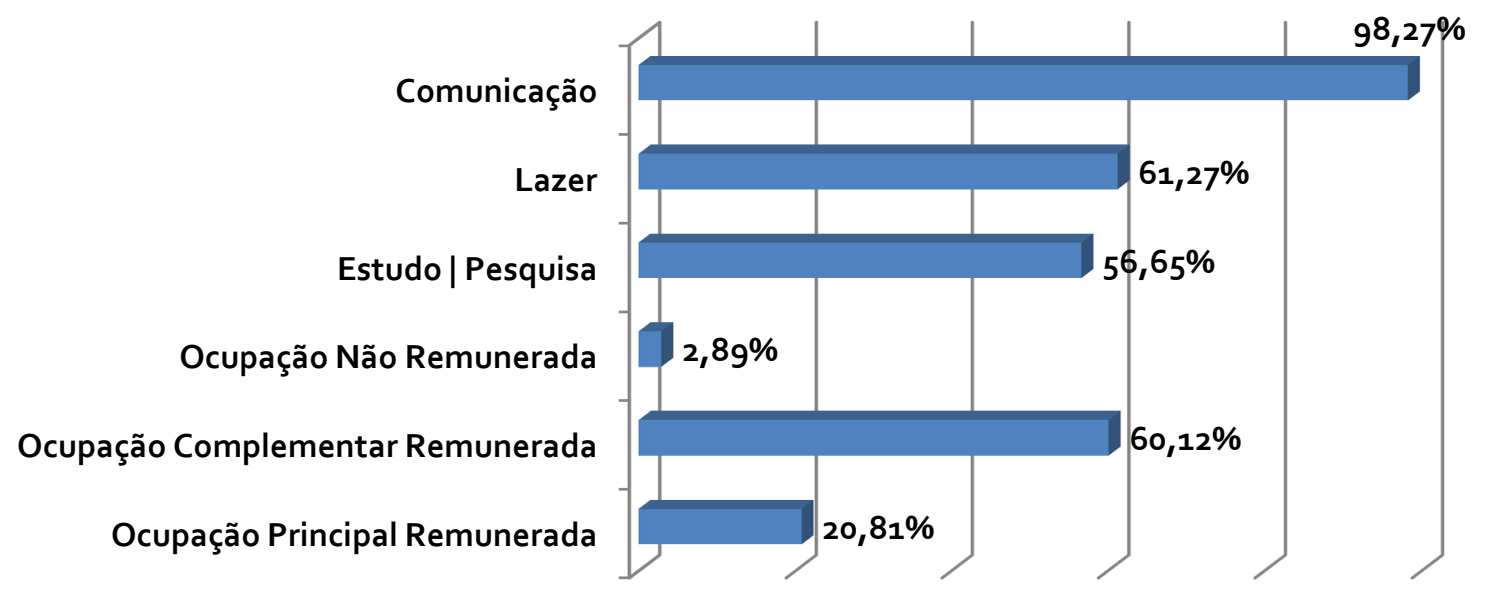




\section{Porcentagem segundo a Tipologia de Uso e Ocupação}

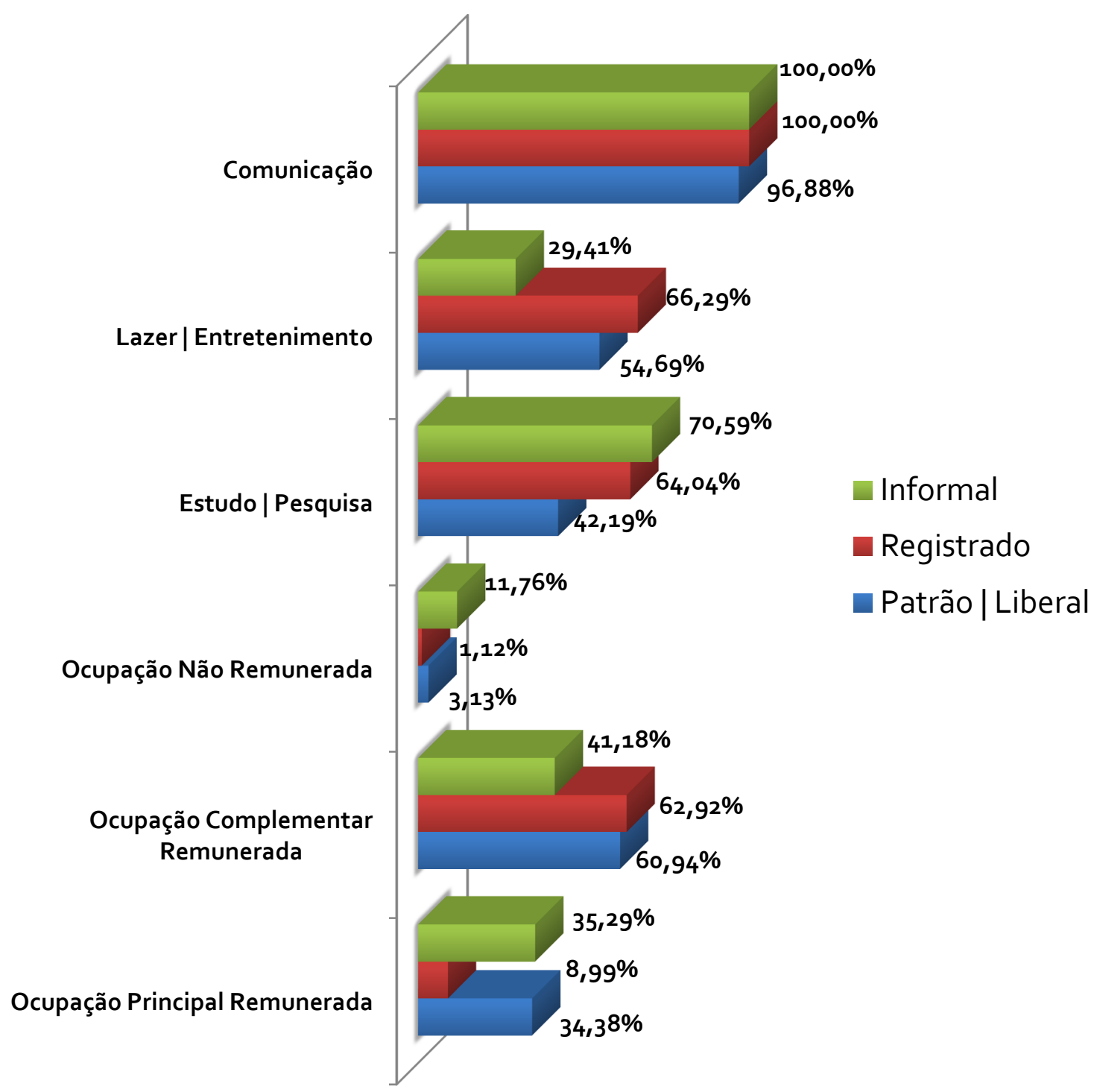


Porcentagem porTipologia de Implantação

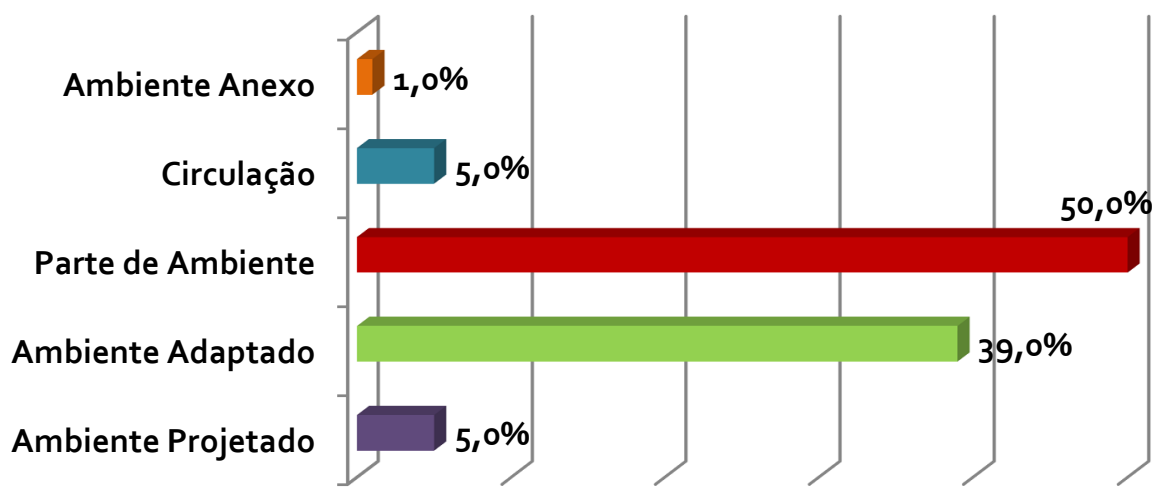

Área Média do Posto de Trabalho por

Tipologia de Implantação $\left(\mathrm{m}^{2}\right)$

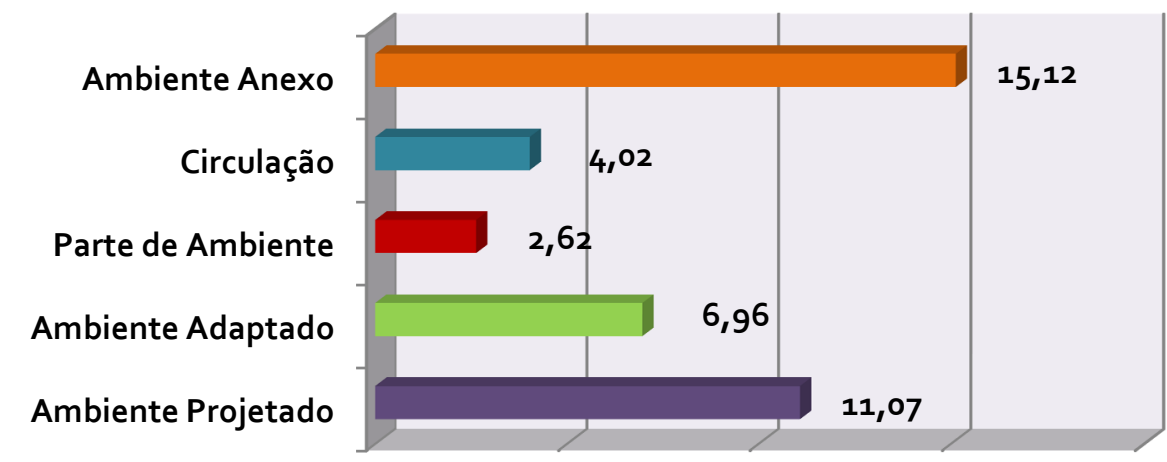

Porcentagem por Ambiente de Implantação

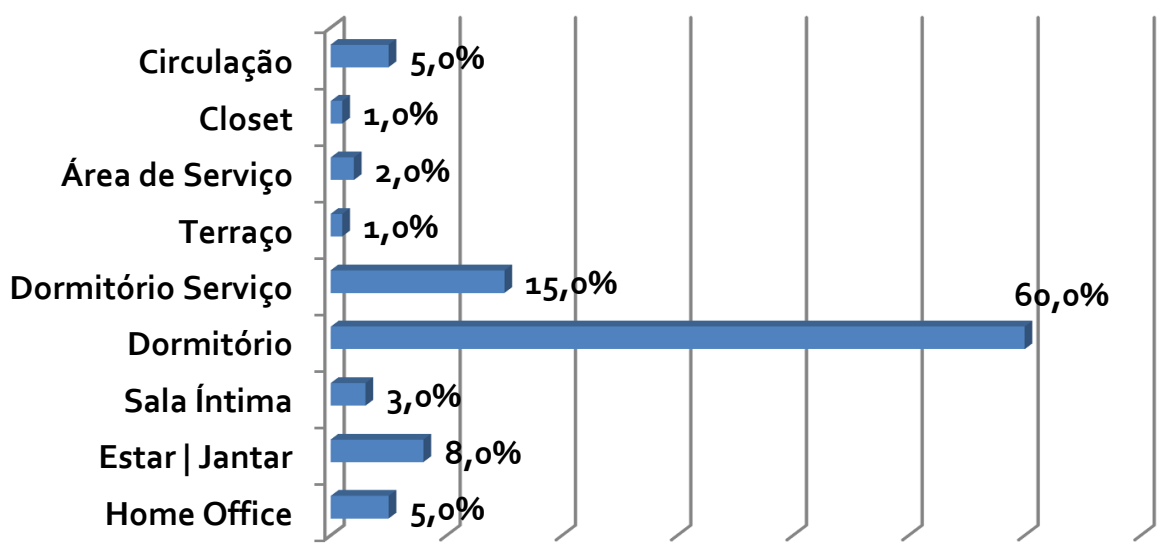


Porcentagem por Ambiente de Implantação em Ambiente Adaptado

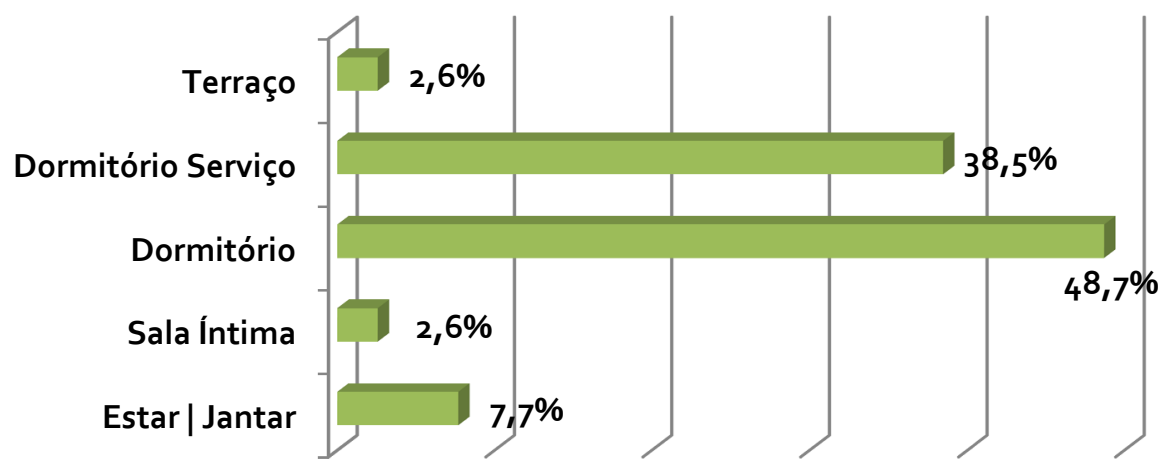

Porcentegem por Ambiente de Implantação em Parte de Ambiente

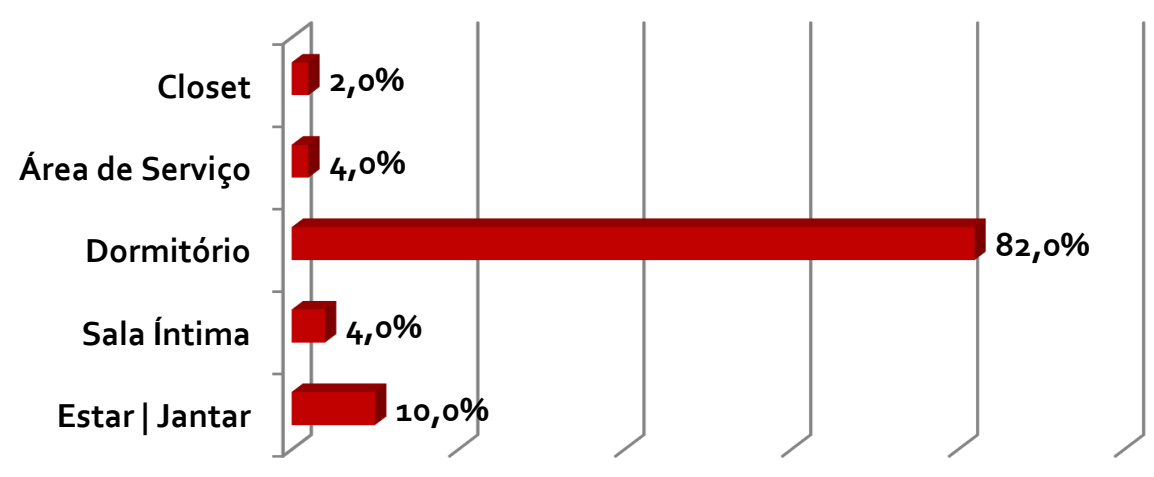

Porcentagem de Implantação por Setor da Habitação

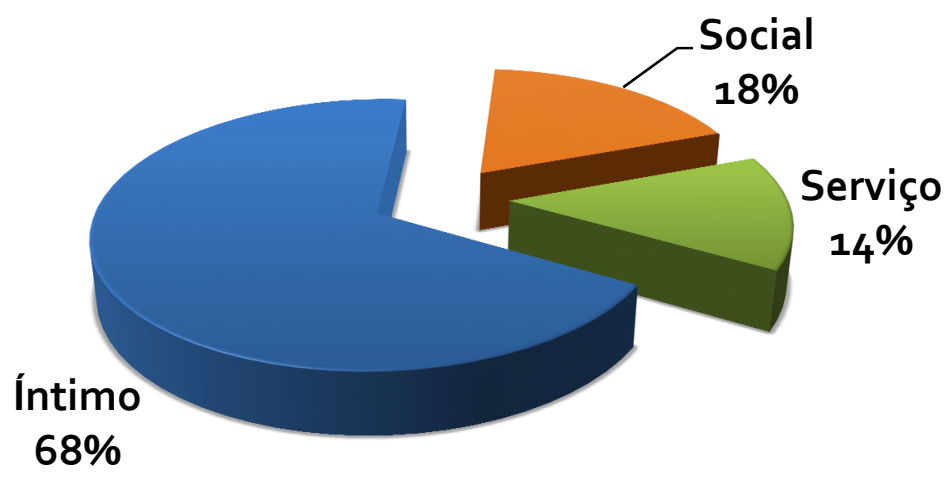




\section{Porcentagem de Postos de Trabalho com Áreas Abaixo da Recomendação}

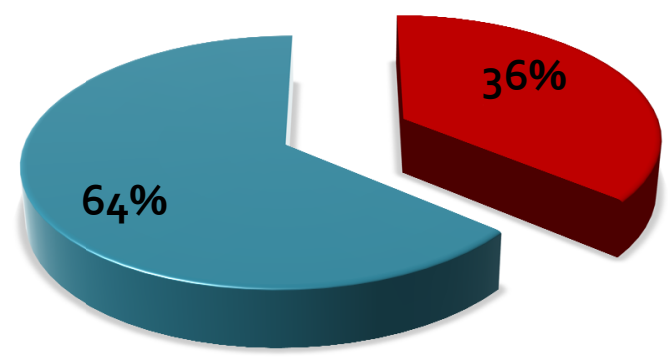

口Área $<2,46 \mathrm{~m} 2$ Não Conforme

$\square$ Área $>2,46 \mathrm{m2}$ Conforme

\section{Porcentagem de Cadeiras por Material}

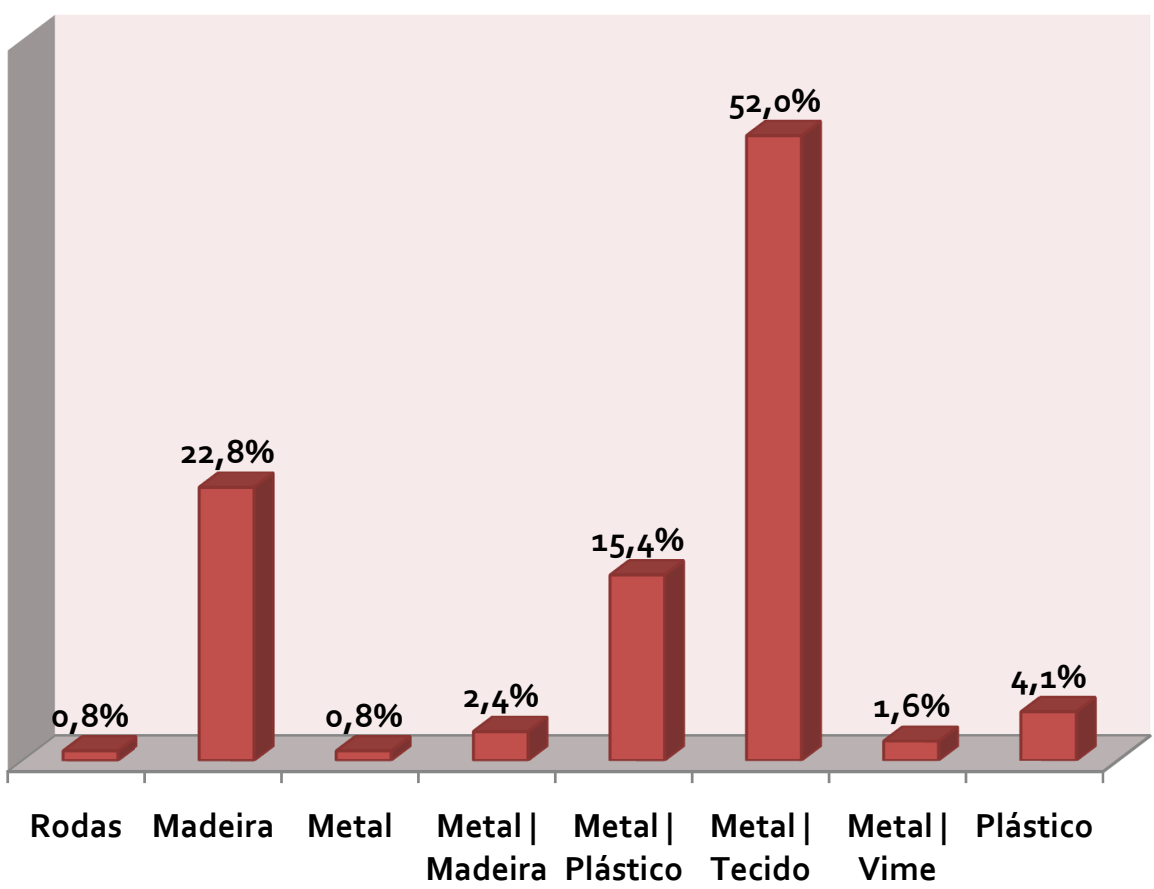




\section{Porcentagem de Cadeiras por Material por} Itens de Não Conformidade

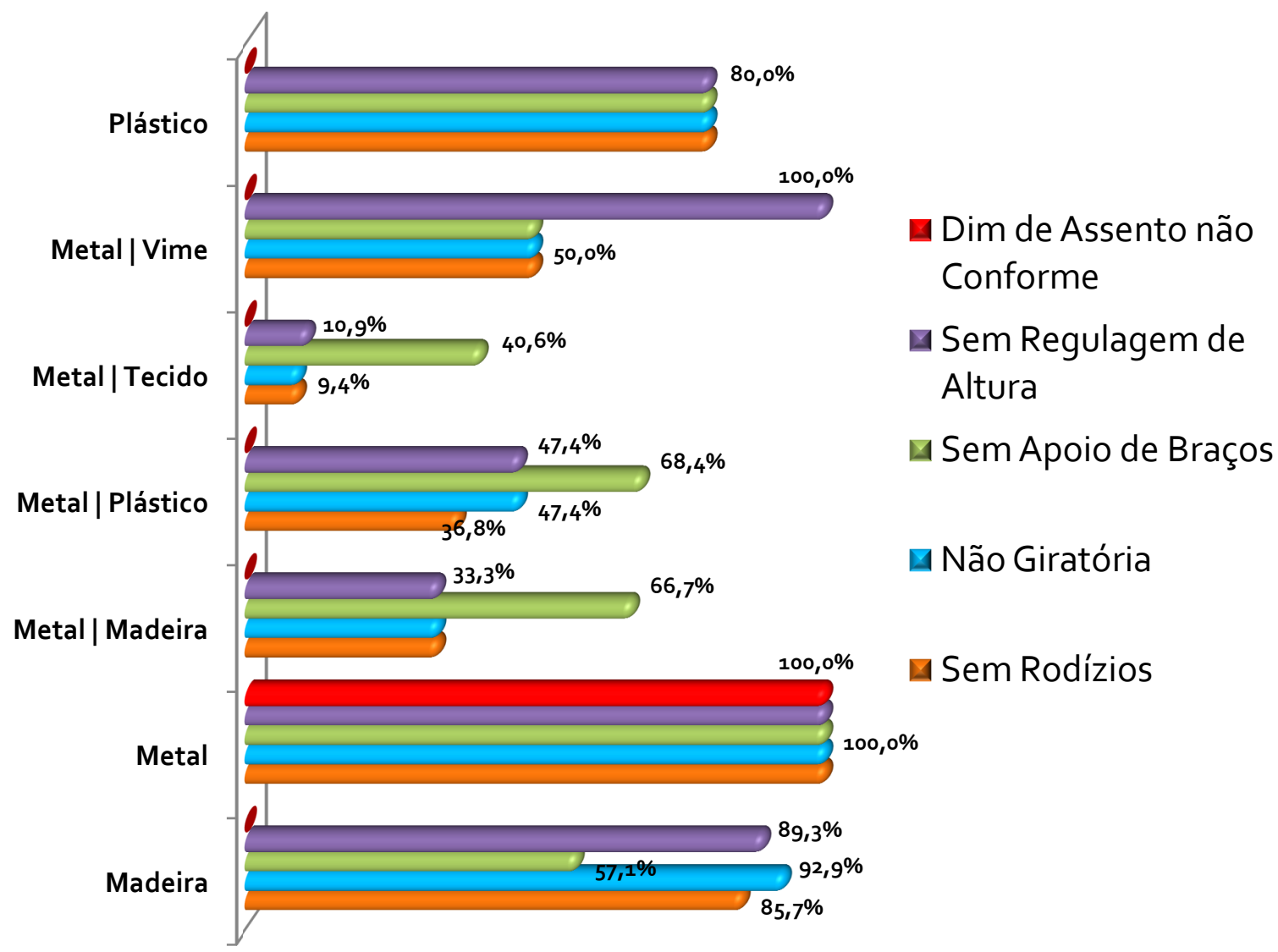

\section{Porcentagem de Cadeiras por Material por Conformidade}

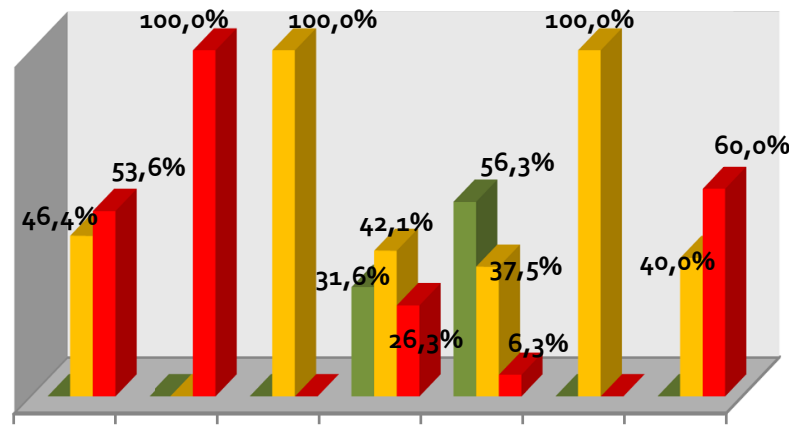

Conforme

Parcialmente Conforme - Não Conforme

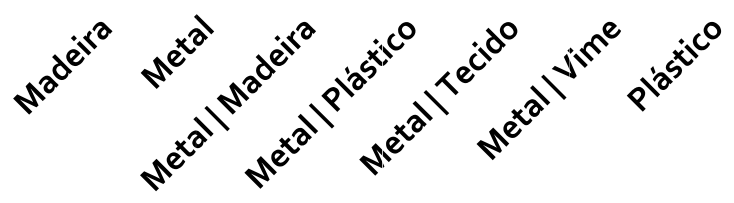




\section{Porcentagem de Mesas por Material}

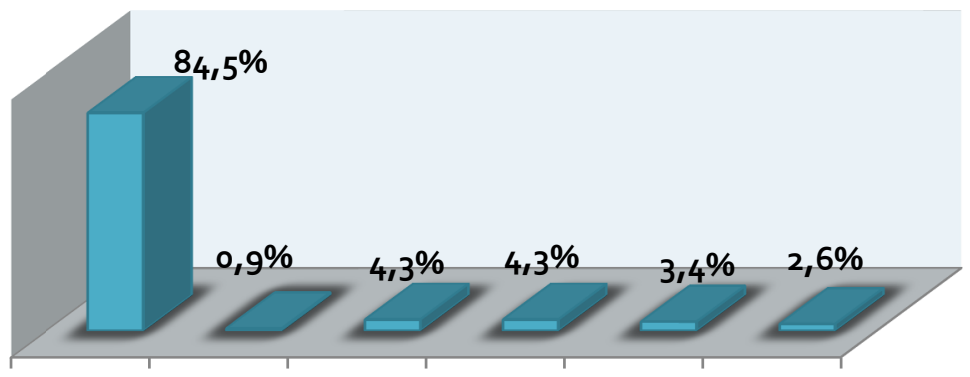

Madeira Madeira Madeira Metal| Metal| Vidro

|Pedra |Vidro Madeira Vidro

Porcentagem de Mesa de Trabalho com

Altura de Tampo Recomendada

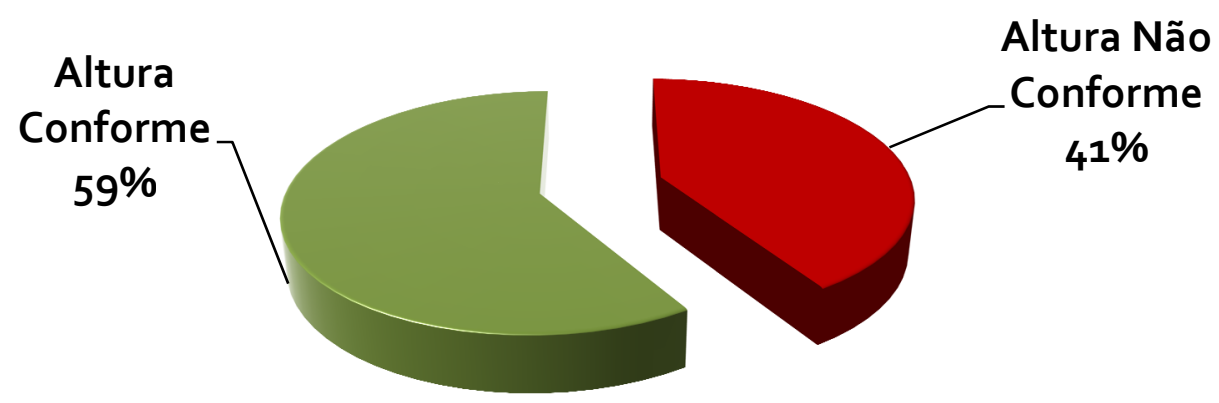

Intervalo de Altura Recomendado: entre 73,7 e 76,2 cm

Porcentagem de Mesas por Material de Revestimento do Tampo

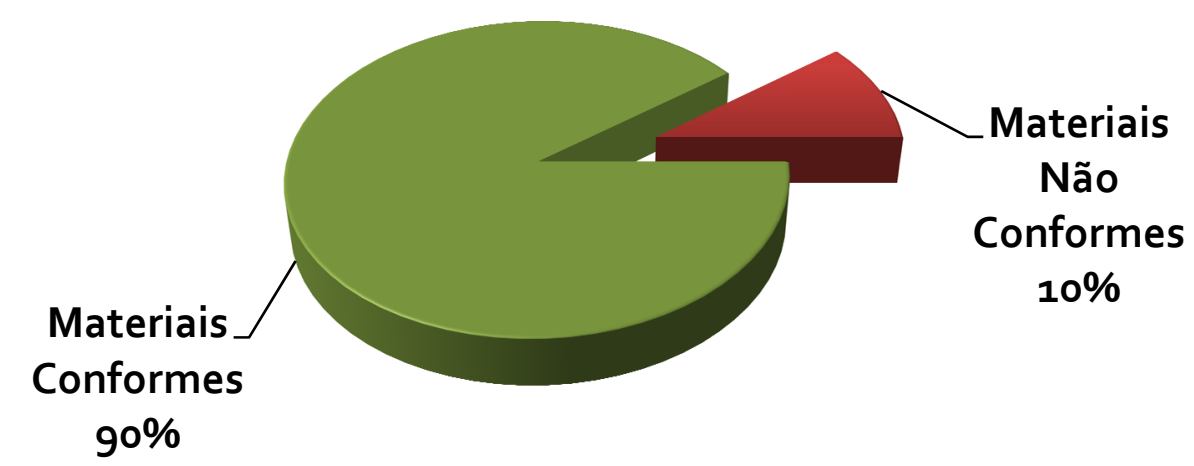


Porcentagem de Microcomputador porTipologia
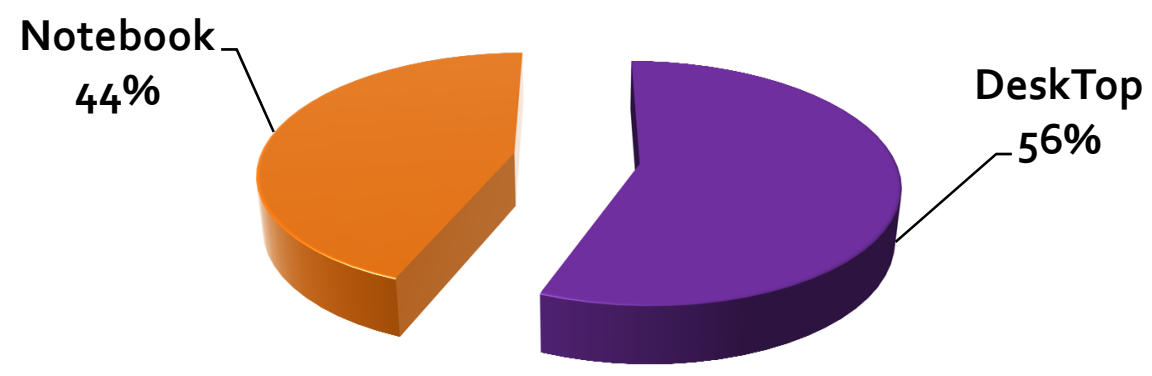

Porcentagem de Monitores por Tipologia

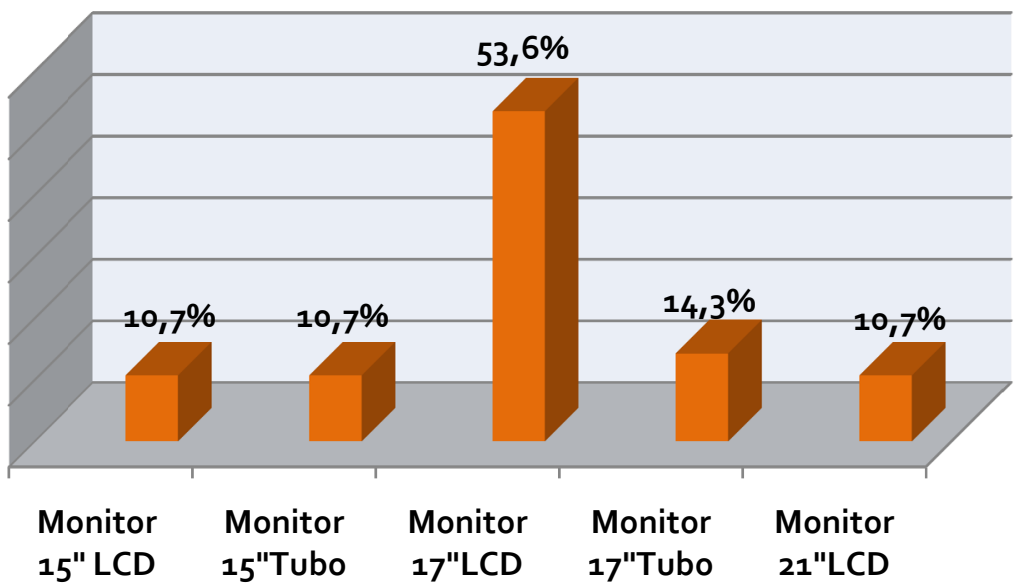

Porcentagem de Monitores em Conformidade segundo a Altura

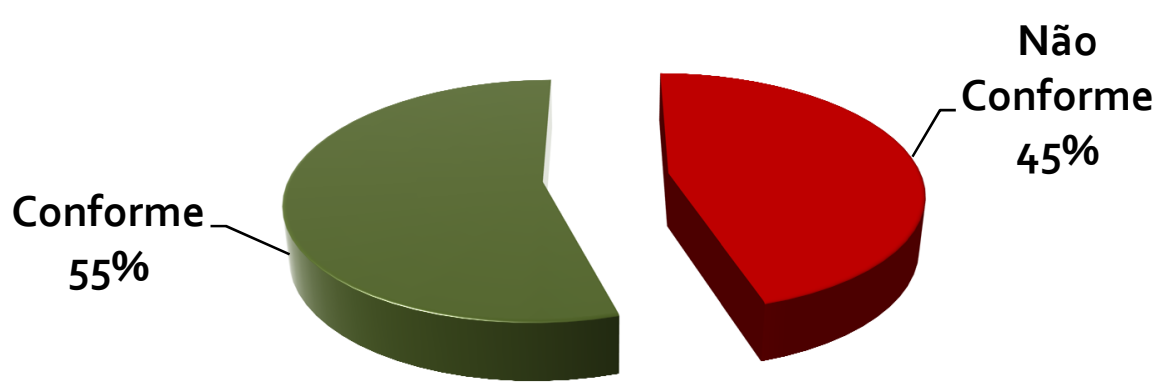


Porcentagem de Teclado em Conformidade segundo a Altura

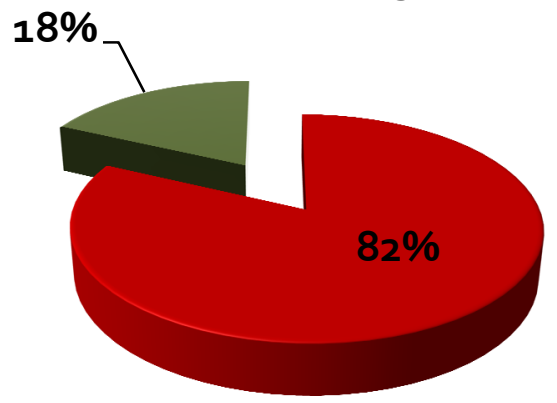

Acima de $66,2 \mathrm{~cm}$ Não Conforme

Q Entre 63,7 e 66,2cm

Conforme

- Caracterização das Instalações do Posto de Trabalho

\begin{tabular}{|c|c|c|}
\hline & Corrente Elétrica: & $100 \%$ \\
\hline & Número Médio de Tomadas: & 2.46 \\
\hline & Telefonia Fixa: & $87 \%$ \\
\hline & Telefonia Móvel: & $93 \%$ \\
\hline & Conexão com Banda Larga: & $97 \%$ \\
\hline & Luz no Forro: & $100 \%$ \\
\hline & Incandescente & $83 \%$ \\
\hline & Fria & $17 \%$ \\
\hline & Arandela: & $2 \%$ \\
\hline & Incandescente & $100 \%$ \\
\hline & Fria & ०\% \\
\hline & Luminária de Mesa: & $37 \%$ \\
\hline & Incandescente & $46 \%$ \\
\hline & Fria & $54 \%$ \\
\hline
\end{tabular}

Porcentagem de lluminação em Não Conformidade

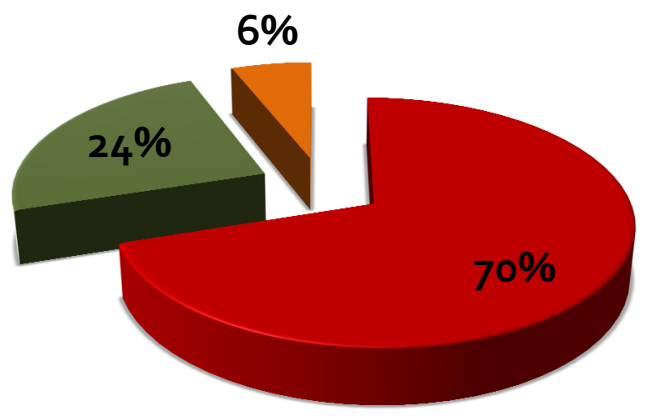

Abaixo de 500 Lux Não Conforme

Entre 500 e 1000 Lux Conforme

$\square$ Acima de 1000 Lux Não Conforme 


\section{Porcentagem dos Fatores Positivos sobre a}

Atividade de Escritório na Habitação

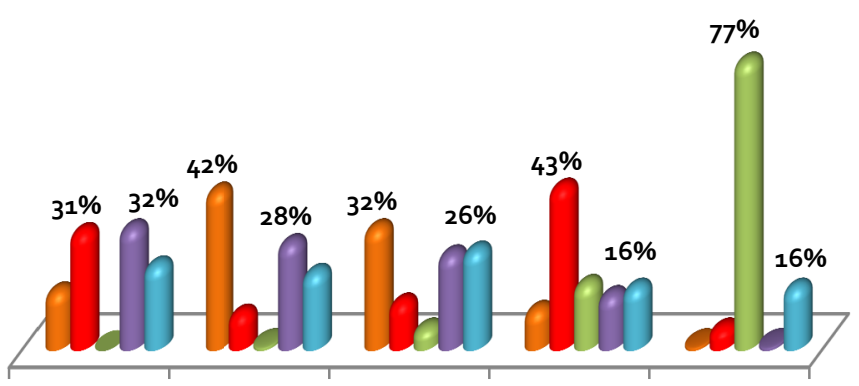

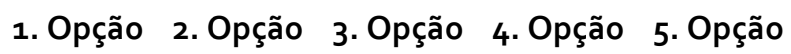

Evita Deslocamentos

Q Gastos com outro local

Meio Ambiente

\ Organização do Tempo

\ Tempo com a Família

\section{Porcentagem dos Fatores Negativos sobre a}

Atividade de Escritórios na Habitação

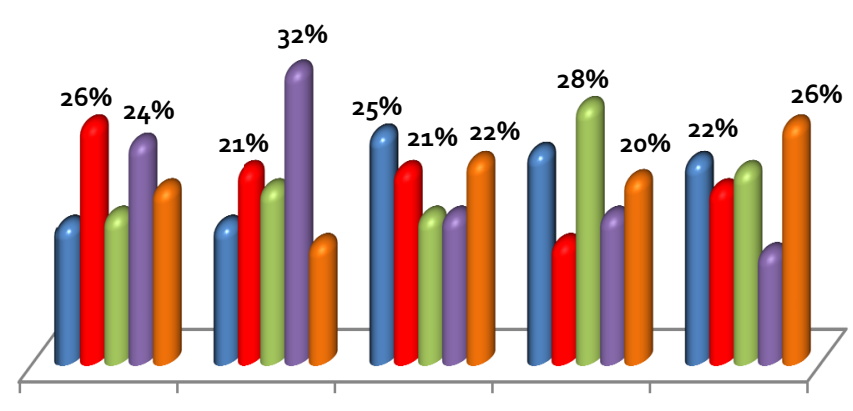

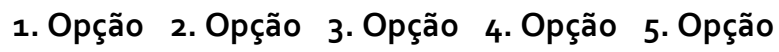

Ambientes Inadequados

Falta de Privacidade

\Gastos com Implantação

Interferências

Domésticas

Porcentagem de Pontos Negativos de Conforto do

Posto de Trabalho Implantado

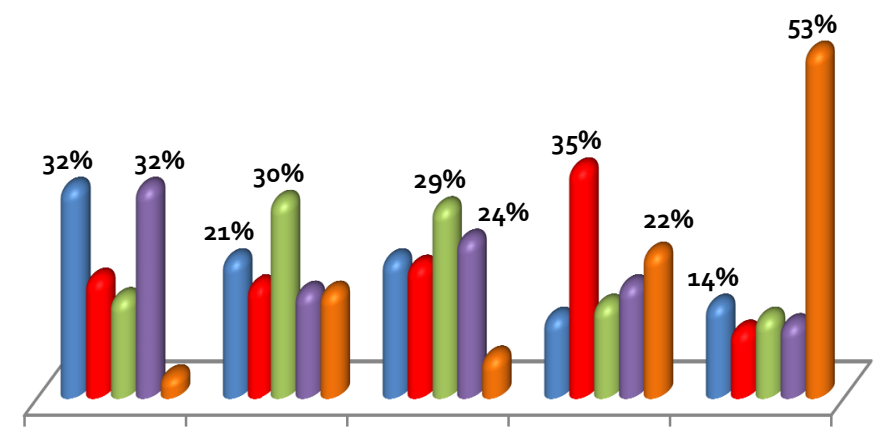

Espaço Físico

Q lluminação

\Mobiliário|Equipamento

Ruído

\ Ventilação
1. Opção
2. Opção
3. Opção
4. Opção
5. Opção 


\subsubsection{Análise e Diagnóstico das Informações Levantadas}

Os dados tabulados devem permitir leituras diretas e o cruzamento de algumas informações para que o processamento destes dados possibilite as análises necessárias às conclusões e objetivos da pesquisa.

Nesse sentido, as seguintes leituras foram os objetivos das investigações:

- A porcentagem de cada tipologia - casa | apartamento

- A porcentagem de cada tipologia - número de dormitórios

- A porcentagem em função da localização por zona na cidade

- O número de habitantes por unidade habitacional

- O número médio de habitantes por unidade habitacional

- A idade média dos habitantes

- A porcentagem dos habitantes por sexo

- A porcentagem dos habitantes por escolaridade

- A porcentagem dos habitantes por Ocupação

- A porcentagem de usuários do posto de trabalho

- A porcentagem dos usuários do posto de trabalho por sexo

- A porcentagem dos usuários do posto de trabalho por Ocupação

- A porcentagem dos usuários do posto de trabalho por ramo de atividade 
- A porcentagem de uso do posto de trabalho em função de dias da semana

- A porcentagem de uso do posto de trabalho em função do período

- A porcentagem de uso do posto de trabalho em função da duração

- A porcentagem segundo a tipologia de uso

- Área média dos postos de trabalho

- A porcentagem de tipologia de implantação

- Área média do posto de trabalho por tipologia de implantação

- A porcentagem por ambiente de implantação

- A porcentagem de implantação por setor da habitação

- A caracterização de cadeiras

- A caracterização de mesas

- A caracterização de equipamentos

- A caracterização das instalações do posto de trabalho

- A porcentagem dos fatores positivos sobre a atividade de escritório na habitação

- A porcentagem de fatores negativos sobre a atividade de escritório na habitação

- A porcentagem de pontos negativos de conforto do posto de trabalho implantado 
Com o encerramento do processamento das informações investigadas e realizadas as análises dos dados, algumas observações podem ser consideradas relevantes para a caracterização do universo dos Home Offices pesquisados e seus usuários, buscando o objetivo inicial, cuja proposta era um primeiro conhecimento acerca do tema, tendo sido divididos em sub-temas, conforme segue:

\section{A. Habitações}

Sobre as unidades habitacionais levantadas, $73 \%$ são apartamentos. A tipologia de 4 dormitórios corresponde a $40 \%$ dos casos investigados, seguida da tipologia de 3 dormitórios com 30\%.

Quanto a localização na cidade, existiu a preocupação de coletar as amostras de maneira homogênea, porém deve-se destacar que a zona Sul proporcionou uma quantidade mais elevada de casos, com $35 \%$ e na zona Centro verificou-se um volume de amostras que atingiu um percentual abaixo das outras regiões - apenas $9 \%$ - em função das dificuldades técnicas de investigação com famílias residentes na região.

\section{B. Habitantes}

O número médio de habitantes por unidade é de 2,91 pessoas, com idade média de 31,5 anos, refletindo os dados apresentados pela Fundação SEADE (Fundação Sistema Estadual de Análise de Dados), em seu relatório "Perfil do Paulistano em 2007", que aponta para um número de 3,2 moradores por domicílio, com idade média de 31,1 anos. 
A composição da população residente nas habitações pesquisadas, por sexo, apresentou uma ligeira vantagem para o número de mulheres, $50,87 \%$ contra $49,13 \%$ dos homens.

Sobre a educação, a população investigada apresenta um alto nível de escolaridade, com $93 \%$ da população com mais de 8 anos de estudo, o que representa um dado divergente da pesquisa SEADE, onde este número é de apenas $46,9 \%$, além do alto índice de indivíduos em nível superior e pós graduação, $62 \%$ contra apenas $13.4 \%$ da pesquisa SEADE.

Em relação às atividades desenvolvidas pela população investigada, temos o Trabalhador com Carteira Assinada Trabalhador Registrado - com 31,5\% de incidência, seguidos pela atividade de Estudo com 30\%. Já os Trabalhadores Informais, Profissionais Liberais e Empregadores somam um total de $31,5 \%$.

\section{Uso do Posto de Trabalho}

Acerca do uso do Posto de Trabalho, $85 \%$ da população residente nas unidades habitacionais investigadas desenvolve algum tipo de atividade no Posto, com equilíbrio entre homens e mulheres, em uma faixa etária de 30.9 anos.

Contrariando as expectativas iniciais, o Trabalhador Registrado é o maior usuário do Posto, com $36 \%$ de incidência, desenvolvendo atividades complementares ao seu trabalho e também utilizando o posto para atividades de comunicação. 
O conjunto de formado pelos Trabalhadores Informais, Profissionais Liberais e Empregadores, que inicialmente pressupunha-se o grupo maior em número de usuários, apresentou cerca de $33 \%$ de incidência, porém vale a ressalva de que este último grupo desenvolve atividades de trabalho remunerado e comunicação com maior freqüência que o primeiro grupo.

Daqueles que usam o posto de trabalho para atividades não profissionais, os estudantes aparecem com cerca de $28 \%$ d incidência, no entanto, $70 \%$ dos usuários desenvolve algum tipo de atividade profissional no posto de trabalho da habitação.

Considerando o ramo de atividade profissional, as atividades relativas ao comércio apresentou $13,1 \%$ de incidência, seguida de atividades de educação|docência, arquitetura e administração.

A permanência dos usuários quando em atividades no posto de trabalho é de 2 a 4 horas na maioria dos casos, com $62 \%$ de incidência.

O uso do posto de trabalho é dividido de maneira homogênea pelos dias úteis da semana, observando-se as segundas-feiras com um volume de uso ligeiramente maior, e as sextas-feiras ligeiramente menor. Nos finais de semana a utilização do posto de trabalho é reduzida em relação aos dias úteis.

No caso do período do dia em que o posto é utilizado, o período da tarde é mais incidente, com $39 \%$ dos casos. Os períodos da manhã e noite têm praticamente o mesmo volume de ocupação. 
Olhando-se para os períodos do dia e analisando em conjunto dos dados dos dias da semana, percebe-se apenas uma leitura mais acentuada da utilização do posto de trabalho no período da tarde aos finais de semana, principalmente no sábado, sendo o período mais requisitado pelos usuários dentre todos os demais.

A atividade de comunicação, sendo praticada por $98 \%$ dos usuários, é a mais incidente como utilização do posto.

A atividade de Ocupação Complementar Remunerado atinge $60 \%$ e a Ocupação Principal Remunerada é atividade desenvolvida por apenas $21 \%$ dos usuários, enquanto lazer, estudo e pesquisa chegam à marca de $60 \%$.

\section{Implantação do Posto de Trabalho}

Acerca da implantação, buscou-se investigar quem efetuou a implantação do posto, qual a tipologia da implantação, em que ambientes foram implantados e em qual setor da habitação.

Em $100 \%$ dos casos, o posto de trabalho foi implantado pelo próprio usuário. Mesmo aqueles que estão vinculados a uma empresa e esta permite que sejam desenvolvidas atividades de escritório fora da área física da empresa, a responsabilidade de implantação e manutenção do posto de trabalho cabe ao usuário. 
Segundo as pesquisas, a maioria dos postos de trabalho encontram-se implantados em locais onde coexistem com outras funções, ou seja, fazem parte de um ambiente préestabelecido na habitação, com índice de $50 \%$.

Deste universo, em $82 \%$ dos casos o dormitório foi utilizado na implantação e $10 \%$ nos locais de estar|jantar.

Em 39\% das amostras, o posto de trabalho foi implantado com a adaptação de um ambiente, alterando seu uso para as atividades de escritório.

Nesses casos, $48,7 \%$ foram implantados em dormitórios e $38,5 \%$ em dormitórios de serviço.

Em apenas $5 \%$ das unidades investigadas foram encontrados Home Offices determinados em projeto, que fizeram parte do programa inicial da habitação.

O setor íntimo da moradia recebeu $68 \%$ das implantações pesquisadas, $18 \%$ no setor social e $14 \%$ no setor de serviço.

A área média dos postos implantados na habitações pesquisadas é de $4,93 \mathrm{~m} 2$, sendo que $64 \%$ encerram áreas iguais ou superiores aos $2,46 \mathrm{~m} 2$ recomendados nesta tese de doutoramento. 
A respeito do mobiliário, equipamentos e instalações do posto de trabalho, foram investigados os principais itens que compõem o posto de trabalho, em relação aos materiais e dimensões.

Acerca das cadeiras, a maioria, 52\%, utilizada as de metal, com revestimento de assento e encosto em espuma e tecido.

$27,6 \%$ do total das cadeiras pesquisadas não possuem nenhum tipo de ajuste ou qualquer elemento que permita giro ou deslocamento.

Já no caso das cadeiras de madeira, plástico e metal, cerca de $80 \%$ não possuem regulagens de altura e são estáticas em relação a rodízios ou giratórias.

No caso das mesas, a grande maioria é de madeira ou fórmica, com índice de $84,5 \%$, sem qualquer tipo de ajustes, e $18 \%$ dos casos apresentaram um apoio para teclado abaixo do plano de trabalho principal, lembrando que $44 \%$ utiliza aparelhos notebooks, que são colocados sobre a mesa.

41\% das mesas apresentaram uma altura divergente do intervalo proposto - entre 73,7 e $76,2 \mathrm{~cm}$, e a altura média ficou em $76,4 \mathrm{~cm}$. 
Os armários e estantes também são, em sua maioria, de madeira, $67,5 \%$ dos casos, com as seguintes dimensões médias: Largura $124 \mathrm{~cm}$, Profundidade $39 \mathrm{~cm}$ e altura $115 \mathrm{~cm}$, utilizados para a guarda e armazenamento de insumos de escritório - 40\%, livros e material didático - 70\%, e arquivos em geral $-58 \%$.

As gavetas seguem a linha da madeira, com $84 \%$ dos casos, sendo utilizadas para a guarda e armazenamento de insumos em $41 \%$ da amostra. As dimensões médias são: Largura $65 \mathrm{~cm}$, Profundidade $52 \mathrm{~cm}$ e altura $60 \mathrm{~cm}$, com uma média de 3,5 gavetas.

No caso dos equipamentos de informática, os microcomputadores de mesa (Desktop) ainda compõem a grande maioria dos postos de trabalho, com $56 \%$ de incidência, com monitores de 15 e 17 polegadas atingindo $89 \%$ dos casos.

Em 49\% das amostras, a Unidade Central de Processamento - CPU - encontra-se no piso, $31 \%$ dos postos de trabalho possuem impressora e scanner separados e $42 \%$ operam com equipamentos multifuncionais, perfazendo um total de $69 \%$ de postos com estes periféricos instalados.

Acerca das instalações, $100 \%$ dos postos de trabalho utilizam a corrente elétrica de 127 Volts, com um número médio de 2,46 tomadas. 
$83 \%$ operam com luz incandescente no forro, com uma média de 187 Watts de iluminação instalados.

Apenas $37 \%$ da amostra apresentou luminárias de mesa instaladas, das quais $54 \%$ utilizam luz fria.

$70 \%$ dos postos de trabalho apresentaram-se abaixo dos 500 Lux recomendados.

Sobre a comunicabilidade externa do posto de trabalho, $80 \%$ operam com telefonia fixa e celular, $7 \%$ apenas com telefonia fixa e $13 \%$ apenas com telefonia celular.

$97 \%$ dos casos possuem conexão de banda larga, $2 \%$ operam com conexão discada e $1 \%$ não possui conexão.

\section{F. Fatores de Conforto e Usabilidade do}

Posto de Trabalho

Acerca dos fatores de conforto e usabilidade, a pesquisa investigou a opinião dos usuários sobre os aspectos positivos e negativos do uso da habitação para o desenvolvimento de atividades de escritório, e ainda quais os pontos que estes usuários consideram que estejam em desacordo em seus postos para que as atividades sejam plenamente desenvolvidas.

Como fatores positivos, a organização do tempo e a economia de gastos vêm como primeira opção de resposta, praticamente empatadas em $32 \%$ das pesquisas. 
Pode-se perceber ainda, que a questão ambiental é praticamente irrelevante, sendo que $94 \%$ da amostra apresentou este fator como 4ㅇ ou 5ㅇo opcão.

Dentro dos fatores negativos, a falta de privacidade e a interferência doméstica ficam em posição de destaque, aproximadamente $25 \%$ cada das respostas na 1 o opção.

Somando-se a 1 을 2 e opções, observa-se que as interferências domésticas continuam sendo o fator de maior conflito com $56 \%$ das respostas, e a questão da falta de privacidade aparece com apenas $47 \%$. Com $35 \%$, os gastos com implantação do posto de trabalho vem em terceiro lugar nas respostas agrupadas.

A questão do conforto dimensional, representado pelo espaço físico, e o ruído, foram apresentadas como os principais fatores negativos pelos usuários em seus postos de trabalho, com $32 \%$ de respostas para cada um dos itens.

Em respostas acumuladas, com 1 을 2 o opções, o espaço físico fica em destaque, com 53\%.

O segundo fator negativo, é a questão do ruído, porém, vale observar que, se somadas as 1 으 e 2 으 opções de respostas, existe um equilíbrio entre a questão do ruído e das condições de mobiliário e equipamentos, com cerca de $47 \%$ do universo para cada um. 


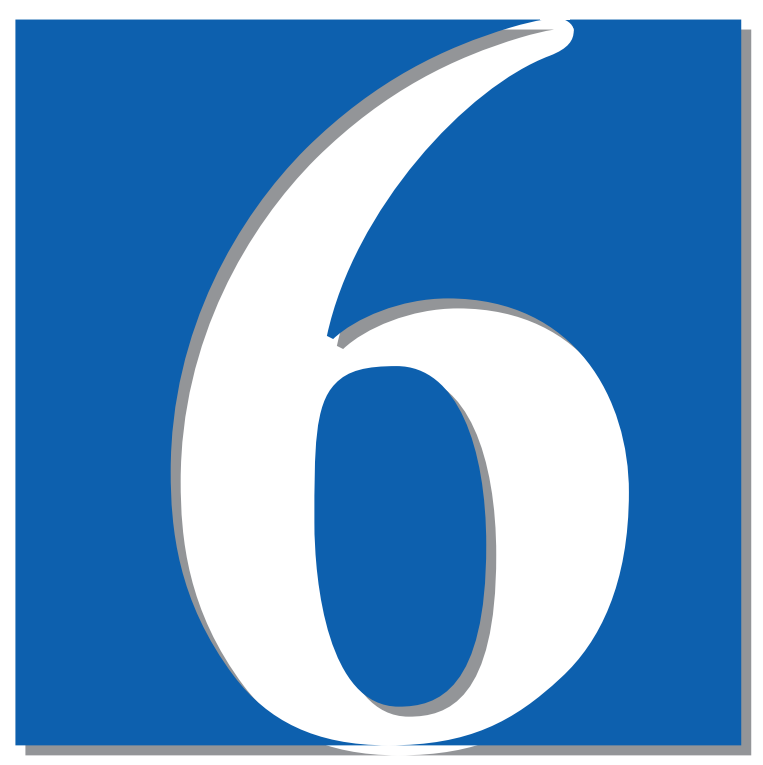

Conclusões Reflexões e Recomendações

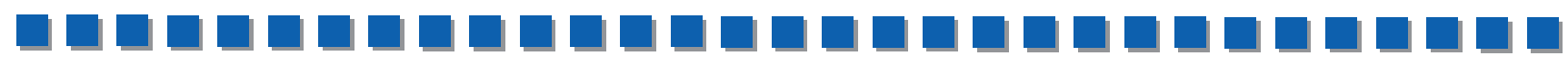

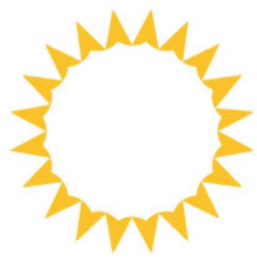




\section{CAPÍTULO 6. CONCLUSÕES, REFLEXÕES E RECOMENDAÇÕES}

\subsection{Considerações Preliminares}

O desenvolvimento de atividades relativas ao trabalho de escritório vem se tornando cada vez mais comum na vida dos moradores das grandes cidades.

Esta tese de doutoramento procurou por respostas sobre o tema por meio da investigação acadêmica e, após um ciclo de pesquisas de quatro anos, várias das questões levantadas podem ser elucidadas e compreendidas.

\subsection{Verificação de Comprovação da Hipótese}

Foi colocada a hipótese como linha mestra para o desenvolvimento deste trabalho e neste momento existe a verificação se a hipótese enunciada confirma-se, ou não, à luz da pesquisa realizada. 


\subsubsection{Verificação da Hipótese - parte A}

"Os projetos de arquitetura que afirmam contemplar o Home Office, na verdade não inseriram um novo ambiente na habitação, mas sim estão adaptando espaços já existentes a estas atividades e disponibilizando a possibilidade de serem utilizados para esta finalidade."

Em relação a esta hipótese, a pesquisa procurou nos lançamentos imobiliários residenciais no município de São Paulo, entre os anos de 2006 e 2009, os dados necessários para a verificação do enunciado da hipótese.

Por meio da investigação e análise do material coletado, chega-se aos seguintes resultados:

- quando se trata de "ambiente" destinado ao Home Office, apenas $22 \%$ das plantas apresentam esta área;

- quando se trata de "posto de trabalho", foi verificado que $68 \%$ das plantas apresentam esta área;

- apenas $9 \%$ das plantas apresenta Home Offices "projetados", $18 \%$ são ambientes que foram "adaptados" e $73 \%$ o posto de trabalho faz "parte de ambiente" e compartilha da área com outras funções da habitação. 
Com estes dados, pode-se concluir que não existe uma nova área incorporada à habitação destinada especificamente ao Home Office, mas uma adequação de espaços préexistentes, com outras funções da rotina doméstica.

Para ilustrar esta afirmação, temos o empreendimento "Tribeca Personal Club", lançado no final do ano de 2006.

$\mathrm{Na}$ ficha técnica do lançamento, verifica-se que o empreendimento é caracterizado como um "4 dormitórios", porém ao analisarmos as plantas disponibilizadas no material de vendas, nenhuma das opções contempla claramente 4 dormitórios.

Figura 17

Esta prática é comum no universo da promoção e venda do ramo imobiliário, onde a oferta por um número maior de dormitório pode influenciar na decisão de compra e, não raro, encontram-se plantões de vendas com apartamentos decorados cuja opção implantada não oferece o número de dormitório anunciado no material promocional.

Da mesma maneira, quando se anuncia " 4 dormitórios com Home Office", existe a possibilidade de estar se tratando de uma unidade habitacional onde $04^{\circ}$ dormitório pode ser revertido em uma ampliação de sala ou utilizado como Home Office, perdendo a característica anunciada de 4 dormitórios. 


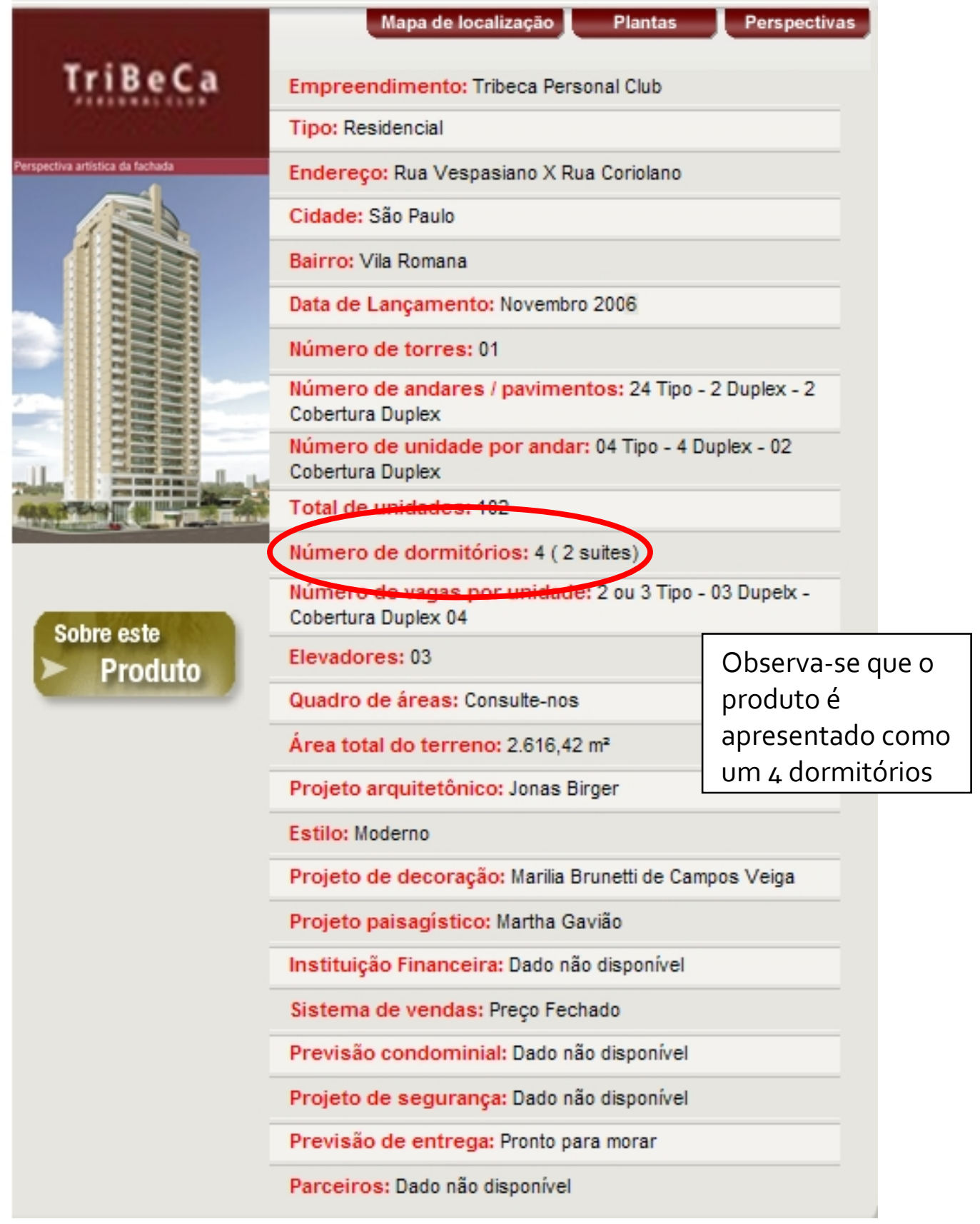

Figura 17 - Ficha de Empreendimento Imobiliário Fonte: Itaplan 
Em relação à hipótese colocada, a planta "opção A" deste empreendimento, possui uma área para uso de computador inserida em um dos dormitórios e um posto de trabalho maior que compartilha uma área que, intuitivamente, deveria estar instalado $04^{\circ}$ dormitório como anunciado, porém é apresentado como uma sala íntima ou um espaço de trabalho, cujo mobiliário é distinto daquele indicado nos dormitórios. Observa-se, ainda, que a opção contempla o dormitório de serviço.

Figura 18

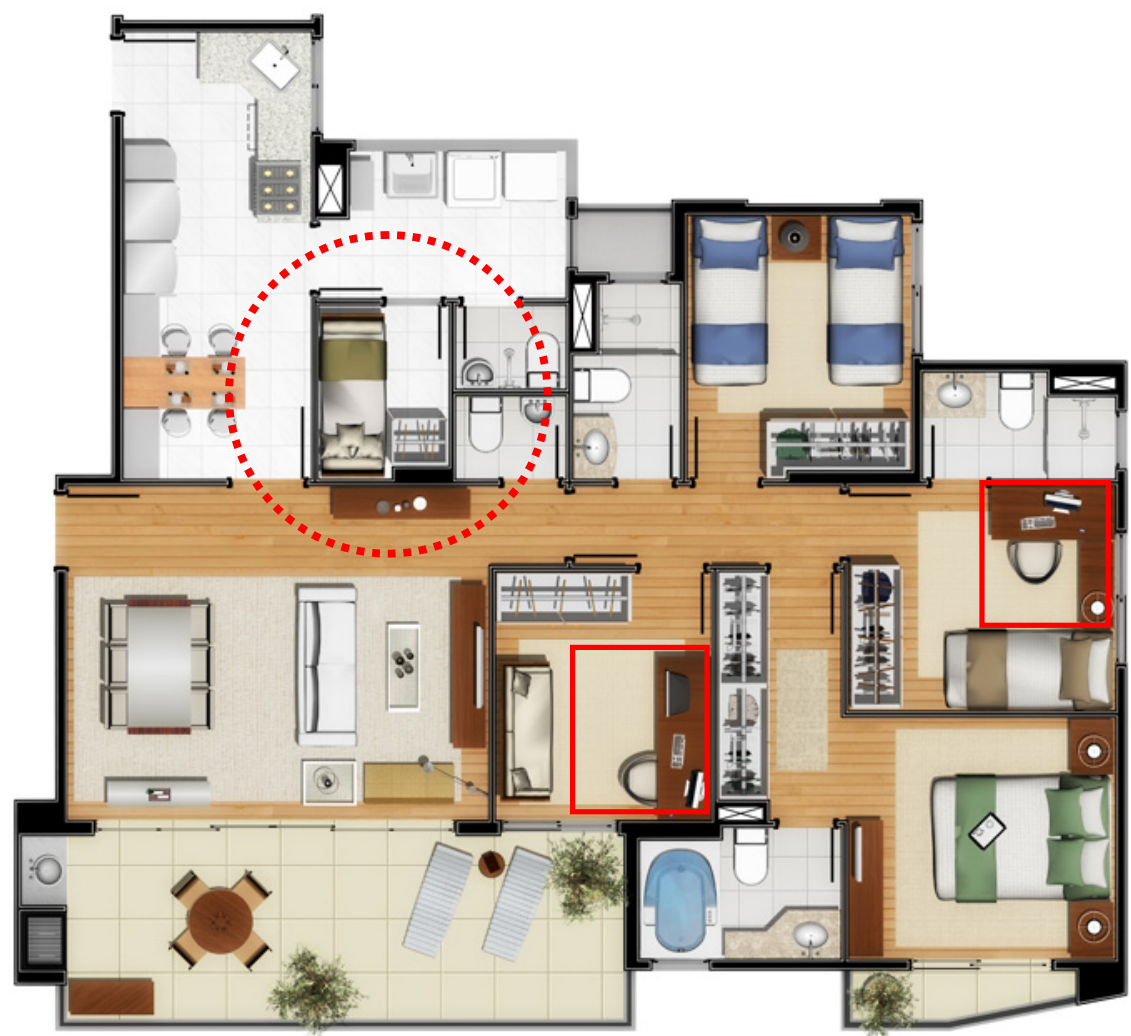

Figura 18 - Empreendimento Tribeca Personal Club - Opção A Fonte: Itaplan 
Pode-se, porém, observar que na "opção B" do mesmo empreendimento, o Home Office é alocado na área projetada para o dormitório de serviço, a sala é ampliada onde existia a sala íntima e o closet da suíte principal ganha mais uma linha de armário. Figura 19

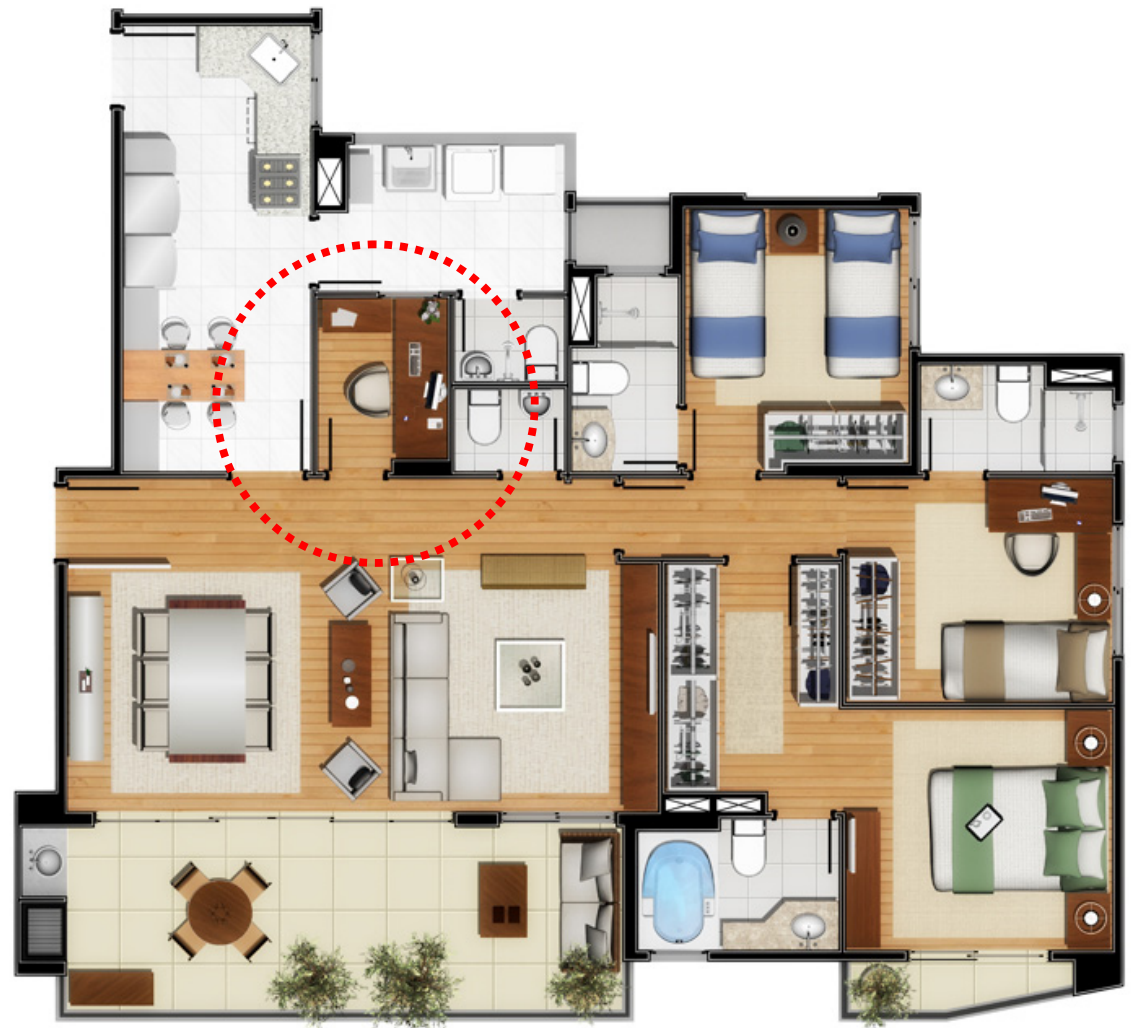

Figura 19-Empreendimento Tribeca Personal Club - Opção B Fonte: Itaplan

O fato da pesquisa ter apresentado apenas $18 \%$ dos casos onde o "ambiente" foi destinado exclusivamente ao Home Office por uma adaptação e em contrapartida $73 \%$ das plantas oferecem o posto de trabalho compartilhando ambientes é um indicativo de que não existe de fato uma preocupação dos projetistas em uma área específica para as atividades de escritório, portanto, fica comprovada a primeira parte da hipótese proposta.

\subsubsection{Verificação da hipótese - parte B}


"Existe uma atividade com características de trabalho de escritório e que é distinta das atividades administrativas pessoais e familiares que são realizadas no ambiente residencial e este ambiente não oferece condições de abrigar estas atividades, nomeadamente nos seguintes aspectos e condições de conforto:

- Área Física

- Mobiliário

- Equipamentos

- Iluminação

- Atividade Doméstica | Atividade Profissional"

Em relação a esta hipótese, a pesquisa investigou trabalhadores que desenvolvem suas atividades de escritório em suas residências, em período integral ou parte dele, no município de São Paulo.

Alguns dos resultados obtidos delineiam as conclusões apresentadas, quais sejam:

a. Sobre a atividade de trabalho de escritório nas residências:

- Observa-se que $85 \%$ dos moradores das residências pesquisadas são usuários do posto de trabalho;

- Destes usuários, 70\% desenvolvem algum tipo de atividade profissional quando da utilização do posto de trabalho; 
- Os períodos da manhã e tarde associados e os dias úteis da semana são aqueles onde as atividades são predominantemente desenvolvidas;

- $65 \%$ dos usuários utilizam o posto de trabalho por uma duração diária entre 2 e 4 horas;

Fica, portanto, comprovada a colocação de que existem atividades com características de trabalho de escritório que estão sendo realizadas no ambiente residencial.

b. Sobre a área física:

- $50 \%$ dos casos possuem o posto de trabalho como "parte de ambiente", ou seja, compartilham o espaço com outras atividades;

- $39 \%$ adaptaram algum ambiente pré-existente para a implantação do Home Office;

- Os dormitórios e os dormitórios de serviço são os ambientes que mais foram adaptados ou que recebem esta função de Home Office;

- $64 \%$ dos casos apresentou área física do posto de trabalho superior a $2,46 \mathrm{~m} 2$;

- $32 \%$ responderam ser o espaço físico o ponto negativo do posto implantado.

Na questão da área física, embora os ambientes onde estão sendo desenvolvidas as atividades de escritório sejam adaptados, ou façam parte de um ambiente onde este é compartilhado por outras funções, a área destinada ao posto de trabalho é suficiente par atender as necessidades da atividade, segundo o parâmetro proposto no Capítulo 3 deste trabalho. 
Em contraponto, deve-se considerar que os usuários apontam como a falta de espaço físico o item mais negativo de seus postos de trabalho instalados na habitação.

Portando, embora a sensibilidade dos usuários apontem para a necessidade de uma área física distinta daquela em que estão desenvolvendo as atividades de trabalho de escritório, não se comprova a colocação de que a área física não é adequada ao desempenho das atividades de escritório no ambiente residencial.

c. Sobre o mobiliário:

- Sobre as cadeiras, a maioria analisada, com 42,6\%, encontra-se em situação "parcialmente conforme", onde apenas alguns itens atendem aos parâmetros e requisitos definidos no Capítulo 3, porém é grande a incidência de cadeiras "não conformes" $27,6 \%$, onde a totalidade dos parâmetros e requisitos propostos deixam de ser atendidos;

- Em relação à altura do tampo de trabalho, as mesas apresentam 59\% de situações "conformes", e 90\% de conformidade em relação ao tipo de material de revestimento do tampo de trabalho;

- Apenas $18 \%$ dos casos apresentou a altura do teclado no intervalo proposto, portanto, $82 \%$ encontram-se em situação "não conforme";

- $47 \%$ dos usuários afirmaram que o mobiliário, ao lado do ruído, é o segundo item que mais incomoda por não atender suas necessidades no posto de trabalho instalado em suas residências. 
Sobre o mobiliário, existe um equilíbrio entre os pontos que atendem e os que não atendem aos parâmetros e requisitos propostos e, embora não se tenha chegado a um cenário contundente, a pesquisa mostrou que existem várias questões a serem resolvidas.

Portanto, considera-se comprovada a colocação de que o mobiliário utilizado nos postos de trabalho para atividades de escritório implantados nas residências não estão plenamente adequados ao desempenho destas atividades.

d. Sobre os equipamentos:

- $75 \%$ dos postos de trabalho que se utilizam de desktop estão equipados com monitores com tecnologia LDC e $44 \%$ do total dos casos utiliza notebooks;

- $55 \%$ do monitores estão instalados a uma altura "conforme" em relação ao usuário;

- 69\% possuem periféricos instalados para 0 desenvolvimento das atividades de escritório;

- $80 \%$ operam com telefonia fixa e celular;

- $97 \%$ operam com conexão de banda larga.

Em relação aos equipamentos, não existem pontos "não conformes" que se destaquem, portanto, a colocação de que os equipamentos não atendem às necessidades dos usuários não se comprova. 
e. Sobre a iluminação:

- $100 \%$ possui iluminação artificial, com ponto de luz no forro;

- Apenas $37 \%$ dos casos possui luminária de mesa;

- 70\% dos casos apresentaram-se com iluminação abaixo dos 500 LUX.

Embora a iluminação não tenha sido apontada pelos usuários como item negativo do posto de trabalho implantado, as medições mostraram que existe uma deficiência na iluminação da área de trabalho, com $44 \%$ dos casos operarem inferior à marca de 250 LUX, ou seja, menos que a metade da necessidade proposta.

Confirma-se, portanto, a colocação de que a iluminação não atende às necessidades para o desempenho de atividades relativas ao trabalho de escritório no ambiente residencial.

f. Sobre as atividades domésticas e as atividades profissionais:

- $26 \%$ dos casos aponta a "falta de privacidade" como ponto principal ponto negativo sobre a atividade de escritório na habitação;

- Considerando os valores da $1^{a}$ e $2^{a}$ opções de resposta, a "interferência da vida doméstica" aparece em destaque, com $56 \%$ das respostas;

- $32 \%$ responderam ser o espaço físico o ponto negativo do posto implantado. 
- $48 \%$ no valor agregado da $1^{a}$ e $2^{a}$ opções de resposta, indicaram o ruído como fator negativo de seus postos de trabalho implantados;

A implantação dos postos de trabalho no ambiente da habitação gera uma nova dinâmica na vida da residência e, de acordo com as pesquisas existe de fato uma interferência, quer seja pela falta de privacidade do trabalhador, quer seja pelo ruído causado pelas atividades da vida doméstica.

Fica comprovada a colocação de que existe a interferência da vida doméstica na vida profissional quando são desenvolvidas atividades de trabalho com características de escritório no ambiente residencial. 


\subsection{Conclusões, Reflexões e Recomendações}

O caminho foi percorrido. Desde a idéia inicial de se produzir um estudo acadêmico de pós graduação sobre o tema dos escritórios residenciais, das investigações que fizeram parte da dissertação de mestrado até a verificação das hipóteses colocadas nesta tese de doutoramento, conclui-se agora esta etapa de estudos, pesquisas, produção de textos, imagens, discussões e aprendizado.

O conhecimento adquirido ao longo destes anos dificilmente poderá ser medido, pois vai muito além do que se relaciona ao tema, passa por metodologias, conceitos, posturas e tantas outras questões que fazem parte de um conjunto muito maior do que a própria tese.

Talvez, o maior dos ganhos seja o exercício da reflexão, que nos permite observar, elaborar conexões e chegar a conclusões claras e fundamentadas.

Neste sentido, coloco agora minhas observações e conclusões não só como pesquisador do assunto, mas também como usuário de escritório residencial há pelo menos 15 anos.

Conforme estudado, historicamente as funções de trabalho e moradia compartilharam do espaço da habitação. 
O Museo de Artes y Costumbres Populares de Sevilla, tem em sua mostra a reconstituição do que foi uma morada do início do século $X X$, que abrigava tanto as funções do lar como as funções de trabalho, e descreve:

"A dedicação da família Diaz Velásquez para com o negócio de confecção e bordados, influenciou de maneira notável na configuração de sua morada, de modo que o piso principal da casa, na rua Brasil, esteve integralmente ocupado pelas dependências laborais do negócio. Ainda que a partir de 1924, a maior parte das encomendas eram destinadas a bordadeiras particulares que trabalhavam em seus domicílios, seguiram mantendo o escritório e as dependências laborais $[\ldots]^{\prime \prime}$

Como pode-se observar pelo texto, não só existia uma habitação adaptada às necessidades laborais, como outros colaboradores desenvolviam suas atividades de trabalho em suas residências, mostrando que, de fato, o desenvolvimento do trabalho na habitação sempre foi uma atividade presente no ambiente doméstico, quer seja em atividades de artesanato, pequenas indústrias ou trabalhos de escritório. Figura 20 


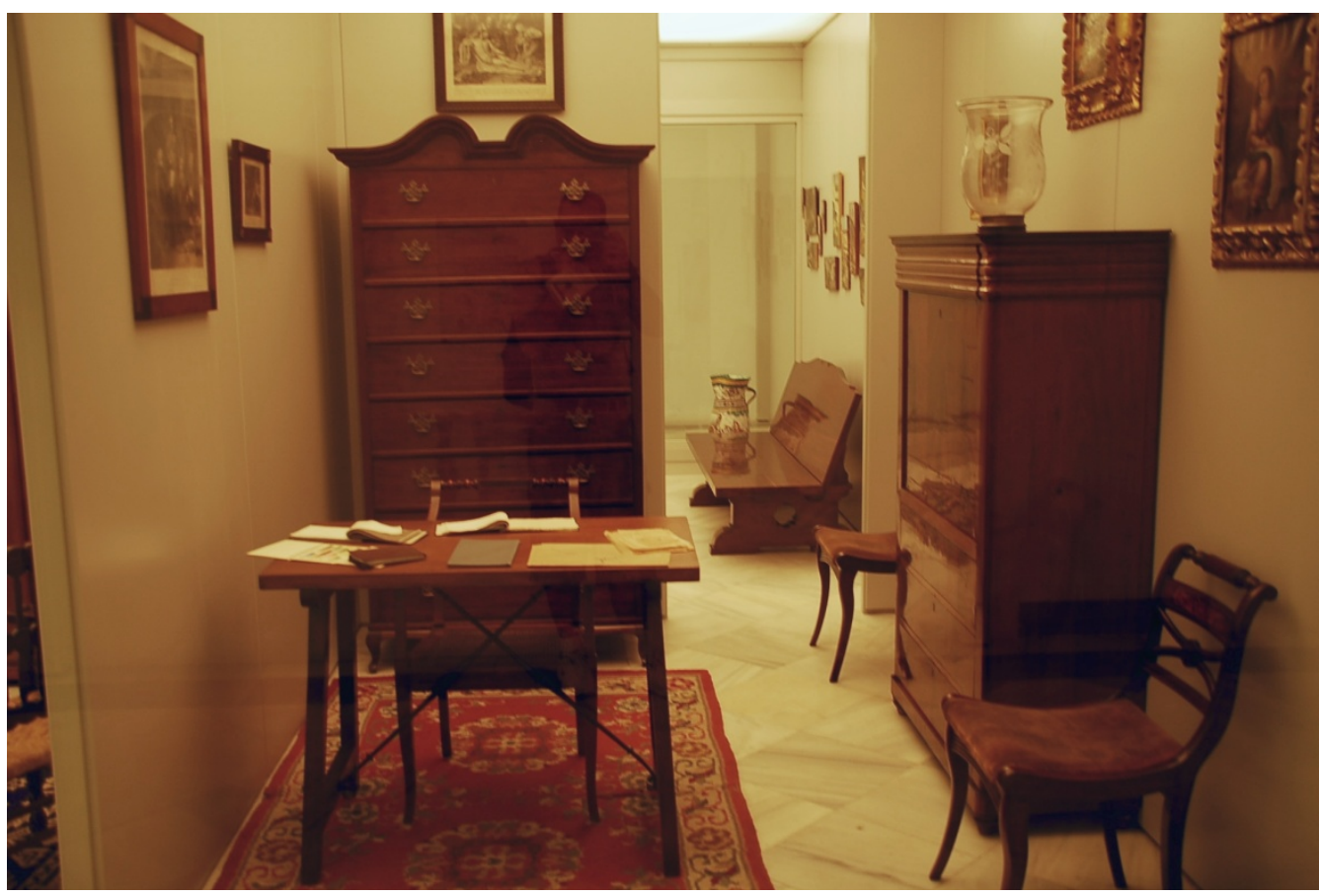

Figura 20 - Escritório Residencial Família Velásquez Museo de Artes y Costumbres Populares de Sevilla Foto do autor

Como este exemplo, vários outros podem ser citados, em várias épocas diferentes, nas mais diversas culturas.

Com o surgimento das novas tecnologias de informação e comunicação - TICs, houve um impacto no modo de vida da sociedade pós-industrial.

A tecnologia em si e sua crescente proliferação nos mais diversos setores das atividades humanas, passaram a alterar o modo de vida dessa sociedade.

Alteraram os meios de comunicação e sua velocidade de transmissão; alterou o volume de novas informações e o universo com o qual elas são compartilhadas; os espaços passaram a ser organizados considerando novas demandas e se utilizando de novas tecnologias para serem construídos e utilizados; as novas tecnologias impactaram na saúde humana com diagnósticos e monitoramentos mais precisos; e também alterou a vida profissional, abrindo oportunidades do trabalho intelectual ser desenvolvido em qualquer lugar e a qualquer hora. 
Uma das questões colocadas como objetivo deste trabalho foi analisar se o mercado imobiliário paulistano, por meio de seus lançamentos residenciais, estava de fato envolvido com o atendimento de uma demanda por ambientes na habitação destinados ao desenvolvimento de atividades de escritório.

Quando observamos que $68 \%$ dos casos de lançamentos residenciais pesquisados apresentam ambiente ou posto de trabalho com estas características em uma das suas opções de plantas de vendas e que $22 \%$ são espaços projetados para estes fins, podemos concluir que sim, existe uma demanda e o mercado está atento para suprir estas necessidades e mais, comparados a um levantamento prévio realizado em 2005, onde apenas $12 \%$ das unidades lançadas tinham esta preocupação, podemos afirmar que existe uma tendência de crescimento da incorporação de espaços para o desenvolvimento de atividades pertinentes ao trabalho de escritório na habitação.

Em relação à qualidade destes espaços propostos nos lançamentos imobiliários residenciais, e se eles atendem ou não as reais necessidades dos usuários, passa a ser apenas uma questão de interpretação da área física proposta em planta que, como visto, atende à área mínima indicada nesta tese para o desenvolvimento da atividade, porém, nenhuma outra observação sobre a qualidade destes espaços pode ser feita. 
Como proposta para pesquisa futura, é sugerida uma investigação de como os usuários finais das unidades habitacionais disponibilizadas pelo mercado se apropriam dos espaços da habitação e em que proporção as opções de ocupação dos espaços definidos no material de vendas são seguidas na distribuição de mobiliário e funções da moradia.

Embora tenha existido a preocupação de se obter estas informações, esse dado não se mostrou relevante para os incorporadores e representantes de vendas dos imóveis quando questionados, pois, para eles, o atendimento ao cliente se encerra quando da conclusão da venda e entrega do produto, não fazendo parte de seu escopo de trabalho o modo de ocupação dos espaços da unidade.

Uma outra questão é analisar como a atividade de trabalho retornou à habitação.

"Nos aglomerados pré-industriais, o espaço de habitação e o espaço de trabalho estavam intimamente integrados. Os camponeses viviam junto às searas, com seus animais, no campo. Os artesãos viviam por cima das suas lojas, na cidade. Os acadêmicos viviam em dormitórios, próximos das suas bibliotecas(...) mais, as cidades sempre integraram bairros profissionais onde os artesãos de determinados ofícios viviam em trabalhavam em conjunto(...) 
(...) reagindo aos críticos do urbanismo industrial, os primeiros planejadores modernistas buscaram estratégias de zoneamento e segregação de atividades incompatíveis(...) levando ao aparecimento de cidades-satélite que obrigam os trabalhadores a percorrer grande distâncias até chegar ao trabalho. Em outras cidades, os artistas criaram um movimento contrário e edifícios existentes foram convertidos em amplos espaços de trabalho e habitação.(..) não existia qualquer incompatibilidade entre trabalho artístico, relativamente calmo $e$ pacífico, $e$ os requisitos dos ambientes residenciais, o que originou bairros cheios de vitalidade e intensidade durante 24 horas.(...)hoje, tem-se vindo a constatar que o trabalho na área da informação - utilizando computadores e apoiado pelas redes de comunicação - também não é incompatível com ambientes residenciais. Não gera polvição, barulho ou tráfego pesado(...) Bairros de habitação e trabalho tornam-se, uma vez mais, possiveis e atrativos; os teletrabalhadores continuam no que os artistas foram pioneiros."

Este texto de William Mitchell ${ }^{120}$ abre algumas possibilidades para linhas de discussão, sendo a primeira delas é a discussão sobre a questão urbana. 
Tanto o desenvolvimento desorganizado das periferias paulistanas, como os bairros planejados afastados dos centros de produção e de comércio das cidades americanas têm um ponto em comum: a distância.

Existe a preocupação verificada pela Worldatwork(2009), que aponta a necessidade de uma nova opção para a redução dos gastos com combustíveis e tempo de deslocamento casa-trabalho-casa, preocupação esta já demonstrada pela cidade de Los Angeles em meados de 1996, com seu "Telecommunting-telework Program"121 (1996), e em 12 de maio de 2000, umas das manchetes do jornal americano "Business Journal" da cidade de Seattle, foi "Teleworking one answer to traffic problems"122 Teletrabalho uma resposta ao problema do tráfego tráfego este gerado pela distância em relação aos centros de produção e consumo onde os bairros foram planejados, obrigando a construção de estradas e aos cidadãos se utilizarem de seu veículo particular para percorrê-la, onde o automóvel sempre foi ícone de uma economia forte e pujante.

Hoje, o teletrabalho vem como opção de resposta para solucionar o problema e os urbanistas respondem com "A Carta do Novo Urbanismo"123 (1996), onde existe uma reflexão sobre o modelo de urbanismo industrial implantado cujo "princípio 12" - ao todo são 27 princípios a carta apresenta:

\footnotetext{
121 County of Los Angeles Telecommuting-telework Program - 1996 Disponível em http://www.naco.org/Content/ContentGroups/County/Codes/Personnel/hro43.pdf

122 Business Journal Teleworking one answer to traffic problems Disponível em http://seattle.bizjournals.com/seattle/stories/2000/05/15/editorial3.html

123 Leccese, M.; McCormick, K. Charter of the new urbanism - Congress for the New Urbanism - New York: McGraw-Hill, 2000
} 
"Muitas atividades do cotidiano podem acontecer a uma distância possível de se percorrer a pé, possibilitando independência àqueles que não dirigem veículos, especialmente o idoso e o jovem. Uma rede interligada de vias pode ser projetada para encorajar o caminhar, reduzir o número e a distância das viagens de automóvel e conservar energia."

A carta ainda apresenta em seu "princípio 15" a necessidade de se planejar as edificações de maneira que a distância ao sistema de transporte público possa ser percorrida à pé.

Fica claro que o uso do automóvel e as distâncias da vida cotidiana devem sofrer alterações em seu formato, daí a importância das TICs nesse processo.

Nas periferias da cidade de São Paulo, pode-se fazer a mesma leitura da necessidade de deslocamento do trabalhador ao seu local de trabalho.

Nesse caso, o carro é utilizado pela deficiência do serviço de transporte coletivo e, mesmo para aqueles que se utilizam do sistema de transporte urbano, o tempo médio de deslocamento diário para a principal ocupação (trabalho ou estudo) é de 2 h47, segundo a pesquisa do Movimento Nossa São Paulo ${ }^{124}$, divulgada em outubro de 2009 e, aponta ainda que $43 \%$ dos paulistanos deixaria de usar o carro caso houvesse uma boa alternativa para o transporte. 
Porém o que se coloca não é apenas o uso do automóvel ou do sistema de transporte coletivo, mas sim a necessidade de deslocamentos que poderiam ser evitados quando se altera o conceito de trabalho.

Em 1 de junho de 2008, o jornal "O Estado de São Paulo" entrevistou Jaime Waisman, professor de Engenharia de Transportes da Universidade de São Paulo, onde aponta que $70 \%$ dos deslocamentos na cidade são de ida e volta para o trabalho e ainda declara que o resultado do programa de teletrabalho da cidade de Los Angeles, anteriormente citado, reduziu em $6 \%$ este tipo de deslocamento.

O jornal também traz entrevista com Álvaro Mello, professor da Business School de São Paulo, que declara que no Estado da Flórida - Estados Unidos, existem incentivos fiscais para empresas que promovam a redução de carros na cidade.

Portanto, conclui-se que o teletrabalho, especificamente o trabalho a partir de casa, pode contribuir na redução dos deslocamentos intra-urbanos, reduzindo congestionamentos o que representaria um ganho de tempo na vida dos trabalhadores, em economia - em São Paulo, segundo a Secretaria de Estado dos Transportes Metropolitanos, a cidade perde $\mathrm{R} \$ 4,1$ bilhões por ano em congestionamentos - além dos ganhos ambientais pela redução de emissão de polventes.

Outra linha de discussão, gerada pelo texto de Mitchell(1999), é a questão do uso da habitação para as atividades de escritório, ou, como ele coloca, "o uso de computadores apoiados nas redes de comunicação". 
Segundo as definições da OIT - Organização Internacional do Trabalho - existem quatro grandes modalidades ou formas de executar o teletrabalho:

- O trabalho em casa com recurso de microcomputador - neste caso o trabalhador encontra-se eventualmente ligado a um escritório central ou sede, ou ser desenvolvido por profissional liberal. Este trabalho em casa pode assumir diversos regimes: tempo parcial, tempo integral ou trabalho por contrato de serviço pré estabelecido;

- O trabalho nos centro-satélites - neste caso o trabalhador situa-se em um escritório pertencente à empresa, mas situado longe da sede, normalmente próximo à residência do morador;

- O trabalho nos centros de vizinhança (telecentros) - nesse caso, o trabalhador está em um escritório, geralmente perto da residência, e compartilha com outros trabalhadores (independentes ou de empresas) o espaço e os equipamentos. Os telecentros também podem ser utilizados para telefonemas, telecompras, lazer, etc.

- O trabalho móvel - neste caso o trabalhador está em contínuo movimento e não se fixa em um local.

A pesquisa ateve-se ao primeiro caso, onde o trabalhador desenvolve suas atividades à partir de casa.

No entanto, vale observar que, de acordo com a ANATEL, as leis de concessão para fornecimento de conexões exige um mínimo de apenas $10 \%$ da velocidade contratada. 
Além da falta de confiabilidade das conexões, existe ainda a questão da disponibilidade de atendimento ao ponto solicitado pois as concessionárias não atendem à totalidade do município, sendo as áreas mais afastadas do centro as menos favorecidas com a rede e, mesmo onde existe a disponibilidade da tecnologia, nem sempre há disponibilidade de conexão, devido ao excesso de clientes que esgotam os limites da rede instalada.

A questão econômica também deve ser considerada, e entender que o trabalho à partir de casa requer equipamentos e conexões exige que se considere o poder aquisitivo da população a ser atendida.

No caso dos equipamentos, nomeadamente os de informática, onde fatores como a isenção de impostos, novas empresas no mercado e redução das taxas de câmbio ajudaram no aumento das vendas e maior penetração no mercado.

Segundo a Associação Brasileira de Indústria Elétrica e Eletrônica - ABINEE ${ }^{125}$, entre 2006 e 2008 os computadores de mesa (desktops) tiveram um crescimento de vendas de $24,1 \%$, enquanto os portáteis (notebooks) o crescimento chegou a $183 \%$ estes, com uma redução de preço final ao consumidor na casa dos $30 \%$.

Já no caso das conexões, o Governo do Estado de São Paulo promoveu um programa de massificação de acesso à banda larga em associação com as concessionárias, com o valor controlado da tarifa mensal para a velocidade mínima. 
Porém, o que se observa é que a tarifa só é respeitada por um determinado período de tempo e sofre um reajuste significativo após este período.

Portanto, esta é uma barreira a ser vencida pelo agentes responsáveis pela inclusão digital, particularmente à novas tecnologias de informação e comunicação.

Pensar na possibilidade de que os escritórios residenciais venham a ser uma resposta factível para alguns dos problemas urbanos, deve levar em conta que o acesso às redes de conexão devam de fato serem massificados e chegar ao usuário mais afastado do centro, onde a necessidade de deslocamento é mais acentuada.

Em 2008 os levantamentos de dados primários para a tese investigou sobre a inserção dos escritórios residenciais nas habitações de interesse social e se os projetos destas habitações consideravam esta atividade.

Segundo o arquiteto João Alberto Canteiro, então Superintendente da COHAB-SP - Companhia Metropolitana de Habitação de São Paulo, atual Diretor do Departamento de Edificações do Município de São Paulo, a população de baixa renda, que ocupa as áreas mais afastadas do município, não tem poder aquisitivo para aderir às redes de banda larga, assim esta população usa os telecentros ou as lan houses de suas comunidades, portanto, esta é uma atividade que não está presente nestas habitações. 
Fica assim demonstrada a lacuna que existe para que a realidade dos escritórios residenciais chegue a ser disponibilizada a todos os extratos sociais e, principalmente às classes menos favorecidas.

Para aqueles cujo conjunto de oportunidades permitem optar pelo trabalho à partir de suas residências, existem outras questões que serão abordadas na seqüência.

Passar a trabalhar a partir de casa requer que sejam tomadas uma série de atitudes para que o desenvolvimento do trabalho seja eficiente e eficaz.

Como já visto, as TICs permitiram a possibilidade de um novo modo de se trabalhar longe da área física da empresa, e que as casas fossem eleitas como o local preferido para que estas atividades fossem desenvolvidas.

Um dos primeiros passos observados para quem segue esse novo caminho é a escolha do local onde na habitação onde esta atividade será desempenhada.

Quando se faz o uso do microcomputador para estas atividades, os de mesa (desktops) definem de uma maneira mais clara qual será este espaço e em qual ambiente será implantado.

No caso dos portáteis (notebooks), aliados aos equipamentos para conexão de rede sem fio, definir um local pode tornar-se uma tarefa mais complexa. 
Em ambos os casos, porém, as pesquisas mostraram que o desenvolvimento de um trabalho profissional, geralmente intelectual, requer um local calmo, com baixo nível de ruído, onde possa haver concentração.

De maneira diversa do que acontece nas empresas, onde os locais de trabalho são elaborados por profissionais que consideram, ou pelo menos deveriam considerar as questões de conforto e segurança em todos os seus níveis de abordagem, o trabalhador que passa a desempenhar as atividades em sua casa raramente tem a orientação de um profissional qualificado.

Talvez o único item que seja destaque para acomodar as necessidades das atividades a serem desenvolvidas no posto de trabalho sejam os equipamentos, que variam de acordo com escopo de trabalho de cada ramo de atividade, porém, na grande maioria dos casos, os postos de trabalho são resultado de adaptações, tanto dos ambientes, como de mobiliários.

A escolha do local de trabalho dentro da habitação, vem acompanhada de algumas preocupações dos usuários, que nem sempre têm uma ordem hierárquica de necessidades e exigências, mas sim a possibilidade de adaptação atender à maioria dessas necessidades, com os recursos que estão disponíveis.

Para aqueles que trabalham em período integral no Home Office, geralmente o ambiente de trabalho é exclusivo para esta função, no máximo compartilha com atividades de "estar" ou lazer e estudo. 
Quando os escritórios são implantados em um local onde compartilha com atividades de repouso, percebe-se que o usuário que desenvolve atividades profissionais exerce essa função em tempo parcial e não integral.

Portanto, conclui-se que a escolha do local está vinculada ao tempo de uso, tipo de atividade e número de pessoas que utilizarão o posto de trabalho, mesmo que em horários diversos.

Quando apenas estes fatores são levados em consideração, outros aspectos importantes deixam de compor os requisitos mínimos para a implantação, como a iluminação - natural e artificial, onde destaca-se a elevada ocorrência de ambientes e postos de trabalho que não oferecem as condições adequadas de iluminação aos seus usuários, além da ventilação, ruído e demais itens que devem estar relacionados para o desenvolvimento da atividade e que, a longo prazo, podem trazer transtornos e distúrbios das mais variadas naturezas aos usuários.

No caso do mobiliário, a questão se apresenta mais grave, principalmente no tocante às cadeiras, já que as mesas, de maneira geral, não comprometem de maneira significativa o desempenho a saúde ou a segurança do usuário.

As cadeiras são os itens que mais apresentam a caracterização da adaptação. Na maioria dos casos percebe-se que são utilizadas as cadeiras já existentes na casa, sem nenhuma preocupação dos requisitos ergonômicos que devem ser respeitados. 
O universo encontrado nas pesquisas apresentou inúmeras formas, dimensões e materiais, desde cadeiras apropriadas para o tipo de atividade, até cadeiras plásticas e metálicas que não atendem nenhum dos requisitos necessários.

Por se tratarem de postos de trabalho onde raramente existe o atendimento ao público, clientes ou fornecedores, estes são os itens de mobiliário que realmente devem ser observados e atenderem às questões de conforto e segurança, ainda mais quando existe a possibilidade de que o posto de trabalho seja utilizado por várias pessoas que possuem diferentes padrões antropométricos.

Outro ponto de discussão sobre o tema são as causas e conseqüências que fazem com que o trabalhador passe a desenvolver suas atividades profissionais a partir de casa.

No Brasil, a pesquisa mostra que, no caso das empresas, no máximo existe a permissividade para que o trabalhador desenvolva parte de suas atividades na residência mas, na maioria dos casos, é o trabalhador que usa a habitação para complementar uma tarefa ou organizar questões das atividades da empresa.

Nos outros casos, dos profissionais liberais em geral, essa é uma decisão financeira ( $27 \%$ dos casos), onde a casa tornase o local preferencial por não gerar custos com outro local.

Conclui-se assim, que o principal motivo para desenvolver o trabalho na residência no caso paulistano é de caráter econômico. 
Uma das conseqüências a ser analisada é a compatibilidade do desenvolvimento do trabalho intelectual com uso de computador e redes nas habitações que deve ser observada como uma via de dupla direção.

Essa atividade não apresenta tarefas que de alguma maneira interfiram com a rotina doméstica exceto, talvez, quando se trata de uma atividade de período prolongado que possa gerar algum tipo de desconforto entre os membros da família.

No entanto, verifica-se que as atividades domésticas podem interferir nas atividades profissionais.

Eletrodomésticos, as tarefas cotidianas de arrumação e higienização da moradia, atividades de crianças e animais de estimação se houver, diferentes necessidades de uso do ambiente ou posto de trabalho quando existe 0 compartilhamento, são exemplos de como essa interrelação pode gerar um desgaste acentuado na convivência.

Nesta questão, conclui-se que as atividades domésticas podem interferir de maneira mais incisiva nas atividades profissionais do que no caso inverso, sendo que, como pesquisado, esta é a questão mais negativa apontada pelos usuários.

As pesquisas, livros, textos e artigos que foram visitados no percurso da dissertação de mestrado e desta tese de doutoramento, apresentaram diversos autores que apontaram vantagens e desvantagens sobre a incorporação do trabalho no ambiente doméstico. 
Sempre existe a imparcialidade dos autores em observar as questões tanto do lado dos trabalhadores como do lado das empresas, assim, para estas, se existe a vantagem de redução de gastos com área física - locação e manutenção, redução de absenteísmo, existe o outro lado que é a falta de controle presencial do trabalhador e a descaracterização da unidade da empresa.

Para os trabalhadores, as vantagens de evitar o deslocamento, organização do próprio tempo e possibilidade de estar mais próximo da família, tem em contra partida o isolamento profissional e social, possibilidade de conflitos familiares e descaracterização do profissionalismo.

Como arquiteto, pesquisador, usuário e adepto da modalidade de Home Office há mais de 15 anos, aponto minhas considerações sobre o tema, que englobam tanto o conhecimento adquirido nestes longos anos de estudo sobre o tema, quanto minha experiência pessoal.

Sobre o motivo pelo qual passei a usar a habitação como base de minhas atividades profissionais, concluo que foi uma opção econômica, onde a residência me possibilitava o pleno desempenho destas atividades sem a incorporação de gastos fixos, me permitindo trabalhar propostas comerciais com valores mais competitivos.

O terceiro dormitório de $11,00 \mathrm{~m} 2$ foi então adaptado para estas atividades, que possui interligação com o estar, no setor social da casa. 
O mobiliário consiste de uma mesa com tampo de 2,10x0,72m de madeira forrada com plástico branco leitoso, sobre cavaletes metálicos a uma altura de $75 \mathrm{~cm}$, uma cadeira de metal|tecido, giratória e com ajustes de altura, sem apoio de braços, o ambiente ainda possui duas poltronas.

O equipamento utilizado é um microcomputador portátil, e uma multifuncional, telefone fixo e celular, gaveteiro com 3 gavetas e armário para livros e arquivos.

O ambiente é provido de luz natural, um ponto de luz no forro com lâmpada incandescente de 100 watts e luminária de mesa com lâmpada fria de 16 watts, sendo que durante o período de atividades $o$ ambiente tem 0 índice de iluminância entre 500 e 700 LUX.

No desempenho das atividades de arquitetura, o atendimento aos clientes é feito fora deste ambiente, me deslocando até a obra, residência ou local de trabalho do cliente.

Todos os contatos com fornecedores são por meio de telefones ou correio eletrônico, sendo as pesquisas de materiais, componentes, equipamentos e preços feitas pela internet, com conexão de banda larga.

Na rotina diária não existe uma preocupação em manter o "aspecto formal ou profissional" que preocupa alguns autores. Considero que o trabalho na habitação me dá a liberdade de trabalhar de maneira mais descontraída e isso, no meu caso, só proporciona maior produtividade. 
A procrastinação, também apontada como um dos possíveis problemas dos Home Offices, tem variações conforme o tipo de atividade que se está desenvolvendo. Quando são tarefas "mecânicas", cuja produção depende menos do esforço intelectual, a tendência de se protelar o trabalho é menor do que quando uma criação está sendo desenvolvida e as informações precisam de um amadurecimento natural.

Já a questão da interferência da vida doméstica, que no caso inclui todos os itens - empregada, crianças, animal doméstico, vizinhança, ruídos e afins, foi administrado com "treinamento" de todos estes elementos, onde cada atividade e interferência que podem ser controlados têm seu momento de acontecer, e o treinamento também passa pela auto-regulação de horários, não permitindo que a jornada de trabalho diária interfira no convívio com a família.

O isolamento pessoal e profissional praticamente não existe pois, diariamente, os meios de comunicação permitem estar em contado on-line com profissionais e pessoas próximas que provavelmente não existiria se o trabalho estivesse sendo desenvolvido em um ambiente corporativo.

Um último aspecto, é a sensação de qualidade de vida quando se tem a liberdade de organizar os horários; decidir se haverá ou não deslocamento e, principalmente, determinar o horário que ele vai ocorrer, evitando os horários de maior fluxo de veículos na cidade; em dias em que as tarefas têm mais fluidez, poder desenvolver outras atividades, evitar situações de aglomerações para determinados eventos ou entretenimentos, ou simplesmente relaxar. 
Depois de longo período trabalhando em Home Office, com as questões de espaço, conforto, ergonômicas, profissionais e de conflito doméstico já solucionadas, o testemunho é de que com as condições favoráveis, desenvolver as atividades profissionais a partir da residência é de fato uma oportunidade de se alcançar uma qualidade de vida melhor.

Quando os computadores passaram a fazer parte do cotidiano das pessoas, várias predições sobre a sociedade da informação foram entoadas, porém, vejamos:

- As pessoas não deixaram de trabalhar, ao contrário, o computador permite que a jornada diária de trabalho se estenda, e se trabalhe em períodos que eram ocupados por outras atividades;

- As fábricas, embora tenham adquirido uma certa robotização, não estão sendo controladas por uma única pessoa;

- O escritório sem papel, totalmente virtual nunca existiv;

- Os cartões eletrônicos e os "home banking" não acabaram com as agências, nem houve uma demissão em massa do setor;

- A vida doméstica não possui um robô que dá conta de todas as tarefas da casa; 
- As livrarias virtuais não levaram à falência as redes de livrarias que continuam a abrir grandes lojas pela cidade;

- Os alunos não estão nas suas casas aprendendo com o professor virtual;

- O correio eletrônico não acabou com o correio tradicional, cujo setor está em crescimento;

- O e-commerce e as compras ao "click do mouse" não desencadearam uma frenética compra desmedida, nem acabaram com os shopping centers;

Portanto, o Home Office também não oferece riscos ao emprego tradicional, mas deverá ser uma forma de trabalho que deverá conviver com tantas outras, adaptando a vida das cidades às necessidades do seus cidadãos e vice-versa.

Novas tecnologias continuam e continuarão a surgir e o futuro poderá surpreender, caso transfira os Home Offices de volta ao ambiente corporativo, não fisicamente, mas de maneira virtual.

Basta que se observe a tecnologia da telepresença, já em utilização pela empresa CISCO, onde ambientes preparados para videoconferência foram aperfeiçoados, com iluminação, câmeras, velocidade de transmissão de dados e voz que permite que até doze pessoas em locais diferentes participem de uma mesma reunião virtual, onde a percepção da distância física desaparece. Figura 22 


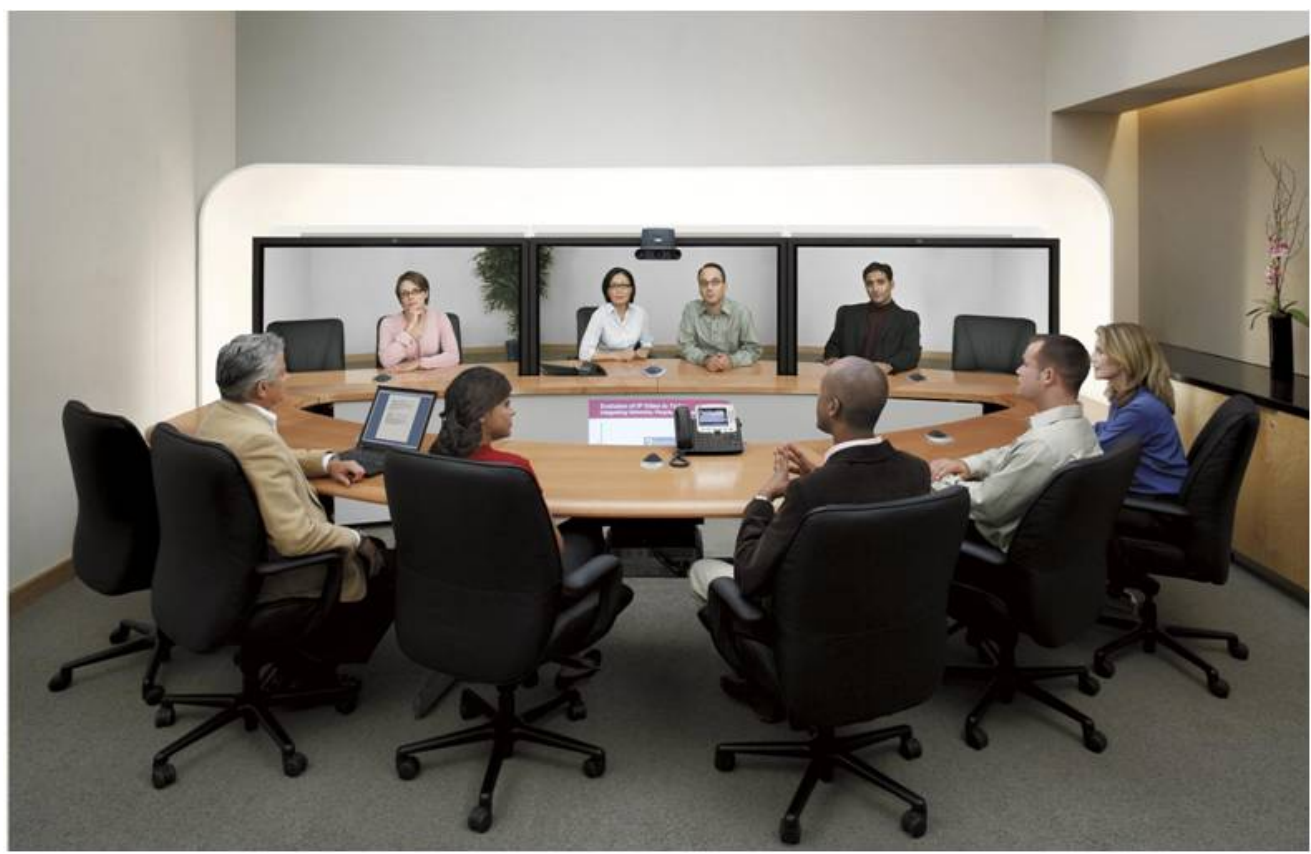

Figura 22 - Sala de Telepresença Fonte: Cisco

Porque então não se pode pensar que em um futuro breve as casas estarão equipadas com esta tecnologia ou similar que nos permita esta interação em tempo real?

Esta página encerra um ciclo de pesquisas e aprendizado.

Acreditamos que a missão foi cumprida e fica para futuras gerações uma fotografia de como os Home Offices existiam na primeira década do século XXI.

Que as novas tecnologias permitam novas pesquisas e que o trabalho sem fronteiras físicas possa vir a ser um ganho na qualidade de vida possível a todos os habitantes dos grandes centros urbanos. 


\subsection{Pesquisas Futuras}

Como contribuição final, seguem algumas opções para o desenvolvimento de pesquisas e investigações futuras que podem vir a complementar esta tese.

- Como os usuários finais dos lançamentos imobiliários residenciais se apropriam dos espaços da habitação comparados aos prospectos de vendas.

- Como a inclusão dos Home Offices nas habitações afeta o deslocamento do consumo de energia do setor produtivo para o setor residencial.

- Em que escala ocorre a redução dos deslocamentos intra urbanos no município de São Paulo em função dos Home Offices e quais os impactos ambientais resultantes desta prática. 


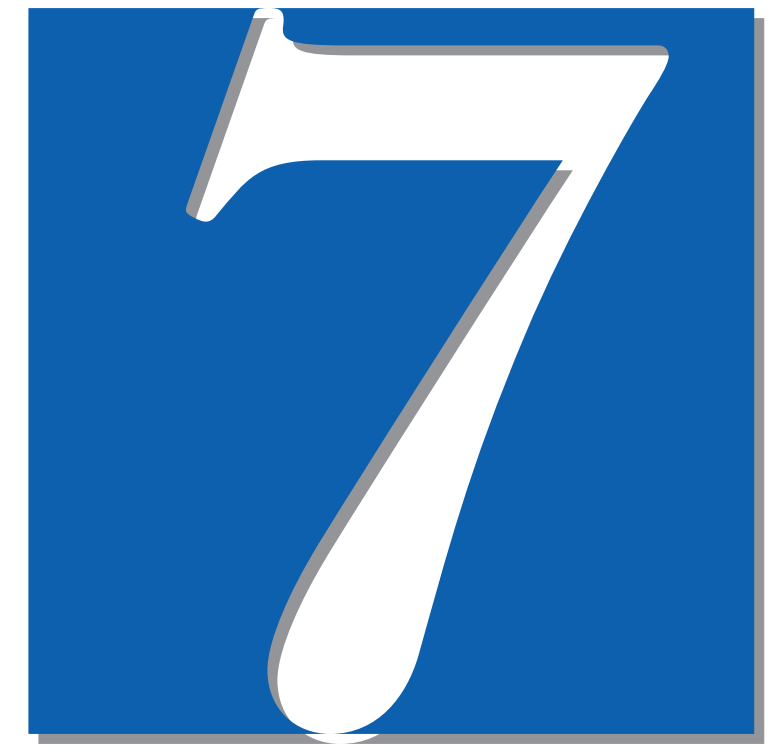

\section{Bibliografia}




\section{CAPÍTULO 7. BIBLIOGRAFIA}

\subsection{Bibliografia Referenciada}

1 - Schoenauer, N. 6000 Years of Housing - W.W. Norton \& Cia Inc. - New York 2000

2 - Péllegrin-Genel, E. The Office - Flammarion-Pere Castor - New York - 1996

3-Mumford, L. The City in History - Harcourt, Brace \& World - New York - 1961

4- Mitchell, W. J. City of Bits - M.I.T. - Boston - 1995

5 - Mumford, L. The Culture of Cities - Secker \& Warburg - London - 1940

6 - Grandjean, E. Ergonomics of the Home - Taylor \& Francis - Florence - 1973

7-Cairncross, F. O Fim das Distâncias - Nobel - São Paulo - 1999

8 - Mitchell, W. J. @-Topia, a Vida Urbana - mas não como a conhecemos - SENAC São Paulo - 2002

9-Smith, A. A Riqueza das Nações - Martins Fontes - São Paulo - 2003

10 - Donkin, R. Sangue, Suor e Lágrimas - A Evolução do Trabalho - Mbooks

São Paulo - 2003

11 - Toffler, A. A Terceira Onda-Record - Rio de Janeiro - 1980

12 - Castells, M. The Informational City - Blackwell - Cambridge - 1989

13 - De Masi, D. O Ócio Criativo - Sextante - São Paulo - 2000

14-Semler, R. Virando a Própría Mesa - Rocco - Rio de Janeiro - 2002

15 - Zimmerman, N. Home Office Design - John Wiley \& Sons - New York - 1996

16 - Fairweather, N. B. Surveillance in employment: The case of teleworking. Journal of Business Ethics, $22-1999$

17 - Kurland, N.B. ; Bailey, D.E. Telework: The advantages and challenges of working here, there, anywhere, and anytime. Organizational Dynamics, 53-1999

18 - Joice, W. Workshop 1: Getting educated. International Telework Association \& Council - September 2000

19 - Ellison, N.B. Social impacts: New perspectives on telework - Social Science Computer Review, 17-1999

20 - Wikipédia Enciclopédia Livre Teletrabalho - Disponível em http://en.wikipedia.org/wiki/teletrabalho

21 - Hyland, M.M. Flexibility in work arrangements: How availability, preferences and use affect business outcomes. The State University of New Jersey - Doctoral Dissertation - 1999

22 - Swanson, R.A. The theory of Human Resources Development - HRD University of Minnesota - Human Resource Development Research Center - 1997

23 - Mokhtarian, P.L.; Bagley, M.N. \& Solomon, I. The impact of gender, occupation, and presence of children on telecommuting motivations and constraints. Journal of the American Society for Information Science. 49 - 1998

24 - Pratt, J.H. America national telework survey 1999: cost/benefits of teleworking to manage work/life responsibilities. The International telework Association \& Council - 1999

25 - Lister, K.; Harnish, T. Undress for success - the naked truth about making money at home - John Wiley \& Sons - New Jersey - 2009

26 - Loverde, M.A. The effects of individual's psychological needs on telecommuting's impact on job performance Illinois Institute of Technology Doctoral Dissertation - 1997 
27 - Bernardino, A.T. Telecommuting: modeling the employee's decision-making process - Garland Publishing - New York-1996

28 - Gainey, T.W.; Kelley, D.E.; \& Hill, J.A. Telecommuting's impact on corporate culture and individual workers: examining the effect of employee isolation. SAM Advanced Management Journal, 64-1999

29 - Ross, K.A. Personality and work style characteristics of the telecommuter San Jose State University Master's Thesis - 1990

30 - Belanger, F. Distributed work arrangements: impacts of advanced information technologies, coordination mechanisms and communications patterns. University of South Florida - Doctoral Dissertation - 1997

31 - McCloskey, D.W. The impact of telecommuting on the work outcomes of professionals. Drexel University - Doctoral Dissertation - 1998

32 - De Lay, N.L. The effects of telecommuting and gender on work-family conflict and satisfaction. Illinois Institute of Technology - Doctoral Dissertation - 1995

33 - Coveyduck, D.H. Investigation of selected factors on job satisfaction among telecommuters. Carleton University - Master Thesis - 1997

34 - Sturgill, A.F.C. Relationship of telecommuting to organizational communication: a preliminary study of group process and communication satisfaction. Cornell University - Doctoral Dissertation - 1998

35 - Welchans, T.D. The effects of telecommuting and communication media on perceived value congruence, organizational support and job satisfaction. Ohio State University - Doctoral Dissertation - 1996

36 - Thompson, S.H.; Vivien, K.G.L.; Wai, S.H. Assessing attitudes towards teleworking among information technology (IT) personnel. Singapore Management Review, 21-1999

37 - Hill, E.J. The perceived influence of mobile telework on aspects of work life and family life: an exploratory study. Utah State University - Doctoral Dissertation 1995

38 - Tucker, D.M. More and less: perceptions and experience of the professional part-time employee. Virginia Polytechnic Institute and State University - Doctoral Dissertation - 1997

39 - Mendonça, M. Escritórios residenciais: aspectos que influenciam a implantação e o uso de ambientes da habitação para o desenvolvimento de atividades de escritório. Universidade de São Paulo - Dissertação de Mestrado - 2005

40 - Bolin, D.J. The economics of telecommuting with an application on manufacturing sector. Purdue University - Doctoral Dissertation - 1995

41 - Callaghan, W.J. Utilization of telecommuting as a tool for retaining logistics professionals. Baker College - Master's Thesis - 1996

42 - International Telework Association \& Council 1999 telework research results International Telework Association \& Council - 2000

43 - Chomiak, A.A. Work/life balance and job flexibility: does teleworking make a difference? The State University of New Jersey - Doctoral Dissertation - 1998

44 - Cree, L.H. Work/family balance of telecommuters. California School of Professional Psychology - Doctoral Dissertation - 1998

45 - Schreiber, P.J. The nature of career development for women who telecommute. University of Georgia - Doctoral Dissertation - 1999

46 - Fireman, S.M. A model of telecommuting withdrawal: employee predicting the reduction or stopping of telework. University of Washigton - Doctoral Dissertation 1999 
47 - Lowry, T. Alternative work arrangements: the effects of distance and media use on the supervisor/subordinate relationship. Rice University - 1996

48 - Khaifa, M. ; Davidson, R. Exploring the telecommuting paradox. Communications of the ACM, 43-2000

49 - Klayton, M.A. The impact of telecommuting on the supervisory performance appraisal process. Virginia Commonwealth University - Doctoral Dissertation - 1994

50 - Rainsch, N.L. Selected communication variables and telecommuting workers. The Journal of Business Communications, 36 - 1999

$\mathbf{5 1}$ - Conner, C.C. The effect of management style on manager's satisfaction with telecommuting. University of Tennessee - Doctoral Dissertation - 1986

52 - Speeth, L.M. The attributes of successful managers of telecommuters and successful telecommuting programs. Golden Gate University - Doctoral Dissertation $-1992$

53-Harvey, D. Condição Pós Moderna - São Paulo: Loyola, 1998

54 - Lannes, L.S. Equipes autogerenciáveis e a forma de organização do trabalho. Universidade de São Paulo - Faculdade de Economia e Administração - Monografia 1998

55 - Wikipédia - Enciclopédia Livre - Home Office - Disponível em http://en.wikipedia.org/wiki/Small_office/home_office

56 - Serviço Brasileiro de Apoio a Micro e Pequenas Empresas SEBRAE Home Office - Disponível em:

http://www.sebrae.com.br/br/parasuaempresa/tiposdenegocios_64.asp

57 - Sternberg, R.J. Psicologia cognitiva - Porto Alegre: Artes Médicas, 2000

58 - Holanda, A.B. Dicionário da Língua Portuguesa - Rio de Janeiro: Nova Fronteira, 1993

59 - Ferreira, P. Comentários à Constituição Brasileira - São Paulo: Saraiva, 1989

60 - Guérin, F. Compreender o trabalho para transformá-lo - São Paulo: Edgard Blücher, 2001

61 - Dicionário Eletrônico da Língua Portuguesa - 2001

62 - Internet World Stats Disponível em http://www.internetworldstats.com

63 - Worldatwork - Telework Trendlines 2009 Disponível em http://www.workingfromanywhere.org/

64-Canadian Telework Association Disponível em http://www.ivc.ca/cta/

65 - Confederation of British Industry - CBI Disponível em http://www.cbi.org.uk/ndbs/staticpages.nsf/StaticPages/home.html

66 - European Working Conditions Observatory - EWCO Disponível em http://www.eurofound.europa.eu/ewco/

67 - Dynamic Markets - Flexible Working 2009 Disponível em http://www.avaya.com

68 - Saloma-Akpedonu, C.; Ching, C.S.; Tan, A. Homeworkers and ICTS in Southeast Asia. Ateneo de Manila University - 2004

69 - Taveras, L.E. The effects of telecommuting on attitudinal and behavioral characteristics of organizational culture. University of Sarasota - Doctoral Dissertation - 1998

70 - Ruppel, C.P. Correlates of the adoption and implementation of programmer/analyst telework: an organizational perspective. Kent State University $-1995$ 
71 - McCloskey, D.W.; Igbaria, M. A review of the empirical research on telecommuting and directions for future research. In Igbaria, M.; Tam, M. The virtual workplace. Idea Group Publishing, 1998

72 - Doherty S.; Andrey, J.; Johnson, L. The economic and social impacts of telework. US Department of Labor conference on telework and new workplaces 2000

73 - Bailey, D.; Kurland, N. A review of telework research: finding, new directions, and lessons for study of modern work. Journal of Organization $\mathrm{H}=$ Behavior, 23- 2002

74 - Robertson, K. How telework in changing the traditional corporate office. 2005 Disponível em http://klr.com/articles/how_telework_changing_office.pdf

75 - Canadian Telework Association - CTA Canadian telework scene 2006 Disponível em http;//www.ivc.ca/canadianscene.html

76 - Yen, J. Interpreting employee telecommuting adoption: an economic perspective. Transportation, 27-2000

77 - Sohn, J.; Kim, T.; Hewings, G. Information technology and urban spatial structure: a comparative analysis of the Chicago and Seoul regions. Annals of Regional Science, $37-2003$

78 - Mokhtarian, P. Defining telecommuting. Transportation Research Record, 1305 $-1991$

79 - Mokhtarian, P.; Collantes, O.; Gertz, C. Telecommuting, residential location, and commute-distance traveled. Environment and Planning, 36910) - 2004

80 - Mokhtarian, P.; Salomon, I.; Choo, S. Measuring the measurable: why can't we agree on the number of telecommuters in the US? Quality and Quantity, $39-$ 2005

81 - International Union for the Conservation of Nature - IUCN World conservation strategy: living resources conservation for sustainable development. Gland: IUCN, 1980

82 - Mariani, M. Telecommuters. Occupational Outlook Quarterly, 4- 2000

83 - Atkins, R.; Blazek, M.; Roitz, J. Measurement of environmental impacts of telework adoption amidst change in complex organizations. Resources, Conservation and Recycling, 36 - 2002

84 - Harpaz, I. Advantages and disadvantages of telecommuting for individual organization and society. Work Study, 51-2002

85-Kithou, E.; Horvath, A. Energy-related emissions from telework. Environmental Science \& Technology, $37-2003$

86 - Finnish Environment Institute - SYKE Statistics Finland 2004. University of Helsinki, 2004

87 - Devuyst, D.; Van Volsen, S. How green is the city? Sustainable assessment and the management of urban environments - New York: Columbia University Press $-2001$

88 - Wackernagel, M.; Rees, W. Our ecological footprint: reducing human impact on the Earth - British Columba: New Society, 1996

89 - Chambers, N.; Simmons, C.; Wackernagel, M. Sharing nature's interest: ecological footprints as an indicator of sustainability - London: Earthscan, 2000

90 - Van Den Bergh, J.; Verbruggen, H. Spatial sustainability, trade and indicators: an evaluation of the ecological footprint. Ecological Economics, 29-1999 91 - Holden, E. Ecological footprints and sustainable urban form. Journal of Housing and the Built Environment, 19-2004 
92 - Wood, R.; Lenzen, M. An application of a modified ecological footprint method and structural path analysis in a comparative institutional study. Local Environment, 84-2003

93 - Hopkinson, P.; James, P.; Maruyama, T. Sustainable teleworking: identifying and evaluating the economic, environmental and social impacts of teleworking.

Disponível em

http://www.sustel.org/documents/deliverable_conceptual52opaper520v2b.rtf

94 - Choo, S.; Mokhtarian, P.; Salomon, I. Does telecommuting reduce vehiclemiles traveled? An aggregate time series analysis for the U.S. Transportation, $32-$ 2005

95 - Wood, G. Modeling the ecological footprint of green travel plans using network analysis: from metaphor to management tool? Environment and Planning, В30 2003

96 - EURESCOM Project 904 - The impacts of telework on sustainable social development and quality of life. Disponível em http://www.eurescom.de/ pub/deliverables/documents/pgoo-

series/pgo4/pg04_brochure.pdf - 2001

97 - Lake, A. Planning in the information age. Disponível em http://flexibility.co.uk/issues/modgov/planning.htm - 2005

98 - Andrey, J.; Burns, K.; Doherty, S. Toward sustainable transportation: exploring transportation decisions making in telework households in a mid-sized Canadian city. Canadian Journal of Urban Research, 13-2005

99 - Levine, D.M.; Berenson, M.L.; Stephan, D. - Estatística: teoria e aplicações LTC - Rio de Janeiro - 2000.

100 - Organização Internacional do Trabalho - OIT Recomendações sobre os serviços de medicina do trabalho nos lugares do emprego. In Mendes, R.; Dias. E.C. Revista da Saúde Pública, 25 - 1991

101 - lida, I. Ergonomia: Projeto e Produção - Edgard Blucher - São Paulo-1992

102 - Kroemer, K. H. E. \& Kroemer, A. D. Office Solutions - Taylor \& Francis - New York - 2001

103 - Ramazzini, B. Diseases of Workers - From the latin text of 1713 , revised with translate and notes by Wright, W.C. - Chicago: University of Chicago Press, 1940

104 - Ministério da Previdência Social Anuário estatístico de acidentes de trabalho - 2008 Disponível em

http://www.previdenciasocial.gov.br/conteudoDinamico.php?id=901

105 - Boueri, J. Livre Docência - FAUUSP - São Paulo - 2004

106 - Canadian Centre for Occupational Health and Safety - CCOHS Disponível em http://www.ccohs.ca/

107 - Associação Brasileira de Normas Técnicas - ABNT NBR5413 lluminância de interiores - 1992 Disponível em http://www.labcon.ufsc.br/anexos/13.pdf

108 - Iluminating Engineering Society of North américa - IESNA Disponível em http://www.iesna.org/

109 - International Organization for Standardization ISO 7730: 1994 - "Moderate Thermal Environments: Determinations of the PMV and PPD indices and specification of the Conditions for the Thermal Comfort".

110 - Occupational Safety and Health Administration - OSHA Disponível em http://www.osha.gov/

111 - Associação Brasileira de Normas Técnicas - ABNT NBR10152 Iluminância de interiores - 2000 Disponível em http://www. filecrop.com/NBR-10152.html

Dicionário Eletrônico HOUAISS da Língua Portuguesa 1.0 - 2001

112 - Karsaklian, E. Comportamento do Consumidor - Atlas - São Paulo - 2000 
113 - Cobra, M. Marketing Básico: uma abordagem brasileira - Atlas - São Paulo 1997

115 - Engel, J.; Blackwell, R. D.; Miniard, P. W. Comportamento do Consumidor Cengage Learning - São Paulo - 2000

116 - Kotler, P.; Armstrong, G. Princípios de Marketing - Pearson Prentice Hall - Rio de Janeiro - 2003

117 - Kotler, P. Adminstração de Marketing - Atlas - São Paulo-1998

118 - Stoner, J. A. F.; Freeman, R. E. Administração-Pearson Prentice Hall - Rio de Janeiro -1985

119 - Sheth, J. N.; Mittal, B.i; Newman, B. I. Comportamento do Cliente: indo além do comportamento do consumidor Atlas - São Paulo - 2001

120 - Duarte, J. P.; Bento, J.; Mitchell, W. J. The Lisbon Charrette Remote Colaborative Design - IST Press - Lisboa - 1999

121 - Mitchell, W.J. Do Teletrabalho: Uma hipótese. In Duarte, J. P.; Bento, J; Mitchell, W.J. - The Lisbon Charrette Remote Colaborative Design. Lisboa: IST Press, 1999

122 - County of Los Angeles Telecommuting-telework Program - 1996 Disponível em http://www.naco.org/Content/ContentGroups/County/Codes/Personnel/hro43.pdf 123 - Business Journal Teleworking one answer to traffic problems Disponível em http://seattle.bizjournals.com/seattle/stories/2000/05/15/editorial3.html

124 - Leccese, M.; McCormick, K. Charter of the new urbanism - Congress for the New Urbanism - New York: McGraw-Hill, 2000

125 - Movimento Nossa São Paulo - Observatório do Cidadão Disponível em http://www.nossasaopaulo.org.br/observatorio/

126 - Associação Brasileira de Indústria Elétrica e Eletrônica Sondagem Conjuntural do Setor Eletroeletrônico - 2008 Disponível em http://www.abinee.org.br/abinee/decon/deconı6.htm

\subsection{Bibliografia Consultada}

Allen, D. Produtividade Pessoal - Campus - Rio de Janeiro - 2001

Alucci, M.P. Conforto térmico, conforto luminoso e conservação de energia elétrica: procedimentos para desenvolvimento e avaliação de projeto de edificações São Paulo: S.N. 1992.

Amaral, C. S. Escritório: o espaço da produção administrativa em São Paulo - São Paulo: dissertação 1995

Altman, I.; Werner, C. M. Home Environments - Plenum - New York-1985

Bauna, J. O Escritório em Casa - Summus - São Paulo - 1998

BILL, B. Approaching home Automation - John Reed Inc.- New York-1998

Boueri, J. Antropometria Aplicada à Arquitetura, Urbanismo e Desenho Industrial Manual de Estudo - Volume I - FAU USP - São Paulo - 1999

Boueri, J. Espaço Mínimo da Habitação - Apostila - FAU USP - São Paulo - 1997

Boueri, J. Espaço de Atividades - Apostila - FAU USP - São Paulo - 1999

Boueri, J. et alli Layout Arranjo Físico dos Ambientes da Habitação - Apostila - FAU USP - São Paulo - 1999

Bredin, A. The Home Office Solution - John Wiley \& Sons - New York-1998

Cantanhede, C. Produtividade, aspecto organizacional - Instituto de Ciências Sociais - Rio de Janeiro, 1960 
Castro Neto, J. S. Edifício de Alta Tecnologia - Cathago \& Forte - São Paulo - 1994 Chiara, J.; Panero, J.; M .Zelnik Time Saver Standards for Housing and Residential Development -Mc Graw-Hill - New York- 1995

DelCarlo, U. Edifícios Inteligentes (EI) e controle das condições ambientais - João Pessoa: Encontro de professores de conforto ambiental - Anais - UFPB, 1994

Dubrin, A. Comparison of the job satisfaction and productivity of telecommuters versus in-house employees. Psychological Report, 68 - 1991

Gama, R. História da Técnica e da Tecnologia - T.A. Queiroz - São Paulo-1985

Gois Filho, J. F. Produtividade, aspecto educacional - Rio de Janeiro, 1960

Goode, W. J.; Hatt, P. K. Métodos em Pesquisa Social. 4 a ed. São Paulo: Nacional, 1972.

Grayson, D.; Hodges, A. Everybody,s Business - Doling Kindersley - London - 2001

Haddon, I.; Brynin, M. The character of telework and the characteristics of teleworkers. New Technology, Work and Employment, 20 - 2005

Hanson, J. Decoding Homes and Houses - Cambridge - New York - 1998

Hanson, J. The Social Logic of Space - Cambridge - New York-1988

Helling, A.; Mokhtarian, P. Worker telecommunication and mobility in transition: consequences for planning. Journal of Planning Literature, 15 - 2001

Holmberg, J.; Lundquist, U.; Robert, K.; Wackernagel, M. The ecological footprint from a systems perspective of sustainability. International Journal of Sustainable Development and World Ecology, 6-1999

Inkeles, G.; Schencke, I. Ergonomic Living - Simon \& Schuster - New York - 1994 Instituto Euvaldo Lodi Homem e a produtividade - Rio de Janeiro, 1971

Johnson, L. Bringing work home: developing a model residentialy-based telework facility. Canadian Journal of Urban Research, 8 - 1999

Johnson, L. The co-workplace: teleworking in the neighbourhood. University of British Columbia Press - Vancouver - 2003

Kanarek, L. Home Office Life-Rockport-Gloucester-2001

Karlen, M. Space Planning Basics - John Wiley \& Sons - New York-1993

Macleod, D. The Office Ergonomics Kit - Lewis Publishers - New York - 1999

Martens, S.; Spaargaren, G. The politics of sustainable consumption: the case of Netherlands. Sustainability: Science, Practice \& Policy, 1 - 2005

Mattar, F. N. Pesquisa de marketing: metodologia, planejamento, execução e análise, 2a. ed. São Paulo: Atlas, 1994, 2V., v.2.

Mello, A. Teletrabalho - O trabalho em qualquer lugar e a qualquer hora... Qualimark - Rio de Janeiro - 1999

Michelson, W. Environmental choice, human behavior and residential satisfaction Oxford University Press - New York - 1977

Moraes, A.; \& Mont'Alvão, C. Ergonomia - Conceitos e Aplicações - 2AB - Rio de Janeiro -1998

NIOSH Elements of Ergonomics Program" - US departament of health and human services USA, 1997

O'Neill, M. Ergonomic Design for Organizational Effectiveness - CRC - New York 1998

Ornestein, S. W. Escritórios sob Controle do Usuário - São Paulo: Arquitetura e Urbanismo, n073, pg 2 -ago/set, 1997

Panero, J. \& Zelnik, M. Human Dimension and Interior Space - The Architectural London 1979 
Pederson, E. O. Transportation in cities - Peramon Press Inc. - London - 1980

Pedro, João B. Programa Habitacional - ITA4 - Espaços e Compartimentos - LNEC - Lisboa - 1999

Pedro, João B. Programa Habitacional - ITA5 - Habitação - LNEC - Lisboa - 1999

Pinto, M. I. M. B. Cotidiano e sobrevivência: a vida do trabalhador pobre na cidade de São Paulo, 189o-1914 - São Paulo, 1978

Polião, M. V. Da Arquitetura-Hucitec-São Paulo-1999

Robins, C. L. Daylight: Design \& Analysis - Van Nostrand - New York - 1986

Romero, M. A. Conservação de energia e o projeto de arquitetura: uma análise geral - Sinopses, n²16, pg 5-9, dez 1991

Romero, M. A. Arquitetura, Comportamento e Energia - São Paulo: FAUUSP - Tese de Livre Docência - 1997

Roy, R.; Caird, S. Household ecological footprints moving towards sustainability? Town and Country Planning, $70-2001$

Santos, M. O Espaço do Cidadão-Nobel - São Paulo-1987

Schallabock, K.; Utznann Telework and sustainable development: a case study with the Global eSustainability Initiative. Digital Europe Information Society Technology Program-2003 Disponível em http://www.digital-eu.org

Shaw, S.; Andrey, J.; Johnson, L. The struggle for life balance: work family, and leisure in the lives of women teleworkers. Wolrd Leisure, 45-2003

Simmons, C.; Chambers, N. Footprint UK households: how big is your ecological garden? Local environment, 3-1998

Tayyaran, M.; Khan, A.; Anderson, D. Impact of telecommuting and intelligent transportation systems on residential location choide. Transportation Planning and Technology, 26-2003

Uemoto, K.L.; Ikematsu, P.; Agopyan, V. Impacto ambiental das tintas imobiliárias - Coletânea Habitare - Vol 7 - Construção e Meio Ambiente - Porto Alegre - 2006

Van Kooten, C.; Bulte, E. The ecological footprint: useful science or politics? Ecological Economics, 32 - 2000

Vasconcelos, E. A. Transporte urbano, Espaço e Equidade - FAPESP - São Paulo 1996

Visches, J. C. Workspace Strategies: environment as a tool for work - Chapman \& Hall - New York - 1996

Wassily, L.; Duchin, F. The future impact of automation on workers - Oxford University Press - Oxford - 1986

Werdiger, W.; Niebuhr, A. Euro-telework: trends and scenarios. - 2000 Disponível em http://www.telework-mirti.org/dbdocs/werdigie.pdf 